Prelinhary Design of Axtal Flow Wy:rocarbon Titrine Generator Set for CeothermalApplications

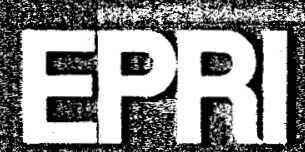

EPRIIER 513 Project $928-1$ Final Report May 1979
Keywords:

Hydrocarbon

Axia)

Dew point:

Fasibinty

Vapor pome $x$
1.6.

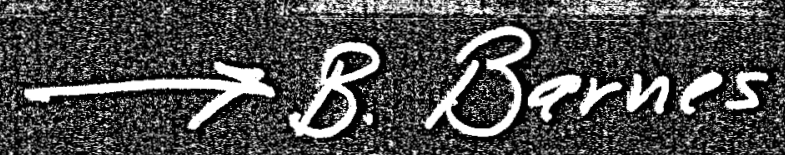

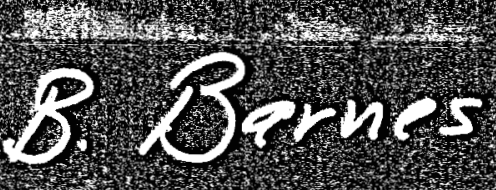

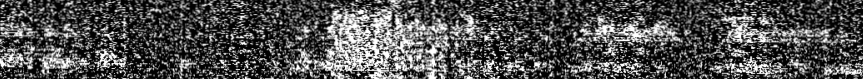

1.8.

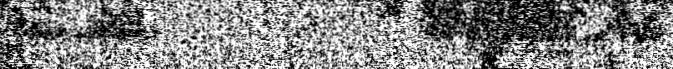

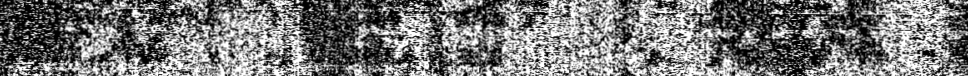

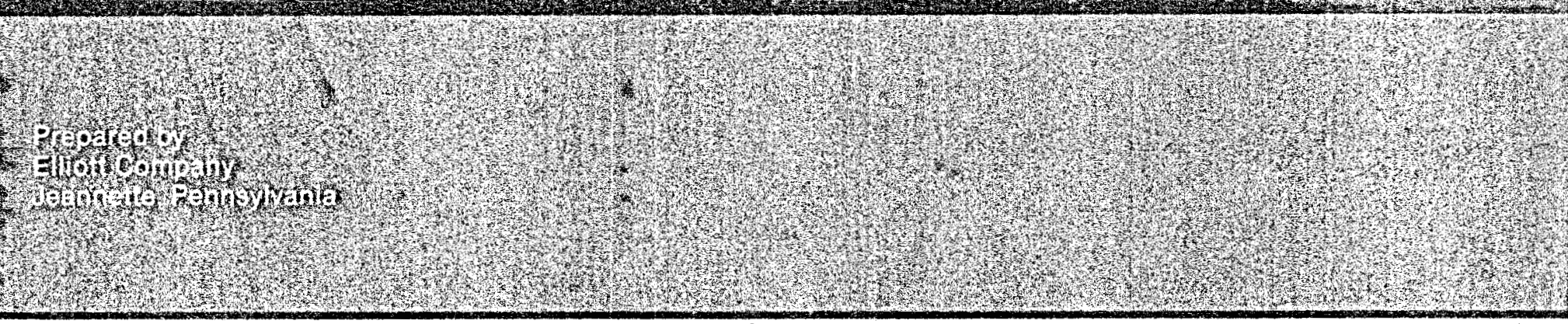

ELECTRIC POWER RESEARCH INSTITUTE 


\section{DISCLAIMER}

This report was prepared as an account of work sponsored by an agency of the United States Government. Neither the United States Government nor any agency Thereof, nor any of their employees, makes any warranty, express or implied, or assumes any legal liability or responsibility for the accuracy, completeness, or usefulness of any information, apparatus, product, or process disclosed, or represents that its use would not infringe privately owned rights. Reference herein to any specific commercial product, process, or service by trade name, trademark, manufacturer, or otherwise does not necessarily constitute or imply its endorsement, recommendation, or favoring by the United States Government or any agency thereof. The views and opinions of authors expressed herein do not necessarily state or reflect those of the United States Government or any agency thereof. 


\section{DISCLAIMER}

Portions of this document may be illegible in electronic image products. Images are produced from the best available original document. 


\title{
Preliminary Design of Axial Flow Hydrocarbon Turbine/Generator Set for Geothermal Applications
}

\author{
ER-513 \\ Research Project 928-1
}

Final Report, May 1979

\author{
Prepared by \\ ELLIOTT COMPANY \\ 900 North Fourth Street \\ Jeannette, Pennsylvania 15644 \\ Principal Investigators \\ N. A. Samurin \\ J. R. Shields
}

\section{Prepared for}

Electric Power Research Institute 3412 Hillview Avenue

Palo Alto, California 94304

EPRI Project Manager

D. A. LeZotte

Fossil Fuel and Advanced Systems Division 


\section{ORDERING INFORMATION}

Requests for copies of this report should be directed to Research Reports Center (RRC), Box 10090, Palo Alto, CA 94303, (415) 961-9043. There is no charge for reports requested by EPRI member utilities and affiliates, contributing nonmembers, U.S. utility associations, U.S. government agencies (federal, state, and local), media, and foreign organizations with which EPRI has an information exchange agreement. On request, RRC will send a catalog of EPRI reports.

EPRI authorizes the reproduction and distribution of all or any portion of this report and the preparation of any derivative work based on this report. in each case on the condition that any such reproduction. distribution, and preparation shall acknowledge this report and EPRI as the source.

\section{NOTICE}

This report was prepared by the organization(s) named below as an account of work sponsored by the Electric Power Research Institute. Inc. (EPRI). Neither EPRI, members of EPRI, the organization(s) named below, nor any person acting on their behalt: (a) makes any warranty or representation, express or implied. with respect to the accuracy, completeness, or usefulness of the information contained in this report, or that the use of any information, apparatus, method, or process disclosed in this report may not infringe privately owned rights; or (b) assumes any liabilities with respect to the use of, or for damages resulting from the use of, any information, apparatus, method, or process disclosed in this report.

Prepared by

Elliott Company

Jeannette, Pennsylvania 
This report outlines the design of a $65 \mathrm{MW}$ (e) gross turbine generator set in which a hydrocarbon gas mixture is used as the motive fluid. The turbine generator set is part of a geothermal binary cycle electric power plant proposed for the Heber site in the Imperial Valley, California. Aerodynamic design considerations and estimated unit performance for three hydrocarbon gas mixtures are presented. Real gas properties and equations of state are reviewed as they affect the turbine design and the thermodynamic cycle. The mechanical designs for the casing, rotor dynamics, shaft sealing and unit construction are detailed. Support systems such as the lube and seal supply system, turbine controls, etc., are reviewed. An extensive hydrocarbon turbine general specification is also included. 

EPRI PERSPECTIVE

\section{PROJECT DESCRIPTION}

This final report prepared for Research Project 928-1, is one of three reports focusing on the preliminary design of hydrocarbon turbine-generator sets for application with secondary working fluid (binary) cycles for development of geothermal power plants.

This report represents the results of a preliminary design study for an axial-flow hydrocarbon turbine designed to operate with a working fluid mixture of $80 \%$ isobutane $/ 20 \%$ isopentane at inlet conditions of 34.5 bars ( 500 psia), $146^{\circ} \mathrm{C}\left(295^{\circ} \mathrm{F}\right)$, and a back pressure of 5.0 bars ( 72 psia). RP928-3 and RP928-4 describe, respectively, in a similar design study, a radial inflow hydrocarbon turbine and the experimental measurements of selected thermodynamic properties for a $80 \%$ isobutane/20\% isopentane mixture and pure isobutane.

\section{PROJECT OBJECTIVES}

The broad objective of this project was to determine whether any advances in the state of the art would be required to scale-up turbine designs from present commercial practice and to construct a commercial-size axial flow hydrocarbon turbine for geothermal applications. This included development of a preliminary design for a $65 \mathrm{MW}$ (e) (gross) axial-flow hydrocarbon turbine/generator set, evaluation of turbine design and off-design performance, preliminary control system design, and selection and integration of a compatible generator.

\section{PROJECT RESULTS}

In focusing on the preliminary design of an axial-flow hydrocarbon turbine-generator set, the following parameters were investigated: gas properties at different turbine operating points, blade path aerodynamic designs, turbine performance, turbine mechanical and auxiliary component design, generator selection and turbine maintenance and reliability. 
The results of this study show that an axial flow hydrocarbon turbine-generator set with a capacity of up to $65 \mathrm{MW}$ (e) is well within the present state of the art. Specifically, existing turbine casing, rotor and blade design, and fabrication techniques are directly applicable; current turbine shaft seal technology will satisfy hydrocarbon containment requirements. Also, the design can be such that maintenance of the turbine can be accomplished without disconnecting the turbine inlet and exhaust piping. No new materials are necessary and the generator is a standard off-the-shelf item.

The results of this project indicate that if a utility desired to purchase an axialflow hydrocarbon turbine for geothermal service, it would be possible to do so with minor development risk up to $65 \mathrm{MW}(\mathrm{e})$. In this respect, the axial-flow turbine appears to have a slight advantage over the radial inflow turbine; however, the radial inflow turbine appears to have certain other advantages worthy of consideration. The main disadvantage of the axial-flow turbine is that it does not perform well under condensing conditions; therefore, throttling may be necessary to assure operation in the vapor region. Since neither machine has seen geothermal. service, it is not possible to precisely determine which is best. Test or service data for both types under similar conditions are needed to make further comparisons.

This information will be beneficial in selecting turbine configurations and assessing whether or not to proceed with geothermal development based on the binary cycle.

Denis A. LeZotte, Project Manager

Fossil Fuel and Advanced Systems Division 


\section{CONTENTS}

Section

1 SUMMARY

1-1

2 INTRODUCTION

2-1

3 GAS PROPERTIES

3-1

Avallable Heat

3-1

Dew Line

3-6

Purity Effects

3-7

Real Versus Ideal Gas

3-8

4

AERODYNAMIC DESIGN

4-1

Design Gas Selection

4-1

Blade Path Design

4-1

Turbine Losses

4-3

Turbine Performance

4-7

Turbine Scaling

4-17

5 MECHANICAL DESTGN

5-1

Mechanical Design Objectives

5-1

Flange Design

5-2

Outer Casing

5-4

Endwall and Endwall Bolting

j-7

Rotor

5-7

Bearings

5-9

Shaft Seals

5-9

Rotation Blades

5-10

Stator Diafram

5-13

Inner Casing

5-13

Coup1ing

5-13

Trip Device

5-13

Materials

5-14

Unit Assembly

5-16

Instrumentation 
6 AUXILIARY COMPONENTS

Lube and Seal 0il System

Turbine-Generator String

6-5

Turbine-Generator - Torsional Critical Speed Analysis

6-6

Turbine Design - System Interaction

6-9

Gas Piping Loads and Thermal Growth

6-12

Turbine Specifications

6-12

7 SYSTEM AND CONTROLS

$7-1$

Controls

$7-1$

Turbine Trip

7-3

Auxiliary Controls and Instrumentation

$7-5$

Turbine Governor Control

Contro1 Response

$7-6$

Trip and Throttle Valve

7-6

Cycle Thermal Efficiency

7-9

8 MAINTENANCE AND RELIABILITY

8-1

Maintenance

8-1

Reliability

8-2

Spare Parts

8-3

Manufacturer's Shop Testing

8-4

Field Performance Tests

8-4

Guarantee and Warranty

8-4

9 PRICE AND DELIVERY

9-1

Price

9-1

Delivery

9-1

Bill of Material

9-1

Spare Parts Pricing

9-3

10 REFERENCES

$10-1$

APPENDIX

A-1 GAS TABLES

Al-1

B-1 EPRI 65MW AXIAL FLOW HC TURBINE-CRITICAL SPEED AND UNBALANCED

B1-1 RESPONSE ANALYSIS-STIFF ROTOR

B2-1

B-2 ROTOR CRITICAL SPEED AND UNBALANCE RESPONSE ANALYSIS EPRI 65 MW AXIAL FLOW HC TURBINE-FLEXIBLE ROTOR 
C-1 SPECIFICATIONS FOR HYDROCARBON TURBINE-GENERATOR SET

1. General

C1-1

2. Turbine Design

C1-4

3. Lubrication and Seal 0il System Design

C1-8

4. Generator Design

C1-13

5. Instrumentation and Protective Devices

C1-13

6. Inspection

C1-15

7. Testing

C1-15

8. Preparation for Shipment

C1-16

D-1 API 614 (9/73) LUBE AND SEAL OIL SYSTEMS-ELLIOTT COMMENTS

D1-1 AND EXCEPTIONS

D-2 OIL SYSTEM COMPONENTS

D2-1

Oil Reservoir

D2-1

oil Coolers

D2-1

Transfer Value

D2-1

0il Filters

D2-1

Main and Auxiliary Pumps

D2-1

Pump Drivers-Motors

D2-2

Accumulators

D2-2

Auxiliary Pump Control

D2-2

Back Pressure Regulator

D2-2

Pressure Regulators

D2-2

Thermometers

D2-2

Pressure Gauges

D2-3

Sight Flow Indicators

D2-3 
Switches

D2-3

Rellef Valves

D2-3

Customer Connections and Piping

D2-3

E-1 ELLIOTT COMPANY GEOTHERMAL APPLICATION-HYDROGEN COOLED

E1-1 GENERATOR 
ILLUSTRATIONS

Figure

$\underline{\text { Page }}$

3-1 Isentropic Heat Drop - 80\% Iso-Butane - 20\% Iso-Pentane 3-3

3-2 Isentropic Heat Drop - 90\% Iso-Butane - 10\% Propane 3-4

3-3 Isentropic Heat Drop - Commercial Iso-Butane 3-5

3-4 Temperature Versus Enthalpy - Iso-Butane - Iso-Pentane 3-9 Mixture

3-5 Mol1ier Chart - Iso-Butane - Iso-Pentane Mixture 3-10

3-6 Temperature Versus Enthalpy - Iso-Butane - Propane Mixture 3-11

3-7 Mollier Chart - Iso-Butane - Propane Mixture 3-12

4-1 Ideal Gas Blade Path 4-2

4-2 Real Gas Blade Path $\quad 4-4$

4-3 Turbine Losses $\quad$ 4-5

4-4 Inlet and Exhaust Losses Versus Flow $\quad$ 4-8

4-5 Turbine Output Versus Efficiency Iso-Butane Mixture 4-9

4-6 Mass Flow Versus Generator Output $\quad$ 4-10 0.8 Iso-Butane/0.2 Iso-Pentane:

4-7 Mass Flow Versus Generator Output $\quad 4-11$ Commercial Iso-Butane

4-8 Mass Flow Versus Generator Output $\quad 4 \quad 12$

0.9 Iso-Butane/0.1 Propane
4-9 Flow Function Versus Pressure Ratio Iso-Butane Mixture

4-10 Blade Path, Efficiency Versus Pressure Rat1o : 4-15

4-11 Power Correction Versus Exhaust Pressure Rat1o $\quad$ 4-18

4-12 Blade Path Efficiency Versus Pressure Ratio $\quad$ 4-19

5-1 Turbine Cross Section Layout $\quad$ 5-3

5-2 Turbine Hardware $\quad \therefore \quad \therefore \quad$ 5-5

5-3 Combined (Pressure and Therma1) Hoop Stress $\quad$ 5-6

5-4 Goodman Diagram - 65MW - Hydrocarbon Turbine : ' 5-11

5-5 Campbe11 Diagram - 65MW - Hydrocarbon Turbine $\quad$ 5-12

6-1 Schemat1c Diagram, 011 Flow 6-3 


\begin{tabular}{|c|c|c|}
\hline $6-2$ & Turbine Generator Outline & $6-6$ \\
\hline $6-3$ & Torsional Critical Speeds Analysis & $6-8$ \\
\hline $6-4$ & Torsional Critical Speeds Analysis & $6-10$ \\
\hline $6-5$ & Turbine Generator Outline - Above Condensers & $6-11$ \\
\hline $6-6$ & Turbine Generator Outline - Discharge Plenum & $6-13$ \\
\hline $6-7$ & Maximum Allowable Piping Loads on Nozzles & $6-14$ \\
\hline $6-8$ & $\begin{array}{l}\text { Allowable Combination of Piping Force and Moment on } \\
\text { Each Nozzle }\end{array}$ & $6-15$ \\
\hline $6-9$ & Nozzle Thermal Growths & $6-16$ \\
\hline $7-1$ & Initial Conditions - $80 \%$ Iso-Butane/20\% Iso-Pentane & $7-2$ \\
\hline $7-2$ & Final Conditions - $90 \%$ Iso-Butane/10\% Propane & $7-4$ \\
\hline $7-3$ & Isenthalpic Valve Throttle & $7-7$ \\
\hline $7-4$ & Throttle Valve Available Heat Loss & $7-8$ \\
\hline $9-1$ & Pricing - Hydrocarbon Turbine-Generator Set & $9-2$ \\
\hline B1-1 & Rotor Analytical Model & B1-2 \\
\hline B1-2 & Rotor Computer Input Data & B1-3 \\
\hline B1-3 & Support Stiffness Versus Critical Speed & $\mathrm{B} 1-7$ \\
\hline B1-4 & Support Stiffness Versus Critical Speed & $\mathrm{B} 1-8$ \\
\hline B1-5 & Amplitude Versus Speed- Thrust End Bearing - Static & B1-9 \\
\hline B1-6 & Amplitude Versus Speed - Coupling End Bearing - Static & B1-10 \\
\hline B1-7 & Amplitude Versus Speed - Thrust End Bearing - Dynamic & B1-11 \\
\hline B1-8 & Amplitude Versus Speed - Coupling End Bearing - Dynamic & B1-12 \\
\hline B2-1 & Rotor Analytical Model & B2-2 \\
\hline$B 2-2$ & Rotor Computer Input Data & B2-3 \\
\hline B2-3 & Support Stiffness Versus Critical Speed & B2-7 \\
\hline B2-4 & Support Stiffness Versus Critical Speed & $\mathrm{B} 2-8$ \\
\hline B2-5 & Rotor Mode Shape & B2-9 \\
\hline B2-6 & Rotor Mode Shape & $\mathrm{B} 2-10$ \\
\hline B2-7 & Amplitude Versus Speed - Coupling End Bearing - Static & B2-11 \\
\hline B2-8 & Amplitude Versus Speed - Thrust End Bearing - Static & B2-12 \\
\hline B2-9 & Amplitude Versus Speed - Coupling End Bearing - Dynamic & B2-13 \\
\hline B2-10 & Amplitude Versus Speed - Thrust End Bearing - Dynamic & B2-14 \\
\hline
\end{tabular}


TABLES

\begin{tabular}{rlr} 
Table & & Page \\
\hline $2-1$ & Specified Design Point Data & $2-2$ \\
$3-1$ & Dew Points 8\% Iso-Butane-20\% Iso-Pentane & $3-2$ \\
$3-2$ & Isentropic Heat Drop & $3-6$ \\
$3-3$ & Dew Points/.8 Iso-Butane/.2 Iso-Pentane & $3-7$ \\
$3-4$ & Vapor Pressure of Hydrocarbons & $3-7$ \\
$4-1$ & Flange Flow Requirements & $4-1$ \\
$5-1$ & Flange Design Data & $5-2$ \\
$5-2$ & Rotor Critical Speed Results & $5-8$ \\
$5-3$ & Turbine Materials & $5-15$ \\
$6-1$ & Auxiliary Service & $6-4$ \\
$6-2$ & Turbine Generator Component Weights & $6-5$ \\
$6-3$ & Inertia and Spring Constants & $6-6$ \\
$7-1$ & Cycle Thermal Analysis & $7-9$ \\
A-1 & 80\% Iso-Butane - 20\% Iso-Pentane & A1-1 \\
A-2 & 90\% Iso-Butane - 10\% Propane & A2-1 \\
A-3 & Commercial Iso-Butane & A3-1 \\
B1-1 & Bearing Parameters-Journal End & $B 1-4$ \\
B1-2 & Parameters-Thrust End & B1-5 \\
B2-1 & Bearing Parameters-Journal End & $B 2-4$ \\
B2-2 & Bearing Parameters-Thrust End & $B 2-5$
\end{tabular}


Section 1

SUMMARY

A feasibility design study for a 65 MW (e) (gross) turbine generator set operating with an iso-butane mixture as the motive fluid has been completed. A design hardware-oriented concept was used to prove out feasibility within today's state-of-the-art for such a unit.

The barrel type axial flow hydrocarbon turbine was designed to operate on an $80 \%$ 1so-butane $20 \%$ iso-pentane mixture at inlet conditions of 34.5 bar ( 500 psia), $146^{\circ} \mathrm{C}\left(295^{\circ} \mathrm{F}\right)$ and a back pressure of 5.0 bar $(72 \mathrm{psia})$. The design proceeded to the point where construction feasibility has been selected. In addition, performance was computed for the operation of this turbine on commercial iso-butane gas as well as the $90 \%$ iso-butane $10 \%$ propane gas mixture with appropriate changes in the inlet and discharge conditions.

The unit was designed using gas properties calculated by modified Benedict-WebbRubin equations-of-state. It was found that the specified design point was very close to the liquid region, and that a temperature decline of $2.8^{\circ} \mathrm{C}\left(5^{\circ} \mathrm{F}\right)$ would put the entire turbine operation within the vapor dome instead of being in the super-heat region. The gas properties, as used for this turbine design, were verified by cross correlation with other standard gas equations-of-state. Experimental data should be generated to verify these properties and thereby prove-out the turbine design assumptions.

The turbine is a double flow unit with three stages of expansion. The operating speed is 3600 RPM and it is direct-coupled to a two-pole hydrogen cooled generator putting out $65 \mathrm{MW}$ at 13,800 volts. The turbine-generator is well within the state of the art:

- There are no new materials being utilized.

- The turbine aerodynamics are subsonic and the stages are adapted from gas and steam turbine vane profiles. 
- The turbine shaft seals keep the gas within the system to avoid hazardous leakage conditions and are we11 proven.

- The generator is an "off-the-shelf" item designed for use with gas turbines for standard power plant applications.

Individual oil systems will be supplied to the turbine and the generator. These oil systems will not be combined due to the hydrogen atmosphere within the generator and the possible difficulties with contamination.

A control scheme for this system has been proposed and is outlined within the report. The control scheme is based on combining current practices of steam generation and chemical processing systems. A control system analysis should be undertaken to establish contro1 response requirements for system stability. 
Section 2

\section{INTRODUCTION}

The purpose of this report is to demonstrate the feasibility of a large $65 \mathrm{MW}_{\mathrm{e}}$ (gross) axial design double-flow hydrocarbon turbine-generator untt. The project objectives are as follows:

- Evaluate the present state-of-the-art for the design and construction of an axial double-flow hydrocarbon turbine.

- Establish a conceptual design for a nominal $65 \mathrm{MW}$ (gross) axtal double-flow hydrocarbon turbine.

- Evaluate off-design performance for seasonal variations and long term thermal depletion.

- Establish a conceptual turbine-system control scheme.

- Size and select a generator compatible with the proposed turbine concept.

To achieve these objectives, a hardware oriented design was initiated. The turbine design parameters specified by the Electric Power Research Institute (EPRI) are 1isted in Table 2-1. The design steps were as follows:

- Define the gas properties and the conceptual turbine design point.

- Size the aerodynamic blade path and establish the flow requirements.

- Rough out mechanical design to contain the blade path.

- Evaluate rough design components and revise as required.

- Layout the conceptual turbine cross-section.

- Compute performance for off-design conditions.

- Select auxiliary components and review control concepts.

The overall objectives of this project have been achieved in that a 65 MW (gross) axial flow hydrocarbon turbine concept is proposed and is within the present stateof-the-art.

The primary area of uncertainty is the actual properties of the iso-butane gas mixtures. The definition of the vapor dome is critical since the specified design 
Table 2-1

SPECIFIED DESIGN POINT DATA

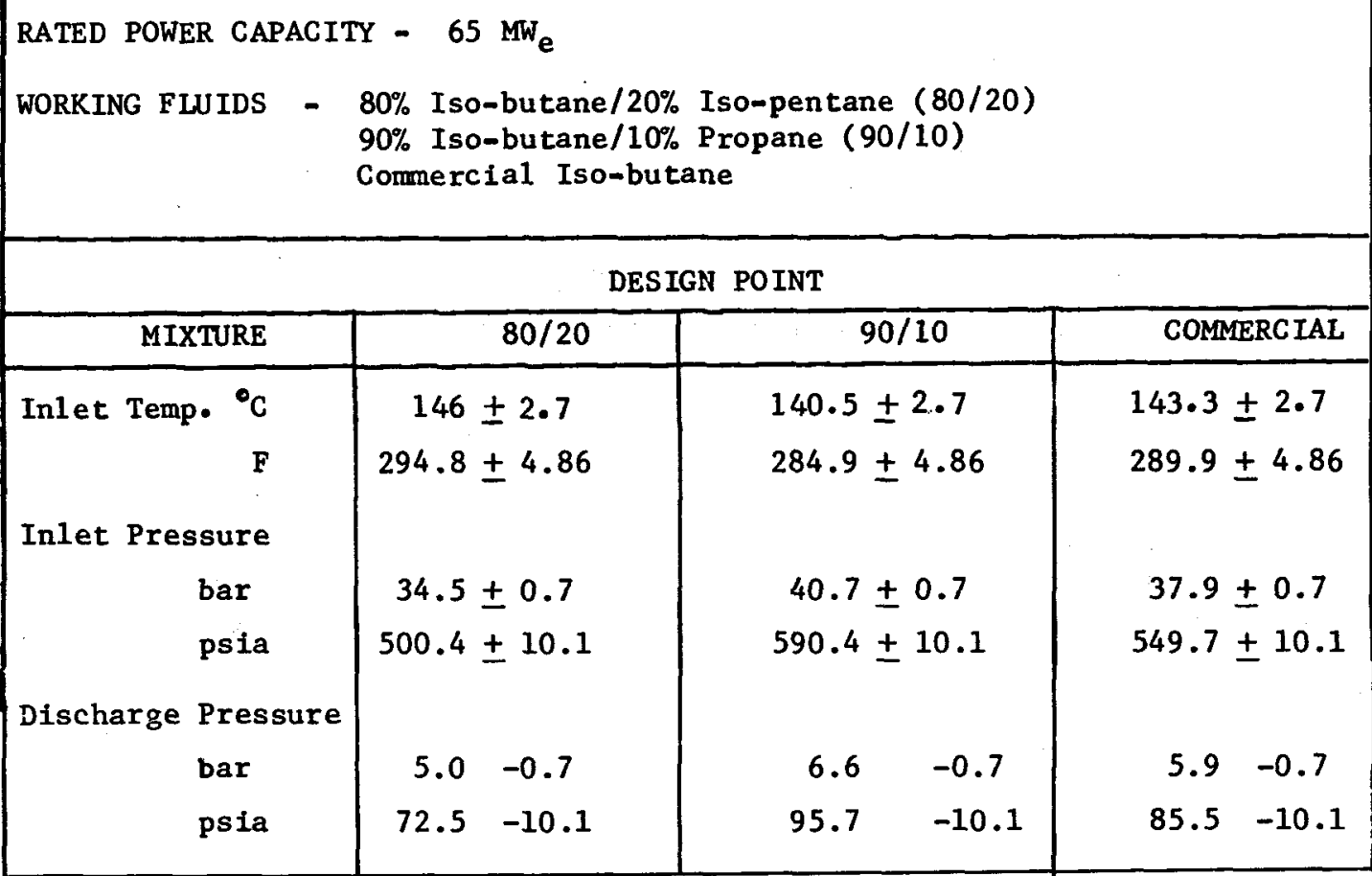

point is quite near the saturation line. Experimental data should be generated for the specified gas mixtures to define the mixture properties and the vapor dome.

The generator design information was supplied by Westinghouse Electric Corporation, East Pittsburgh, Pennsylvania. 
Section 3

GAS PROPERTIES

The gas properties for the 1so-butane mixtures were computed using modified BenedictWebb-Rubin equations of state (BWR). Mollier chart data were generated for the three specified gases:

- $80 \%$ Iso-butane - $20 \%$ Iso-pentane $(80 / 20)$

- $90 \%$ Iso-butane - $10 \%$ Propane (90/10)

- Commercial iso-butane - 96.8\% Iso-butane, $2.8 \% \mathrm{~N}$-butane, $0.4 \%$ Propane

Appendixes $\mathrm{Al}, \mathrm{A} 2$, and $\mathrm{A} 3$ are a compilation of the necessary point data needed for constructing Mollier charts for the three gas mixtures. The dew point data, which defines the vapor dome, is listed in Table 3-1 for the $80 / 20,90 / 10$ and commercial iso-butane mixtures. The Mollier charts for the $80 / 20$ and $90 / 10$ gas mixtures are shown in Figures $3-1$ and 3-2 respectively. The chart for the commercial mixture is shown in Figure $3-3$

\section{AVAILABLE HEAT}

The available heat is defined as the enthalpy change due to an isentropic expansion. It is the heat available to the turbine for conversion to mechanical power. Projected on the Mollier charts (Figure 3-1, 3-2, 3-3) is the isentropic expansion from the specified inlet pressure and temperature to the specified discharge pressure. Isentropic expansions are also for the extremes of the inlet temperature, $\pm 2.7^{\circ} \mathrm{C}\left( \pm 5^{\circ} \mathrm{F}\right)$. For both gases, the design expansion crosses the vapor region. In the case of the $-2.7^{\circ} \mathrm{C}\left(-5^{\circ} \mathrm{F}\right)$ condition, the expansion is "wet" in that it is entirely under the vapor dome. This "wet" expansion results in less avallable heat, lower turbine efficiency and possible turbine blade erosion problems from droplet formation. The maximum inlet pressure, 35.2 bar ( 510 psia), also results in a "wet" expansion.

To insure turbine operation in the "super-heat" region, a throttle valve was included in the control system. This valve will provide sufficient isenthalpic pressure drop (constant enthalpy) to maintain the turbine inlet conditions in the gaseous region. 
Table 3-1

DEW POINT DATA

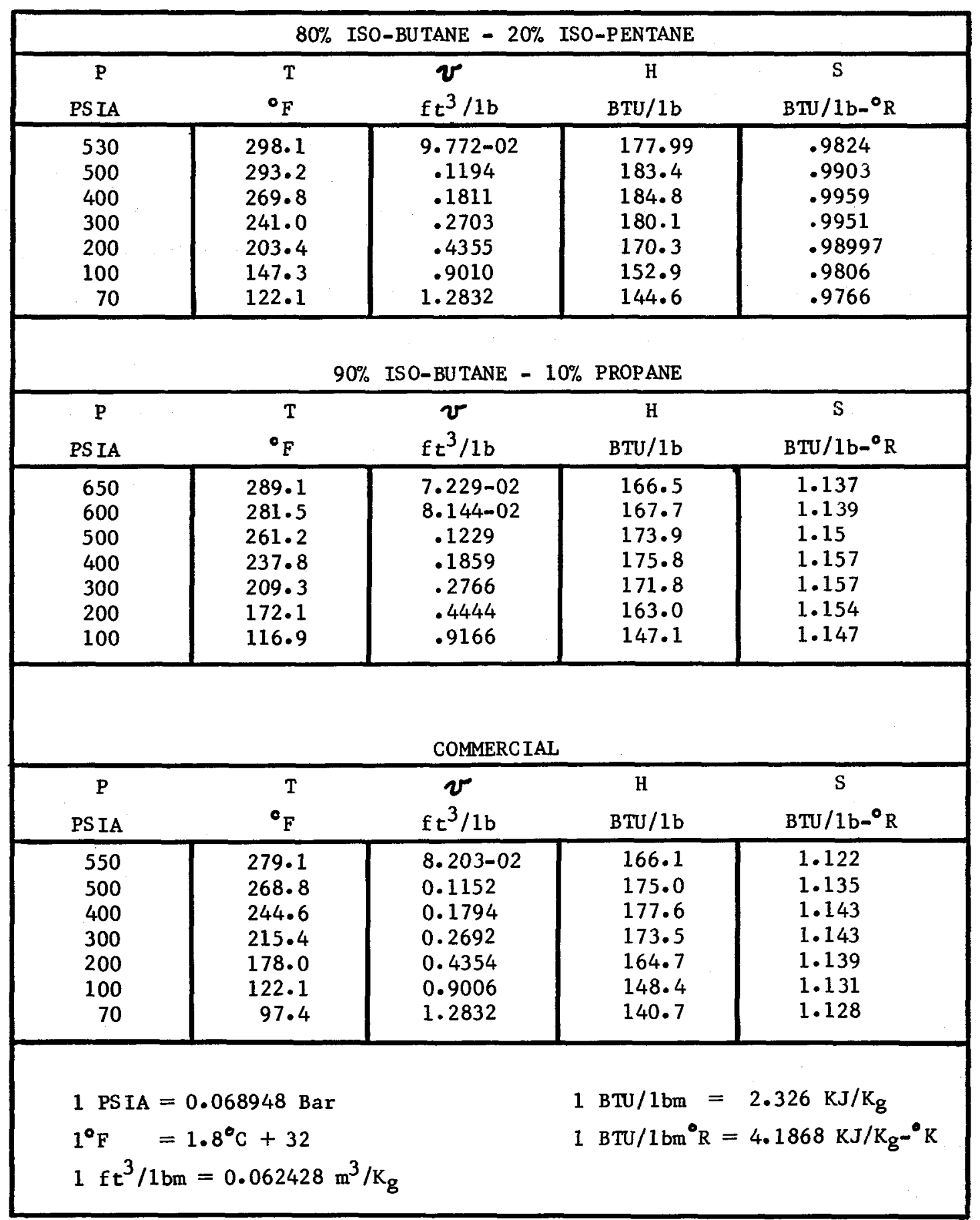




\section{ISENTROPIC HEAT DROP}

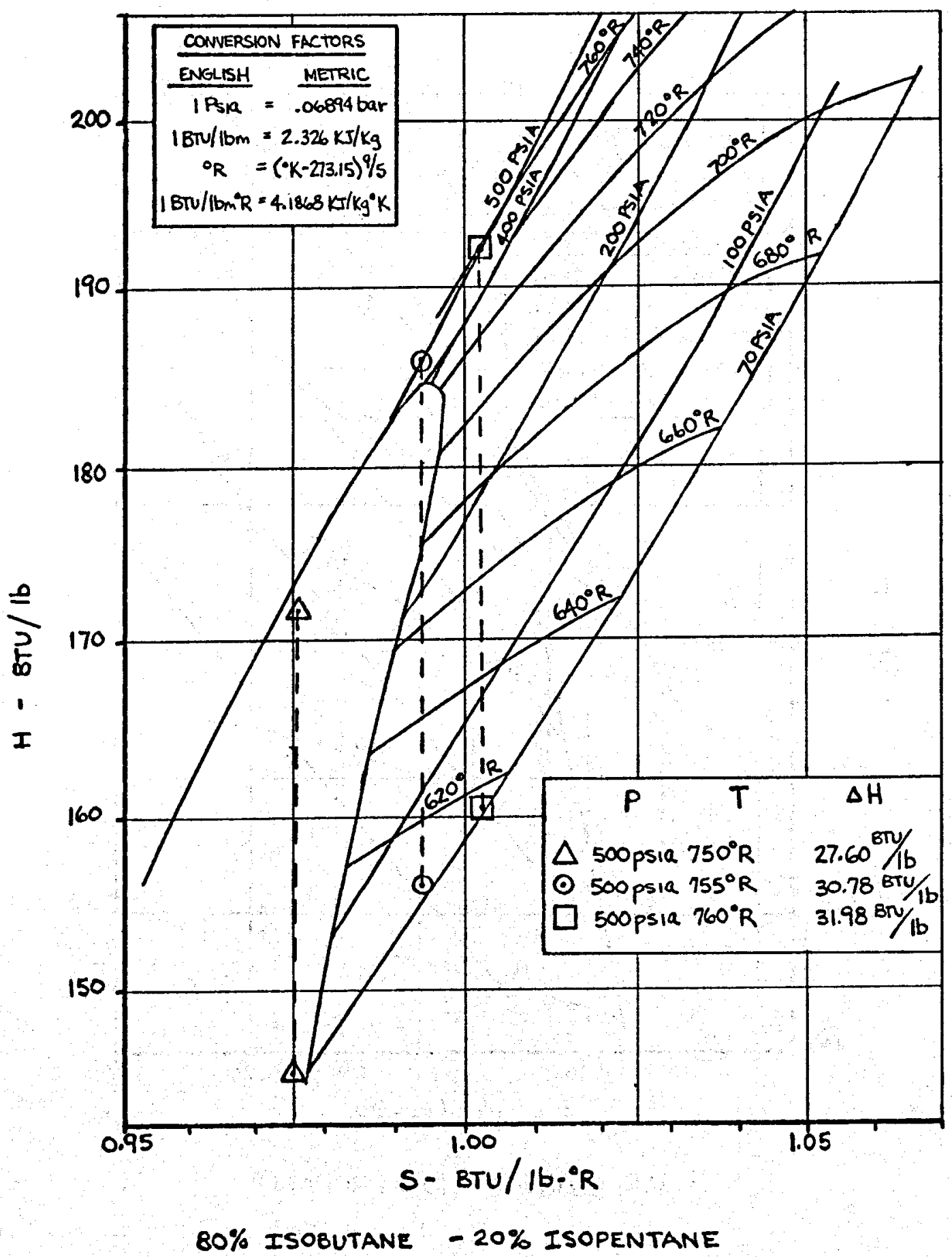

Figure 3-1. Isentropic Heat Drop - $80 \%$ Iso-Butane - $20 \%$ Iso-Pentane 


\section{ISENTROPIC HEAT DROP}

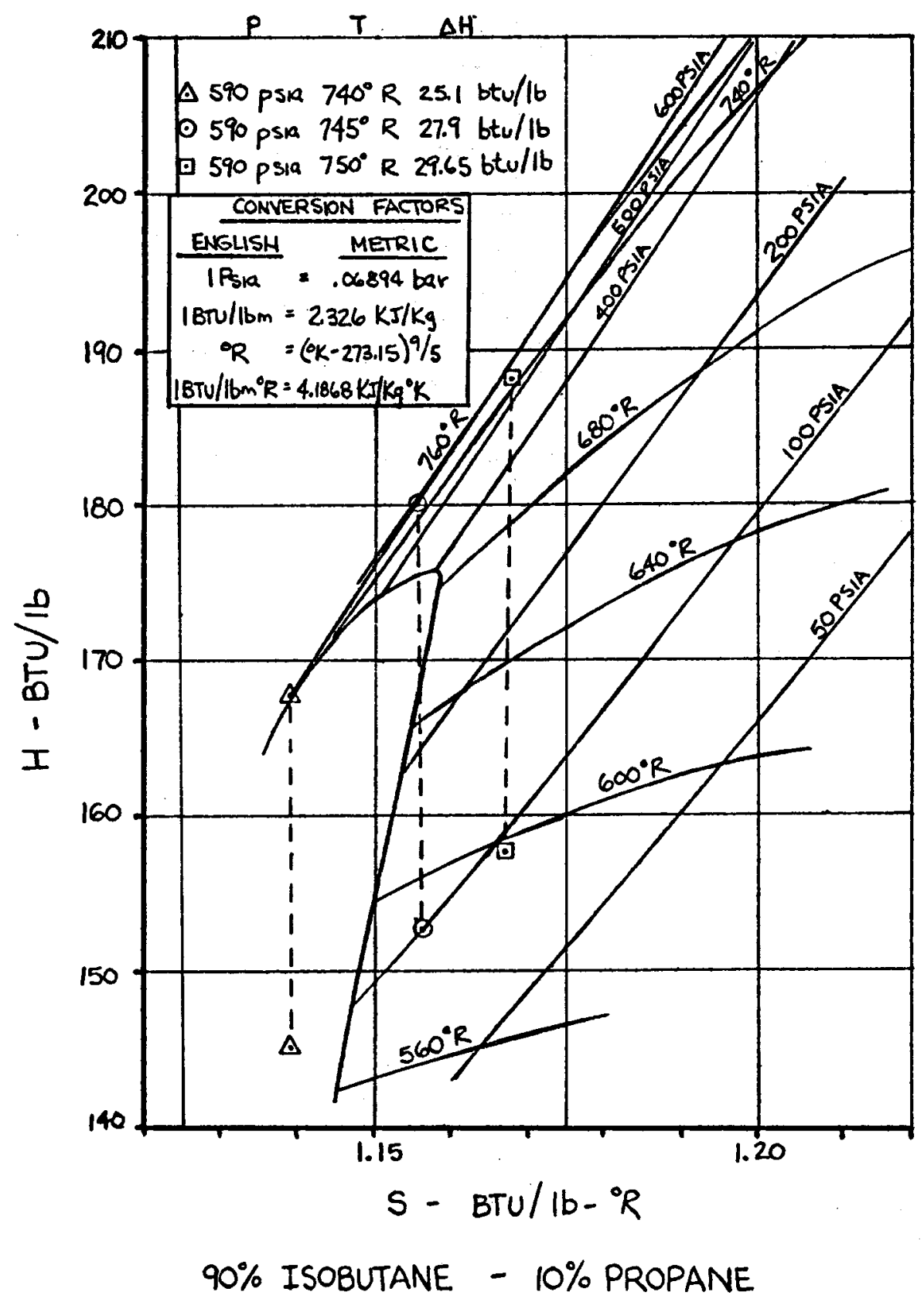

Figure 3-2. Isentropic Heat Drop - $90 \%$ Iso-Butane - $10 \%$ Iso-Pentane 


\section{ISENTROPIC HEAT DROP}

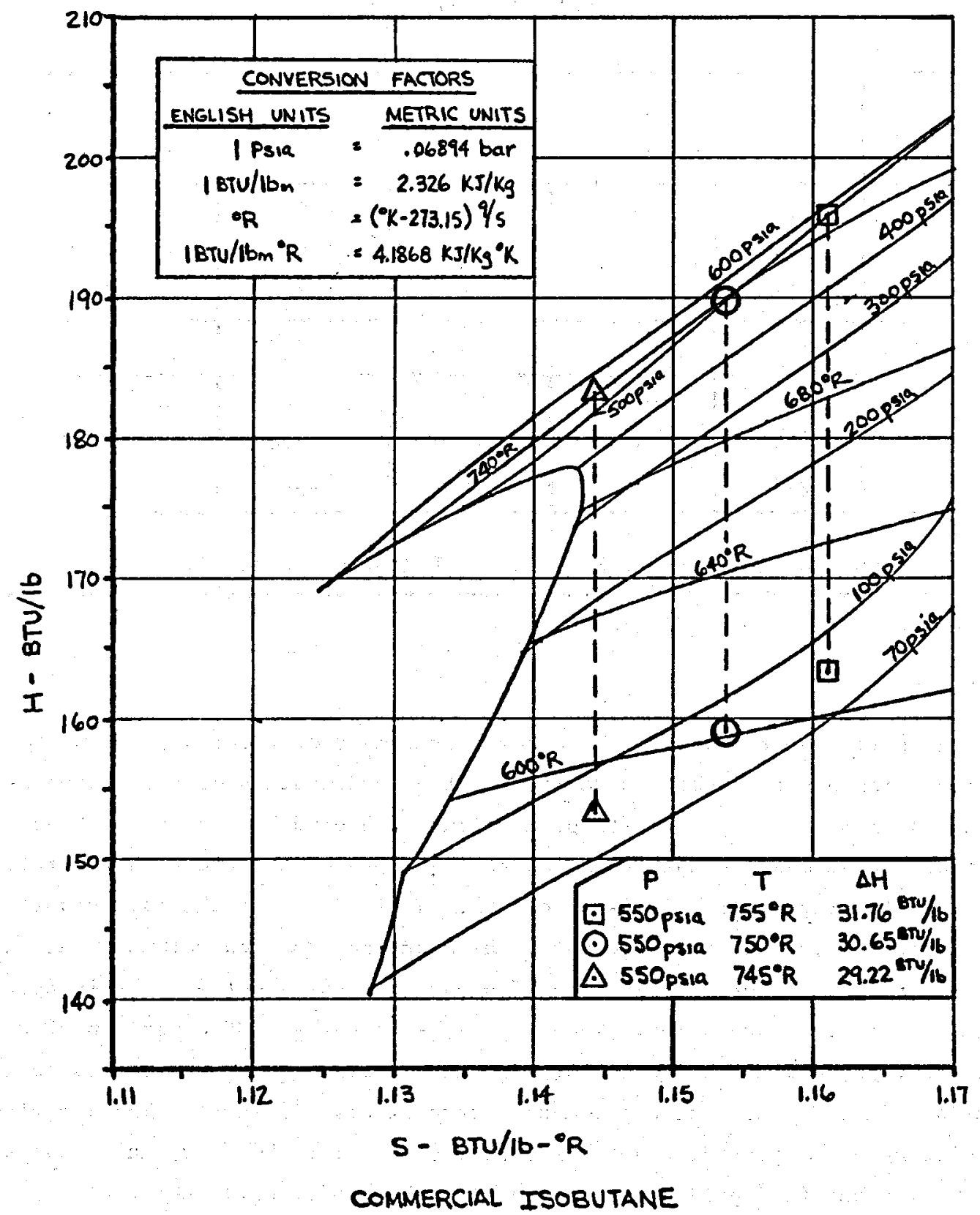

Figure 3-3. Isentropic Heat Drop - Commercial Iso-Butane 
Table 3-2 is a summary of the design points and the available heat associated with them.

Table 3-2

ISENTROPIC HEAT DROP

\begin{tabular}{|c|c|c|c|c|c|}
\hline MIXTURE & $\begin{array}{c}\mathrm{P}_{1} \\
\text { psia }\end{array}$ & $\stackrel{\mathrm{T}}{1}_{\mathrm{F}}$ & $\begin{array}{c}\mathrm{P}_{2} \\
\text { psia }\end{array}$ & $\begin{array}{l}\mathrm{T}_{2} \\
{ }^{\circ} \mathrm{F}\end{array}$ & $\underset{\mathrm{Btu} / 1 \mathrm{~b}}{\Delta_{\mathrm{H}}}$ \\
\hline \multirow[t]{3}{*}{$80 / 20$} & 500 & 300 & 72 & 155.9 & 31.98 \\
\hline & 500 & 295 & 72 & 145.5 & 30.78 \\
\hline & 500 & 290 & 72 & 123.8 & 27.60 \\
\hline COMMERC IAL & 550 & 295 & 85 & 140.7 & 29.3 \\
\hline \multirow[t]{3}{*}{$90 / 10$} & 590 & 290 & 96 & 137.9 & 29.65 \\
\hline & 590 & 285 & 96 & 125.8 & 28.10 \\
\hline & 590 & 280 & 96 & 128.4 & 25.12 \\
\hline
\end{tabular}

DEW LINE

The definition of the vapor dome becomes extremely critical as a result of the location of the specified design point. Verification of the BWR equations was made by comparing its predictions with predictions of the PengRobinson equations-of-state (NGPA), Mark V gas properties (General Electric), and the Starling equations-of-state. (See Table 3-3) of the four equations, three are in substantial agreement. The Starling equation values agree with the other three at pressures above 27.6 bar ( 400 psia) but are not in agreement at the lower pressures. Table 3-4 is a comparison of experimental data for a pure gas with the results of BWR and Starling. The BWR results agree within $1^{\circ} \mathrm{C}\left(2^{\circ} \mathrm{F}\right)$ with the experimental data at al1 pressures. The Starling results agree at pressures above 27.6 bar ( $400 \mathrm{psi}$ ); however, the results below 27.6 bar ( $400 \mathrm{psi}$ ) do not agree with the experimental data. 
Table 3-3

DEW POINTS $80 \%$ ISO-BUTANE - $20 \%$ ISO-PENTANE

\begin{tabular}{|c|c|c|c|c|}
\hline PRESSURE & \multicolumn{3}{|c|}{ TEMPERATURE } \\
\hline PS IA & $\begin{array}{c}\text { BWR } \\
{ }^{\circ} \mathrm{F}\end{array}$ & $\begin{array}{c}\text { MARK V } \\
{ }^{\circ} \mathrm{F}\end{array}$ & $\begin{array}{c}\text { PENG ROB } \\
{ }^{\circ} \mathrm{F}\end{array}$ & $\begin{array}{c}\text { STARLING } \\
{ }^{\circ} \mathrm{F}\end{array}$ \\
\hline 500 & 293.48 & 295.86 & 291.9 & 292 \\
450 & 281.96 & 284.09 & 281 & 181.5 \\
400 & 270.14 & 271.71 & 269 & 267.5 \\
300 & 241.44 & 242.70 & 240.5 & 233.3 \\
200 & 203.67 & 205.33 & 203 & 190 \\
100 & 147.66 & 149.70 & 147.5 & 122 \\
50 & 100.92 & 102.75 & 101 & 75.8 \\
\hline
\end{tabular}

Table 3-4

VAPOR PRESSURE OF HYDROCARBONS

\begin{tabular}{|c|c|c|c|c|c|c|}
\hline \multirow[t]{3}{*}{ PRESSURE } & \multicolumn{6}{|c|}{ TEMPERATURE } \\
\hline & \multicolumn{3}{|c|}{ ISO-BUTANE } & \multicolumn{3}{|c|}{ ISO-PENTANE } \\
\hline & $\begin{array}{l}\text { Exp } \\
{ }^{\circ} \mathrm{F}\end{array}$ & $\begin{array}{c}\text { strlg } \\
{ }^{\circ} \mathrm{F}\end{array}$ & $\begin{array}{l}\text { BWR } \\
O_{F}\end{array}$ & $\begin{array}{c}\text { Exp } \\
{ }_{\mathrm{O}}\end{array}$ & $\begin{array}{c}\text { Strlg } \\
{ }^{\circ} \mathrm{F}\end{array}$ & $\begin{array}{l}\text { BWR } \\
{ }^{\circ} \mathrm{F}\end{array}$ \\
\hline 500 & 268 & 268 & 268 & (370) & 375 & 369 \\
\hline 400 & 245 & 239 & 244 & 345 & 342 & 347 \\
\hline 300 & 216 & 206 & 214 & 312 & 304 & 314 \\
\hline 200 & 179 & 165 & 177 & 270 & 256 & 271 \\
\hline 100 & 122 & 104 & 122 & 210 & 185 & 209 \\
\hline 50 & 76 & 55 & 76 & 156 & 128 & 157 \\
\hline
\end{tabular}

\section{PURITY EFFECTS}

The closed loop system normally requires a recoverable gas bleed and will continuously need a make-up flow. Due to the method of injecting make-up gas into the system, the purity of the system may vary with time. This may affect the actual operating conditions and operating point of the power plant. 


\section{Iso-Butane/Iso-Pentane Mixture}

A temperature-enthalpy (T-H) diagram (Figure 3-4) was prepared for three mixtures of iso-butane/iso-pentane, specifically, the design 80/20 mixture, a $75 / 25$ mixture, and an 85/15 mixture. The T-H diagram shows the variation of the vapor dome or dew line with relation to purity. A Mollier chart, Figure 3-5 was prepared for the same mixtures. The isentropic expansion from 34.5 bar (500 psia), $146^{\circ} \mathrm{C}\left(295^{\circ} \mathrm{F}\right)$ to 5.0 bar ( 72 psia) is plotted on the Mollier Chart for each mixture. A $5 \%$ increase in the iso-pentane component, the $75 / 25 \mathrm{mix}$ ture, caused the isentropic expansion to be completely under the vapor dome and resulted in a $16 \%$ decrease in the available heat compared with the design mixture.

\section{Iso-Butane/Propane Mixture}

The properties for a $5 \%$ change in the iso-butane/propane mixture were computed. A temperature enthalpy (T-H) diagram and a Mollier chart were constructed (Figures 3-6 and 3-7). As can be seen on the Mollier chart, a decrease in the propane component of $5 \%$ would decrease the available heat by $7.4 \%$ and force the turbine to operate completely in the wet region (under the vapor dome).

Care must be exercised in making purity measurements. The system should be constantly monitored to avoid difficulties with the turbine as well as other components of the system, such as the condenser, pump or vapor generator.

REAL VERSUS IDEAL GAS

The Mollier tables list the compressibility factor, $Z$, for each computed state point. This factor is used as a correction to the Ideal Gas relationship:

$$
\text { - } \quad \mathrm{PV}=\frac{\mathrm{ZRT}}{\mathrm{MW}}
$$

where:

- $\quad \mathbf{P}=$ Pressure

- $\quad \mathrm{V}=$ Specific Volume

- $\quad R=$ Universal Gas Constant

- $\mathrm{MW}=$ Gas molecular weight

- $\mathrm{T}=$ Temperature

- $\quad \mathrm{Z}=$ Compressibility 


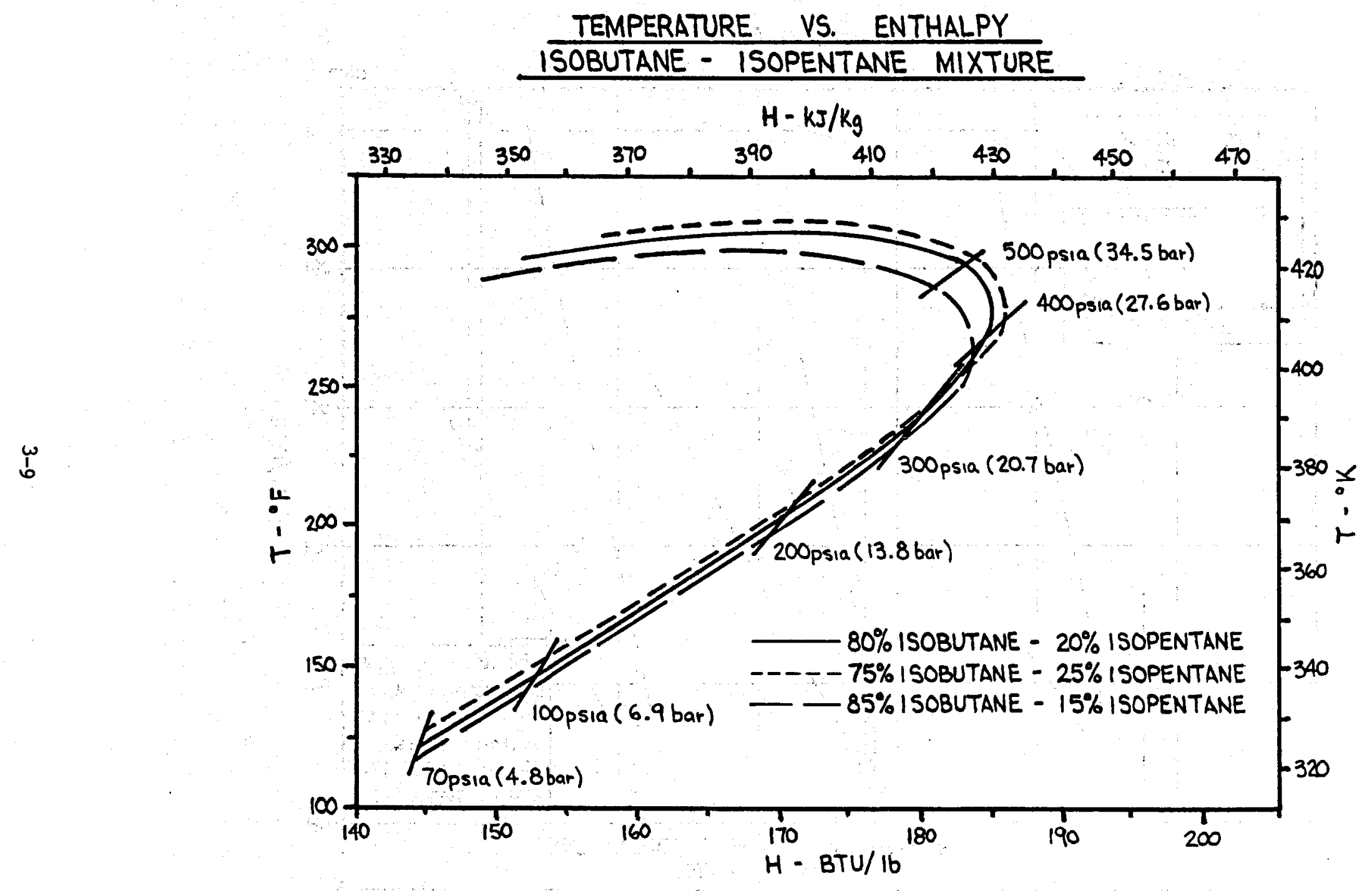

Figure 3n4, Temperature Versus Enthalpy - Iso-Butane - Iso-Pentane Mixture 


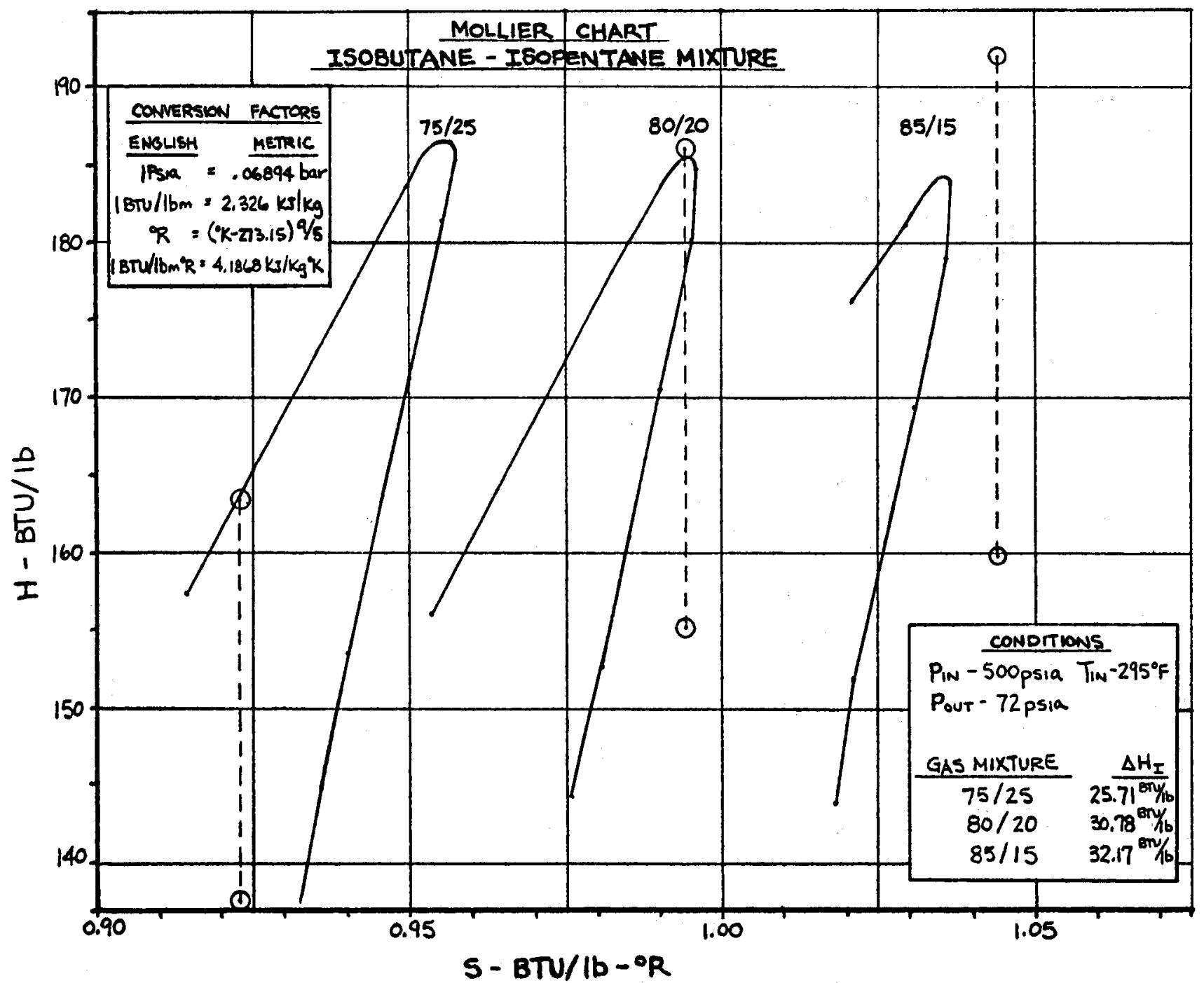

Figure 3-5. Mollier Chart - Iso-Butane - Iso-Pentane Mixture 


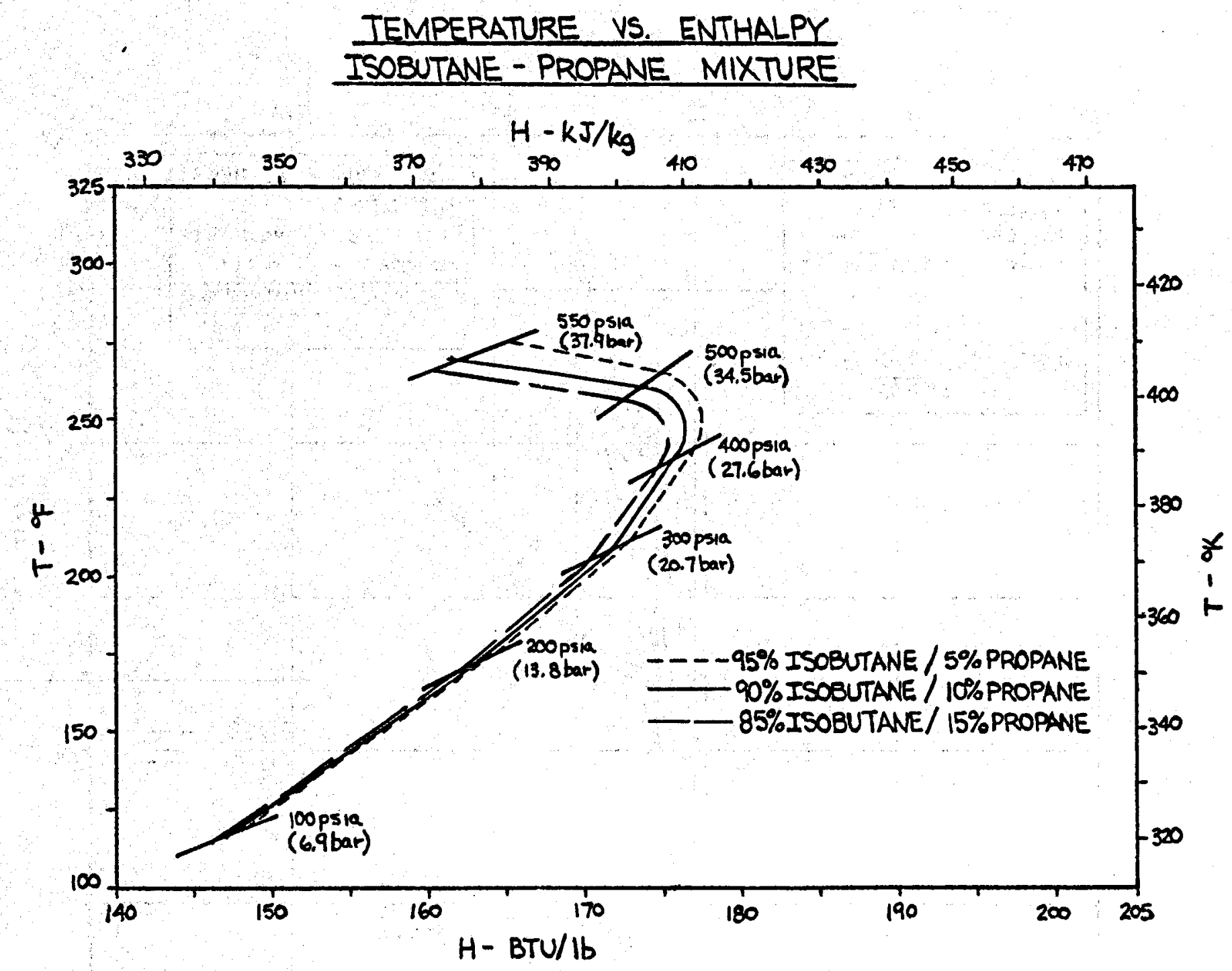

Figure 3-6. Temperature Versus Enthalpy - Iso-Butane - Propane Mixture 


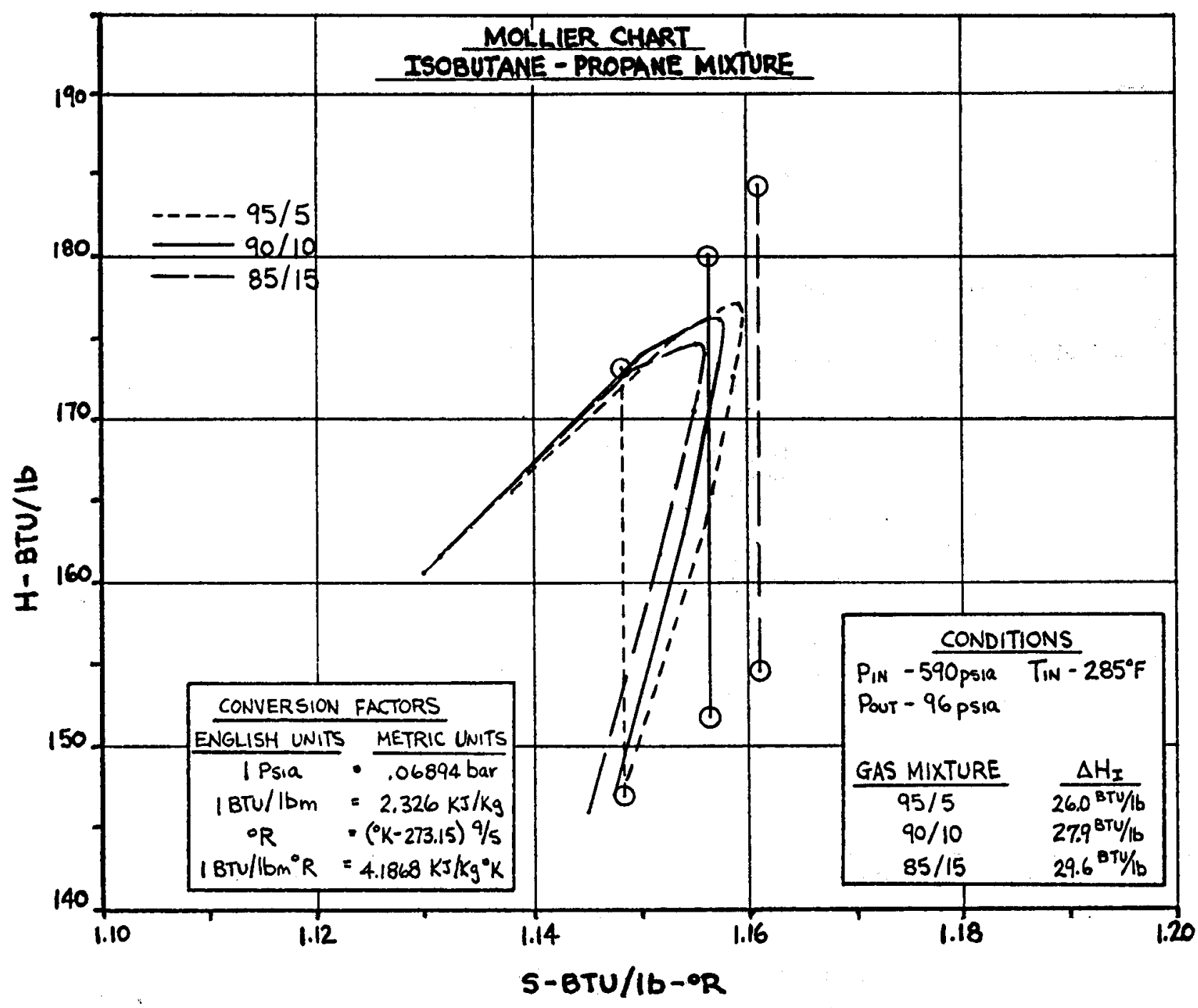

Figure 3-7. Mollier Chart - Iso-Butane - Propane Mixture 
A truly ideal gas has a $z=1.0$. The $80 / 20$ mixture has a $z=0.47$ at turbine inlet conditions.

The isentropic expansion for an ideal gas is defined by the relationship:

$$
\text { - } \frac{\mathrm{T}_{2}}{\mathrm{~T}_{1}}=\left(\frac{\mathrm{P}_{2}}{\mathrm{P} 1}\right) \quad \frac{\mathrm{K}-1}{\mathrm{~K}}
$$

The specified conditions are:

- $\quad \mathrm{P}_{1}=$ Inlet Pressure $=34.5$ bar

- $\mathrm{T}_{1}=$ Inlet Temperature $=419^{\circ} \mathrm{K}$

- $\mathrm{K}=$ Isentropic Exponent $=1.21$

- $\quad \mathrm{P}_{2}=$ Discharge Pressure $=5.0$ bar

which result in:

- $\mathrm{T}_{2}=419((5.0 / 34.5) \exp (1.2-1 / 1.2))$

- $\mathrm{T}_{2}=303.6 \mathrm{~K}=30.7^{\circ} \mathrm{C}$

For these same conditions, the Mollier chart predicts a $\mathrm{T}_{2}=62.8^{\circ} \mathrm{C}$ or an error of $32^{\circ} \mathrm{C}$ between the ideal gas expansion and the actual gas properties.

Based on the above calculation, the turbine blade path should only be computed using actual state point properties and not ideal gas relationships. 
Section 4

AERODYNAMIC DESIGN

DESIGN GAS SELFCTION

The design point for this turbine was established by rough sizing a turbine for both the $80 / 20$ and $90 / 10$ gas mixtures. It was found that the $80 / 20$ mixture required a larger flow area in the turbine than did the $90 / 10$ mixture. The $90 / 10$ mixture used in a turbine designed for the $80 / 20 \mathrm{mixture}$ would produce full power, but at a reduced efficiency. If the turbine design were sized for the $90 / 10$ mixture, the $80 / 20$ mixture would not attain full design power as the efficiency losses would off-set increases in mass flow rate. Tabulated in Table 4-1 are the estimated volume flow rate $\left(\mathrm{m}^{3} / \mathrm{h}\right)$ requirements at the inlet and discharge for the $80 / 20$ and 90/10 mixtures at their respective design points. These values were obtained from the required power, 65MW, the available heat and an assumed efficiency of 0.85 .

Table 4-1

FLANGE FLOW REQUIREMENTS

\begin{tabular}{|c|c|c|c|c|c|c|}
\hline & \multirow{2}{*}{$\underset{\mathrm{KJ} / \mathrm{Kg}}{\Delta \mathrm{H}_{\mathrm{I}}}$} & \multirow{2}{*}{$\begin{array}{c}\mathrm{G} \\
\mathrm{Kg} / \mathrm{s}\end{array}$} & \multicolumn{2}{|c|}{ INLET } & \multicolumn{2}{|c|}{ DISCHARGE } \\
\hline & & & $\mathrm{M}^{3} / \mathrm{Kg}$ & $M^{3} / h$ & $M^{3} / \mathrm{Kg}$ & $M^{3} / h$ \\
\hline $80 / 20$ & $71 \cdot 57$ & 1068.9 & 0.00778 & 29897 & 0.0823 & 316767 \\
\hline $90 / 10$ & 65.41 & 1165. & 0.00637 & 26712 & 0.0618 & 259000 \\
\hline
\end{tabular}

BLADE PATH DESIGN

Once the design gas composition had been established, a preliminary blade path was computed using modified ideal gas relationships. The specific heat, viscosity, and molecular weight were modified to account for the effects of compressibility at each expansion stage. Figure 4-1 shows a blade path with the computed pressures 


\section{IDEAL GAS BLADE PATH}

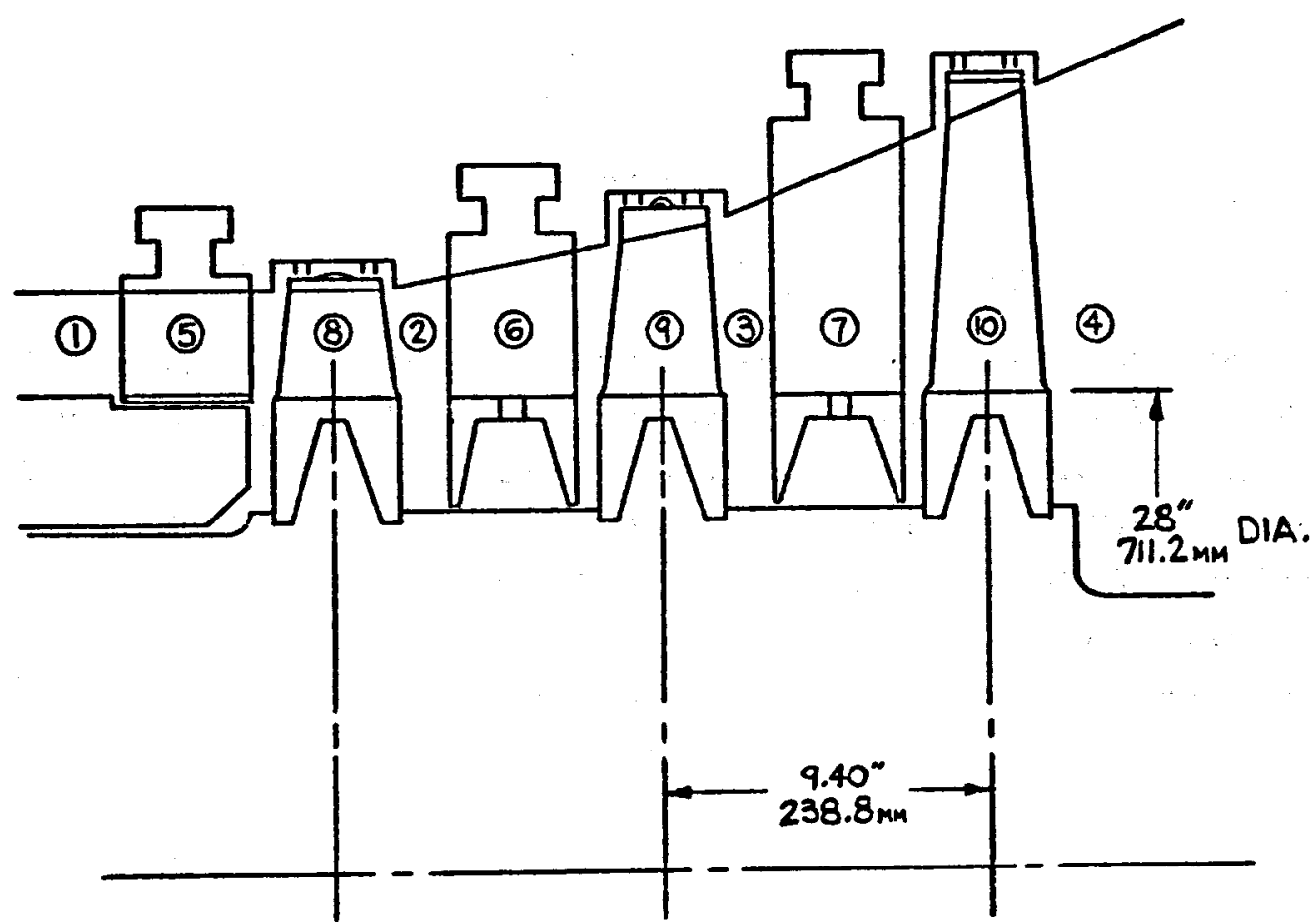

GAS - $80 \%$ ISOBUTANE - $20 \%$ ISOPENTANE

FLOW $-2614 \mathrm{lb} / \mathrm{sec}-1185.4 \mathrm{~kg} / \mathrm{sec}$

$$
M W-63.7
$$

EFFICIENCY-.808

$$
\begin{aligned}
& \text { POINT (1) } P=500 \text { psia } T=295^{\circ} \mathrm{F} \\
& \text { (2) } P=225_{p s i a} \quad T=266^{\circ} \mathrm{F} \\
& \text { (3) } P=125 \text { pise } T=243^{\circ} \mathrm{F} \\
& \text { (4) } P=72 p s i a \quad T=223^{\circ} \mathrm{F} \\
& \text { (5) } A=81 \mathrm{in}^{2} \\
& \text {.6) } A=206 \mathrm{in}^{2} \\
& \text { (7) } A=389 \mathrm{in}^{2} \\
& \text { (3) } H_{T}=2.874^{\prime \prime} \quad A=116 \mathrm{in}^{2} \\
& \text { (9) } H_{T}=5.438^{\prime \prime} \quad A=294 \mathrm{in}^{2} \\
& \text { (10) } H_{T}=10.5^{\circ} \quad A=556 \mathrm{in}^{2}
\end{aligned}
$$

$$
\begin{gathered}
P=34.5 \text { bar } \quad T=419.8^{\circ} \mathrm{K} \\
P=15.5 \text { bar } \quad T=403.7^{\circ} \mathrm{K} \\
P=8.6 \text { bar } \quad T=390.9^{\circ} \mathrm{K} \\
P=5.0 \text { bar } \quad T=379.8^{\circ} \mathrm{K} \\
A=52.258 \mathrm{~mm}^{2} \\
A=132,903 \mathrm{~mm}^{2} \\
A=250,967.2 \mathrm{~mm}^{2}
\end{gathered}
$$

$$
\begin{array}{ll}
H_{T}=73 \mathrm{~mm} & A=74,838.6 \mathrm{~mm}^{2} \\
H_{T}=150.8 \mathrm{~mm} & A=189,677 \mathrm{~mm}^{2} \\
H_{T}=266.7 \mathrm{~mm} & A=358,709 \mathrm{~mm}^{2}
\end{array}
$$

Figure 4-1. Ideal Gas Blade Path 
and temperatures for the interstage conditions based on the modified ideal gas relationships. This calculation, while not accurate, provided information for initially selecting the vane profile and establishing the rotor blade base diameter for the turbine design.

Figure 4-2 indicates the final blade path designed using the actual gas properties. The interstage pressures and temperatures are included on this diagram. The area schedule, based on the ideal gas calculations is different from that of the real gas calculation. : The final design required a greater inlet area and a smaller discharge area than that predicted by the ideal gas approximation. The blade path efficiency for this design using the real gas properties is 0.8766 where as the efficiency computed for the ideal case was 0.808 . The real gas calculation allowed for a 3.4 bar ( $50 \mathrm{psi}$ ) pressure drop for control valve and inlet losses. The energy loss associated with this pressure drop was computed by assuming an isenthalpic throttling. With design inlet conditions upstream of the valve, the blade path inlet conditions would be 31 bar ( $450 \mathrm{psi}), 139^{\circ} \mathrm{C}\left(283^{\circ} \mathrm{F}\right)$.

\section{TURBINE LOSSES}

The total available energy to the turbine cannot be completely converted to mechanical power due to the flow and frictional losses. The major losses are shown in Figure 4-3 on an Enthalpy-Entropy Diagram. The losses shown start with the isenthalpic throttling of the supply fluid which at design point was assumed to be a 3.4 bar (50 psi) pressure drop. The selected valve design is capable of a 1.7 bar (25 psi) drop at design flow conditions. The additional 1.7 bar (25 psi) was assumed for control purposes. The next loss is the inlet loss which is an isenthalpic pressure drop reducing the avallable energy. The blade path losses include the blade tip leakage, fluid friction, and fluid turbulence. The final loss is the exhaust pressure drop. All of these losses affect the thermal efficlency of the turbine, that is the amount of available heat not converted to mechanical power. The turbine also has mechanical losses due to friction in the journal and thrust bearing. These losses are normally subtracted from the mechanical power since they represent a constant power drain.

\section{Inlet Discharge Losses}

The turbine inlet was designed following standard practices for turbine and compressor designs. Basically, the flow path areas are computed to provide a constant velocity from the flange, down through the nozzle, and into the annulus around the periphery of the inlet guide vanes. The gas stream is then accelerated through the guide vanes and turned to flow axially into the inlet of the first stage. 


\section{REAL GAS BLADE PATH}

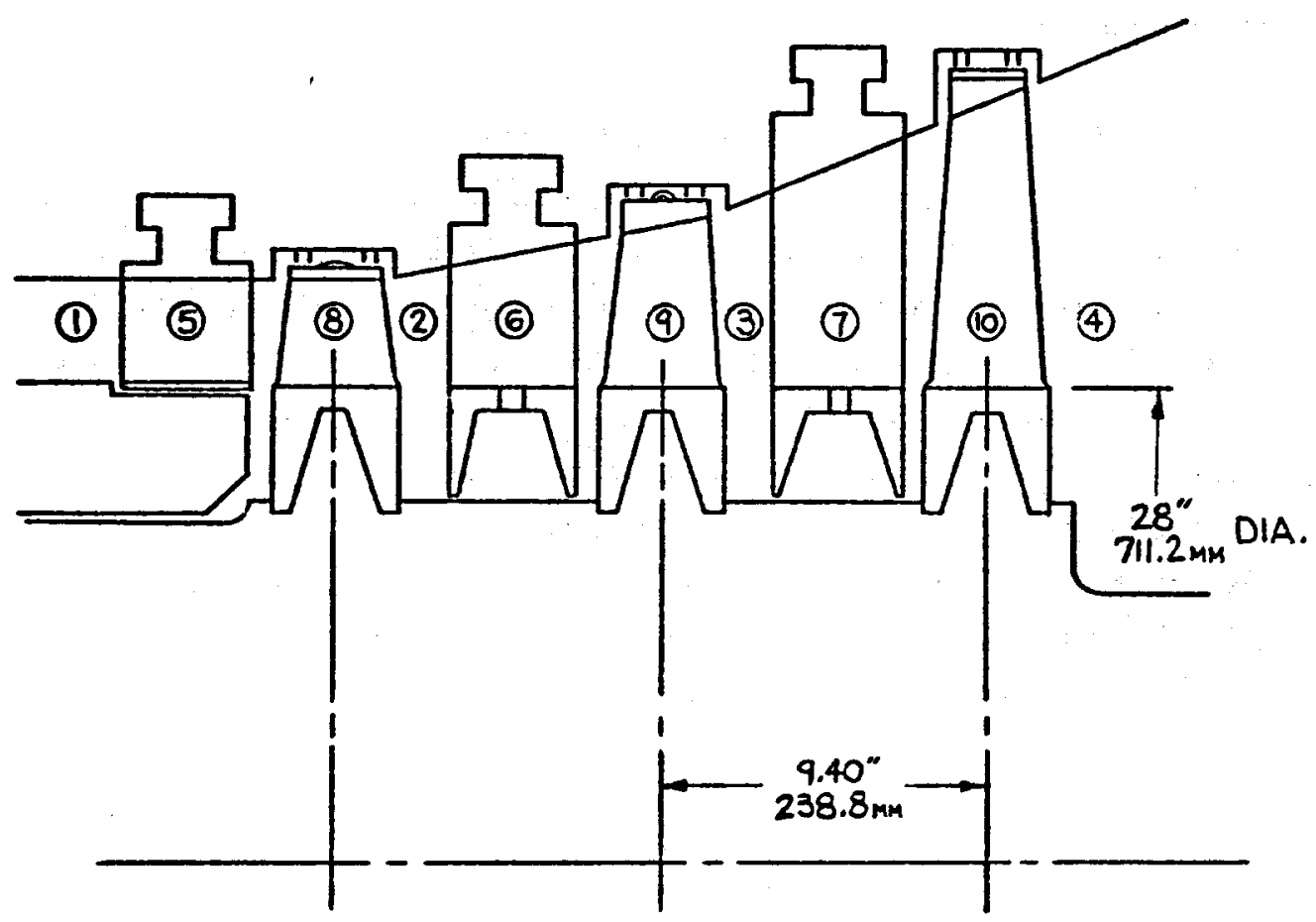
GAS - $80 \%$ ISOBUTANE - $20 \%$ ISOPENTANE
FLOW - $2424 \mathrm{lb} / \mathrm{sec}-1099.3 \mathrm{~kg} / \mathrm{sec}$.
MW - 65.9
EFFICIENCY - .8766

POINI (1) $P=450$ psia $T=285^{\circ} \mathrm{F}$

(2) $P=234$ psia $T=247^{\circ} \mathrm{F}$

(3) $P=122$ psia $T=196^{\circ} \mathrm{F}$

(4) $P=72 p s i a \quad T=156.5^{\circ} \mathrm{F}$

(5) $A=921 \mathrm{n}^{2}$

(6) $\quad A=171 \mathrm{in}^{2}$

(7) $\quad A=326 \mathrm{in}^{2}$

(8) $H_{T}=3.2^{\prime \prime} \quad A=131 \mathrm{ln}^{2}$

(9) $H_{T}=5.05^{\prime \prime} \quad A=248 \mathrm{in}^{2}$

(10) $H_{T}=9.0^{\prime \prime} \quad A=466 \mathrm{in}^{2}$

$$
\begin{array}{cc}
P=31 \text { bar } & T=414.2^{\circ} \mathrm{K} \\
P=16.1 \text { bar } & T=393.1^{\circ} \mathrm{K} \\
P=8.4 \text { bar } & T=364.7^{\circ} \mathrm{K} \\
P=5 \text { bar } \quad T=342.8^{\circ} \mathrm{K} . \\
A=59,354.7 \mathrm{~mm}^{2} \\
A=110,322.4 \mathrm{~mm}^{2} \\
A=210,322.2 \mathrm{~mm}^{2}
\end{array}
$$

$H_{T}=81.3 \mathrm{~mm} \quad A=84.516 \mathrm{~mm}^{2}$

$H_{T}=128.3 \mathrm{~mm} \quad A=159,999.7 \mathrm{~mm}^{2}$

$H_{T}=228.6 \mathrm{~mm} \quad A=300,644.6 \mathrm{~mm}^{2}$

Figure 4-2. Real Gas Blade Path 
TURBINE LOSSES

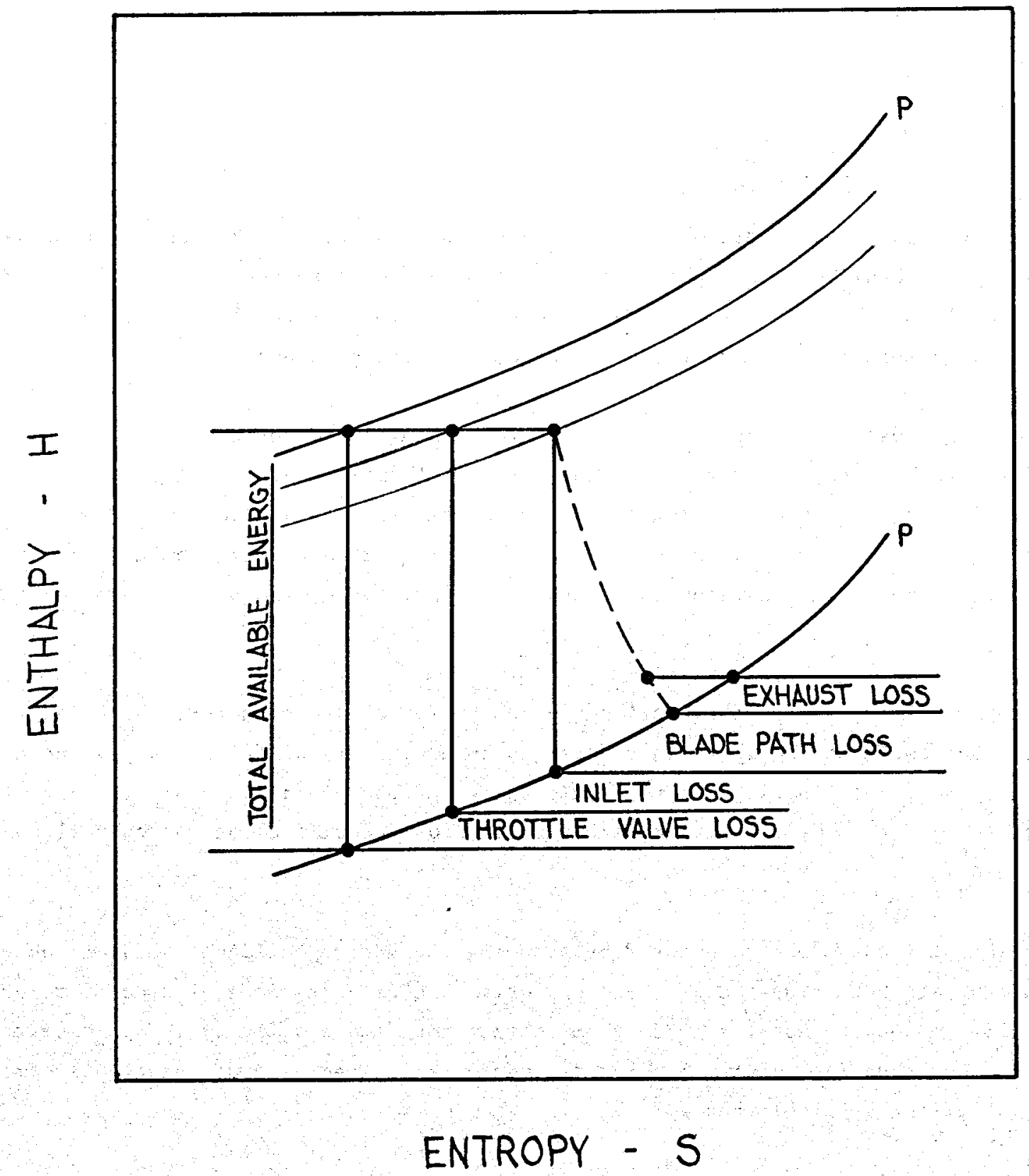

Figure 4-3. Turbine Losses 
The inlet flange has an inside diameter of $737 . \mathrm{mm}$ and an area of $0.426 \mathrm{sq}$. m. For the design gas, ( $80 / 20$ mixture) the inlet flow results in a flange velocity of $24.7 \mathrm{~m}$ per sec. Based on extensive tests and empirical data, the loss factor for this type of inlet would be 1.5 velocity heads. One velocity head as referenced at the flange is defined as:

$$
\text { - } \frac{\rho v^{2}}{2 g}
$$

where:

$$
\begin{aligned}
\rho & =\text { density } \\
V & =\text { gas velocity } \\
g & =9.81 \mathrm{~m} / \mathrm{sec}^{2}
\end{aligned}
$$

For the design point conditions and the inlet loss factor of 1.5, the inlet pressure drop is 0.475 bar ( $6.9 \mathrm{psi})$. This is equivalent to an energy 10 ss of $0.6 \%$ of the overall available heat. It should be noted that the inlet loss is normally lumped with that of the throttle valve since both are pressure losses.

The average absolute velocity leaving the third stage rotor at design conditions is $78.9 \mathrm{~m} / \mathrm{sec}$. The energy represented by this velocity is $4.4 \%$ of the overall available heat. With an optimum designed exhaust diffuser and collector; 50-60\% of this might be recoverable. However, this would require much more shaft 1 ength and an increase in casing diameter that cannot be justified by the power saved for this type of design.

Within the limits set by the bearing span and outer casing dimeter, the best diffuser that could be incorporated results in an area ratio of 1.5 and a predicted efficiency of $35 \%$ (Ref. 16): The static pressure recovery across the diffuser will be of the order of 0.06 bar ( 1 psi) and energy 1 oss about $1.6 \%$ of the overall available heat.

The exhaust losses were calculated by assuming the entire meridonal velocity head component at the diffuser exit would be lost. The exhaust flange inside diameter is 1483 . $\mathrm{mm}$ and the area is $1.73 \mathrm{sq}$. $\mathrm{m}$ so that the flange velocity is approximately $26.8 \mathrm{~m} / \mathrm{sec}$ at design point. The losses due to the collector and exhaust will amount to $1.5 \%$ of the available heat.

The total discharge loss will then amount to $3.1 \%$ of the overall available heat or a recovery of $30 \%$ of the discharge velocity energy. 
The total loss in performance due to the inlet and discharge components will amount to $3.7 \%$ of the overall design available heat. Figure 4-4 is the heat loss of the inlet and discharge as a function of the volume flow rate (CFM).

\section{Mechanical and Electrical Losses}

Turbine. Mechanical losses for this unit are composed of the power absorbed in the unit shaft seals and bearings. These losses are:

$\begin{array}{lll}\text { Shaft Seals } & 37 \quad \mathrm{KW} \text { each } & 74 \mathrm{KW} \\ \text { Journal Bearings } & 18.5 \mathrm{KW} \text { each } & 37 \mathrm{KW} \\ \text { Thrust Bearing } & & \frac{30 \mathrm{KW}}{141 \mathrm{KW} \text { to tal }}\end{array}$

The total mechanical losses are $141 \mathrm{~kW}$ for the turbine.

Generator. The electrical efficiency of the generator at $40^{\circ} \mathrm{C}$ rating point is:

\begin{tabular}{cc} 
Load & Efficiency $\%$ \\
\hline $4 / 4$ & 98.6 \\
$3 / 4$ & 98.6 \\
$1 / 2$ & 98.3 \\
$1 / 4$ & 97.5
\end{tabular}

The total mechanical losses for the generator bearings and seals are $130 \mathrm{KW}$.

\section{TURB INE PERFORMANCE}

Overall turbine performance power versus efficiency is plotted in Figure 4-5 for the 3 mixtures of iso-butane. The turbine operating with the design $80 / 20$ mixture for $65 \mathrm{MW}$ output has an overall efficlency of 0.82 . Included are the inlet and discharge losses as well as all mechanical power losses and throttling loss at the trip and throttle valve. This turbine design using the comercial grade 1so-butane mixture had an efficiency of 0.80 and using the $90 / 10$ mixture had an efficiency of 0.79 at the $65 \mathrm{MW}$ power output level. The peak efficiency obtained for the $80 / 20$ mixture design can also be obtained when the design gas is commercial 1so-butane or the $90 / 10$ mixture by redesigning the rotor and stator blade geometries for the specific gas condition.

Figures 4-6, 4-7, and 4-8 are the system performance curves of the generator electrical output in megawatts vs. the mass flow rate of the motive fluid. These curves were computed for constant inlet conditions upstream of the throttle valve. 


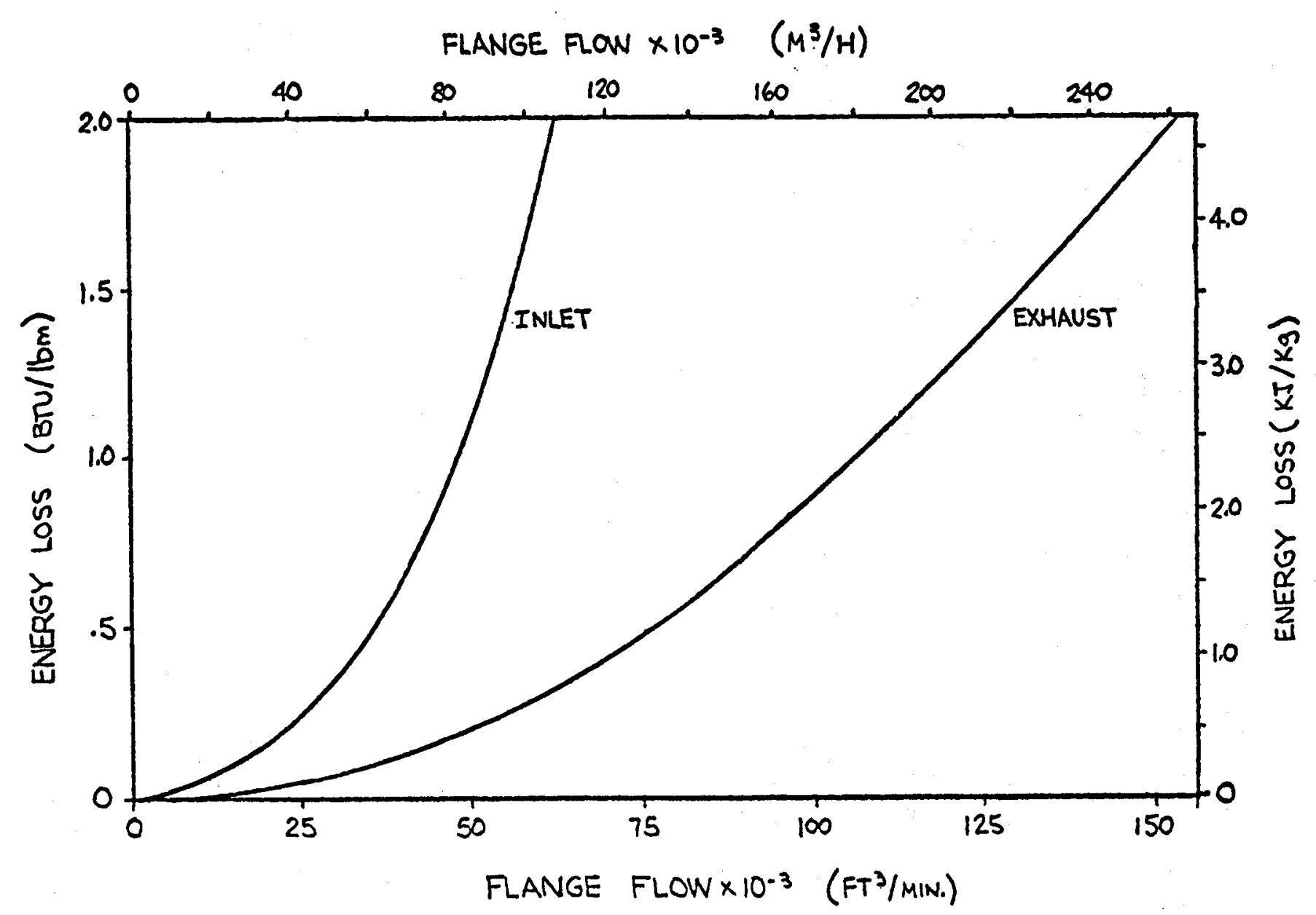

Figure 4-4. Inlet and Exhaust Losses Versus Flow 


\section{TURBINE OUTPUT VS. $h$ ISOBUTANE MIX}

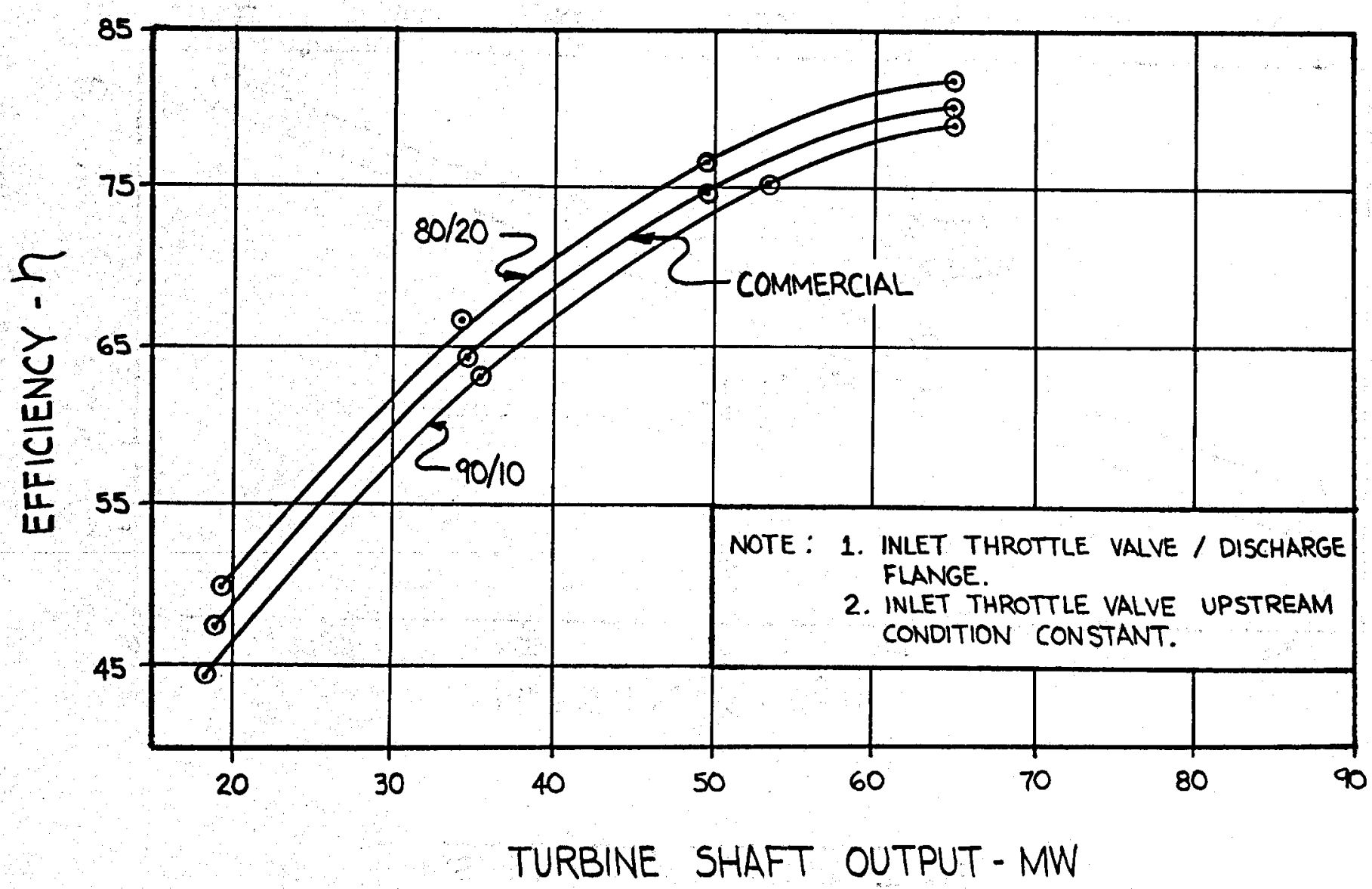

Figure 4-5. Turbine Output versus Efficiency - Iso-Butane Mixture 
MASS FLOW VS. GENERATOR OUTPUT

.8 ISOBUTANE /. 2 ISOPENTANE

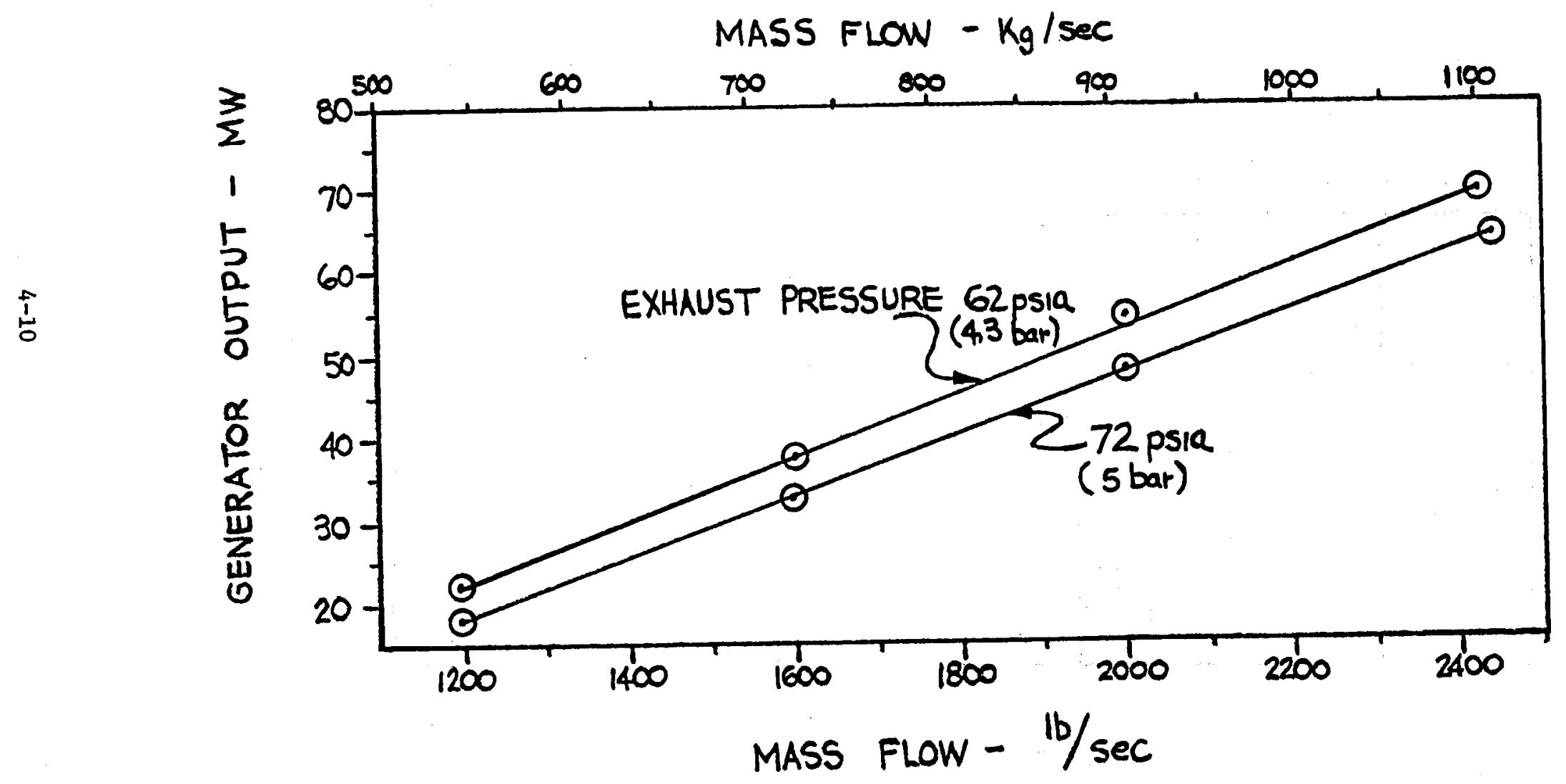

Figure 4-6. Mass Flow versus Generator Output - .8 Iso-Butane/.2 Iso-Pentane 
MASS FLOW VS. GENERATOR OUTPUT COMMERCIAL ISOBUTANE

MASS FLOW - $\mathrm{kg} / \mathrm{seC}$

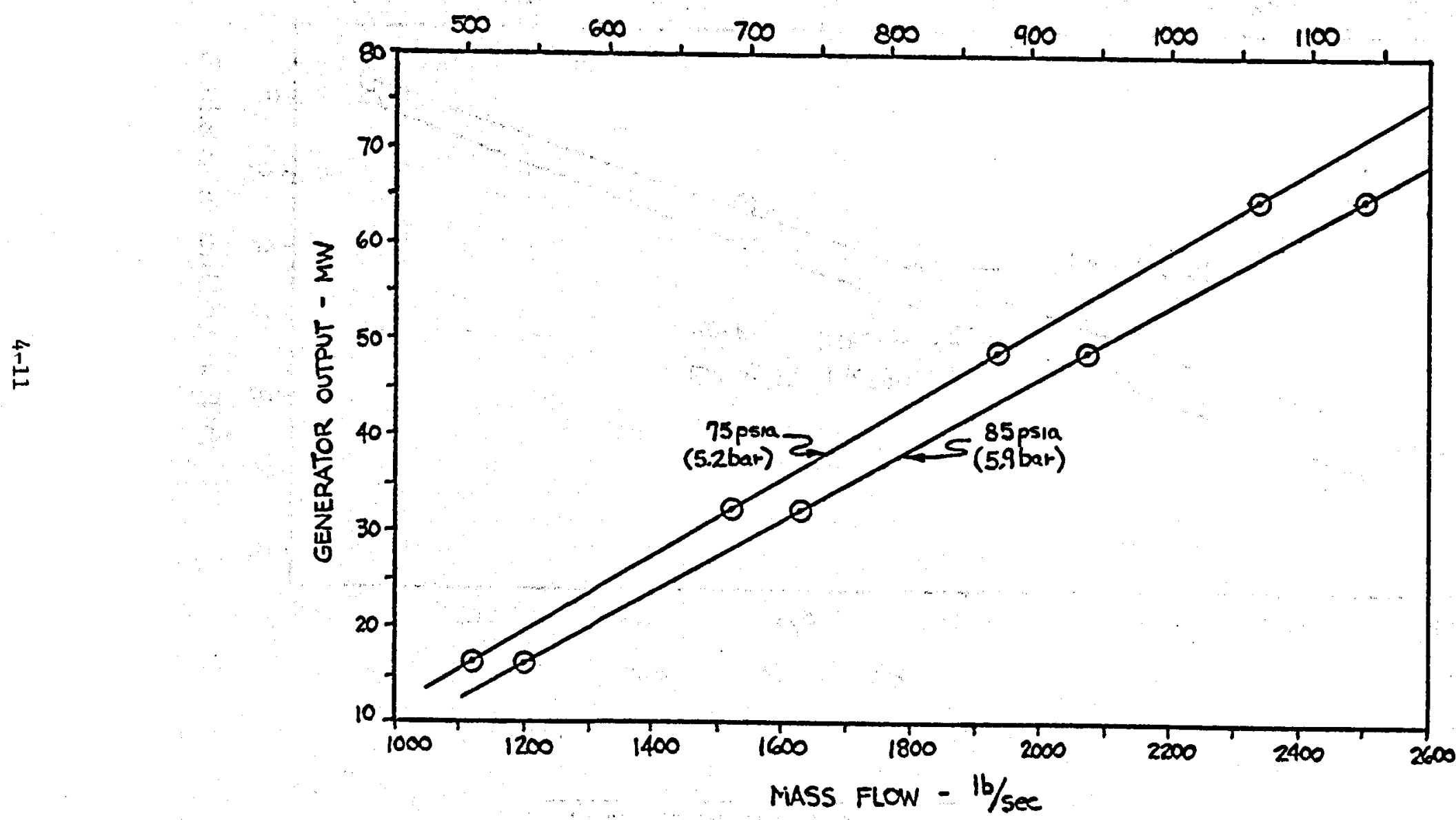

Figure 4-7. Mass Flow versus Generator output - Commercial Iso-Butane 
MASS FLOW VS. GENERATOR OUTPUT

.9 ISOBUTANE/. 1 PROPANE

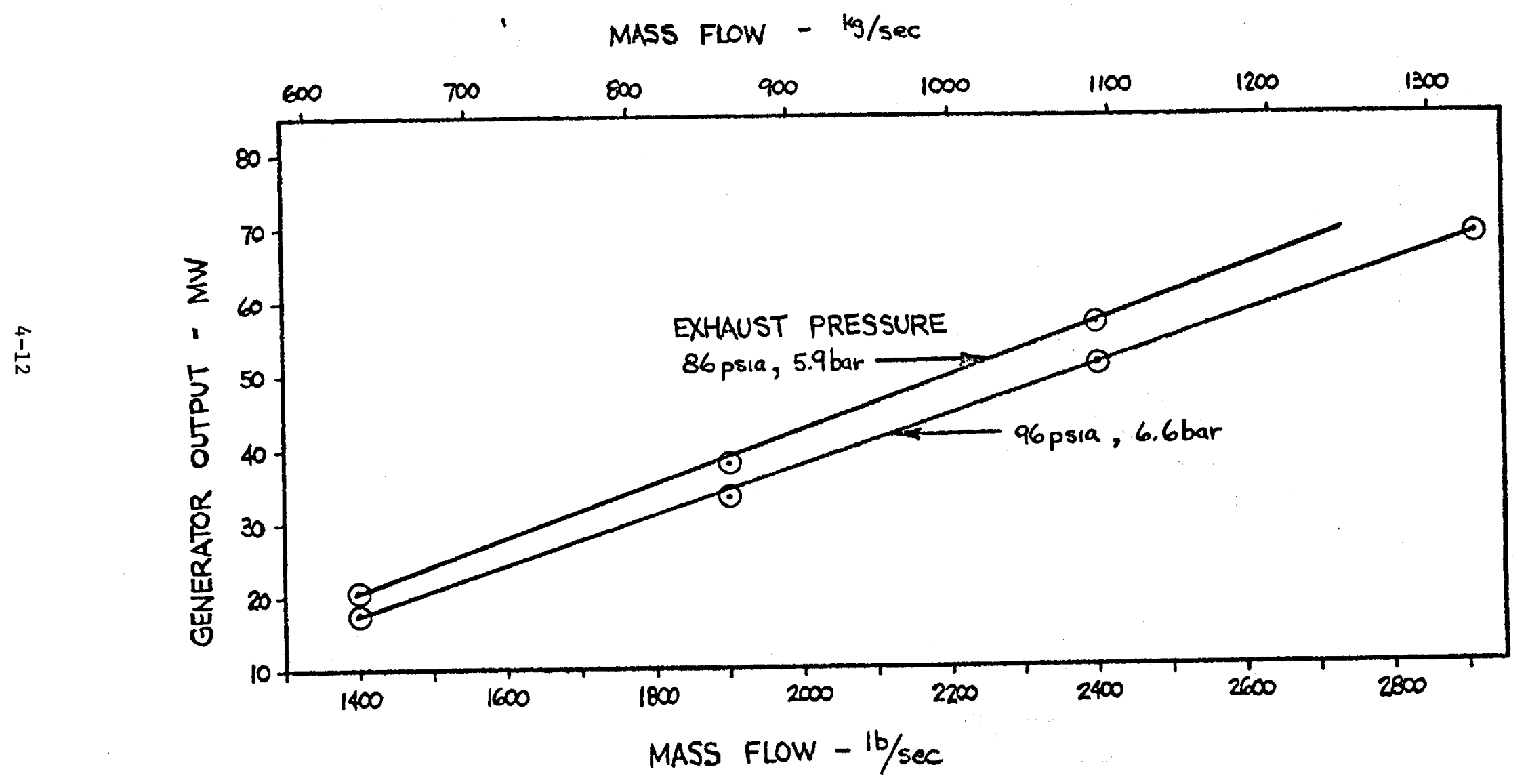

Figure 4-8. Mass Flow versus Generator Output - .9 Iso-Butane/.1 Propane 
The flow is varied by changing the throttle valve setting causing a greater pressure drop across the valve. The two exhaust pressures on Figure 4-6, 4-7, and 4-8, indicate the effect of the change of condenser water cooling capacity on turbine performance. As the cooling capacity of the condenser increases, the turbine back pressure decreases allowing more power to be generated.

An attempt was made to correlate the single design unit on a flow function basis, similar to gas turbine industry practice. A modifled flow function was empirically obtained which gave the best fit for straight lines. This flow function took the form of:

$$
\text { - } \quad \frac{G \mathrm{~T}^{\frac{1}{2}} \mathrm{Z}^{\frac{1}{4}}}{\mathrm{P} M \mathrm{~W}^{\frac{1}{2}}}
$$

where:

- $\mathrm{G}=$ Mass flow $1 \mathrm{~b} / \mathrm{sec}$

$\mathrm{T}=$ Inlet temp. ${ }^{\circ} \mathrm{R}$

$z=$ Compressibility

$\mathrm{P} \quad=$ Inlet Pressure psia

MW $=$ Gas Mixture Molecular Weight

Figure 4-9 is a curve of the modified flow function versus the blade path pressure ratio. The blade path pressure ratio is the ratio of the first stage stator inlet pressure to the third stage rotor discharge pressure. This function does not directly correlate data since all gases should describe a single curve. The flow function curves obtained for each gas are a function of actual gas properties and reflect the non-ideality of the gas used. However, with the three curves, it is possible to interpolate to other mixtures thereby obtaining the required mass rate of flow. This mass rate is for only one half the total turbine flow.

The turbine blade path efficiency is plotted in Figure 4-10 as a function of the blade path pressure ratio.

The turbine output power can be estimated by the following:

- Establish the inlet pressure and temperature, the discharge pressure and gas composition.

- From the Mollier chart, find the available heat, $\Delta H$, from the isentropic expansion and establish the isentropic discharge temperature. 
FLOW FUNCTION VS. PRESSURE RATIO ISOBUTANE MIX

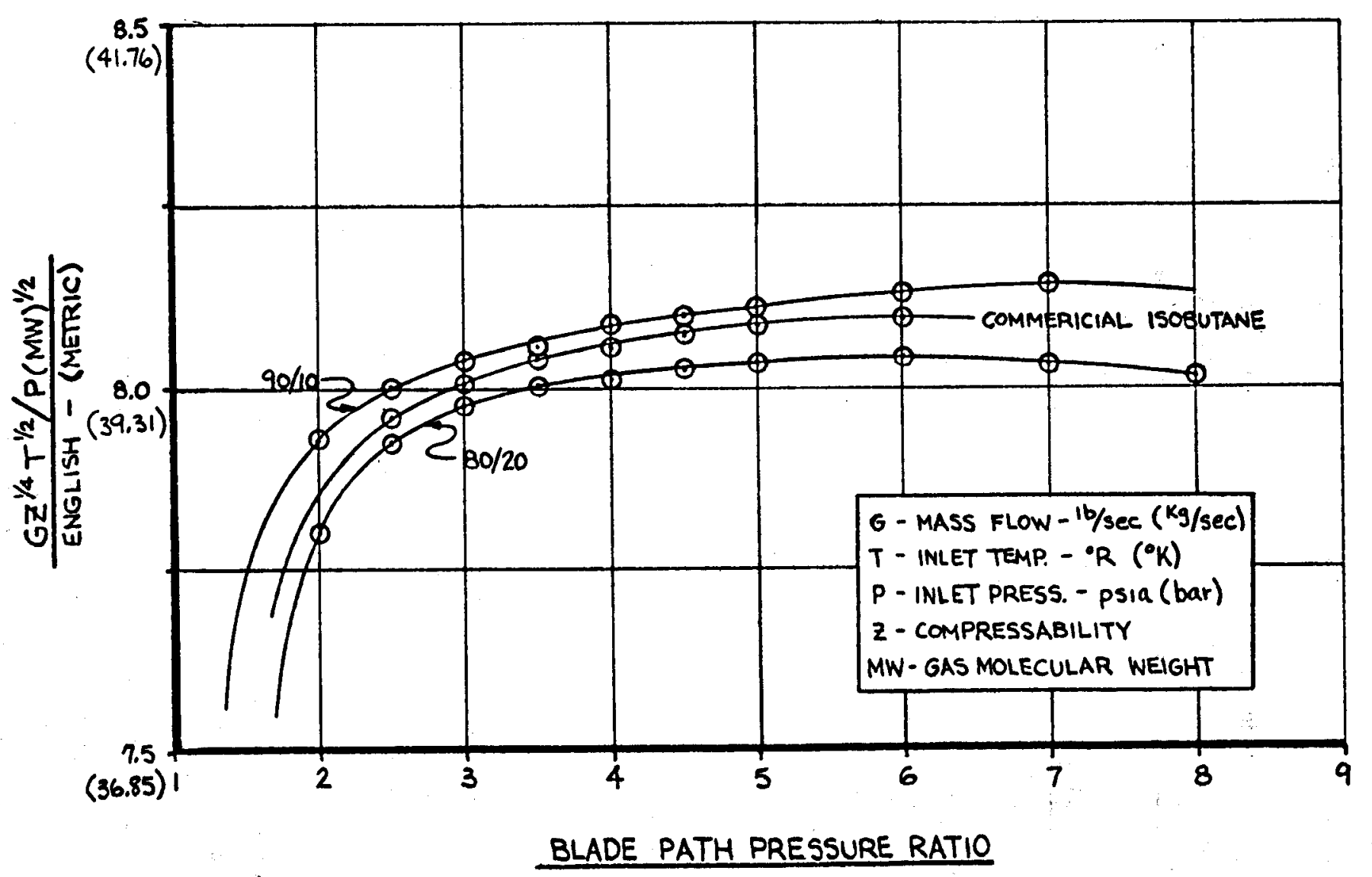

Figure 4-9. Flow Function versus Pressure Ratio - Iso-Butane Mixture 
EFFICIENCY VS. PRESSURE RATIO

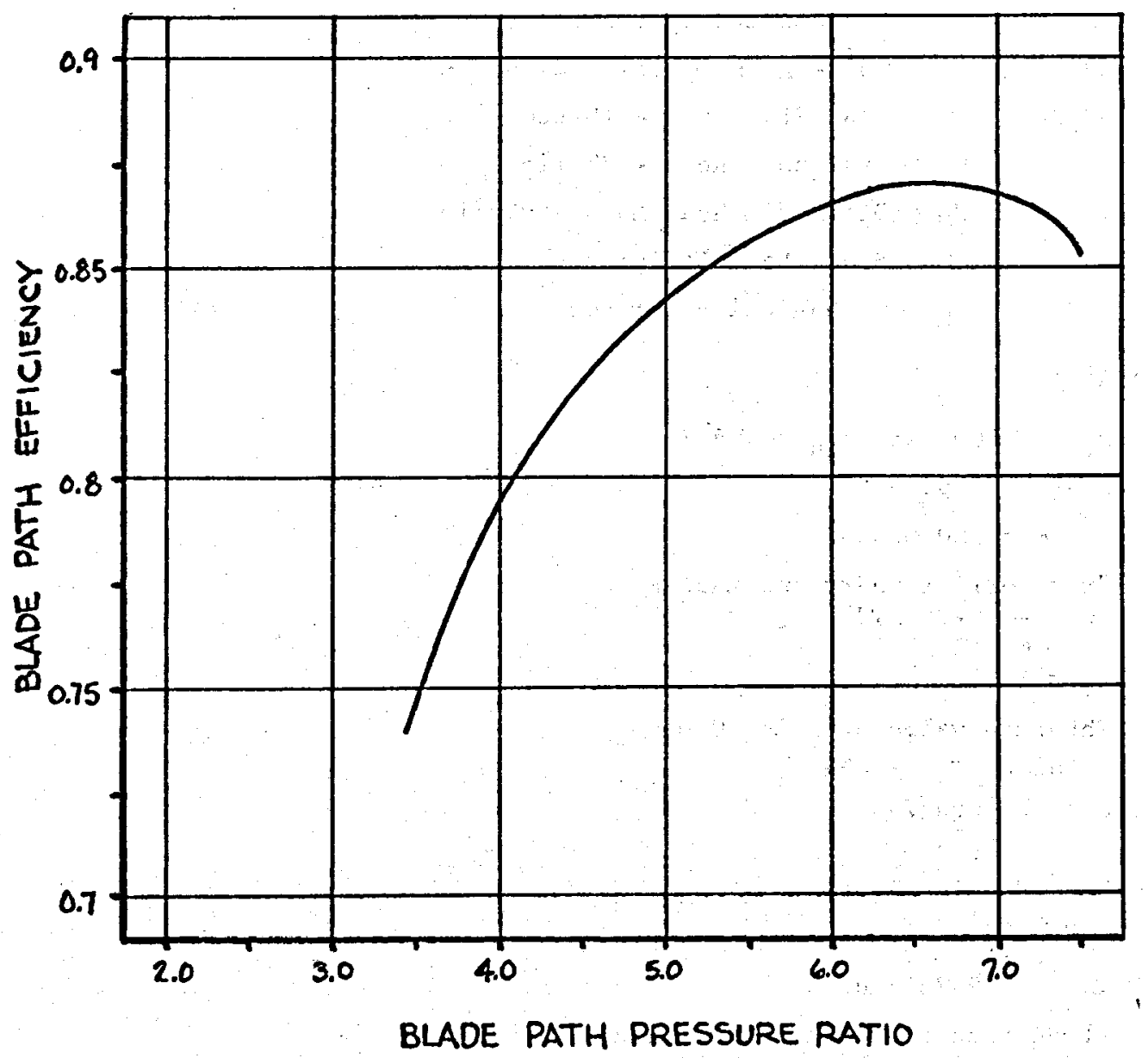

Figure 4-10. Blade Path, Efficiency versus Pressure Ratio 
- Estimate the throttle valve pressure drop. From Figure 7-3 or Mollier chart, obtain the inlet temperature at the estimated blade path inlet pressure. From the Mollier tables, obtain the compressibility, $Z$, and new available heat, $\Delta H^{\prime}$, at these conditions.

- Obtain the mass flow rate, G, from Figure 4-9.

- Obtain the blade path efficiency, 7, from Figure 4-10.

- Estimate the flange discharge CFM. From Figure 4-4, obtain the heat loss for the discharge $\left(\Delta H_{D}\right)$. (Note: Inlet loss is lurped with throttle valve pressure drop.)

- The power can be computed by the relationship:

$$
\begin{aligned}
\mathrm{KW}=(2 \mathrm{G})( & \left.\Delta \mathrm{H}^{\prime}-\Delta \mathrm{H}_{\mathrm{D}}\right) \zeta(1.0542)-\mathrm{KWM} \\
\text { WHERE: } \quad \mathrm{G} & =\text { Mass Flow Rate }-1 \mathrm{~b} / \mathrm{sec} \\
\triangle \mathrm{H} & =\text { Available Heat }-\mathrm{BTU} / 1 \mathrm{~b} \\
\triangle \mathrm{HD} & =\text { Discharge Heat Loss }-\mathrm{BTU} / 1 \mathrm{~b} \\
\zeta & =\text { Blade Path Efficiency } \\
\mathrm{KW}_{\mathrm{M}} & =\text { Mechanical Power Loss }
\end{aligned}
$$

As an example:

- $\mathrm{P}_{\text {in }}=500$ psia $\mathrm{T}_{\text {in }}=295^{\circ} \mathrm{F}$

Pout $=72$ psia

Gas - 80/20 mixture

- From Mollier chart and tables

$\Delta \mathrm{H}=30.78 \mathrm{BTU} / 1 \mathrm{~b}$

$\mathrm{T}_{2}=605^{\circ} \mathrm{R}$

$\mathrm{v}_{2}=1.32 \mathrm{ft}^{3 / 1 b}$

- Throttle valve drop is 50 psia

$\mathrm{P}_{\mathrm{blade}}=450$ psia

From Figure 7-3

$$
\mathrm{T}=743^{\circ} \mathrm{R}
$$

From Mollier Table

$$
\begin{aligned}
\mathrm{z} & =.5169 \\
\mathrm{~V}_{1} & =.150 \mathrm{ft}^{3} / 1 \mathrm{~b} \\
\Delta \mathrm{H}^{\mathrm{t}} & =29.75 \mathrm{Btu} / 1 \mathrm{~b}
\end{aligned}
$$

- Blade path pressure ratio $=6.25$

$\frac{G T^{\frac{1}{2}} Z^{\frac{1}{4}}}{P M W^{\frac{1}{2}}}=8.05$

$\mathrm{G}=1223.1 \mathrm{~b} / \mathrm{sec}$ per half.

$\eta=0.87$ 
- Discharge $\mathrm{CFM}=\mathrm{G} \mathrm{V}_{2} \times 60$

$$
=96900 \text {. }
$$

$$
\Delta \mathrm{H}_{\mathrm{D}}=0.80 \cdot \mathrm{BTU} / 1 \mathrm{~b}
$$

- $\mathrm{KW}=(2 \times 1223)(29.75-0.80)(0.877)(1.0542)-144=65300$

Applying this analysis to the generator results in a final decreased electrical power or:

$$
\begin{aligned}
-\quad & \quad \text { gen }=.986 \\
-\quad & \mathrm{KW} \text { gen }=130 \\
-\quad \because \mathrm{KW} & =.986 \times 65300-130 \\
& =64300
\end{aligned}
$$

This value agrees with the generator output of Figure $4-5$ at the required mass flow. The overall efficiency is 0.81 based on inlet conditions and a power factor of 1.0 .

The effects of varying the turbine back pressure while maintaining constant flow were explored. Figure 4-11 is a plot of the back pressure power correction factor as a function of the exhaust pressure ratio based on design conditions. As the back pressure increases, the turbine output power drops severely.

\section{TURBINE SCALING}

Scaling of this turbine design was investigated for increasing and decreasing power output using the $80 / 20$ gas mixture. Reducing the gas flow and blade height while maintaining peak efficiency, resulted in a unit which will have a 35 megawatt output and an overall efficiency of 0.81 . Changes in base diameter and blade geometries would result in higher unit efficiencies and allow the power output drop to approximately $25 \mathrm{MW}$ for an overal1 efficiency of 0.81 . For smaller double flow units, the blade path parasitic losses increase and these units would tend to show markedly lower efficiencies (0.75) than the 1 arger unit. A single flow unit could be built for as low as $10 \mathrm{MW}$ but will have an efficiency penalty due to thrust balancing leakage flow amounting to $1 \%$ to $2 \%$ of total inlet flow.

Power in the double flow unit could be increased from 65 to 80 MW before reaching the mechanical 1 Imits of the blades. Higher powers on the order of $130 \mathrm{MW}$ could be obtained by double ending the generator and putting a single turbine on either end. The generator manufacturer indicates this has been done in the past.

As the blade path pressure ratio was decreased, the third stage became less and less effective and at approximately a pressure ratio of 3.5 this stage became para- 
POWER CORRECTION US. EXHAUST PRESSURE RATIO

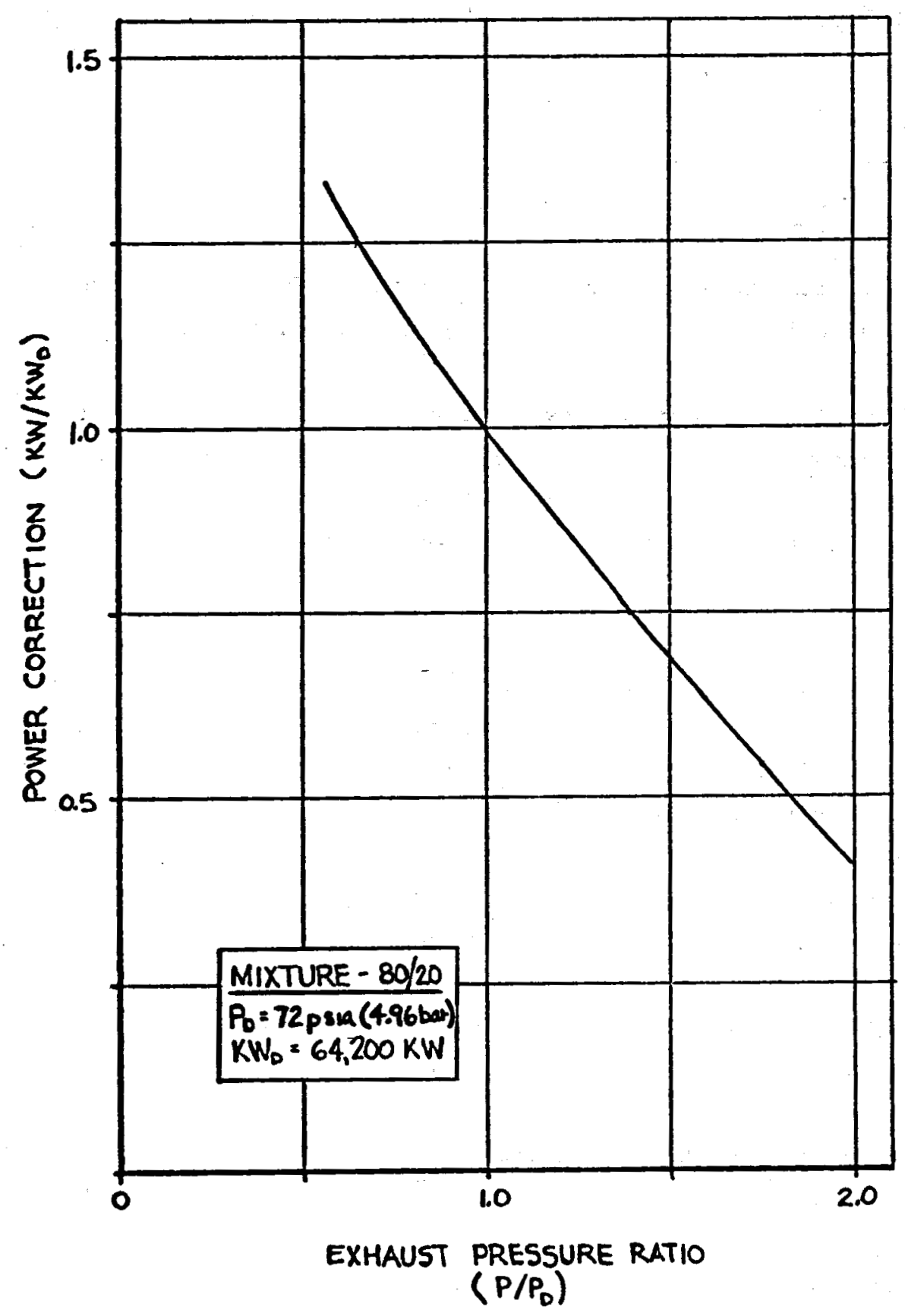

Figure 4-11. Power Correction versus Exhaust Pressure Ratio 
BLADE PATH

EFFICIENCY VS. PRESSURE RATIO

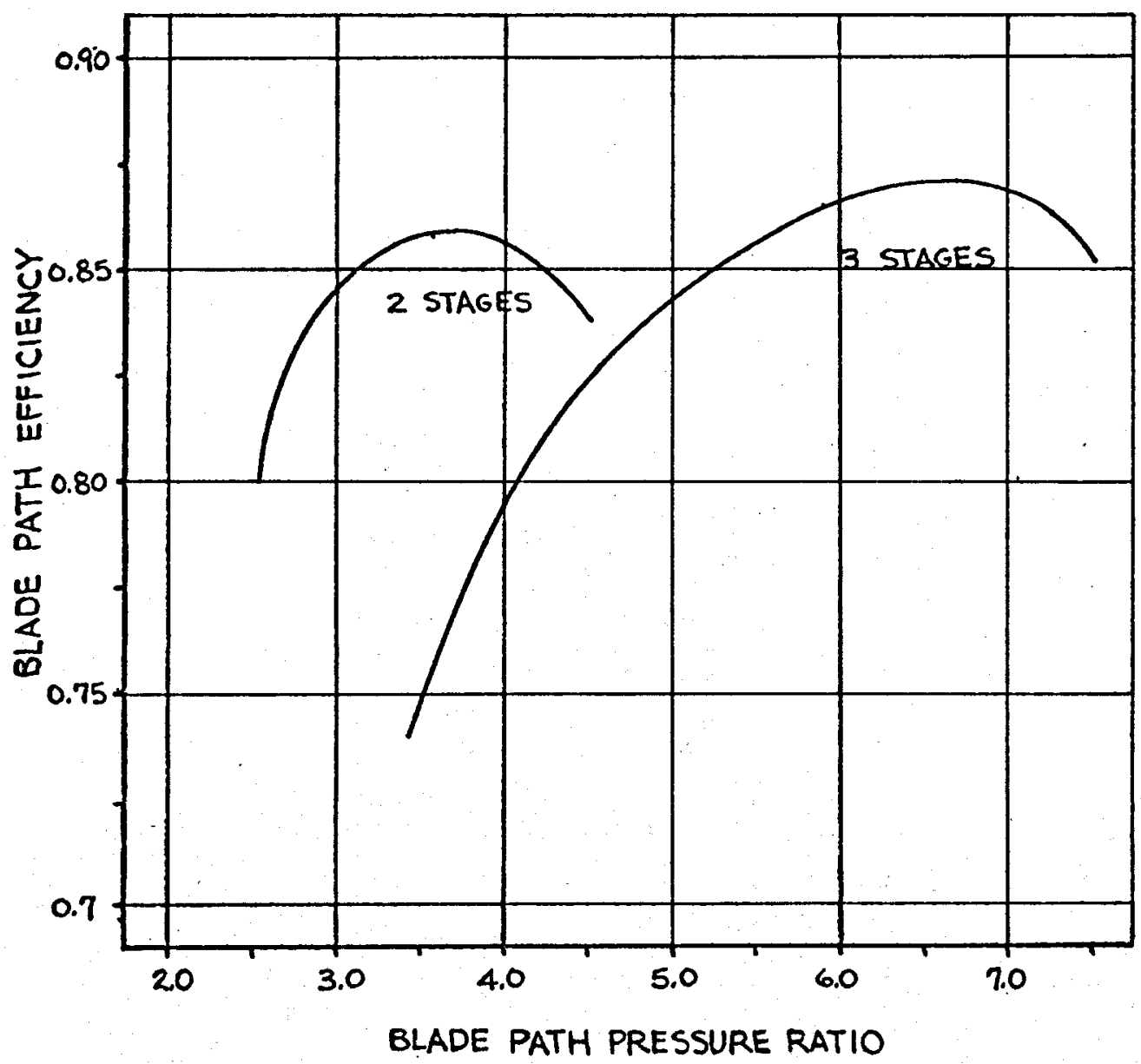

Figure 4-12. Blade Path Efficiency versus Pressure Ratio 
sitic (it was not producing power but actually absorbing power). Further decreases in pressure ratio were obtained by removing the third stage from the computation. The blade path efficiency as a function of the blade path pressure ratio is shown in Figure 4-12 for the two and three stage designs. The difference in the peak efficiency between the two and three stage designs is due to blade path losses becoming a greater percentage of the available heat. The available heat for an expansion from 34.5 bar ( 500 psia) $146.1^{\circ} \mathrm{C}$ $\left(295^{\circ} \mathrm{F}\right)$ to $10.34 \mathrm{bar}(150 \mathrm{psia})$ is approximately $46.5 \mathrm{~kJ} / \mathrm{K}_{\mathrm{g}}(20 \mathrm{BTU} / 1 \mathrm{~b})$ or a $30 \%$ reduction in available heat. 
Section 5

MECHANICAL DES IGN

MECHANICAL DESIGN OBJECTIVES

Prior to the start of any design effort, design objectives must be established. The following objectives were established for the mechanical design of the axial flow hydrocarbon turbine:

- Turbine is to direct drive the generator; preferably 3600 rpm.

- The hydrocarbon gas is flamable therefore positive casing sealing is required.

- The shaft end seals should not leak the hydrocarbon gas to the atmosphere in the event of loss of pressurized seal oil.

- Assembly and disassembly of the turbine internals should not disturb the generator, nor the inlet and discharge gas piping.

- Bearings and seals shall be inspected or replaced without opening the main casing.

- Accepted engineering practice will be followed and standard components will be used wherever possible.

The above objectives can be attained by the following:

- Design the rotor bearing system such that no harmful or objectionable frequencies be within $\pm 20 \%$ of the operating speed, 3600 RPM.

- Utilize barrel construction on the turbine casing to provide full continuous sealing at the joints.

- Utilize the Elliott Company patented iso-carbon type seal with shutdown features for virtual leak proof conditions with zero sealing oil pressure.

- Design the barrel-type turbine such that the internal parts are removable from one end and that simplified assembly and disassembly fixtures can be utilized for this removal.

- Use all applicable codes including NEMA, API, and ASME as a design guide for the machine and components. 
The results of the conceptual design effort are shown in the cross-section layout of the turbine, Figure 5-1.

FLANGE DESIGN

Two basic parameters affect the design of the flanges: the gas velocity at the flange sets its size; the working pressure level sets the flange rating. Nominal flange velocities were 1 imited to $30.48 \mathrm{M} / \mathrm{sec}(100 \mathrm{ft} / \mathrm{sec})$ for this design to minimize the inlet and discharge pressure losses which would affect the overall machine performance. Using standard flange sizes, it was found that a $762 \mathrm{~mm}$ (30") flange on the inlet $736.6 \mathrm{~mm}$ (I.D.), and a 1524mm (60") flange on the discharge $1485.9 \mathrm{~mm}$ (I.D.) will meet the above required velocity limits. Pressure ratings are based on maximum expected working pressures. For the inlet conditions of the $90 / 10$ gas mixture, the working pressure would be 40.7 bar ( 590 psia). The flange design pressure was selected as 44.8 bar (650 psia) to allow for process upsets.

The maximum specified operating discharge pressure was 6.6 bar (96 psia). However, under shutdown conditions it was found that the pressure could reach as high as 13.8 bar ( $200 \mathrm{psia}$ ). This was selected as the maximum working pressure for the discharge flange. Based on the above conditions and utilizing the API 605 code for large flanges, the inlet flange is a 300 lb. rating and the discharge flange is a 150 1b. rating.

Table 5-1 lists the design conditions, flange ratings, maximum working pressures and maximum hydrotest pressure capabilities for these flanges. Once the flanges have been sized, they establish the minimum overall axial length of the outer casing and set the minimum limits for the rotor bearing span.

Table 5-1

FLANGE DESIGN

\begin{tabular}{|c|c|c|c|c|c|}
\hline Flange Size & $\begin{array}{l}\text { Nominal } \\
\text { Rating }\end{array}$ & $\begin{array}{l}\text { Design } \\
\text { Working } \\
\text { Pressure }\end{array}$ & $\begin{array}{c}\text { Maximum } \\
\text { Working } \\
\text { Temperature }\end{array}$ & $\begin{array}{c}\text { Rating } \\
\text { at } \\
\text { Temperature }\end{array}$ & $\begin{array}{l}\quad \text { Max. } \\
\text { Hydrotest } \\
\text { Pressure }\end{array}$ \\
\hline $762 \mathrm{~mm}$ & $3001 \mathrm{~b}$ & $\begin{array}{r}44.8 \text { bar } \\
649.8 \text { psia }\end{array}$ & $\begin{array}{r}149^{\circ} \mathrm{C} \\
300.2^{\circ} \mathrm{F}\end{array}$ & $\begin{array}{r}46.9 \text { bar } \\
680.3 \text { psia }\end{array}$ & $\begin{array}{r}75.83 \text { bar } \\
1099.9 \text { psia }\end{array}$ \\
\hline $1524 \mathrm{~mm}$ & $150 \mathrm{lb}$ & $\begin{array}{c}13.8 \text { bar } \\
200.1 \text { psia }\end{array}$ & $\begin{array}{r}93^{\circ} \mathrm{C} \\
199.4^{\circ} \mathrm{F}\end{array}$ & $\begin{array}{r}18.4 \text { bar } \\
266.9 \text { psia }\end{array}$ & $\begin{aligned} 29.3 & \text { bar } \\
425.0 & \text { psia }\end{aligned}$ \\
\hline
\end{tabular}




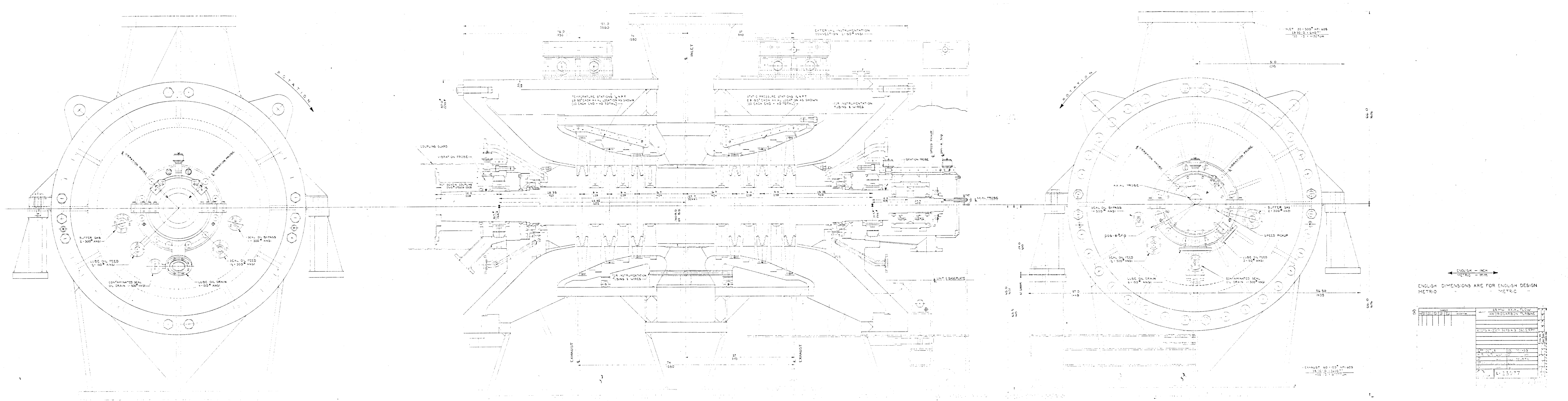




\section{OUTER CASING}

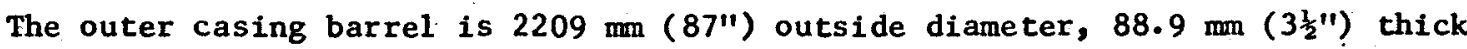
and 3251 (128") long. This barrel contains two welded internal rings and an innercasing support barrel. (See Figure 5-2) The barrel stresses were computed for pressure as well as thermal gradients. Figure 5-3 shows the relationship between casing differential temperature and wall thickness. A heat transfer analysis of the casing with an inlet temperature of $149^{\circ} \mathrm{C}\left(300^{\circ} \mathrm{F}\right)$ indicated that the thermal boundary layer on the outside of the machine would be turbulent. Once this was determined, the standard heat transfer equations (Ref. 1) established the temperature difference in the metal for various casing thicknesses. Figure 5-3 also shows the total tangential (hoop) stress as a function of wall thickness and casing diameter. The tangential stresses, for the $2209 \mathrm{~mm}$ ( $\left.80^{\prime \prime}\right)$ I.D. was minimized at $139.7 \mathrm{~mm}$ ( $\left.5 \frac{1}{2} "\right)$. However, for material savings and ease of fabrication, an $88.9 \mathrm{~mm}\left(3 \frac{1}{2} "\right)$ thick casing would only incur a $7 \%$ increase in stress, that is $67561 \mathrm{kPa}$ (9800 psia) to $72387 \mathrm{kPa}(10,500$ psia). The ASME code allowable working stress is $103410 \mathrm{kP}_{\mathrm{a}}(15,000 \mathrm{psi})$ at this temperature so the casing design is conservative.

The space between the inner barrel and the horizontally split innercasing will be vented to the discharge pressure, resulting in no differential pressure across it. This inner barrel will act as a support member for the innercasing.

Yielding may occur at the junction of the inlet nozzle and the outer casing. Further analysis indicated that the welded rings (Figure 5-2) would add further stiffening and thereby reduce the stress concentration factors. This casing should be further analyzed by finite element techniques, specifically in the area of the nozzle. Casings of this diameter and thickness have been built for higher working pressures and have not experienced any field difficul ties.

The ASME code requires a hydrotest at 1.5 times the working design pressure. The casing will be compartmentally hydrotested. The inlet section of the casing will be separated from the discharge casing by appropriate fixtures and hydrotested at a pressure commensurate with the flange and casing service rating. For this particular case, 67.2 bar ( 975 psi). Once the inlet section hydrotest is completed, the fixtures will be removed. The entire casing, with endwalls, will then be hydrotested to 20.7 bar ( 300 psi) (1.5 times the maximum discharge service pressure). 

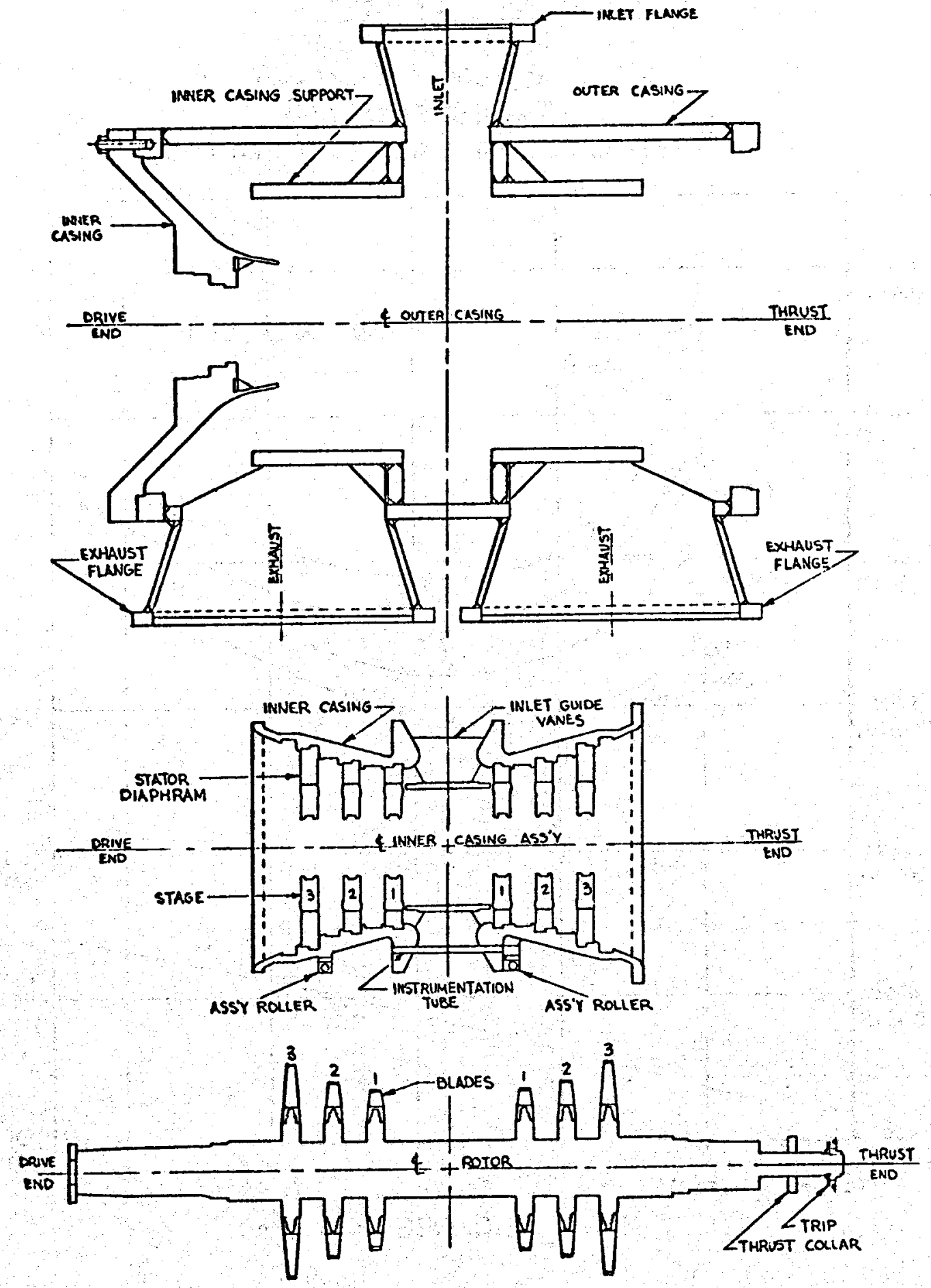

Figure 5-2. Turbine Hardware 
COMBINED (PRESSURE \& THERMAL) HOOP STRESS

THICK WALL CYLINDER

$$
\begin{aligned}
& T_{i}=300^{\circ} \mathrm{F}\left(422.6^{\circ} \mathrm{K}\right) \\
& P_{i}=600 \mathrm{psi}(41.34 \mathrm{bar}) \\
& T_{a m b}=80^{\circ} \mathrm{F}\left(300.2^{\circ} \mathrm{K}\right)
\end{aligned}
$$

FOR MAX. TENSILE STRESS (AT OUTER EDGE)

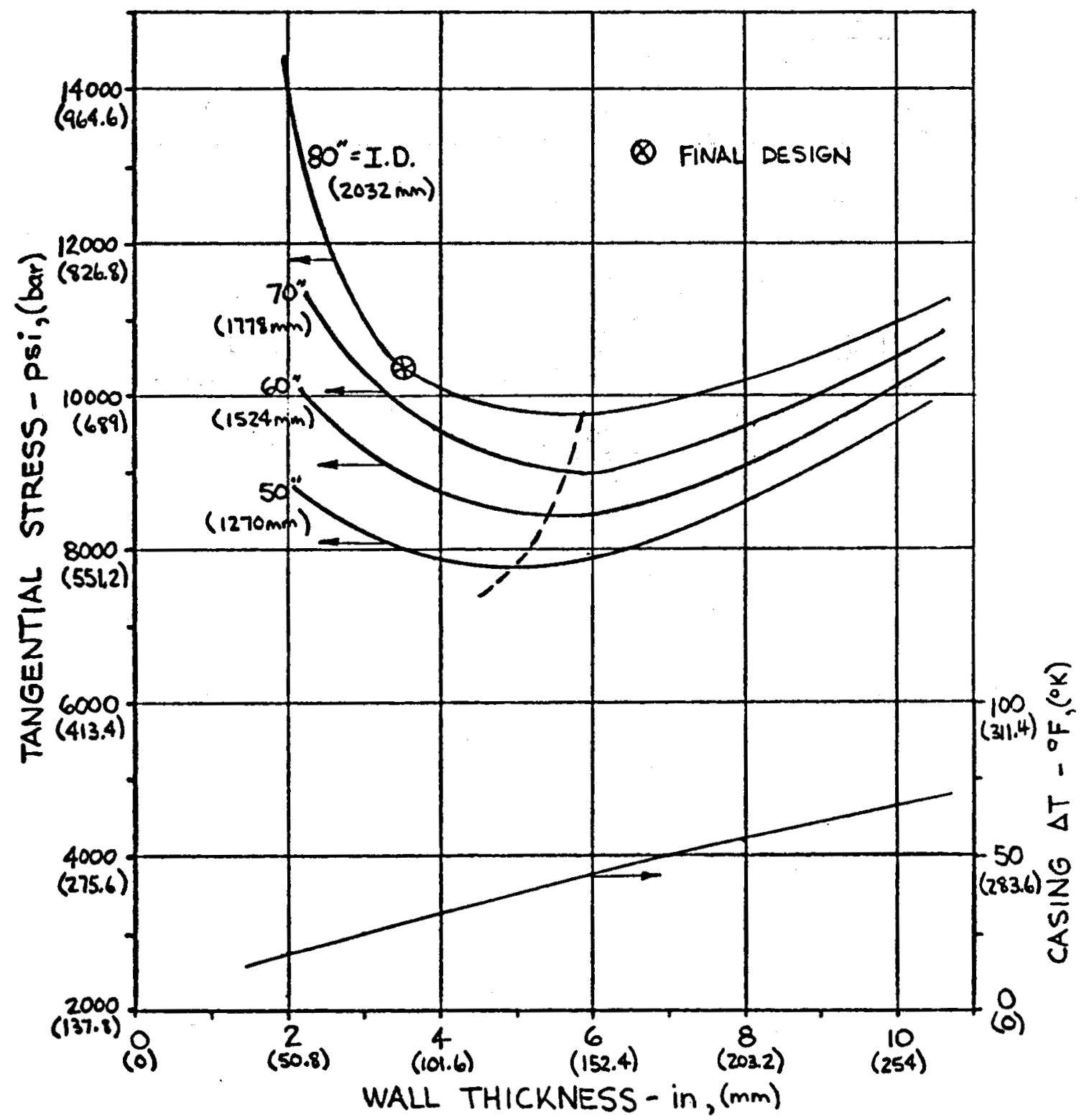

Figure 5-3. Combined (Pressure and Thermal) Hoop Stress 
ENDWALL AND ENDWALL BOLTING

The endwall and endwall bolting have been designed to take the 200 psi working pressure and the 20.7 bar ( 300 psi) hydrotest pressure without yielding. A simplified plate analysis (Ref. 9) of the endwall indicates that the maximum tensile strength should be well below $34470 \mathrm{kPa}_{\mathrm{a}}$ ( $5000 \mathrm{psi}$ ) and deflection should be less than $.381 \operatorname{man}\left(0.015^{\prime \prime}\right)$ at the hydrotest pressure. Under normal operation, these endwalls will be very lightly loaded. The endwall was checked against a finite element analysis made on a similar design of lighter construction.

The endwall bolting will require thirty-six $50 \mathrm{~mm}$ bolts equally spaced around a 2108m (83") diameter. The bolts will be torqued to provide a tensile stress of $206820 \mathrm{kPa}(30,000 \mathrm{psi})$. This bolting will be identical at both ends of the machine.

ROTOR

\section{Construction}

The final rotor construction utilized a solid forging with integral discs. Other construction methods such as separate discs attached to a shaft have been investigated and were found to be less desirable than a solid rotor for this application.

\section{Critical Speed}

Multiple rotor geometries have been evaluated in order to satisfy the critical speed requirements. Two types of rotors were analyzed for this project.

- Stiff Shaft - Operating below the first critical speed.

- Flexible Shaft - Operating between the first and second critical speeds.

The results indicate that this size machine should be built as a flexible shaft design, since it has better rotor characteristics in the range of operating speed. The flexible design also allowed for:

- Better axial spacing for the aerodynamic diffuser on the blade path discharge

- Better placement of the seals and bearings for maintenance accessibility 
- Additional room if needed to separate the lube oil from the seal oil

- Smaller bearings and seals requiring less oil flow and power loss

The initial designs were directed toward a stiff shaft unit operating below the first critical speed. The initial critical speeds, assuming rigid supports, indicated that this unit could be very readily built. However, the rotorbearing flexibility conditions did not meet the design criteria for the vibrational specifications.

A more sophisticated means of analysis was required to determine the acceptability or non-acceptability of the shaft design. An unbalance response analysis was run for the stiff shaft concept. The results can be found in Appendix Bl. Al though the first critical was within the allowable margin, the shape of the vibration curve indicated an unacceptable characteristic possibly causing high rotor vibration. Therefore, a flexible design was evolved and checked utilizing the same procedures. These results are shown in Appendix B2. Tab1e 5-2 indicates the critical speed on stiff support as well as the flexible support speeds for both rotor configurations. There are no difficulties in running the turbine between its first and second criticals as the generator design is also operating between its first and second critical. The turbine criticals have been tuned to avoid the generator first critical.

Table 5-2

ROTOR CRITICAL SPEED RESULTS

\begin{tabular}{|c|c|c|}
\hline \multirow[b]{2}{*}{ SUPPORTS } & \multicolumn{2}{|c|}{ ROTOR } \\
\hline & $\begin{array}{l}\text { FLEXIBLE } \\
\text { RPM }\end{array}$ & $\begin{array}{c}\text { STIFF } \\
\text { RPM }\end{array}$ \\
\hline \multirow{2}{*}{$\begin{array}{r}\text { Undamped Bearings } \mathrm{N}_{\mathrm{c}} 1 \\
\mathrm{~N}_{\mathrm{c} 2}\end{array}$} & 2580 & 6690 \\
\hline & 8600 & 14400 \\
\hline \multirow{2}{*}{ Damped Bearings $\begin{aligned} \mathrm{N}_{\mathrm{cl}} 1 \\
\mathrm{~N}_{\mathrm{c}} 2\end{aligned}$} & 2400 & .4200 \\
\hline & 5300 & 6400 \\
\hline
\end{tabular}


BEARINGS

\section{Journal Bearing}

The bearing design will be a $267 \mathrm{~mm} \times 102 \mathrm{~mm}\left(10 \frac{1}{2}\right.$ " $\left.\times 4^{\prime \prime}\right)$ flve shoe tilt pad type with a diametral clearance of $0.280-0.33 \mathrm{~mm}(0.011-0.013$ inch). This bearing will utilize a central pivot position for the tilting pads. Additionally, a load between the pad arrangement will be utilized to distribute the rotor weight over two pads, which will lower the slow roll loading and improve the bearing wear under start-up conditions. A load between the pad arrangement also results in more equalized characteristics between the horizontal ( $K_{y y}$ ) and vertical ( $K_{x x}$ ) stiffness. The parameters for this bearing are given In Appendix B2.

\section{Thrust Bearing}

A $46451 \mathrm{sq}$. mm. (72 sq. in.) thrust bearing has been selected to take up the generator thrust loading and the thrust due to manufacturing tolerances on the blade rows on either side of the double flow unit. The thrust bearing is a Kingsbury type self-equalizing that is double acting to provide positive positioning of the rotor. The thrust collar is removable from the shaft. The thrust shoes are steel with the wearing face babbitt lined. Leveling links under these shoes insure equal load distribution to each shoe.

A forced lubrication system feeds cool oil into the center of the bearing along the shaft. The oll is removed tangentially from the bearing to insure a uniform distribution of the cool oil throughout the bearing. This type of thrust bearing has been used in both turbines and compressors for many years.

\section{SHAFT TEALS}

Three basic types of rotor-casing seals are used in turbines and compressors for contalning the motive fluid from leaking out along the shaft. These are:
- Labyrinth Seals
- Bushing Seals
- Face Seals

The labyrinth seal allows for some type of leakage along the shaft. The bushing type seal allows for a controlled oil flow in the direction of the motive fluid and an oil dam to provide the sealing. The face seal normally has a rubbing face and also, utilizes the oil to do the major part of the sealing. 
For this unit, the labyrinth type seal was ruled out in that it is a leakage seal and the operating conditions do not allow for leakage of the motive fluid to the atmosphere. This leaves either the bushing or face seal for this type of application. The bushing type seal is a close clearance ring which fits around the shaft; and through the action of a controlled orifice allows minimal amount of oil leakage through the seal to the gas side. The pressure of the oil is maintained at normally 5, psi above the gas pressure. Under the conditions for this unit, this seal would have a large amount of oil leakage going towards the gas compared to the face type seal. Additionally, the $5 \mathrm{psi}$ differential would have to be maintained by an overhead tank system compounded to a 35 to 50 psid. The face seal can be controlled by a differential control and requires 35-50 psid. Looking at all factors in this unit the face seal was selected for use in this design.

The face seal requires cool pressurized seal oil to be injected into the seal from the lube and seal oil system. Between the seal oil and the gas zone is a metal reinforced carbon ring. The carbon ring is sandwiched between a stationary metal sleeve and a rotating seal ring. The sealing face of each of these elements is ground to a flatness measured in light bands. Because the carbon ring is symetrical, no net axial thrust is imposed on the ring due to variations in oil or gas pressure. A system of springs acting through a stationary sleeve can apply an accurately controlled fixed pressure between the three elements, that is, the stationary sleeve, the rotating $r i n g$ and carbon ring. A slight flow of seal oil through the seal faces towards the gas zone prevents any outward flow of gas. This flow is recoverable and does not enter the main gas stream. It serves to continually flush the seal face discouraging the encroachment of damaging abrasives on the seal face. A series of orifices around the circumference of the seal direct cooling jets of oil against the carbon ring. In the outward direction, a floating ring or series of rings (if the oil pressure demands it) breaks down the seal oil pressure to atmospheric pressure and thus forms a pressurized isolated oil chamber. During idle periods, devices can be applied to the seal design which permits the seal oil system to be shut down even though the unit is still pressurized with gas. This "automatic shutdown feature" has been applied to many machines in multiple field applications for this and other type gases. Primarily, the seal is used on compressors to contain hydrocarbons within chemical plant processes but has been applied to special turbines.

\section{ROTATION BLADES}

Figures 5-4 and 5-5 are the Goodman and Campbell diagrams, respectively, for the proposed third stage rotor blade. These blades are the longest and therefore have 


$$
\frac{\text { GOODMAN DIAGRAM }}{\text { 65MW - HYDROCARBON TURBINE }}
$$

ESTIMATEO NATURAL FREQUENCIES : $560,1100,2140 \mathrm{~Hz}$ OPERATING SPEED : $60 \mathrm{~Hz}$ BLADE PASSING FREQUENCY : $2880 \mathrm{~Hz}$

TENSILE STRESS OF AISI 403 STAINLESS MATERIAL (MINIMUM)

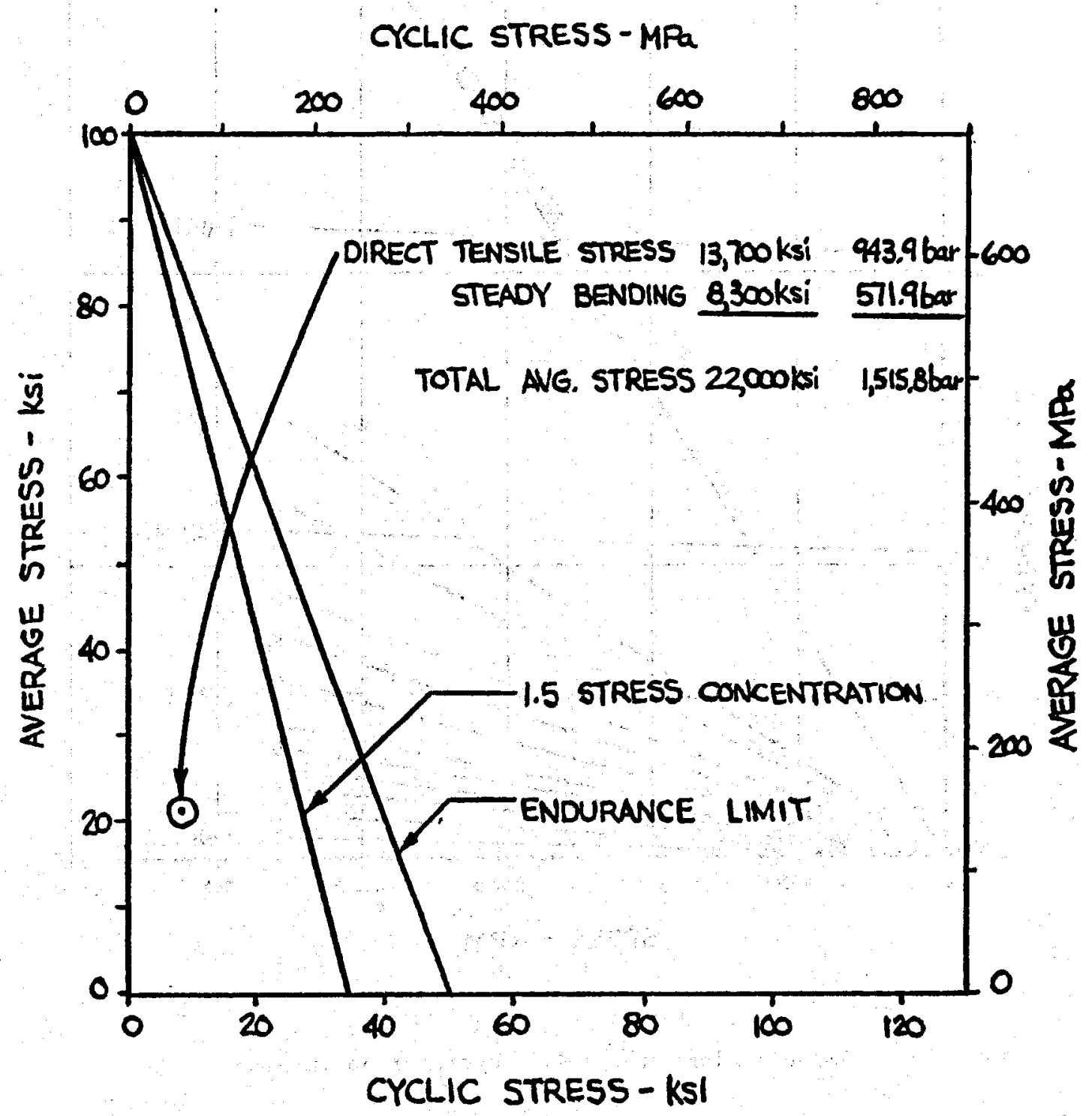

Figure 5-4. Goodman Diagram - 65MN - Hydrocarbon Turbine 
CAMPBELL. DIAGRAM

65MW - HYOROCARBON TURBINE

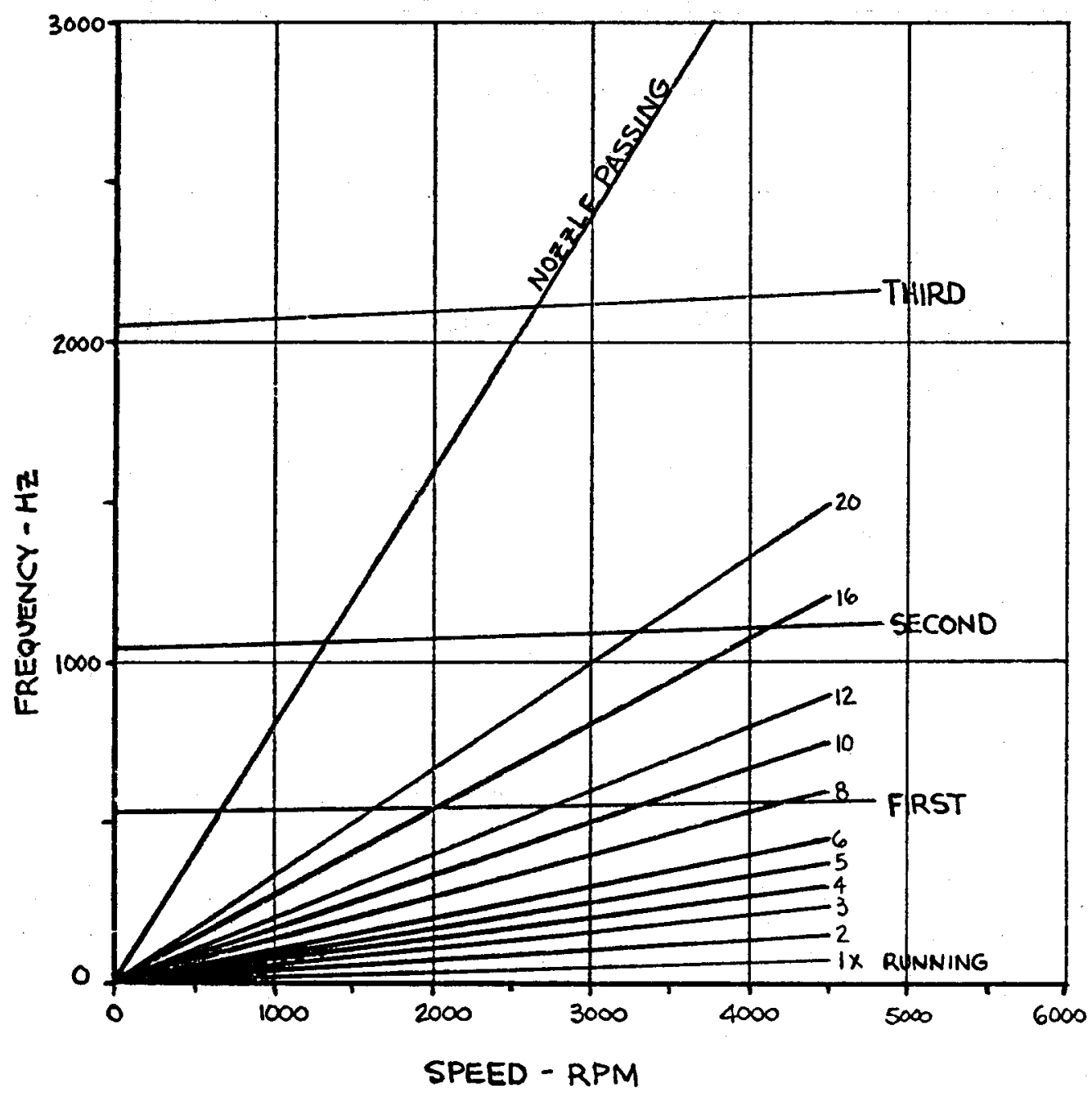

Figure 5-5. Campbell Diagram - 65MW - Hydrocarbon Turbine 
the highest stresses and lowest natural frequencies; the other blades are shorter and have lower stresses and higher natural frequencies. Since the third stage blade indicates no stress or vibration problems, there is no need to further check the other blades.

Maximum bending stress in this blade is $57220 \mathrm{kPa}(8,300 \mathrm{psi})$ at the hub trailing edge as shown on Fig. 5-4 on the Goodman diagram. The maximum allowable stress would be $179244 \mathrm{kPa}(26,000 \mathrm{psi})$ or more than three times the present design. The natural frequencies for this blade design are shown on the Campbell diagram Fig. 5-5. The fundamental natural frequency is more than nine times operating speed.

\section{STATOR DIAFRAM}

The stator diafram stresses and deflections were computed for gas loading, checked for gas bending stresses, and utilizing standard calculation procedures. These deflections and stresses are well within Engineering limits.

\section{INNER CASING}

The function of the inner casing is to support and position the stationary stator diaframs and to direct the flow from the inlet through the rotor to the discharge. This casing is horizontally split and is fabricated from two half castings which are welded to the inlet guide vanes to form the top and bottom casing halves. The inner casing is also provided with instrumentation for evaluating the aerodynamic performance of this turbine. The instrumentation is on both double flow sections. The thermocouple wires and pressure tubing are collected at a common point in the inner casing and then brought through the outer casing.

\section{COUPLING}

The coupling between the turbine and generator will be of a flexible design This type of coupling has been applied successfully in this power range in gas turbine type electrical generation installations. The coupling allows for a greater misalignment tolerance and therefore simplified assembly of the units. Additionally, to rque lock is eliminated and lubrication is not required.

\section{TRIP DEVICE}

The turbine will be provided with the trip device to allow for the shut off of the motive fluid as a result of an overspeed condition. There are many 
types of devices that are in use today, all of which will do the job. They consist of a speed sensing device and a mechanism for interupting an oil circuit to trip the main valve. The device selected for this unit is a dished disc with weights located around the circumference of the disc. This assembly is inherently in dynamic balance. At the trip speed, the centrifugal forces cause the disc to snap to the trip position hugging the trip lever. Pivoting of the trip lever releases a piston in the control oil circuit which instantaneously causes the pressure to decay and close the trip valve. Another device which could be used is a spring opposing a bolt which is not within the turbine shaft. As the speed increases, the bolt tries to fly out against a calibrated spring. As the trip speed is achieved, the bolt is extended far enough from the shaft to strike the trip lever and thereby activate the trip valve.

This turbine will also be equipped with a manually operated trip so that it may be tripped simply by turning the trip handle at any speed.

\section{MATER IALS}

The materials selected for this expanding turbine unit have been used in both turbine and compressor design. Table 5-3 lists these materials for the hydrocarbon turbine. Also listed are the forms of the raw material to be utilized in construction, minimum material yield stress and estimated maximum working stress.

\section{Casing}

The casing will be formed out of plate and rolled with one continuous seam weld along the horizontal axis. The ASME SA516, Grade 60 material has been utilized in turbine and compressor casing design. The nozzles and the inner barrel support will also be made of the same material.

\section{Endwalls}

The endwalls will be a welded fabrication from three forgings. The forgings will consist of two forged rings for the outer and inner sections and a forging for the cone section. The material used will be ASME Grade SA266, class 1.

\section{Inner Casing}

The inner casing will be a cast steel fabrication. The two half sections will be castings welded together with a fabricated vane assembly. The cast material 
will be ASME SA216, Grade WCB. The vane assembly will be the ASME SA516, Grade 60 plate material.

\section{Rotor}

The rotor will be a forging, with integral discs, made of ASTM A470 Class 7 material. This has been used commonly for turbine and compressor designs.

\section{Rotating Blades}

The rotating blades will be forged out of AISI 403 stainless material. This is a standard material utilized in turbine design.

\section{Stator Diafram Assembly}

The stator blades, one piece shroud and inner ring will be made from ASTM Al76, Type 405 strip material. The center diafram disc will be welded to the inner ring and made of the ASME SA516, Grade 60 plate.

Table 5-3

TURBINE MATERIALS

\begin{tabular}{|c|c|c|c|c|c|}
\hline & PART & MATERIAL & $\begin{array}{l}\text { MIN. } \\
\text { YIELD } \\
\text { kPa }\end{array}$ & $\begin{array}{c}\text { MAX. } \\
\text { STRESS } \\
\text { kPa }_{a}\end{array}$ & $\begin{array}{l}\text { RAW } \\
\text { MAT'L. } \\
\text { FORM }\end{array}$ \\
\hline 1) & Casing & $\begin{array}{l}\text { ASME SA-516 } \\
\text { Grade } 60\end{array}$ & 221000 & 72000 & Plate \\
\hline 2) & End Walls & $\begin{array}{l}\text { ASME SA-266 } \\
\text { Class } 1\end{array}$ & 207000 & 35000 & Forged \\
\hline 3) & Inner Casing & $\begin{array}{l}\text { ASME SA-216 } \\
\text { Grade WCB }\end{array}$ & 248000 & 77000 & Cast \\
\hline 4) & Shaft & $\begin{array}{l}\text { ASTM A- } 470 \\
\text { Class } 7\end{array}$ & 655000 & 124000 & Forged \\
\hline 5) & B1ades & AISI Type 403 & 483000 & 152000 & Forged \\
\hline \multirow{3}{*}{ 6) } & Diaframs & & & & \\
\hline & a) Nozzles & $\begin{array}{l}\text { ASTM Al76 } \\
\text { Type } 405\end{array}$ & 172000 & 112000 & Strip \\
\hline & b) Center & ASME SA-516 & 221000 & 113000 & Plate \\
\hline
\end{tabular}


UNIT ASSEMBLY

The unit assembly procedes as follows:

- The outer casing is placed on the baseplate on its supports.

- The drive end endwall is bolted to the outer casing.

- The diafram halves are assembled into the inner casing in both the top and bottom half.

- The rotor is then placed in the bottom half.

- A clearance check is then made with the top half in position.

- Once this clearance check is approved, the top half is bolted onto the bottom half of the inner casing with the rotor resting on the stator diaframs. The bottom half of the inner casing is provided with rollers to allow for ease of assembly.

- Assembly fixtures (supplied with the unit) are attached to the outer casing.

- The inner casing assembly, with the rotor, is positioned on the assembly fixtures, rolled into the outer casing and positioned.

- The endwall is then brought into position and bolted to the outer casing.

- The drive end shaft seals are installed.

- The drive end bearing case is bolted on to the endwall and the bottom half bearing is installed.

- The same procedures are applied to the thrust end of the unit.

- A check is then made of the rotor runout, with respect to its two bearings, to assure that they are concentric and not off-set.

- The journal bearings, thrust bearing and instrumentation are installed and the bearing cases are closed.

- The coupling is then mounted on the rotor.

A preliminary alignment is made between the turbine and the generator. Once the alignment has been achieved, the gas and oil piping are installed and the alignment rechecked and readjusted if necessary. After this is completed, the coupling spacer is made up, the oil turned on, and the unit is ready for operation.

Procedures for disassembly would be the reverse of the assembly. However, once the unit is in the field, the casing gas piping and drive end endwall would remain in position. 
INSTRUMENTATION

\section{Aero Performance Instrumentation}

The turbine has been designed to include monitoring of pressures and temperatures within the blade path. These pressures and temperatures will be measured at five stations on each double flow section of the machine. Four measurements will be made around the circunference at each station. The five measurement stations are:

- Before the first stage stator

- After the first stage stator

- Before the second stage stator

- Before the third stage stator

- After the third stage rotor

The instrumentation will be installed to avoid interfering with the rotating elements. It will be brought from the inner casing to the outer casing through tubing which will not disrupt the gas flow in the discharge diffuser section.

\section{Mechanical Instrumentation}

The turbine will be provided with mechanical instrumentation to continuously monitor the performance of the mechanical components and indicate malfunctions.

Vibration. The turbine will be equipped with proximity type vibration probes and read-out devices to monitor shaft vibration. Two probes will be provided at each bearing, $90^{\circ}$ apart for the measurement of the horizontal and vertical vibration components.

Axial Position. A proximity probe will be provided for measuring the axial position of the turbine to indicate possible thrust bearing failure.

Speed Pick-up. A magnetic type speed pick-up will be reading off a 60 tooth gear. This unit will be utilized as the speed reference signal to the load control system.

Temperature Measurement. Thermocouples (or RTD's) will be provided in journal and thrust bearings to monitor bearing metal temperature. Additionally, locally mounted thermometers will be placed in the oil drains of the journal bearings, thrust bearing and seals for measurement of oil throw-off temperature. 
Oil Pressure. Locally mounted pressure gages will be mounted in the inlet piping to monitor the seal oil pressure and lube oil pressure. 
Section 6

AUXILIARY COMPONENTS

LUBE AND SEAL OIL SYSTEM

\section{Design Requirements}

Lube and seal oil requirements are:

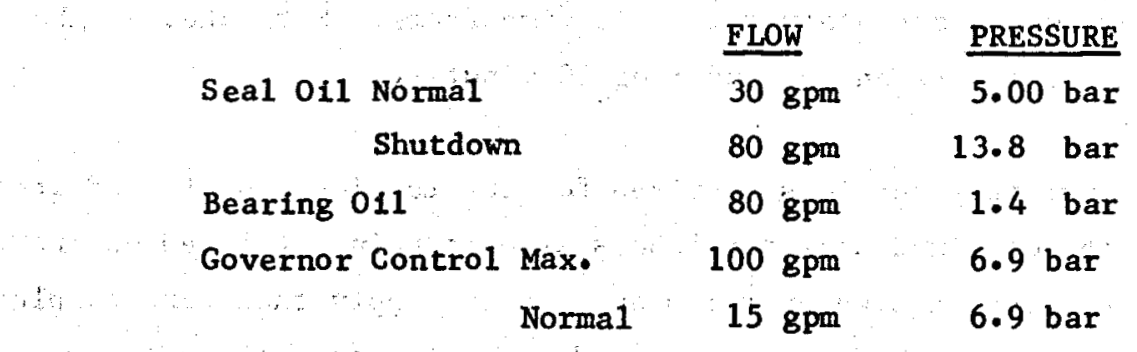

In order to design the combined lube and seal system, several as sumptions were made. These assumptions are:

- API 614 would be utilized throughout; however, the standard Elliott exceptions would apply. (These exceptions are 1isted in Appendix D-1)

- No copper or copper bearing alloys will be in contact with the oil or exposed to the atmosphere.

- An accumulator be required to supply bearing oil and seal ofl for a 5 minute period upon loss of electrical power.

- Nitrogen or another inert gas will be available for the accumulator at 10.3 bar supply.

- The coolers, filters, and accumulators are to be ASME Code design and stamped and the coolers are to be TEMA "C" design.

- Electrical components to be good for NEMA Class 1 , Group "D", Div. 2 areas. All switches to be singlepole, double-throw type.

- A combined lube and seal system will be provided for the turbine and turbine governor controls only. 
The schematic for this console is shown in Figure 6-1. A description of the console elements is contained in Appendix D-2. The design, controls, and operation of the console are well within the present state-of-the-art and no new components or concepts are utilized.

A degassing tank is recommended for use with this system since the lube and seal oil will be combined. The purpose of the degassing tank is to remove the hydrocarbon gases from the contaminated seal oil. This gas should be recovered and reinjected into the system.

An accumulator tank is required to maintain an oil flow for 5 minutes in the event of an electrical failure. It is assumed that standby DC equipment, a diesel generator set or equivalent, would operate within this time frame. Estimates of the coastdown time for the unit are on the order of 10 minutes.

Table 6-1 lists the auxiliary services required for the turbine console and generator console. Since the combined seal and lube system is being utilized on the turbine, it is recommended that the generator manufacturer supply their own complete seal and lube system for their hydrogen seals and journal bearings for the generators. The generator manufacturer has no experience with possible effects of isobutane contamination on the generator materials and this possible contamination will be avoided.

\section{Turbine 0il System Contamination}

A check was made of the literature for the solubility of iso-butane and 1ight turbine oil. Data was available only on N-butane in mineral oil with a mol. weight of 325. This data should approximate the effects of iso-butane in light turbine oil with an average mol. weight of 357. At the condenser pressure of 5.0 bar (72 psi), the butane would be completely soluble at $38^{\circ} \mathrm{C}\left(100^{\circ} \mathrm{F}\right)$. Solubility at $93.3^{\circ} \mathrm{C}$ $\left(200^{\circ} \mathrm{F}\right)$ would be slightly over $10 \%$. At atmospheric pressure, the solubility would be reduced by a factor of 10 or $10 \%$ at $38^{\circ} \mathrm{C}\left(100^{\circ} \mathrm{F}\right)$ and $1 \%$ at $93.3^{\circ} \mathrm{C}\left(200^{\circ} \mathrm{F}\right)$. (Solubility is given in weight butane/weight mixture.)

If $i t$ is assumed that:

- The only source of contamination of oil by iso-butane is from contaminated seal leakage

- Equilibrium conditions exist 


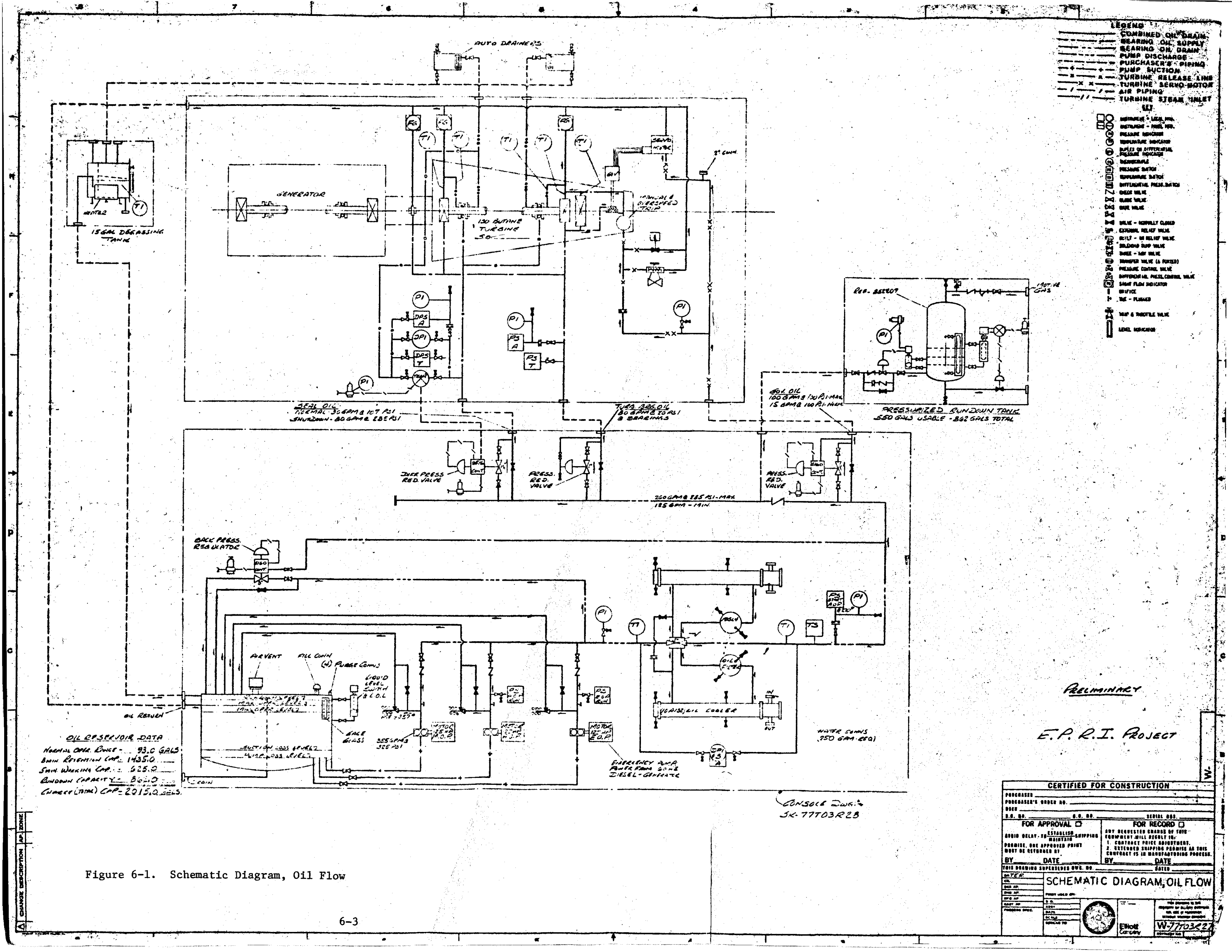



This contamination level should not present any problems to the lubrication system. However, the contamination level could be reduced to 100 parts per million by the use of a vacuum degasifier.

TURBINE-GENERATOR STRING

A layout of the turbine-generator string is shown on Figure 6-2. Dimensions and weights are given on this drawing to assist in the erection and estimation of foundation requirements. The turbine and generator will be on separate baseplates that will not be connected. They will have to sit on a common foundation to allow for alignment, support, etc. The support foundation will be designed for regional seismic conditions.

Table 6-2

TURBINE GENERATOR COMPONENT WEIGHTS

\begin{tabular}{|c|c|c|}
\hline & LB & $\mathrm{Kg}$ \\
\hline TURB INE & 10,000 & 4,500 \\
Rotor & 28,200 & 12,800 \\
Inner Casing Assembly & 7,000 & 3,180 \\
Baseplate & 114,000 & 51,700 \\
Total Unit & & \\
\hline GENERATOR & 45,200 & 20,500 \\
Rotor & 200,000 & 90,700 \\
Stator & 2,500 & 1,130 \\
\hline EXCITER & 9,000 & 4,080 \\
Rotor & & \\
Casing & 311,000 & 141,000 \\
\hline TOTAL GENERATOR AND EXCITER & 425,000 & 192,800 \\
\hline TOTAL STRING & & \\
\hline
\end{tabular}

The overall string is $14.25 \mathrm{~m}$ (561") In length from the end of the turbine thrust end bearing case to the end of the generator exciter. An additional length on the turbine end of $3.86 \mathrm{~m}$ (152") will be required to remove the turbine rotor and inner basing assembly and $5 \mathrm{~m}$ (197") w111 be required on the generator end to remove the generator internals. 
Table 6-2 specifies the weights of the various string components and the to.tal generator turbine package weight. The total turbine unit weight is $51,700 \mathrm{Kg}(114,000 \mathrm{lbs})$ and the total generator and exciter weight is 141,000 $\mathrm{Kg}(311,000 \mathrm{lbs})$. The heaviest unit for maintenance would be the generator stator section which would be $90,700 \mathrm{Kg}(200,000 \mathrm{lbs})$. The heaviest section for turbine maintenance would be the inner casing assembly at $12,800 \mathrm{Kg}$ $(28,200 \mathrm{lbs})$. The turbine lube oil and seal oil piping connections would be connected to a common header on the turbine. (This piping is not shown.) This header piping would be connected to the customer piping and can be brought to either side of the unit depending upon installation requirements. The same would be true for the generator connections.

\section{TURBINE-GENERATOR - TORSIONAL CRITICAL SPEED ANALYSIS}

The turbine generator system has been analyzed for torsional critical speeds. The axial flow hydrocarbon turbine was modeled as multiple masses from the data given in Appendix B-2. The generator and exciter was modeled as a single inertia and spring constant. These values were supplied by Westinghouse. The coupling used for this analysis was a diafram type; Bendix Model 67 E626. Table 6-3 lists the torsional stiffnesses and inertia of the generator exciter and the coupling. Figure 6-3 indicates the results of this analysis.

Table 6-3

INERTIA AND SPRING CONSTANTS

\begin{tabular}{|l|c|c|}
\hline & $\begin{array}{c}\text { INERTIA } \\
\text { LB-IN } 2\end{array}$ & $\begin{array}{c}\text { SPRING CONSTANT } \\
\text { LB-IN/RAD. }\end{array}$ \\
\cline { 2 - 4 } Generator and Exciter & $7.196 \times 10^{6}$ & $5.88 \times 10^{8}$ \\
Coupling & $3.848 \times 10^{4}$ & $2.27 \times 10^{8}$ \\
\hline
\end{tabular}

The first torsional response is at 1.892 RPM. This is well below the operating speed of 3600 RPM. The accepted criteria is that no torsional speed will be within $15 \%$ of the operating speed. Acceleration through this torsional during start-up will present no problems.

A second torsional response was found at 7,566 RPM. This falls within $15 \%$ of two times running frequency. This condition is marginal, and the system should be revised. 
TORS IONAL CRITICAL SPEEDS ANALYS IS

(Coupling Stiffness $=2.27 \times 10^{8} 1 \mathrm{~b}$-in. $/$ rad. $)$

\begin{tabular}{|c|c|c|c|c|c|}
\hline \multicolumn{3}{|c|}{$\begin{array}{l}\text { TORSIONAL } \\
\text { CRITICAL } \\
\text { (RPM) }\end{array}$} & \multirow{3}{*}{\multicolumn{2}{|c|}{$\begin{array}{c}\text { SHAFT } \\
\text { STIFFNESS } \\
\underset{(1 \mathrm{~b} \cdot-\text { in./rad. })}{\mathrm{K}}\end{array}$}} & \\
\hline \multirow{2}{*}{$\begin{array}{l}\text { POINT } \\
\text { NO. } 3 \\
22527 .\end{array}$} & \multirow{2}{*}{\begin{tabular}{|l|}
$\begin{array}{l}\text { POINT } \\
\text { NO. 2 }\end{array}$ \\
7566. \\
\end{tabular}} & \multirow{2}{*}{$\begin{array}{l}\text { POINT } \\
\text { NO. } 1 \\
1892 .\end{array}$} & & & \\
\hline & & & & & \\
\hline$x$ & $x$ & $(x)$ & $265.2 \times 10^{6}$ & $1-2$ & \multirow{10}{*}{ 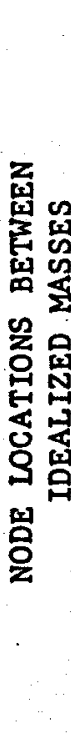 } \\
\hline & & & $374.1 \times 10^{6}$ & $2-3$ & \\
\hline & & & $1726.8 \times 10^{6}$ & $3-4$ & \\
\hline \multirow[t]{4}{*}{$x$} & . & & $4115.6 \times 10^{6}$ & $4-5$ & \\
\hline & & & $4115.6 \times 10^{6}$ & $5-6$ & \\
\hline & $(x)$ & & $846.5 \times 10^{6}$ & $6-7 \mid$ & \\
\hline & & & $4115.6 \times 10^{6}$ & $7-8$ & \\
\hline \multirow[t]{3}{*}{$(x)$} & & & $4115.6 \times 10^{6}$ & $8-9$ & \\
\hline & & & $1744.7 \times 10^{6}$ & $9-10$ & \\
\hline & & & $169.9 \times 10^{6}$ & $\mid a-11$ & \\
\hline 184.4 & $4.5^{*}$ & .47 .4 & \multicolumn{3}{|c|}{$\begin{array}{c}\text { Margin From Nearest } \\
\text { Exciting Freq. }-\%\end{array}$} \\
\hline
\end{tabular}

\begin{tabular}{|c|l|c|}
\hline \multicolumn{2}{|c|}{$\begin{array}{c}\text { IDEALIZED } \\
\text { MASS }\end{array}$} & $\begin{array}{c}\text { WR }^{2} \\
\left(1 \mathrm{~b} \cdot-\text { in }^{2}\right)\end{array}$ \\
\hline 1 & Generaton & 7196112.0 \\
\hline 2 & Coupling & 38476.8 \\
\hline 3 & $\begin{array}{l}\text { Turbine } \\
\text { Disc. \#1 }\end{array}$ & 5344.8 \\
\hline 4 & Disc. \#2 & 433792.7 \\
\hline 5 & Disc. \#3 & 190284.5 \\
\hline 6 & Disc. \#4 & 135313.9 \\
\hline 7 & Disc. \#5 & 135313.9 \\
\hline 8 & Disc. \#6 & 190284.5 \\
\hline 9 & Disc. \#7 & 433792.7 \\
\hline 10 & Disc. \#8 & 7853.8 \\
\hline 11 & Disc. \#9 & 492.4 \\
\hline
\end{tabular}

\begin{tabular}{|c|c|c|}
\hline \multicolumn{2}{|c|}{ EXCITING FREQUENCIES } \\
\hline SOURCE & FREQUENCY-CPM \\
\hline 1 & Turbine & $3600-3960$ \\
\hline 2 & $2 \times$ Turb & $7200-7920$ \\
\hline
\end{tabular}

(X) Indicates first appearance of node.

Notes: 1) "K" and "WR" are referred to low speed shaft. 2) * This mark, if any, shows unacceptable margin.

Figure 6-3. Torsional Critical Speeds Analysis 
An analysis was made using a coupling with $25 \%$ more stiffness than the original. Figure 6-4 indicates these results. Again the first torsional critical has ample margin. However, the effects on the second torsional were very small and did not remove it from the 2 times frequency range. Final design considerations for this turbine generator string should attempt to remove the second torsional critical from the $2 x$ running range.

TURBINE DESIGN-SYSTEM INTERACTION

The turbine design has specific features which will directly effect the overall plant design. The turbine is designed with down discharge nozzles. These down nozzles are required for safety purposes during the start-up of the unit. Since the iso-butane, at atmospheric temperature and normal operating back pressures, would be in liquid form, the down nozzles allow for initial drainage from the turbine. Also, since the design point is very close to the wet region and the operating tolerances actually fall within the wet region, down nozzles have to be used to avoid collecting liquid in the discharge while operating the turbine. Condensing steam turbines normally follow this practice.

Special sight glasses should be installed on the turbine drain lines to check for liquid. Comon practice on steam turbines is to blow the drains to atmosphere to insure the unit is dry. By observing that steam, instead of water, is coming out the drain, the operator is assured the unit is dry. This cannot be done with the iso-butane, hence the need for visual sight glasses.

This requirement of the down discharge affects the overall system piping arrangement. Figure 6-5 shows the power plant with the generator and turbine mounted on a mezanine level with a distribution header beneath it. The header in turn is mounted above the condensers. The arrangement puts the turbine and generator $16.8 \mathrm{~m}$ ( $55 \mathrm{ft}$. ) above ground level. If this mezanine mounting cannot be accomplished due to geological or seismic requirements of the site location, the turbine generator set can be lowered to $6.1 \mathrm{~m}(20 \mathrm{ft}$ ) by using a plenum located below the turbine, as shown in Figure 6-6. Th1s will introduce additional pressure losses amounting to approximately 0.03 bar $(0.4 \mathrm{psi})$. Further pressure drop will occur in piping bends required to direct the flow into the condenser system. 
TORS IONAL CRITICAL SPEEDS ANALYS IS

(Coupling stiffness $=2.84 \times 10^{8} 1 \mathrm{~b}-$ in. $/ \mathrm{rad}$.)

\begin{tabular}{|c|c|c|c|c|c|}
\hline \multicolumn{3}{|c|}{$\begin{array}{l}\text { TORSIONAL } \\
\text { CRITICAL } \\
\text { (RPM) }\end{array}$} & \multirow{3}{*}{\multicolumn{3}{|c|}{$\begin{array}{c}\text { SHAFT } \\
\text { STIFFNESS } \\
\underset{\left(1 b_{\bullet}-\text { in./rad. }\right)_{\text {K }}}{ }\end{array}$}} \\
\hline $\begin{array}{l}\text { POINT } \\
\mathrm{NO} .3 \\
\end{array}$ & $\begin{array}{l}\text { POINT } \\
\text { No. } 2 \\
\end{array}$ & $\begin{array}{l}\text { POINT } \\
\text { No. } 1 \\
\end{array}$ & & & \\
\hline 23674. & 7607. & 2009. & & & \\
\hline \multirow[t]{3}{*}{$x$} & $\mathbf{x}$ & (x) & $288.9 \times 10^{6}$ & $1-2$ & \multirow{10}{*}{ 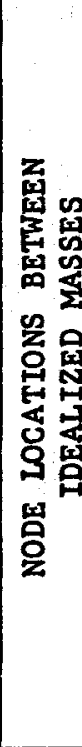 } \\
\hline & & & $448.2 \times 10^{6}$ & $2-3$ & \\
\hline & & & $1726.8 \times 10^{6}$ & $3-4$ & \\
\hline \multirow[t]{4}{*}{$x$} & & & $4115.6 \times 10^{6}$ & $4-5$ & \\
\hline & & & $4115.6 \times 10^{6}$ & $5-6$ & \\
\hline & $(x)$ & & $846.5 \times 10^{6}$ & $6-7$ & \\
\hline & & & $4115.6 \times 10^{6}$ & $7-8$ & \\
\hline \multirow[t]{3}{*}{$(\mathrm{x})$} & 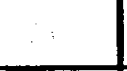 & & $4115.6 \times 10^{6}$ & $8-9$ & \\
\hline & & & $1744.7 \times 10^{6}$ & $9-10$ & \\
\hline & & & $169.9 \times 10^{6}$ & $0-11$ & \\
\hline 198.9 & $3.9 *$ & 44.2 & \multicolumn{3}{|c|}{$\begin{array}{r}\text { Margin From Nearest } \\
\text { Exciting. Freq. - } \%\end{array}$} \\
\hline
\end{tabular}

\begin{tabular}{|c|c|c|}
\hline \multicolumn{2}{|c|}{$\begin{array}{c}\text { IDEALIZED } \\
\text { MASS }\end{array}$} & $\begin{array}{c}\text { WR } \\
\left(1 \mathrm{~b} .- \text { in }^{2}\right)\end{array}$ \\
\hline 1 & Generator & 7196112.0 \\
\hline 2 & Coupling & 38476.8 \\
\hline 3 & $\begin{array}{l}\text { Turbine } \\
\text { Disc. \#1 }\end{array}$ & 5344.8 \\
\hline 4 & Disc. \#2 & 433792.7 \\
\hline 5 & Disc. \#3 & 190284.5 \\
\hline 6 & Disc. \#4 & 135313.9 \\
\hline 7 & Disc. \#5 & 135313.9 \\
\hline 8 & Disc. \#6 & 190284.5 \\
\hline 9 & Disc. \#7 & 433792.7 \\
\hline 10 & Disc. \#8 & 7853.8 \\
\hline 11 & Disc. \#9 & 492.4 \\
\hline
\end{tabular}

\begin{tabular}{|c|c|c|}
\hline \multicolumn{2}{|c|}{ EXCITING FREQUENCIES } \\
\hline SOURCE & FREQUENCY-CPM \\
\hline 1 & Turbine & $3600-3960$ \\
\hline 2 & $2 \times$ Tumb & $7200-7920$ \\
\hline
\end{tabular}

(x) Indicates first appearance of node.

Notes: 1) "K" and "WR" are referred to low speed shaft. 2) * This mark, if any, shows unacceptable margin.

Figure 6-4. Torsional Critical speeds Analysis 

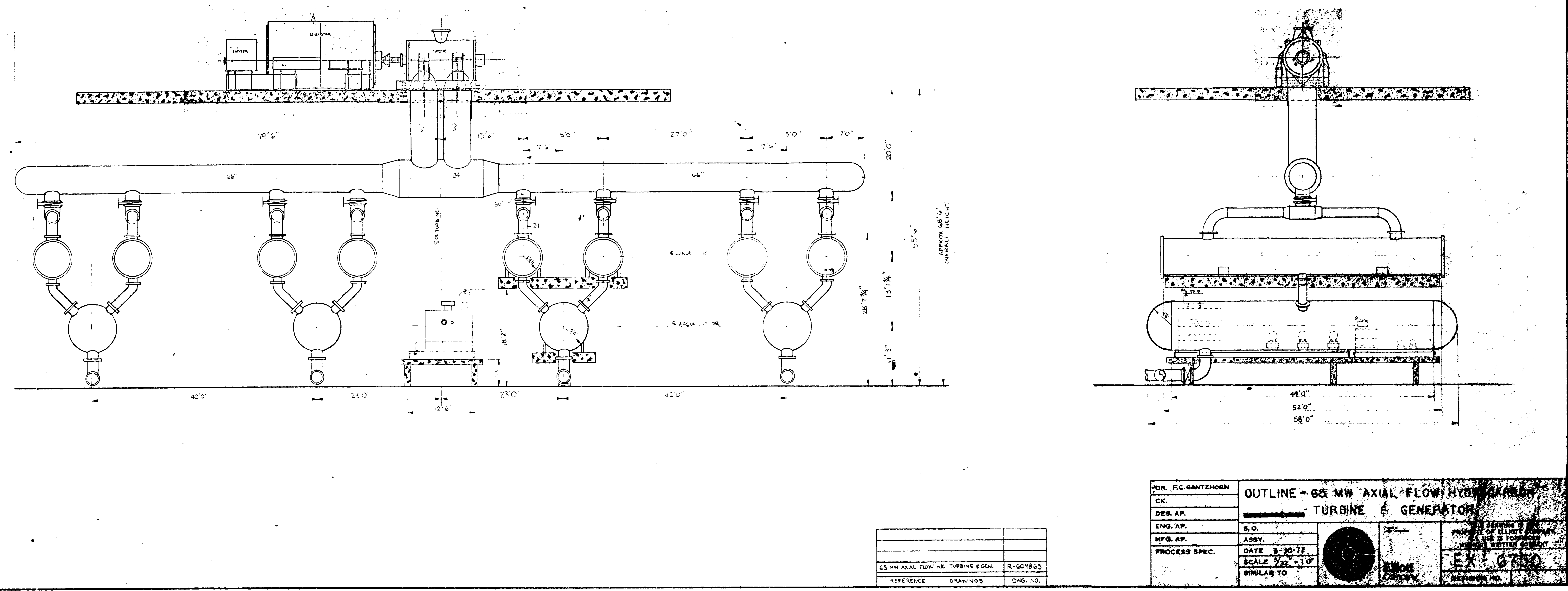


\section{GAS PIPING LOADS AND THERMAL GROWTH}

The maximum allowable loads for the hydrocarbon expander have been computed per NEMA standard SM21 and NEMA standard SM20. These codes are referenced by API 612. Figures 6-7 and 6-8 show a tabulation of the maximum allowable piping forces and moments and a plot of the acceptable combinations of the forces and moments for the individual nozzles.

Figure 6-9 tabulates the expected nozzle movements due to thermal growth.' These are based on $21^{\circ} \mathrm{C}\left(70^{\circ} \mathrm{F}\right)$ ambient conditions, steady state running temperatures of $149^{\circ} \mathrm{C}\left(300^{\circ} \mathrm{F}\right)$ on the inlet and $66^{\circ} \mathrm{C}\left(150^{\circ} \mathrm{F}\right)$ on the discharge, and a thermal coefficient of expansion of $11.34 \mathrm{~mm} / \mathrm{mm}{ }^{\circ} \mathrm{C}\left(6.3 \times 10^{-6}\right.$ inches per inch -F). The support feet are located at the exhaust flange center lines. The coupling end support feet are keyed radially so the axial thermal growth is referenced from that point.

With the above information, the pipe designers should be able to properly design the piping to minimize loads on this turbine. It cannot be over emphasized that good piping design is always required on turbomachinery equipment operating at any speed. It has been proven time and again that poor piping can cause mechanical problems with turbomachinery. Excessive piping loads cause casing strains, warpage of the casing, and proper alignment between the turbine and generator cannot be maintained! Additionally, poor piping will cause vibration problems due to misalignment of the turbine casing, bearing systems, and the rotor.

\section{TURBINE SPECIFICATIONS}

A specification was prepared for the hydrocarbon turbine-generator set. This specification is intended to cover the minimum requirements for the hydrocarbon turbine, lubrication and seal oil system, and generator used for electrical power generation in conjunction with the geothermal binary cycle. These specifications can be found in Appendix "C". They are intended as a guide to give the purchaser and vendor a common ground on which to design and select equipment. 

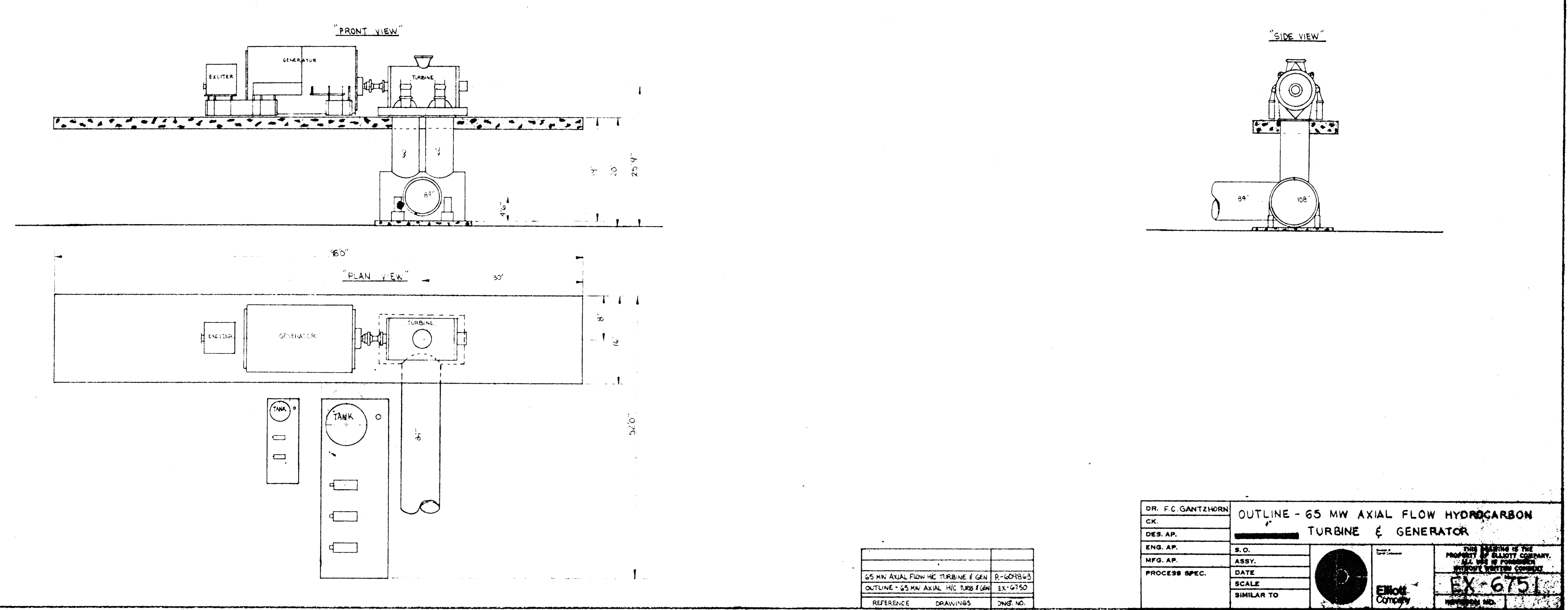
MAX IMUM ALLOWABLE PIPING LOADS ON NOZZLES

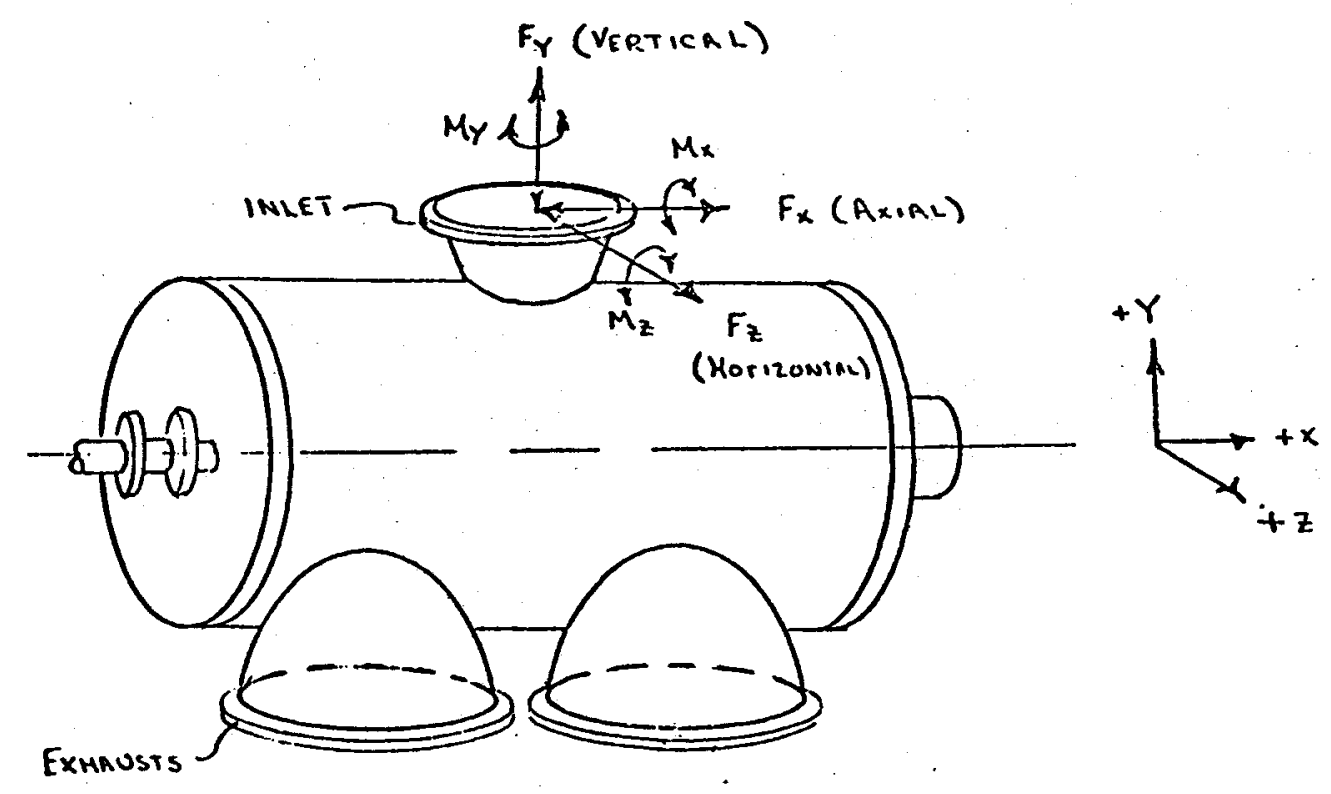

Inlet $\quad$ Exhaust

Maximum Resultant Force (F)

Newtons

11,120 .

18,406 .

Pounds

2,500 .

4,138 .

Maximum Resultant Moment (M)

Newton-Meters

10,162 .

16,821

Pounds-Foot

7,500 .

12,414

$$
\begin{aligned}
& F=\sqrt{F x^{2}+F y^{2}+F_{z}{ }^{2}} \\
& M=\sqrt{M x^{2}+M_{y}{ }^{2}+M_{z}{ }^{2}}
\end{aligned}
$$

Figure 6-7. Maximum Allowable Piping Loads on Nozzles 
ALLOWABLE COMBINATION OF PIPNG FORCE AND MOMENT ON EACH NOZZLE

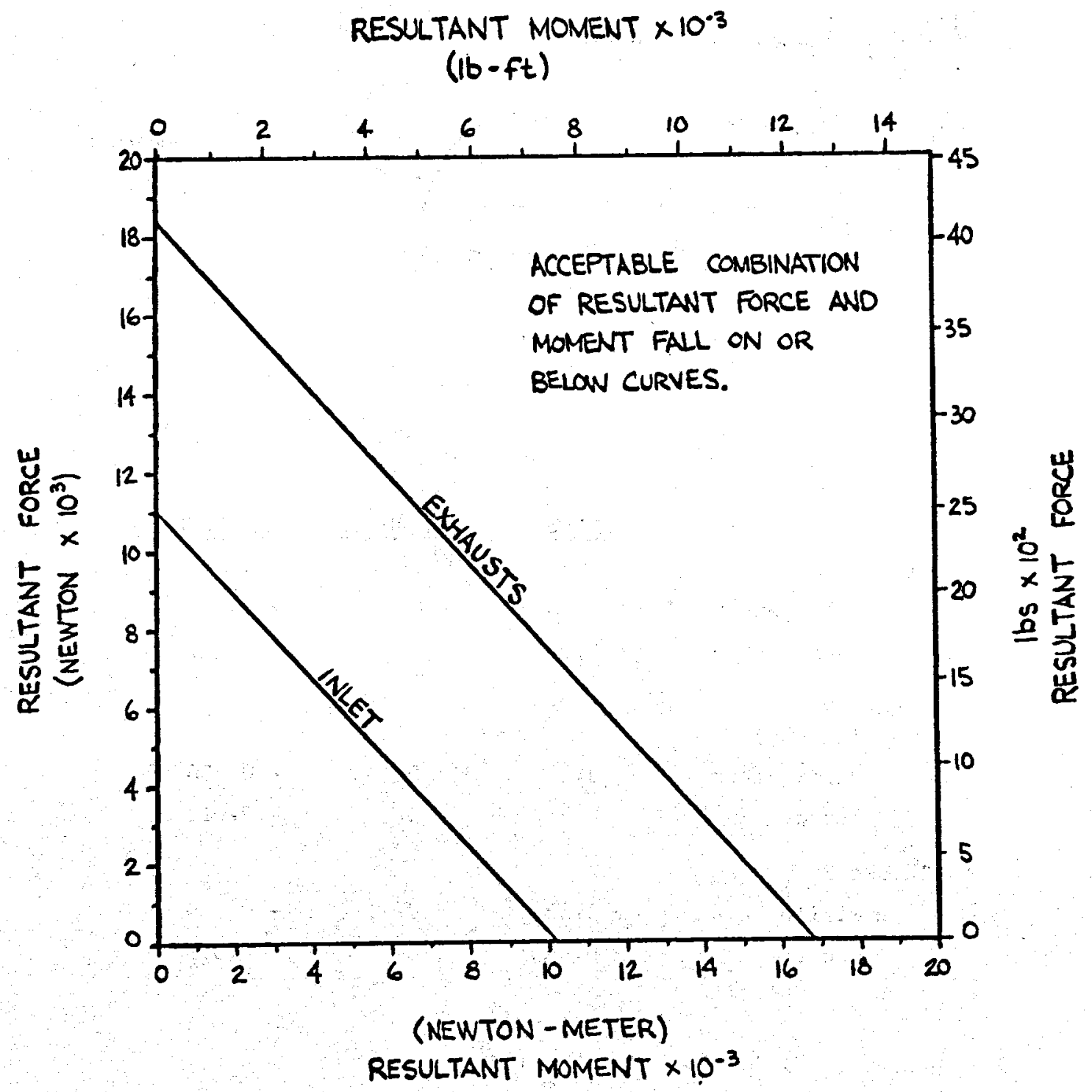

Figure 6-8. Allowable Combination of Piping Force and Moment on Each Nozzle 


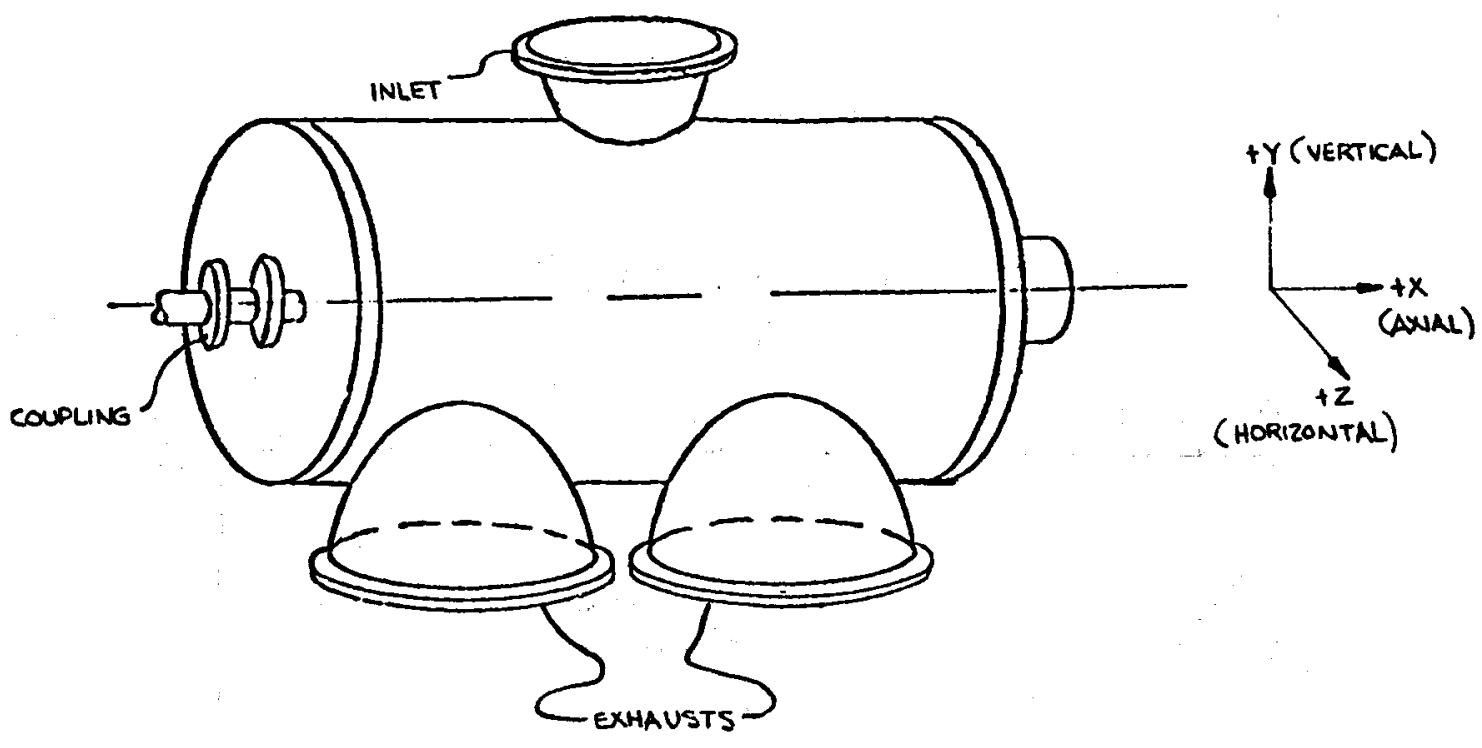

\section{AXIAL HORIZONTAL VERTICAL}

Inlet Nozzle

$\begin{array}{llll}\text { Millimeters } & +0.762 & 0 . & +2.413 \\ \text { Inches } & +0.030 & 0 . & +0.095\end{array}$

Exhaust Nozzle (coupling end)

$\begin{array}{llll}\text { Millimeters } & 0 . & 0 . & -0.330 \\ \text { Inches } & 0 . & 0 . & -0.013\end{array}$

(Thrust End)

$\begin{array}{llll}\text { Millimeters } & +1.524 & 0 . & -0.330 \\ \text { Inches } & +0.060 & 0 . & -0.013\end{array}$

*Based on $21.1 \mathrm{C}\left(70^{\circ} \mathrm{F}\right)$ Ambient Temp.

Figure 6-96 Nozzle Thermal Growths 
Section 7

SYSTEM AND CONTROLS

CONTROLS

The control scheme for this iso-butane closed loop system should be set up utilizing the best available state-of-the-art and allow for minimum anticipated difficulties. The ideal control system should allow for the simplest operation, control the basic variables, and provide maximum flexibility of operation. Figure 7-1 outlines such a control scheme. The basic elements in this cycle are:

- The condenser for taking the iso-butane mixture gas and turning it into liquid

- The pump for taking the liquid and adding the pressure head

- The vapor generator which takes heat from the hot brine and transfers it to the iso-butane mixture, gasifying it

- The turbine which expands this mixture and produces power

- The generator which converts the mechanical power to . electrical power

The control system requires a storage and make-up tank so that the system can be fully supplied with motive fluid. Since. this is a closed loop system, as operating conditions are varied, the only means for changing turbine flow rate is to increase or decrease the total system circulating mass.

Starting at the hydrocarbon pump on Figure $7-1$, the flow direction is as follows: The hydrocarbon pump takes 11 quid at 64 psia from the condenser and pumps it to the vapor generator pressure. For the $80 / 20 \mathrm{mixture,} \mathrm{this} \mathrm{would} \mathrm{be} \mathrm{ap-}$ roximately 555 psia. The pressure controller obtains its control signal from the vapor generator liquid feed, and will bypass flow as needed to maintain the pressure. This bypass 1 iquid goes into a storage and make-up tank maintained at a pressure higher than the condenser so that mass could be added to the system upstream of the condenser. The liquid flow out of the hydrocarbon pump going to the vapor generator flows through the vapor generator and leaves the generator as a gas at 505 psia. 

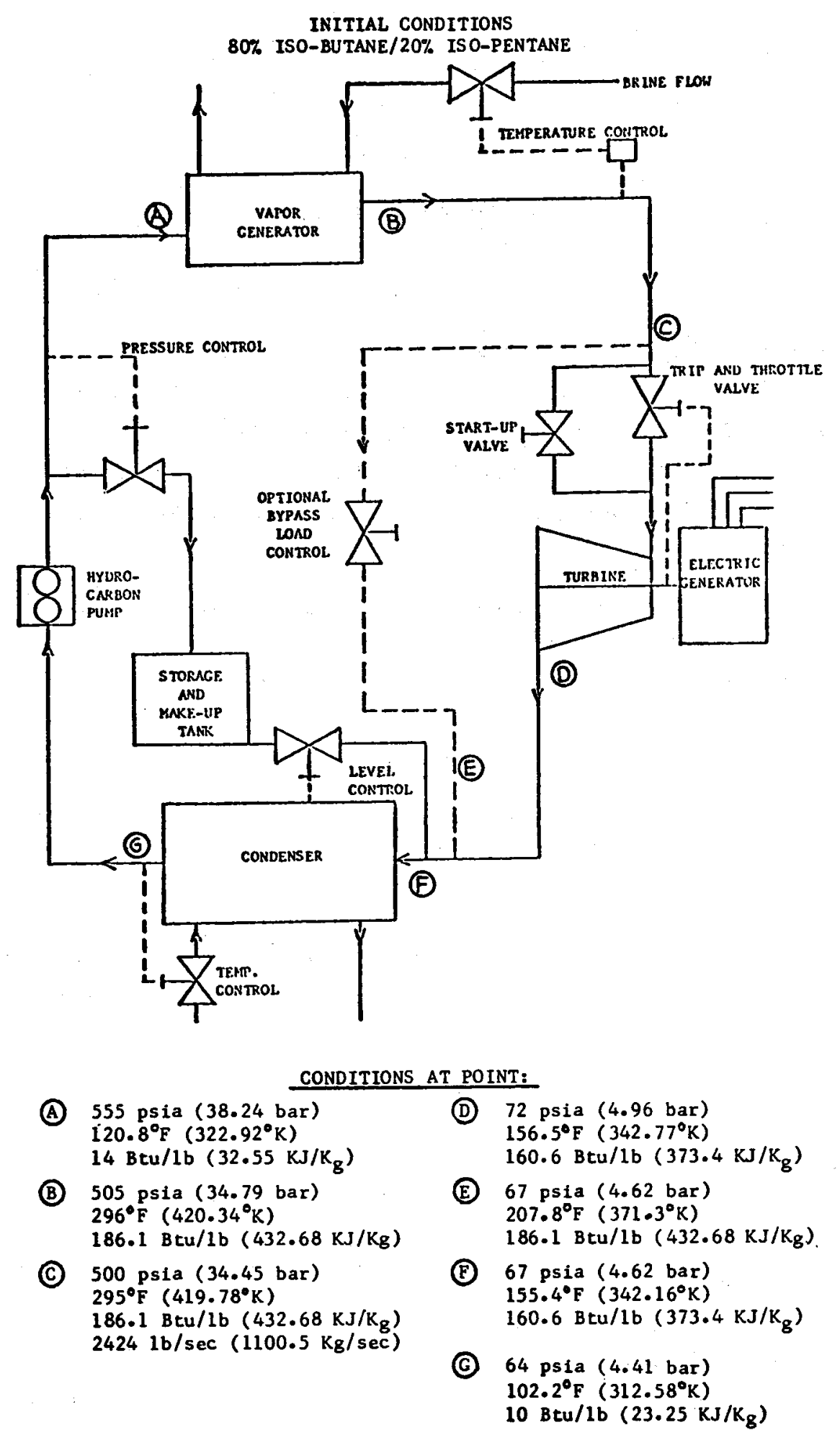

Figure 7-1. Initial Conditions - 80\% Iso-Butane/20\% Iso-Pentane 
A temperature sensor is installed in the gas stream close to the turbine. This sensor generates the input signal to the temperature controller regulating the brine flow. The gas would then be directed to the turbine trip and throttling valve.

The throttling valve allows for accurate control of the turbine and is tied into a load-speed-control scheme. The main trip and throttle valve would be a $30^{\prime \prime}$ valve. There is a smaller 8" bypass control valve around the main throttle valve which is tied into the synchronizing system of the generator. This smaller valve allows for control of the turbine under no load operation such as start-up.

The discharge flow from the turbine goes to the condenser. The condenser is operated on a level control similar to standard steam generation practices. This level control will maintain the condenser level by bleeding make-up fluid from the storage tank as needed. There will always be a liquid bleed which is regulated by this control valve.

An additional (optional) bypass valve is recommended to go around the turbine for initial start-up purposes. This would allow the entire loop to operate on a close system with gas circulation without the turbine having to rotate.

The control scheme operating with the $90 / 10$ mixture is shown in Figure $7-2$. The pressure levels are higher and the mass flow requirement greater than the $80 / 20$ mixture.

TURBINE TRIP

In the event of a turbine trip, the flow would be completely shut-off to the turbine resulting in no flow discharging from the vapor generator. This in effect would cause the vapor generator pressure to start to rise due to the increasing temperature under the no flow conditions since the brine will still be supplying heat. The temperature control sensing point, located close to the turbine inlet, would not see the temperature increase and in fact may see a temperature decrease and increase the brine flow. As the pressure increases, the pressure controller on the liquid line would sense the increased pressure and bypass more 1 iquid maintaining the required pressure at the vapor generator. If under trip-out conditions, the optional start-up bypass valve were 
FINAL CONDITIONS

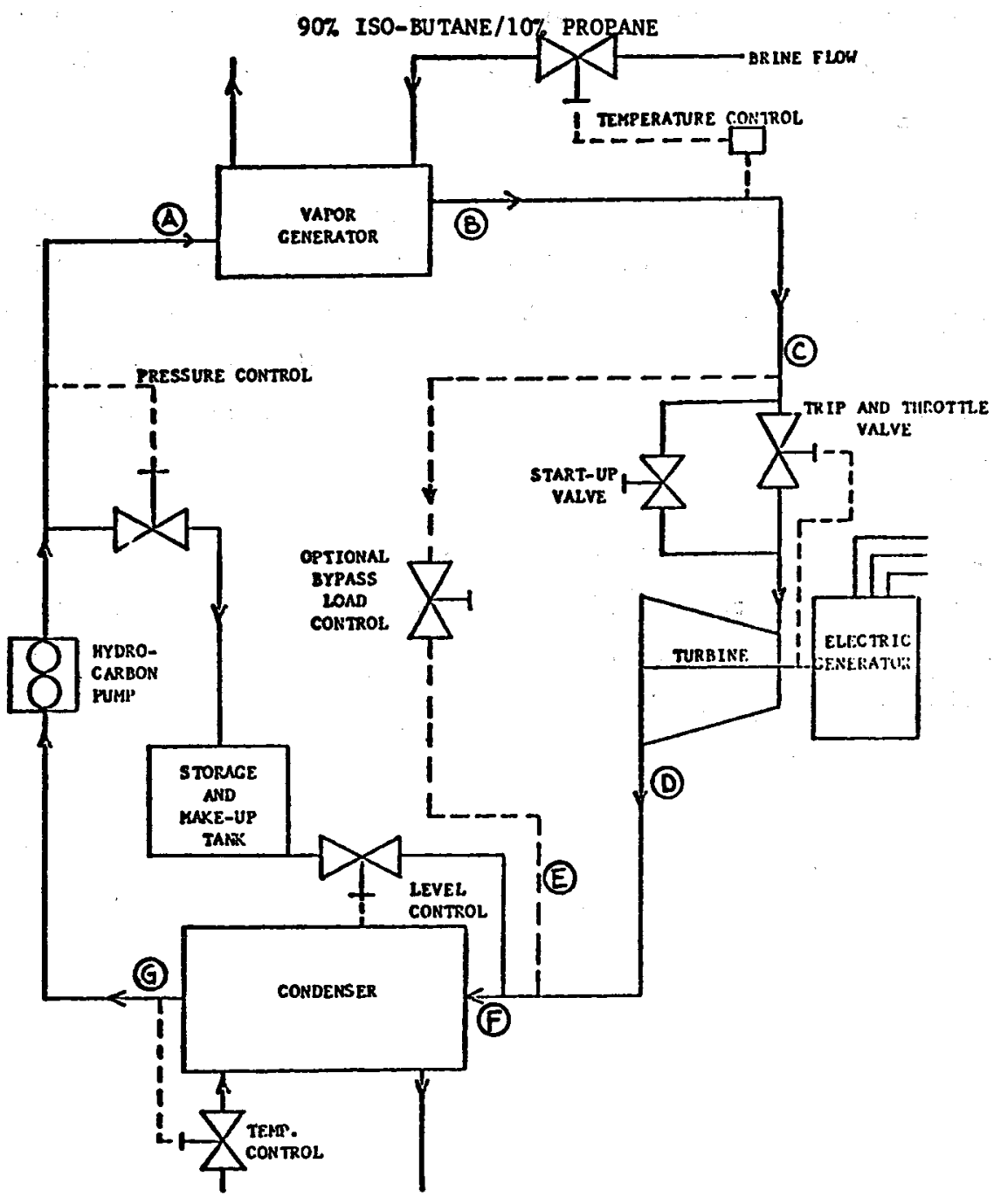
$\begin{array}{ll}\text { (A) } 645 \mathrm{psia}(44.44 \mathrm{bar}) & \text { (D) } 96 \mathrm{psia}(6.61 \mathrm{bar})\end{array}$
$119.9^{\circ} \mathrm{F}\left(322.42^{\circ} \mathrm{K}\right)$
$22.04 \mathrm{Btu} / \mathrm{lb}\left(51.24 \mathrm{KJ} / \mathrm{K}_{\mathrm{g}}\right)$
(B) 595 psia (41.0 bar)
$290.9^{\circ} \mathrm{F}\left(417.5^{\circ} \mathrm{K}\right)$
$187.4 \mathrm{Btu} / 1 \mathrm{~b}\left(435.71 \mathrm{~kJ} / \mathrm{K}_{\mathrm{g}}\right)$
(C) 590 psia ( 40.65 bar) $290^{\circ} \mathrm{F}\left(417^{\circ} \mathrm{K}\right)$
$187.4 \mathrm{Btu} / \mathrm{lb}\left(435.71 \mathrm{KJ} / \mathrm{K}_{\mathrm{g}}\right)$ $2644 \mathrm{lb} / \mathrm{sec}(1200.38 \mathrm{~K} / \mathrm{sec})$ $149.5^{\circ} \mathrm{F}\left(338.88^{\circ} \mathrm{K}\right)$ $163.3 \mathrm{Bcu} / \mathrm{lb}\left(379.67 \mathrm{~kJ} / \mathrm{K}_{\mathrm{g}}\right)$
(E) 91 psia (6.27 bar) $197.5^{\circ} \mathrm{F}\left(365.27^{\circ} \mathrm{K}\right)$ $187.4 \mathrm{Btu} / \mathrm{lb}(435.71 \mathrm{~kJ} / \mathrm{Kg})$
(F) 91 psia (6.27 bar) $148.4^{\circ} \mathrm{F}\left(338.27^{\circ} \mathrm{K}\right)$ $163.3 . \mathrm{Btu} / 1 \mathrm{~b}\left(379.67 \mathrm{KJ} / \mathrm{K}_{\mathrm{g}}\right)$ (C) $88 \mathrm{psia}(6.06 \mathrm{bar})$
$18 \mathrm{Btu} / \mathrm{lb}\left(41.85 \mathrm{~kJ} / \mathrm{K}_{\mathrm{g}}\right)$

Figure 7-2. Fina1 Conditions - 90\% Iso-Butane/10\% Propane 
to be opened for a minimum amount of flow to be passed, then the temperature controller could sense the increased temperature and cut back the brine flow. Another means of temperature control would involve sequencing the brine flow control valve into the turbine trip controls.

AUXILIARY CONTROLS AND INSTRUMENTATION

Controls (not shown in Figure 7-1 or 7-2) will be required for regulating the condenser cooling water flow rate to maintain the proper condenser gas pres=sure. The proposed control scheme as originally stated is within the stateof-the-art on all components and these components should be available as they are currently utilized in chemical and refinery processes.

The gas purity will have to be continuously monitored on line. The entire loop operation requires specific knowledge of the gas make-up to maintain peak operating efficiency and avoid possible equipment problems. In addition to the gas composition analysis, a droplet or molsture detector should be utilized to avoid operating in the wet region.

An operations annunciator panel should be designed to indicate to the operators any malfunctions of the system components such as vibration alarms, auxiliary oil pump running, pump trip indicators, etc. The plant may require computer control to adjust loop controls and brine flow controls, due to ambient condition changes, purity shifts, load changes, etc.

TURBINE GOVERNOR CONTROL

The governor selected for use with this turbine is the Woodward EG electronic type manufactured by Woodward Governor Company, Rockford, Illinois. This control can be operated as an isochronous governor or as a speed droop governor. On an infinite bus (1.e., comercial power), the EG governor can be operated as a conventional speed droop governor, and the load carried by the turbine will be a function of governor speed setting and speed droop setting. As an 1sochronous governor, it will maintain a constant speed for all loads.

The EG governor consists of three separate assemblies: a control box, a speed adjusting potentiometer, and a hydraulic actuator. The output signal of the control box serves as the input signal to the hydraulic actuator; the actuator, in turn, controls the flow of energy medium to the turbine by adjusting the throttle valve. 


\section{CONTROL RESPONSE}

The turbine generator overspeed trip and coastdown conditions were estimated assuming losses for windage friction, bearings, etc. Utilizing standard practice of a $10 \%$ overspeed to trip as outlined by API 612 , the trip will be set at $3960 \mathrm{rpm}$.

Assuming that the trip valve closing time is of the order of $0.2 \mathrm{sec}$. and actuated at $3960 \mathrm{rpm}$, two conditions were estimated.

- With the trip valve set directly on the turbine inlet, the maximum overspeed achieved on sudden loss of generator output would be $4070 \mathrm{rpm}$ occurring in $0.4 \mathrm{sec}$.

- With the trip valve $3.05 m$ (10 feet) upstream on the turbine, the maximum overspeed would be $4200 \mathrm{rpm}$ and occur in $0.7 \mathrm{sec}$.

The maximum allowable speed for the generator rotor is $4200 \mathrm{rpm}$. It is our recommendation that the trip valve be set as close to the turbine inlet as possible and not beyond $3.05 \mathrm{~m}$ (10 feet) upstream.

Coastdown time has been estimated at $10.5 \mathrm{~min}$. with a fixed back pressure of 5.0 bar ( $72 \mathrm{psia})$. Since the console oil accumulators are sized for 5 min., the DC back-up equipment has to be activated within that period of time to allow for a continuous supply of lube and seal oil for coastdown of the unit.

TRIP AND THROTTLE VALVE

Manufacturers have been contacted who would make this type of equipment. It has been found that the equipment is within the state-of-the-art, but these items would not necessarily be an "off-the-shelf" type component.

There are losses associated with a trip and throttle valve. A trip valve by itself would cause an 0.34 bar ( 5 psi) pressure drop in the 1 ine under the design flow conditions for the $80 / 20$ mixture. The throttle valve would cause an additional 1.7 bar ( $25 \mathrm{psi}$ ) drop under the inlet conditions.

Figure 7-3 demonstrates the throttling curves under isenthalpic conditions from the specified inlet conditions for all three mixtures over the range that these valves would have to operate. Figure 7-4 shows the percent available heat loss due to throttling as a function of the throttle pressure drop for the $80 / 20$ gas mixture at design conditions. 


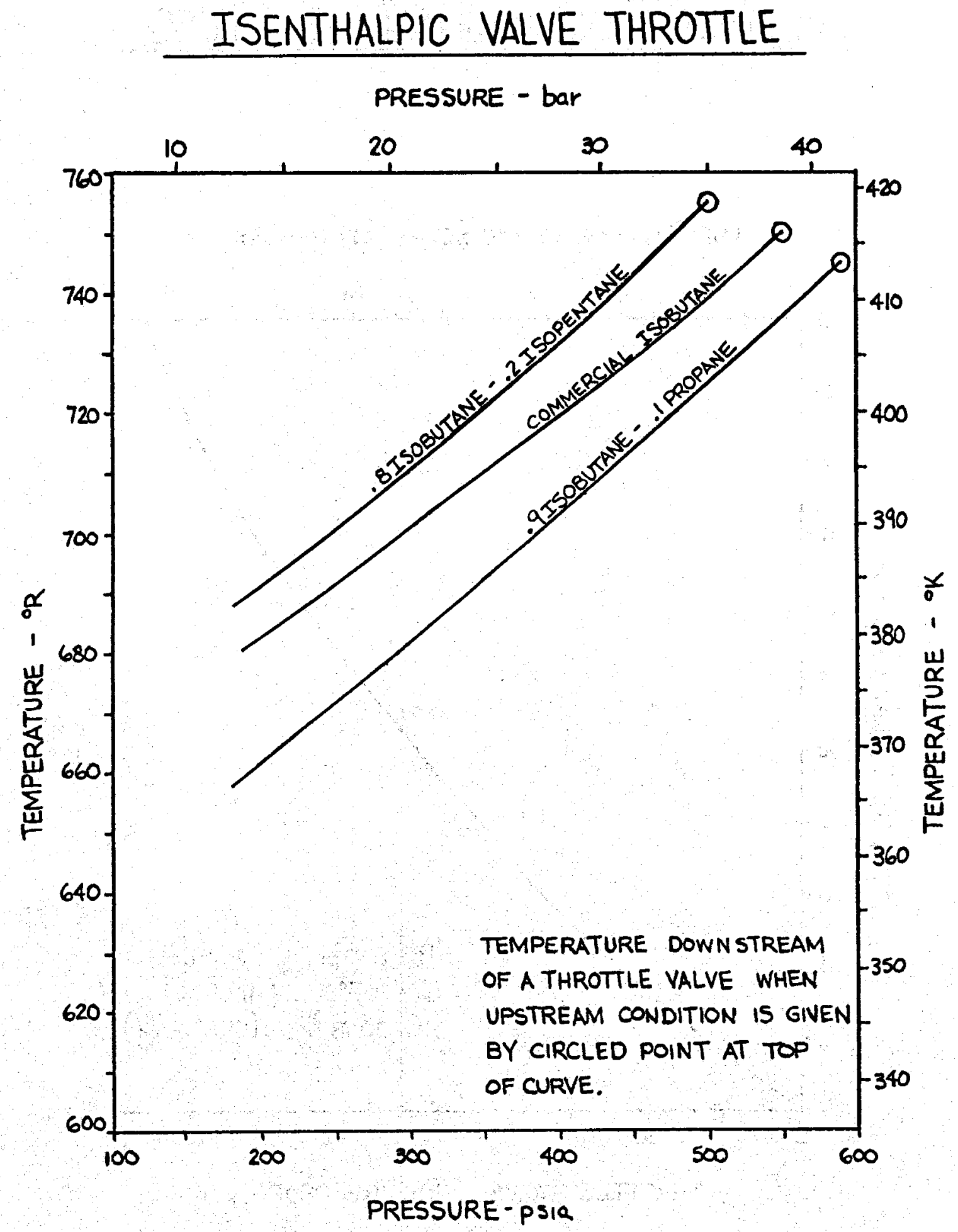

Figure 7-3. Isenthalpic Valve Throttle 


\section{THROTTLE VALVE AVAILABLE HEAT LOSS}

THROTTLE VALVE PRESSURE DROP - bar

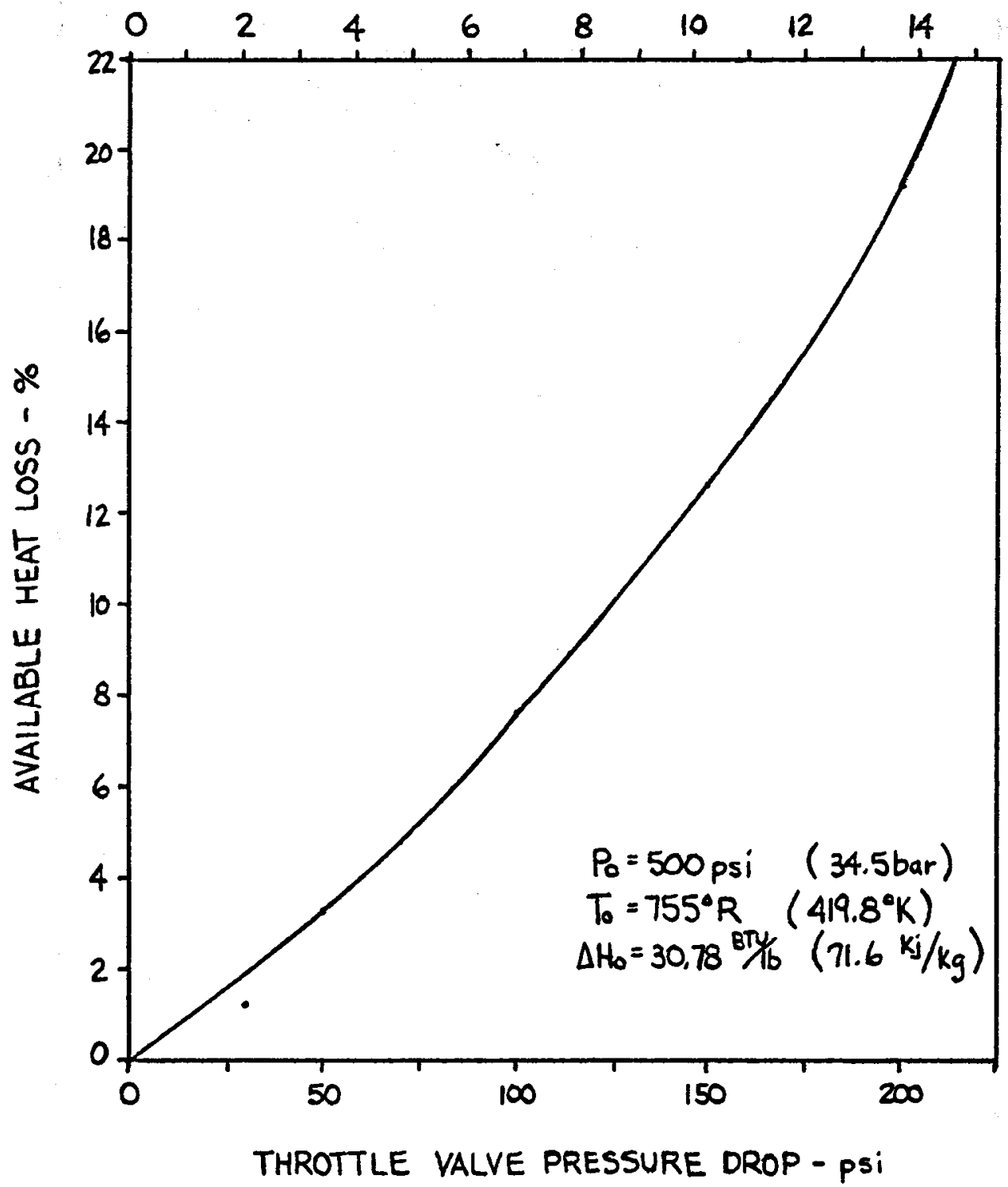

Figure 7-4. Throttle Valve Available Heat Loss 
Table 7-1

CYCLE THERMAL ANALYSIS

\begin{tabular}{|l|cc|}
\hline & $80 / 20$ & $90 / 10$ \\
\cline { 2 - 3 } & Btu/min $\times 10^{-6}$ & Btu/min $\times 10^{-6}$ \\
Vapor Generator - Heat in & 25.0 & 25.0 \\
Turbine - Work out & 3.75 & 3.75 \\
Mechanical-Electrical Conversion - Loss & 0.05 & 0.05 \\
Circulating Pump - Work in & 0.60 & 0.62 \\
Condenser - Heat out & 21.8 & 21.8 \\
\hline Parasitic Losses & & \\
Cooling water pump & 0.15 & 0.24 \\
Cooling tower fans & 0.07 & 0.09 \\
Make-up & 0.03 & 0.04 \\
Miscellaneous & 0.02 & 0.02 \\
Brine Down-hole pump & 0.13 & 0.20 \\
Brine Injection pump & 0.05 & 0.07 \\
Total Parasitic Losses & 0.46 & 0.66 \\
\hline Cycle Efficlency & $12.4 \%$ & $12.3 \%$ \\
\hline Plant Thermal Efficiency & $10.6 \%$ & $9.7 \%$ \\
\hline
\end{tabular}

\section{CYCLE THERMAL EFFICIENCY}

The binary cycle's primary purpose is to convert avallable geothermal heat into electrical power. All systems are made up of thermal or mechanical components. The thermal component either adds heat to or removes heat from the system. The mechanical components elther add work to or extract work from the system. From the first law of thermodynamics, and the definition of a cycle, the net work accomplished is defined as the heat added minus the heat subtracted. The net work is also defined as the difference between the work out minus the work in. The ratio of the net work to the heat added is called thermal efficlency of the cycle, or by equation

- $\eta=\frac{W_{\text {net }}}{Q}$ 
where:

- $\eta=$ cycle thermal efficiency

- $\mathrm{w}_{\text {net }}=$ Net work

- $\mathrm{Q}=$ Heat added

Analysis was made for the $80 / 20$ mixture cycle shown in Figure 7-1. Table 7-1 lists the heat or work of each system component. The $12.4 \%$ cycle efficiency is based on the turbine power output and the pump power input. Using the defined parasitic losses, results in an overall plant efficiency of $10.6 \%$.

A similar analysis was done for the 90/10 iso-butane mixture (Table 7-1) resulting in a cycle thermal efficiency of $12.3 \%$ and a plant thermal efficiency of $9.7 \%$. 
Section 8

MAINTENANCE AND RELIABILITY

\section{MAINTENANCE}

Normal maintenance turnaround for the hydrocarbon turbine would be expected to be:

- Twelve months for the first turnaround

- Twenty-four to thirty-six months for subsequent turnarounds

The first turnaround will involve a complete inspection of bearings, seals, rotor and stationary parts. Subsequent turnarounds will involve inspection of only the bearings and seals. Full turnaround, including the rotor inspection, should be conducted every five to six years.

The lube oil console maintenance and inspection should follow component vendor recommendations. Components such as pumps and coolers should be inspected at each turnaround. Filters, reservoir tank oil level, oil pressures, and temperatures should be checked on a weekly basis to insure proper operation. The oil in the lubrication system should have an inspection and maintenance program to insure that its properties are maintained within the manufacturer's recommended 1 imits. The instrumentation gages, thermocouples, readouts, etc. should be inspected and calibrated at six month intervals.

This turbine has been designed for minimum disassembly for maintenance on the bearings and seals. The bearings can easily be inspected by the removal of the top half bearing cases without disturbing the alignment. The rotor-casing seals require the disassembly of bearing cases and the coupling for the drive end seal. The thrust end seal requires the removal of the bearing case, thrust collar, and trip device. Spectal tools and fixtures for maintenance are provided by the manufacturer for the disassembly of the complete turbine. Such tools will normally include alignment bars, assembly rails, guide rollers, etc.

The manufacturer should also supply a complete instruction book containing a detalled description of assembly and disassembly procedures. Normally, the instruction book will include data on trouble shooting as well as alignment methods and spare parts lists. 


\section{RELIABILITY}

This turbine design is well within the state-of-the-art and should be a highly reliable piece of equipment. The main wearing parts will be the seals and bearings.

\section{Seals}

The face seal design selected for this turbine is used in compressors. This type of seal is presently in use in over 600 different units. The turnaround times vary from process-to-process, however, in clean processes, that is clean gas operations, the turnaround time has been 36 to 60 months. The normal lube oil temperature throw-off is $82.2^{\circ} \mathrm{C}\left(180^{\circ} \mathrm{F}\right)$ maximum with a $48.9^{\circ} \mathrm{C}\left(120^{\circ} \mathrm{F}\right)$ feed.

\section{Bearings}

The journal bearings for this unit are a pressure fed, babbitt lined tilt pad type. These bearings are in use in hundreds of machines, turbines, compressors, pumps, and other types of rotating equipment. Expected bearing 1 ife under normal design operating conditions will be a minimum of 36 to 60 months. The normal temperature rise is $22.2^{\circ} \mathrm{C}\left(40^{\circ} \mathrm{F}\right)$ with a lube oil feed of $48.9^{\circ} \mathrm{C}$ $\left(120^{\circ} \mathrm{F}\right)$.

The thrust bearing is a pressure fed, babbitt lined, double acting, self-equalizing, Kingsbury type, tilt pad design. This bearing design is in use in thousands of machines. The expected bearing life under normal design operating conditions will be 36 to 60 months. The normal lube oil temperature rise will be $27.8^{\circ} \mathrm{C}\left(50^{\circ} \mathrm{F}\right)$ with a $48.9^{\circ} \mathrm{C}\left(120^{\circ} \mathrm{F}\right)$ inlet feed.

\section{Turbine Blades}

By design, this application is a clean gas environment with no entrained solids. The velocities through the gas path are relatively low, i.e. below 500 per feet per second. If the turbine is operated in the gaseous region, there should be no erosion of the blades. If the unit is operated within the vapor dome, for short periods of time, no noticeable blade erosion should occur due to the low velocities. However, if the unit is operated continuously within the vapor dome, so that droplets form and remain throughout the entire gas path, then blade erosion could pccur reducing the operating life of the unit. The means for predicting such erosion by hydrocarbons has not been established at this time. Erosion work is being done with steam droplets and with high velocity 
particles. All of this work is at higher velocities than found in this application. The turbine blades have been designed with ample safety factors to insure a minimum design life of 100,000 hrs. The steady state and cyclic stress have been reviewed to confirm the mechanical blade design.

\section{Couplings}

The coupling selected for this unit has been utilized for gas turbine-generator installations. Normally, these gas turbine installations for power generation have been of the peak loading type where numerous cycles of start-up and shutdown are experienced. Since this is a base load installation, the coupling is well within its design capabilities.

\section{Vibration System}

The vibration monf toring system selected for this unit uses non-contacting, eddy current type probes. The system will be complete with visual analog read-out monitors. These monitors also have provistons for set points for alarms and trips if a vibration problem occurs. The normal set point for this particular unit will be $0.0635 \mathrm{~mm}(0.0025 \mathrm{in}) \mathrm{mils}$ to alarm and $0.127 \mathrm{~mm}$ and $(0.005 \mathrm{in})$ to trip. These vibration monitoring systems have been in use for the last 12 years on turbines and compressors in a wide variety of different applications.

\section{Turbine Trip}

The turbine trip device selected for this unit has been in use on at least 300 machines. There have been no recorded unit fallures due to the device not actuating when properly installed. It is factory set and there is no need for recalibration or re-setting.

\section{SPARE PARTS}

The normal recomended spare parts for this unit will be as follows:

- Journal bearings - 2 One for each end

- : Thrust bearing - 1 set of parts; tilt pads, keys, etc.

- Rotor casing seals - 2 sets; one for each end

- 0-rings - 1 complete set for the entire unit

- Vibration probes - 4 spares should be available

- Oil system parts - 1 set; gaskets, filter cartridges, etc. 
Optional spares to be decided by plant economics.

- Turbine rotor

- Turbine stator diaframs

- Turbine-generator coupling

\section{MANUEACTURER'S SHOP TESTING}

The normal shop test for the hydrocarbon turbine would be a no-load mechanical test of four hours duration. During this test, all mechanical components are checked to insure they are operating within design specifications. The journal and thrust bearing throw-off temperatures are monitored and checked. The shaft vibration levels are monitored and checked, and a frequency scan is taken on each probe to insure no harmful sub-harmonic frequencies are present. The rotor-casing seals are operated with the design differential pressure and the leakage rate is monitored and checked. Once the continuous four hour test is completed, the overspeed trip is demonstrated twice to prove repeatability and proper operation.

On completion of the running test, the bearings and rotor-casing seals are removed and visually inspected to assure proper wear patterns. Any deviations from specified operation are investigated and corrective action taken. The unit will be retested depending upon the problem and correction required.

\section{F IELD PERFORMANCE TESTS}

When a field performance test is required, the manufacturer will work with the customer to insure a meaningful test. Normal1y, the manufacturer will review the instrumentation, gages, thermocouples, transducers, etc. and the placement of the instrumentation in the inlet and exhaust piping. The flow measurement as well as the load measurement will have to be agreed upon prior to testing. The gas composition will have to be measured on test using a mass spectrometer or gas chromatograph. The gas properties for power calculations will have to be agreed upon prior to testing the unit. Due to inherent errors of measurement of temperature, pressure, flow and gas composition, such a field test would be expected to be accurate within $\pm 3 \%$ of measured power output.

\section{GUARANTEE AND WARRANTY}

The standard unit warranty covers material and workmanship for a period of eighteen months after shipment or twelve months after initial start-up, whichever occurs first. 
Section 9

PRICE \& DELIVERY

PRICE

The turbine-generator unit being studied under this contract is well within the state-of-the-art, and many of the sub-assemblies are in production, and therefore, accurate pricing data is avallable. The vertically split, axial flow hydrocarbon expander is a marriage of existing compressor technology, 1.e., casing and seals, and existing steam turbine technology, i.e., blade path. There are no new designs nor materials being utilized. The electric generator is an "off-the-shelf" item design for use in existing gas turbines generator units.

Figure 9-1 is a plot of dollars versus gross megawatt output. From twelve and a half (12.5) megawatts, to thirty-two and a half (32.5) megawatts, the turbine will most likely be single flow. Above this point to approximately sixty-seven and a half $(67.5)$ megawatts, the unit will be double flow. Depending on operating conditions and desired output, there is an area shown on the curve in which the turbine may be single flow up to thirty-five (35) megawatts or the unit may have to be doubled flow starting at approximately thirty (30) megawatts.

\section{DELIVERY}

The delivery of the complete turbine-generator package is approximately twenty-two twenty-four months. This allows sufficient time for minor adjustments in the system which will most likely result from more detailed analysis and engineering.

\section{BILL OF MATERIAL}

- One (1) slxty-five (65) MW vertically split, axial flow, non-condensing, hydrocarbon turbine with pressurized ofl film shaft seals.

- One (1) API 614 oil system supplying lubricating and sea1 oil to the turbine.

- One sixty-five (65) MW $13.8 \mathrm{KV}, 60 \mathrm{HZ}, 0.9 \mathrm{pf}$ - two pole hydrogen cooled synchronous generator with shaft mounted brushless exciter, and static vol tage regulator. 


\section{PRICING \\ HYDROCARBON-TURBINE-GENERATOR SET}

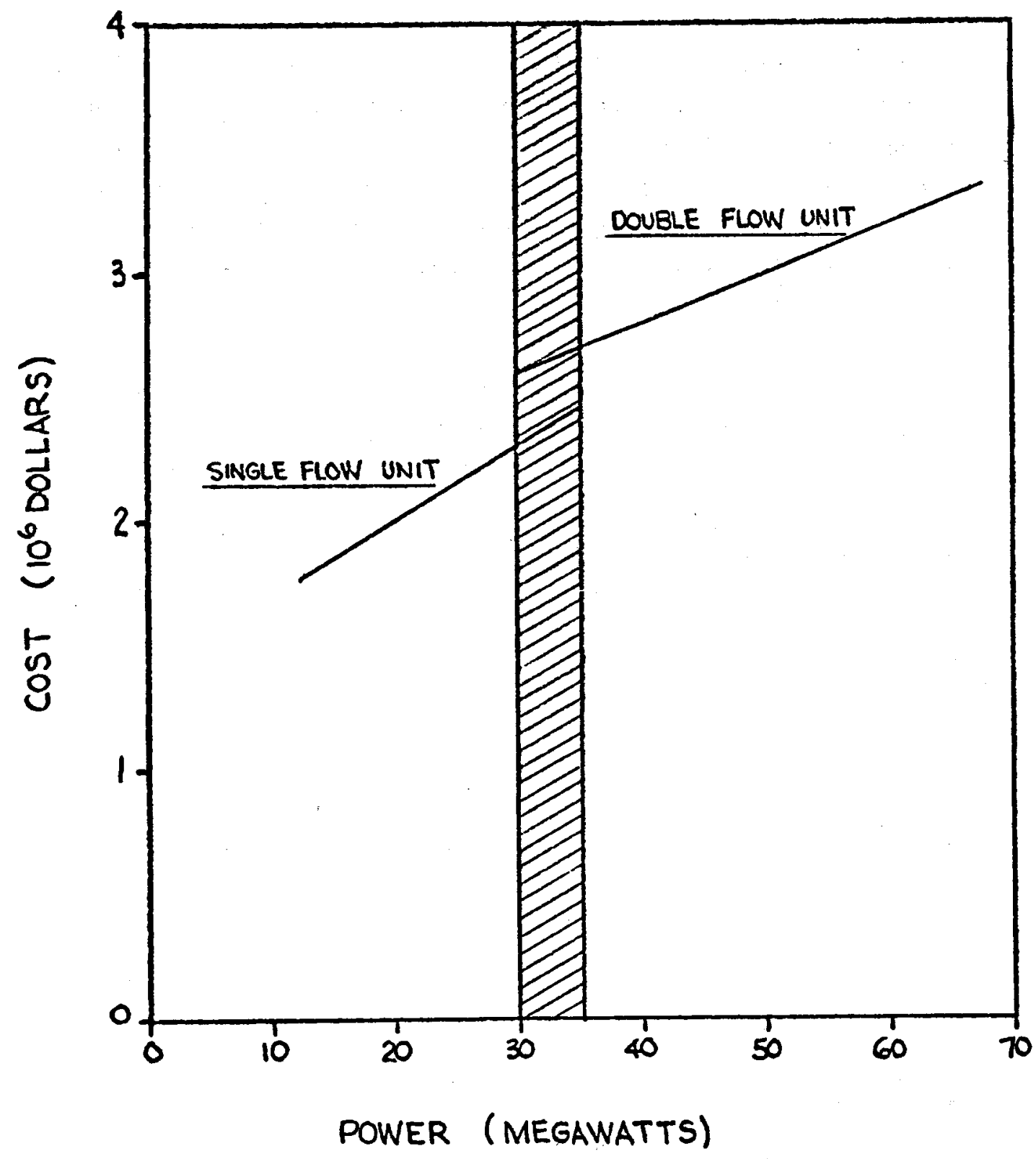

Figure 9-1. Pricing - Hydrocarbon Turbine-Generator Set 
- One (1) hydrogen gas control system including an integrated lube and seal oil system.

- One (1) set of low voltage excitation switch gear.

Total Price $\$ 3,300,000$

Delivery $\quad 22-24$ months

SPARE PARTS PRICING

- Turbine Spare Rotor $\$ 375,000$

- Turbine Spare Diaframs $\$ 395,000$ 
Section 10

References

1. Holman, J. P., Heat Transfer, McGraw-H111, 1963, pp. 159-168, 20-21

2. "Pipe and Tubes for El evated Temperature Service," National Tube Division of U.S. Steel Bulletin, No. 26, Edition 59, 1959, pp. 62-63

3. Marks, Lo, Marks Standard Handbook For Mechanical Engineers, 7th Edition, McGraw-Hill

4. Keenan and Kaye, Gas Tables, John Wiley \& Sons, Inc., 1963

5. Harvey, J. F., Pressure Vessel Design, D. VanNostrand, 1963

6. Chuse, R., Unfired Pressure Vessels, Fourth Ed., F. W. Dodge Corp., 1960

7. EPG (A Gulf and Western Mfg. Co.), Piping Components For Energy Systems, Catalogue 722

8. Tube Turns Catalogue

9. Roark, R. J., Young, Wo C., Formulas for Stress and Strain, Fifth Edition, 1975, McGraw-Hill

10. Hagg, A. C., Sankey, G. O., "Elastic and Damping Properties of Oil Film Journal Bearings for Application to Unbalance Vibration Calculations," ASME Journal of Applied Engineering, March 1958

11. Lund, Jo Wo, Spring and Damping Coefficients for the Tilting-Pad Journal Bearing, ASLE Transactions 7 342-352, 1964

12. API Std. 605, "Large Diameter Carbon Steel Flanges," 1973

13. Rose, R. T., Lane, P. H. R., Wells, A. A., "Stress Analysis of Nozzles in Cylindrical Pressure Vessels," IME paper, 1961

14. O'Connor, J. J., Boyd, J., Arllone, E. A,, Standard Handbook of Lubrication Engineering, McGraw-Hi11, 1968

15. Fox, R. W., Kline, S. J., "Flow Regimes In Subsonic Diffusers," ASME Journal of Basic Engineering, Sept. 1962

16. Sagi, C. J., Johnston, J. P., "Design and Performance of Two-Dimensional Curved Diffusers," ASME Journa1 of Basic Engineering

17. Orion Corporation Engineering Catalogue, "Pivoted Shoe Journal Bearings"

18. Lemmon, R. H., "Aerodynamic Performance of the Second Generation Fabricated M-Compressor Inlet," ECO TR-301, 1970

19. Runstadler, Jr., P. W., Dolan, F. X., Dean, Jr., R. C., Diffuser Data Book, TN-186, Creare Inc., May 1975

20. Spotts, M. F., Mechanical Design Analysis, Prentice Hali, Inc., 1964

21. Lind, N. C., "Approximate Stress-Concentration Analysis for Pressurized Brand Pipe Connections," ASME Paper, 67-WA/PUP-7 
22. Derrickson, G. W., "Sumnary of Tests on Model of 5-50 Gas Turbine Exhaust Diffuser," Elliott T.M. \#3, 1952

23. Maren, J., Sauer, J., Strength of Materials, MacMillan Co., New York, 1954

24. "Multi-S tage Steam Turbines for Mechanical Drive Service," NEMA Standards Pub1. No. SM21, 1970

25. "Direct-Connected Steam Turbine-Synchronous Generator Units," Air-Cooled Publ. No. SMl2, 1967

26. Dean, R. C., Aerodynamic Measurements, MTI Gas Turbine Laboratory, 1953

27. "General Purpose Steam Turbines for Refinery Services," API Std. 611, First Edition, Nov. 1969

28. Hoyt, S. L., Metals and Alloys Data Book, Reinhold Company, 1943

29. Young, J. F., Materials and Processes, John Wiley and Sons, Inc., 1944

30. Shigley, J. E., Mechanical Engineering DesLgn, Third Edition, McGraw-Hil1, New York, 1963

31. Smith, D. M•, "Deflection and Stress in Built-up Half Diaphragn," Fifth International Congress for Applied Mechanics, 1938

32. Siskind, Electrical Machines, McGraw-Hill

33. "ASA S tandard-Synchronous Generators," Synchronous Motors and Synchronous Machines in General, 1955

34. E-M Gas Turbine Generator Seminar

35. Shigley, Mechanical Engineering Design, First Edition, pp. 565, 568-570

36. Elliott Design Manual

37. "Special Purpose Steam Turbines for Refinery Services," API Std. 612, First Edition, Nov. 1969

38. "Centrifugal Compressors for General Refinery Services," API Std. 617, Third Edition, Oct. 1973

39. ASME Boiler and Pressure Vessel Code, Section II and VII, 1974 Edition with aggenda to date

40. "Contoured Flexible Diafram Coupling," by Bendix Electric and Fluid Power Division 


\section{APPENDIX A-1 \\ GAS TABLES}

\section{Table A-1}

$80 \%$ ISO-BUTANE - 20\% ISO-PENTANE

Critical Pressure PS IA

Iso-Butane

Iso-Pentane

$80 / 20$ Mixture
529.056

483.498

519.9
Critical Temp.

734.652

829.80

753.68
Molecular Weight 1b/1b-mole

50.124

72.151

60.929 
BOT ISO-RUTANE - 20\% ISO-PENTANE

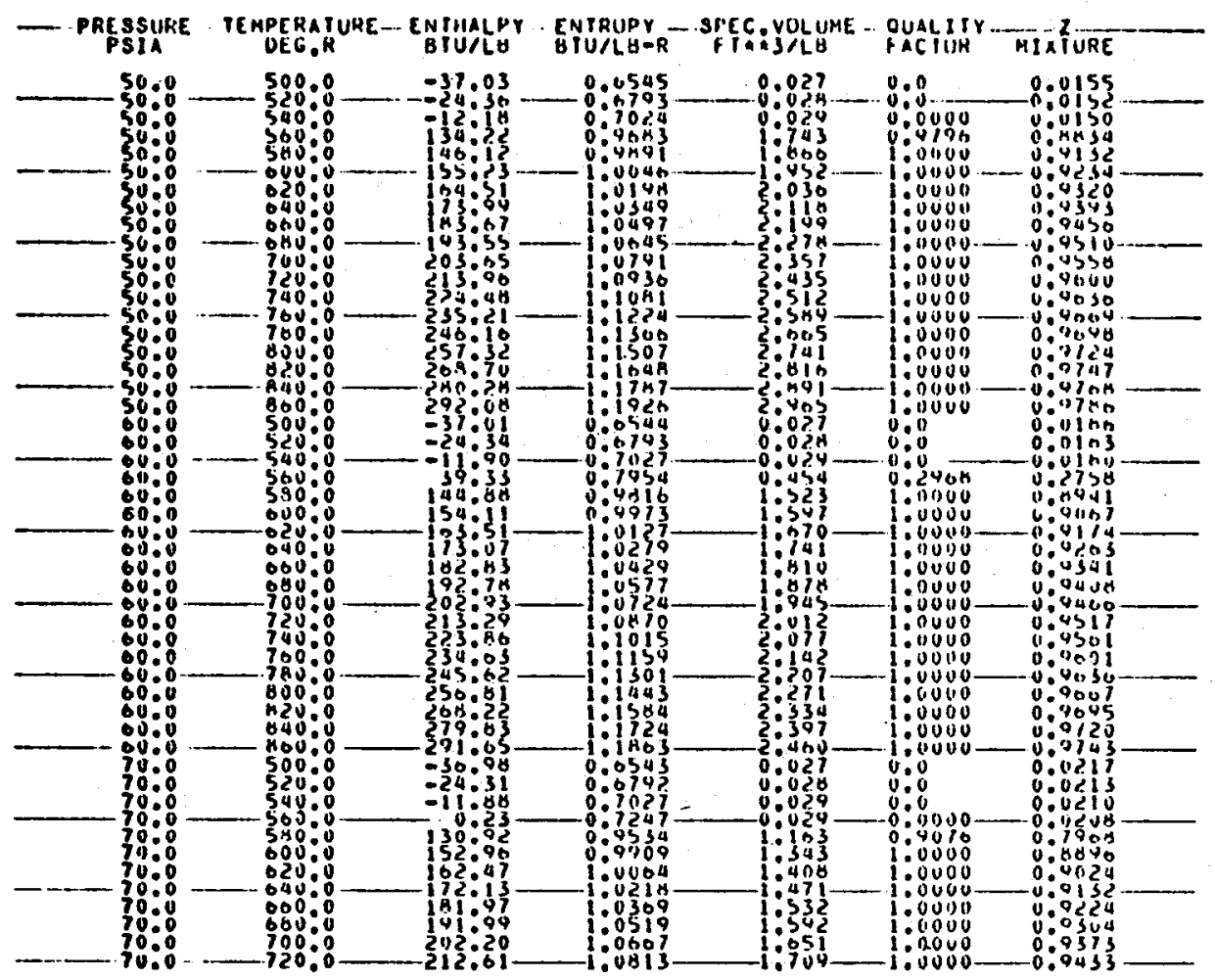

80\% ISO-BUTANE - $20 \%$ ISO-PENTANE

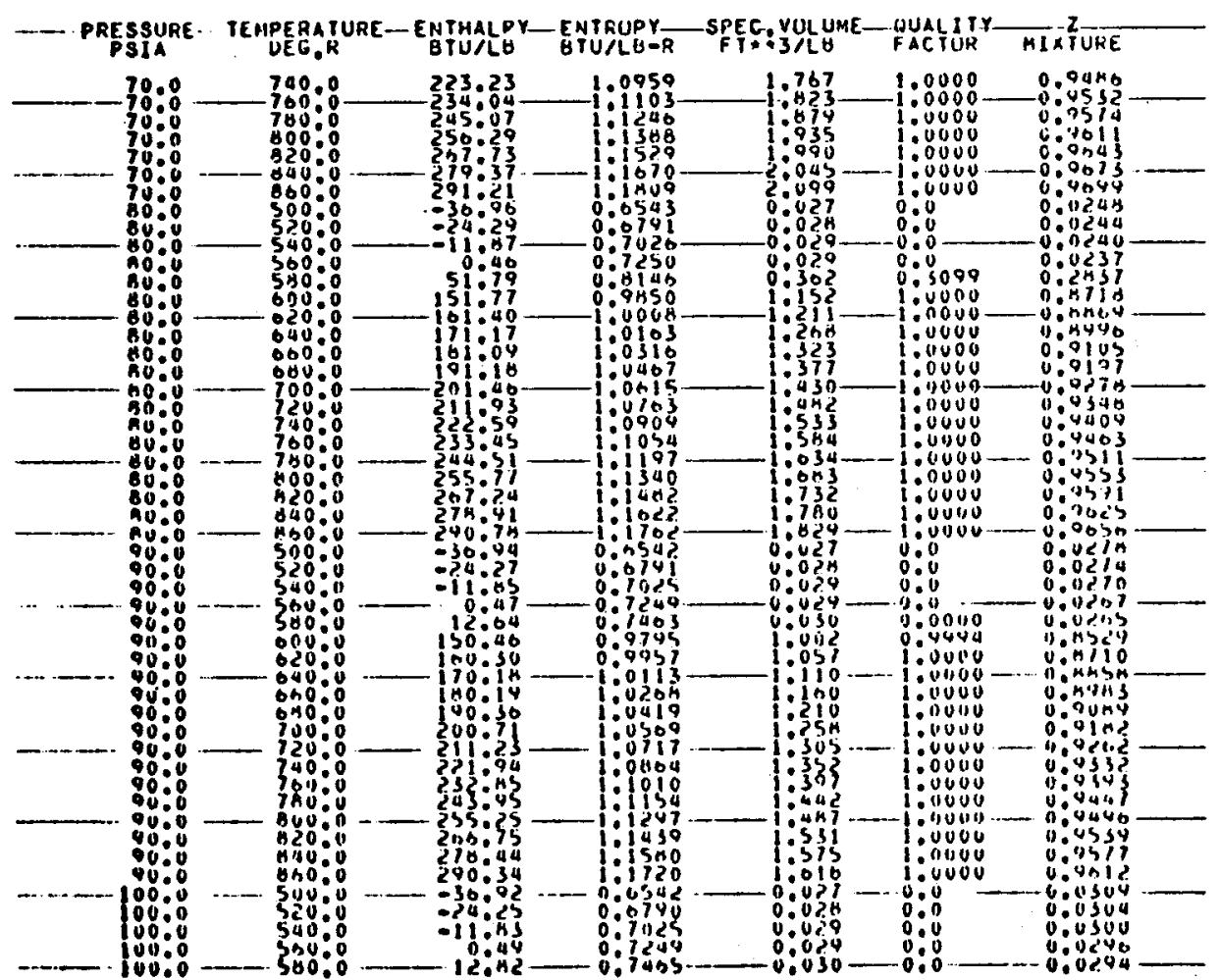


807 ISO-RUTANE - $20 \%$ ISO-PENTANE

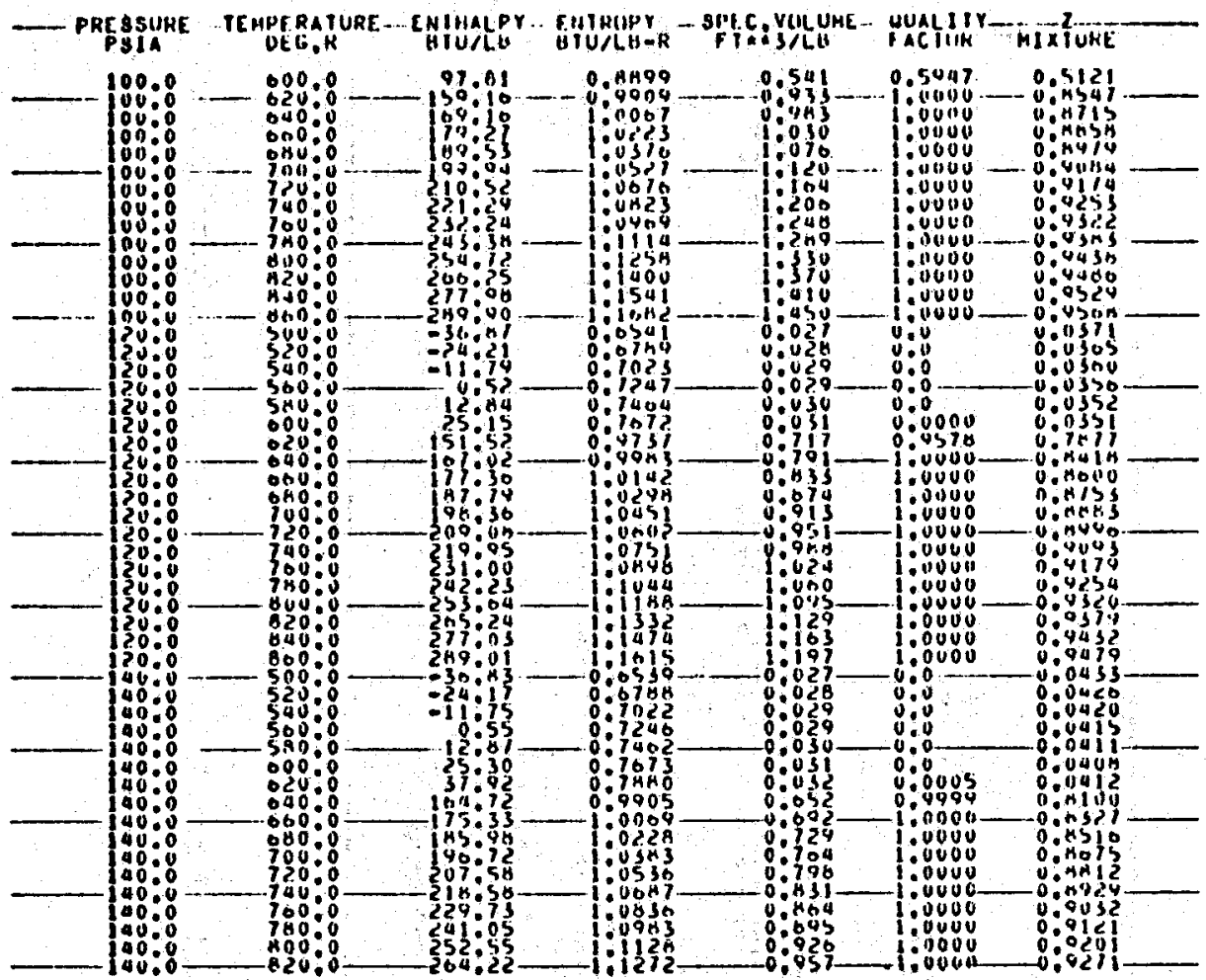

$20 \%$ ISO-BUTANE - $20 \%$ ISO-PENTANE

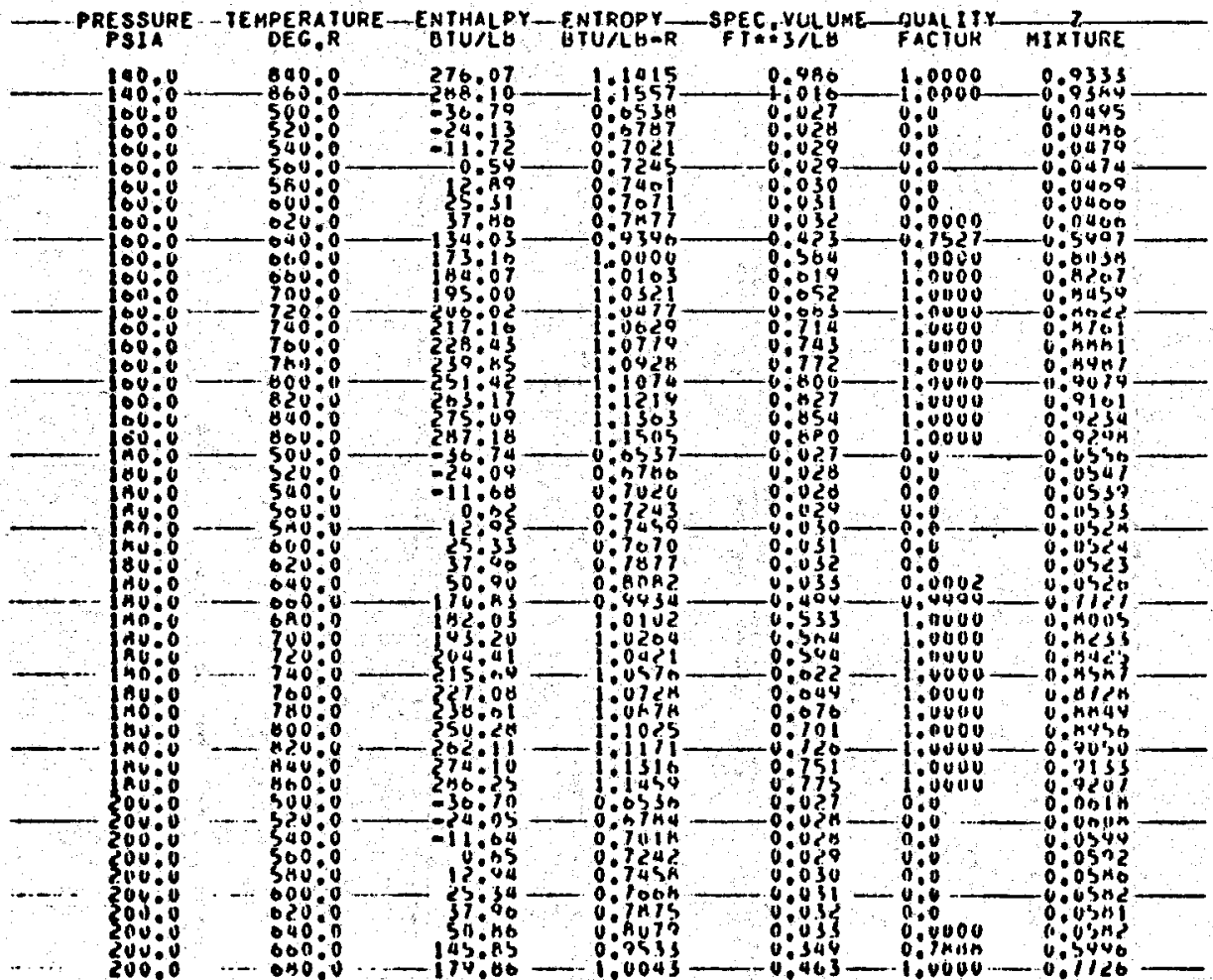


607. ISU-BUTANE - 207 I5O-PENTANE

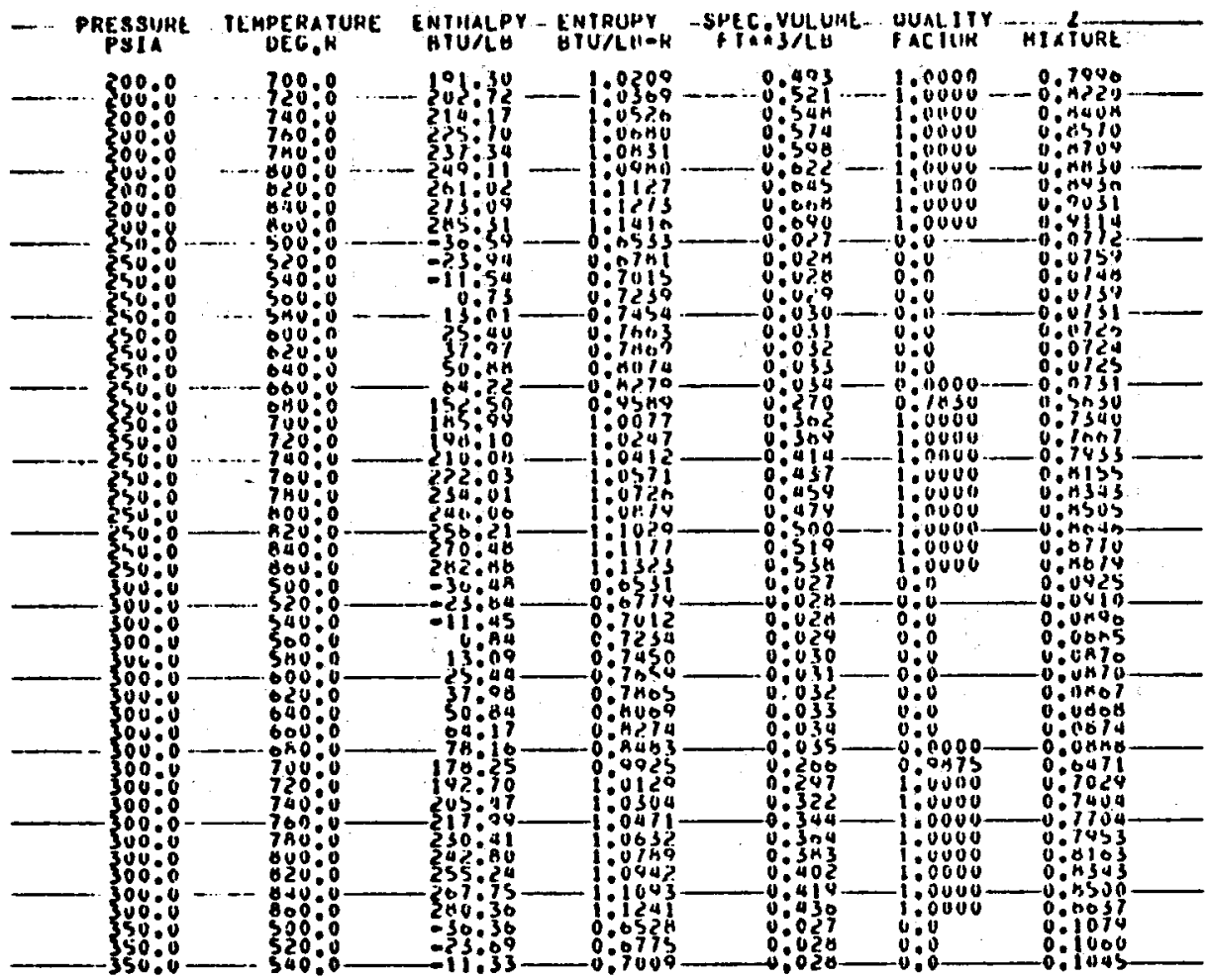

607 ISO-EUTANE - $20 \%$ ISO-PENTANE

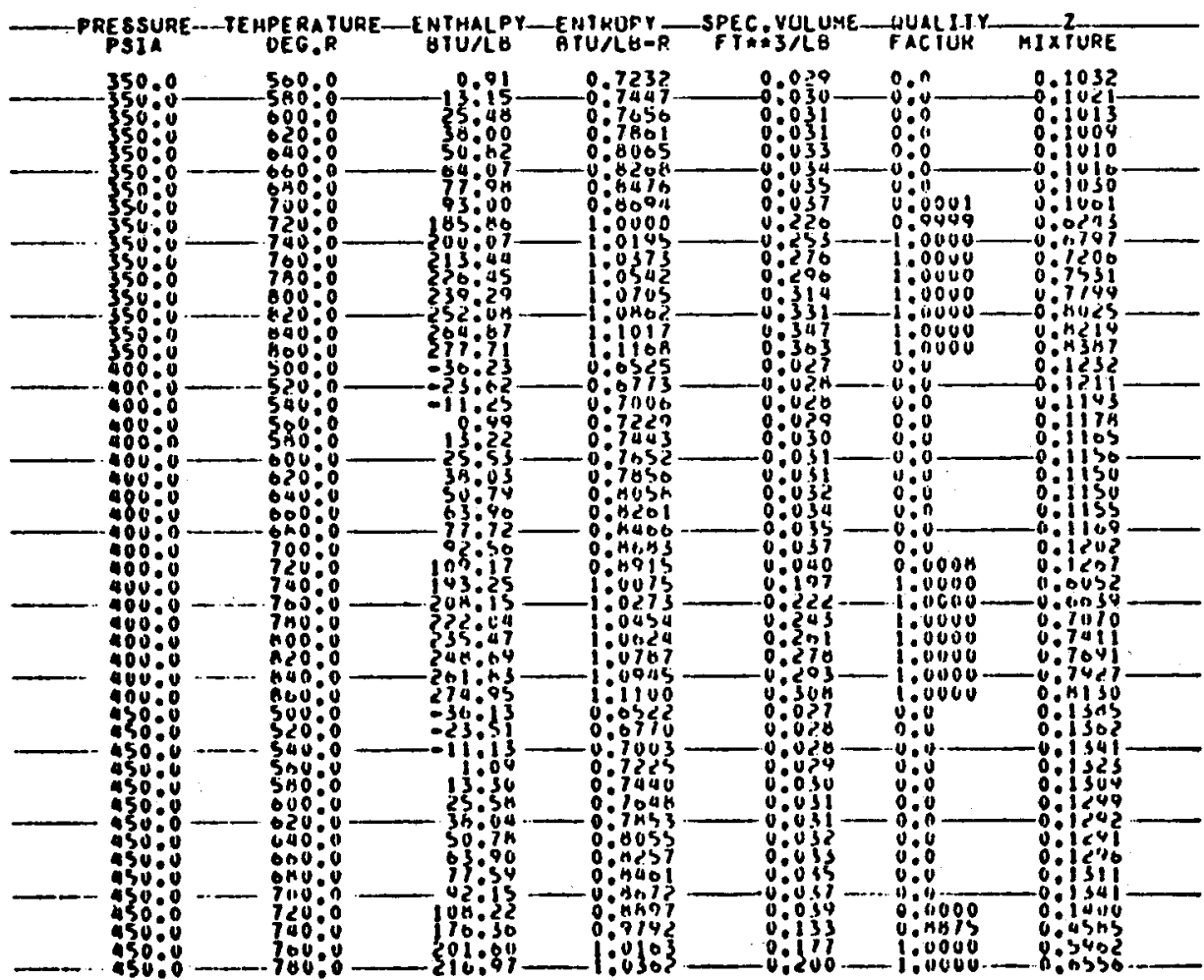


607 ISO- DUITANE - $20 \%$ ISO-PENTANE

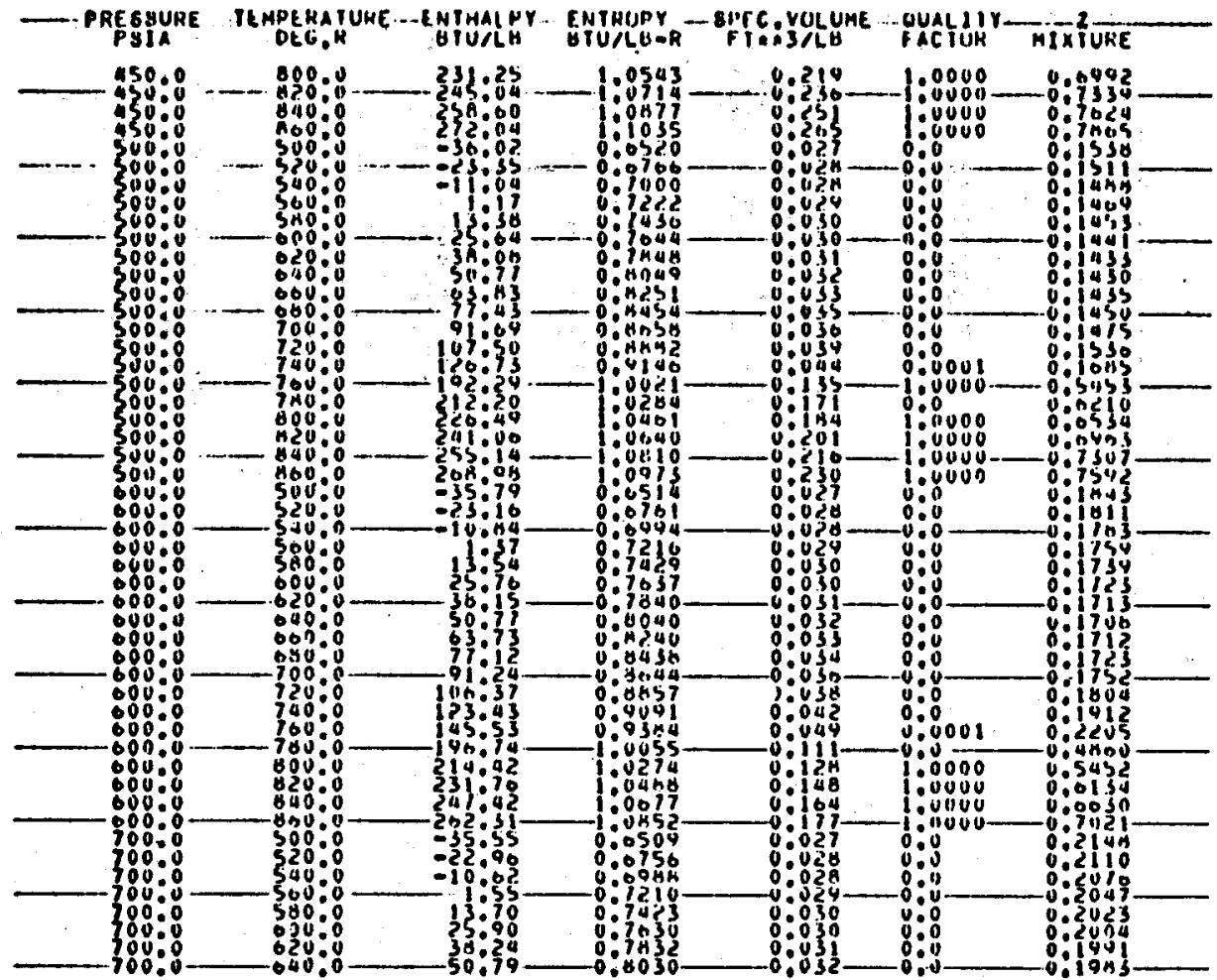

60\% ISO-BUTANE - 20\% ISO-PENTANE

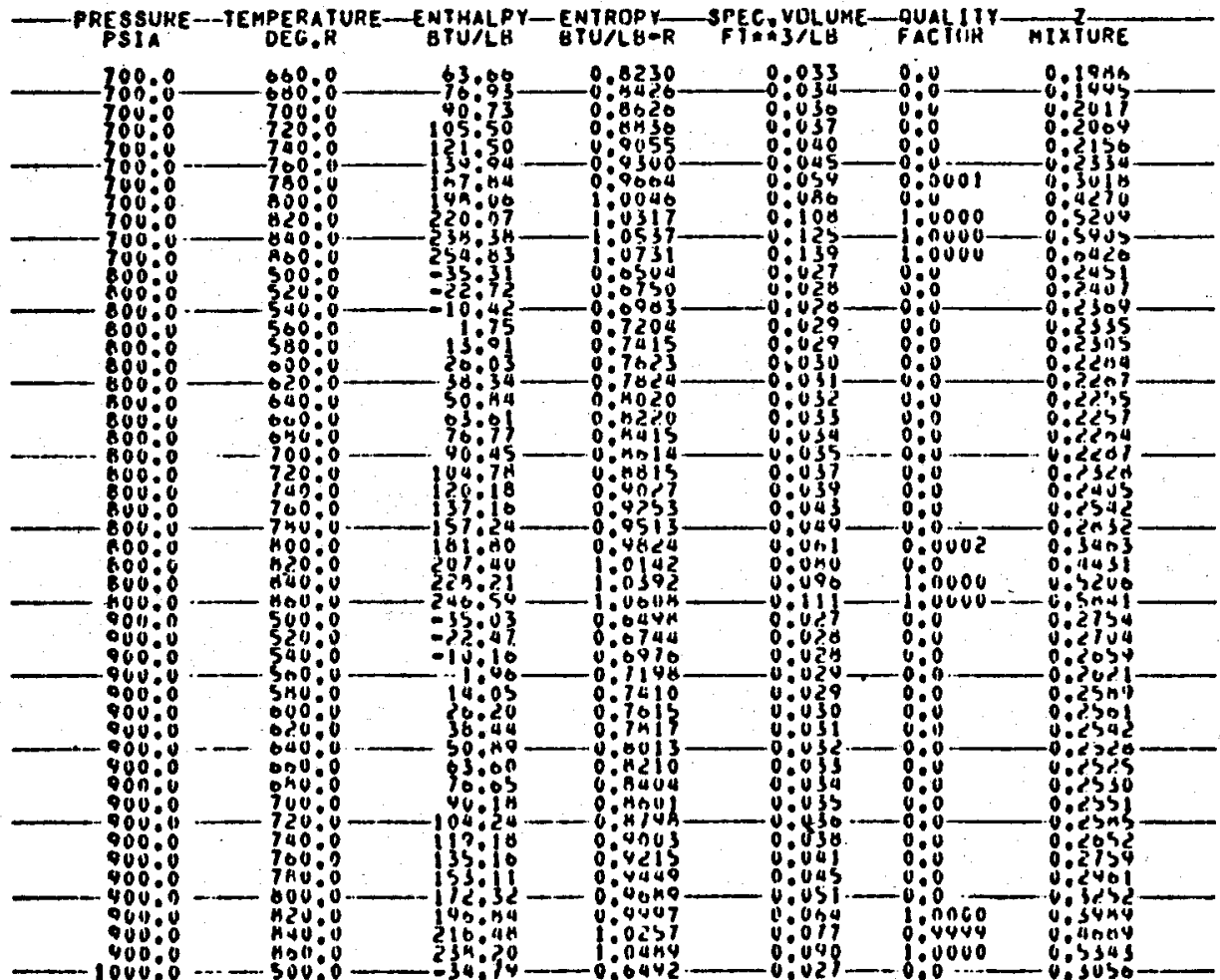


80\% ISO-BUTANE - $20 \%$ ISO-PENTANE

\begin{tabular}{|c|c|c|c|c|c|c|}
\hline $\begin{array}{l}\text { PSIA } \\
\text { PSIA }\end{array}$ & $\begin{array}{l}\text { AERARIL } \\
\text { DEG,R }\end{array}$ & $\begin{array}{l}\text { ENAHA } \\
\text { BIUA }\end{array}$ & $\begin{array}{l}\text { ENTHU } \\
\text { GTUNL }\end{array}$ & & & MIXiv \\
\hline $000 \%$ & $520^{\circ} \cdot 0$ & -22.20 & -0.0734 & 0.027 & $\because 0$ & 0.09499 \\
\hline 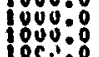 & 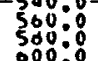 & $2: 13$ & 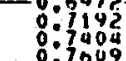 & 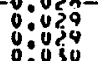 & 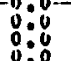 & 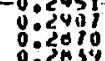 \\
\hline $\begin{array}{l}0000 \\
00000 \\
00000 \\
0000\end{array}$ & 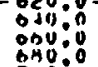 & 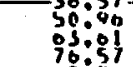 & 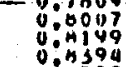 & 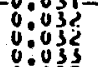 & 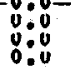 & 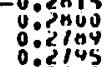 \\
\hline $\begin{array}{l}8000 \\
18000 \\
0800 \\
000\end{array}$ & $\begin{array}{l}725: 0 \\
740: 0 \\
700: 0\end{array}$ & $\begin{array}{r}9+31947 \\
1134 \\
13307\end{array}$ & $\begin{aligned}-0.4211 \\
00 \\
0.0945 \\
0.9184\end{aligned}$ & 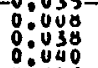 & $\begin{array}{l}0: 0 \\
0 \\
0\end{array} 0 \begin{array}{l}0 \\
0 \\
0\end{array}$ & 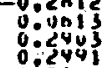 \\
\hline 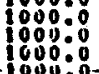 & 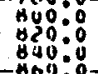 & 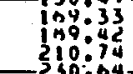 & 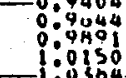 & 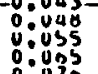 & $\begin{array}{l}0 \\
0 \\
0 \\
0 \\
0 \\
0\end{array}$ & 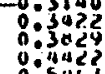 \\
\hline
\end{tabular}


Table A-2

$90 \%$ ISO-BUTANE - 10\% PROPANE

\section{Critical Pressure Critical Temp. Molecular Weight \\ PS IA}

Iso-Butane

529.056

734.652

58.124

Propane

617.232

665.946

44.097

90/10 Mixture

537.9

727.78

56.721 
90\% ISO-BUTANE - 10\% PKOPANE

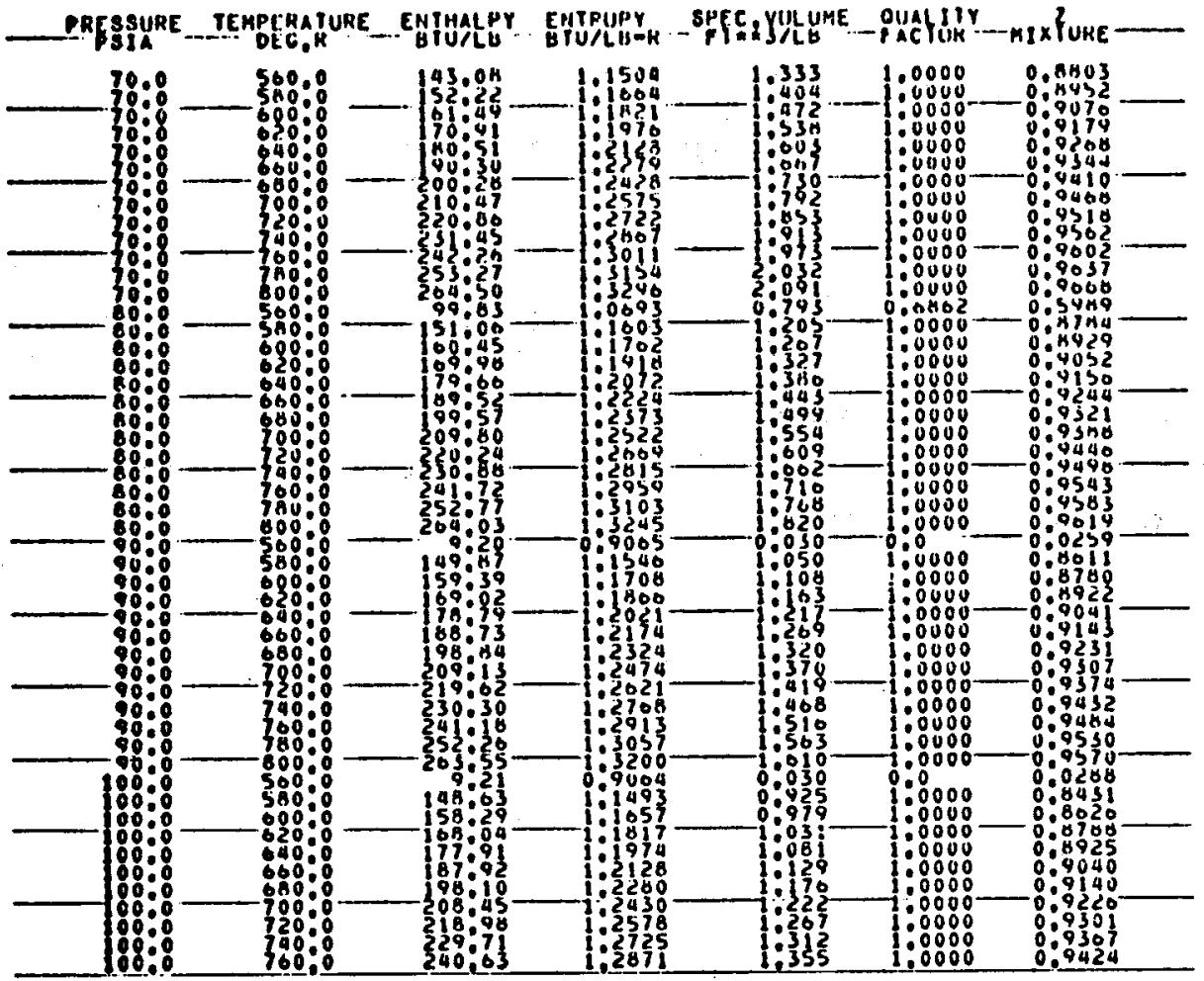

90\% ISO-BUTANE - 10\% PRORANE

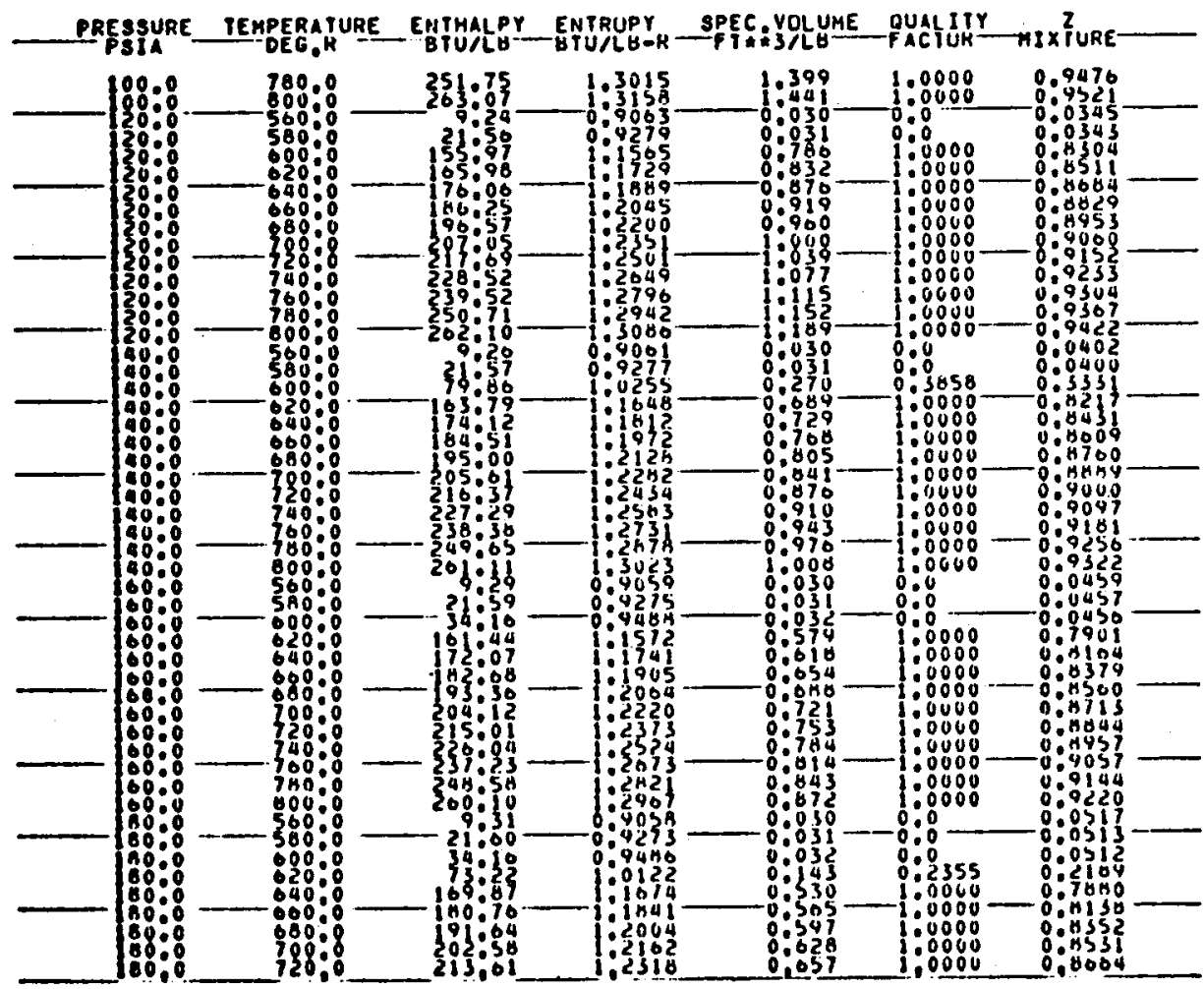


90\% ISO-BUTANE - 10Z PROPANE

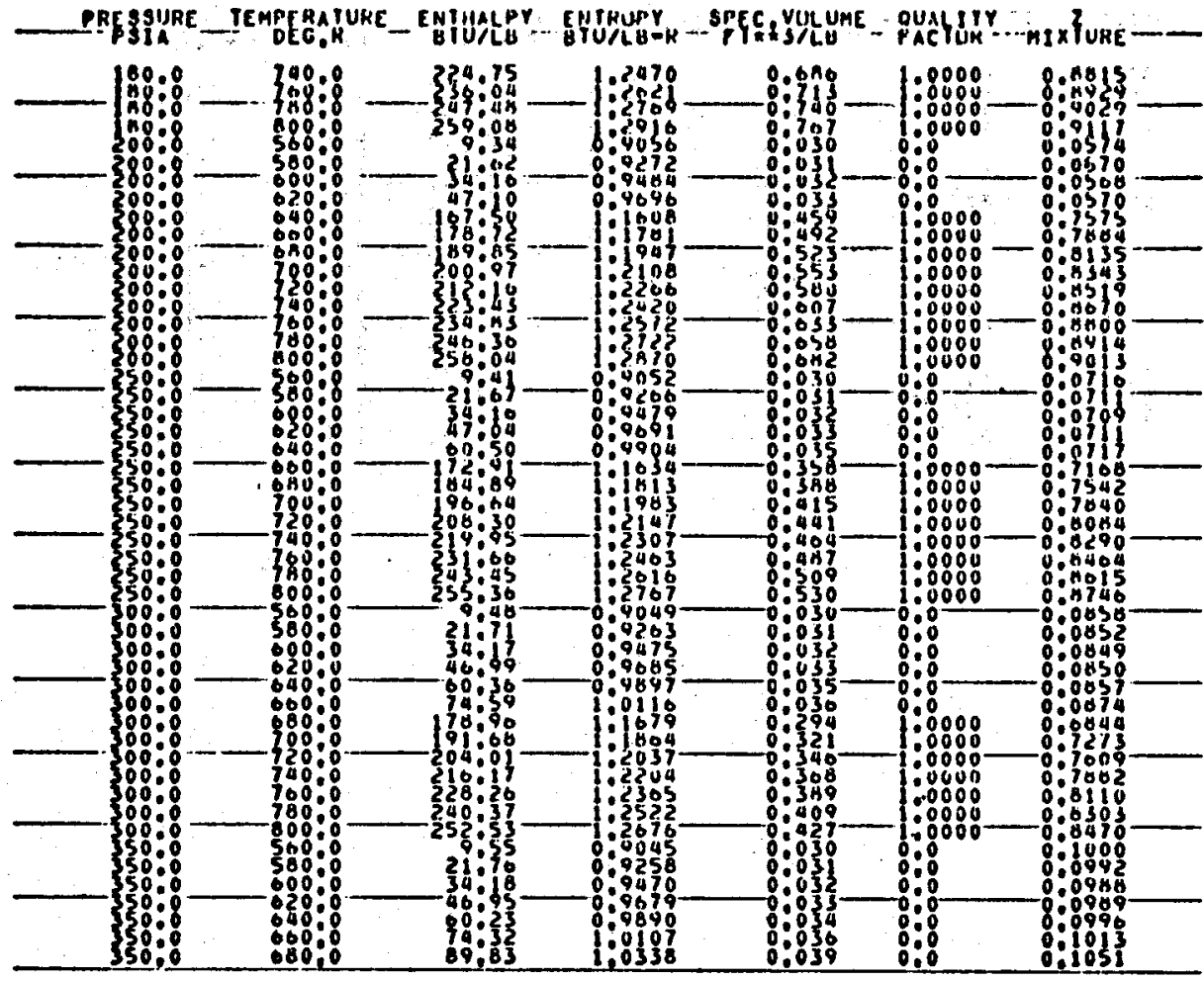

$90 \%$ ISO- EUTANE - $10 \%$ PROPANE

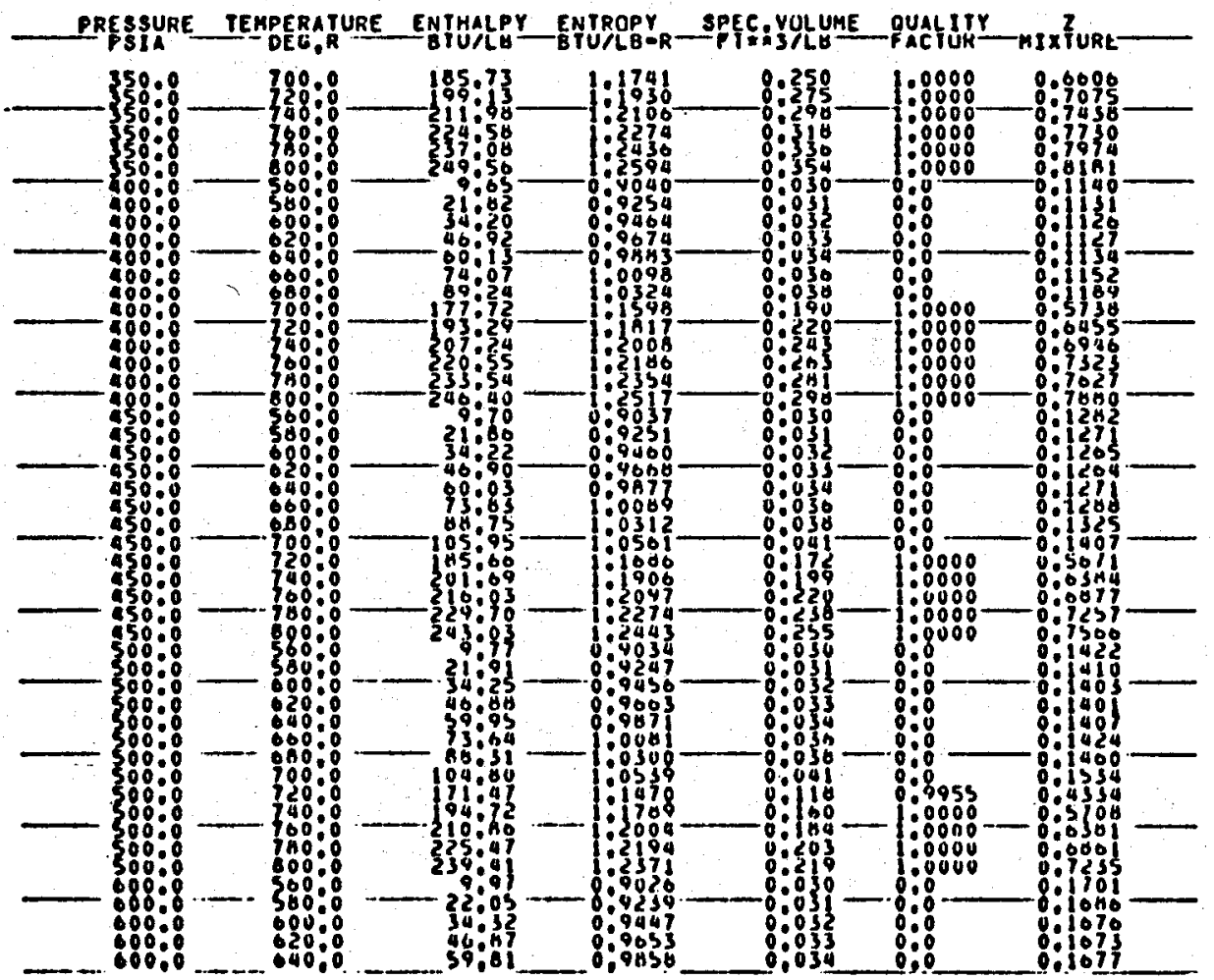


SOZ 'ISO: EUTANE - $10 Z$ PROPANE

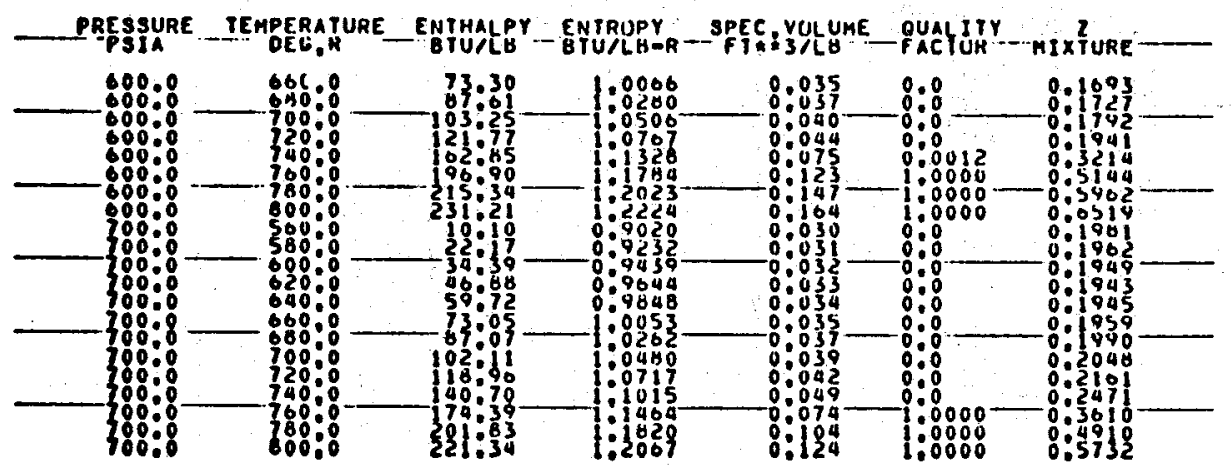


Table A-3

COMMERC IAL ISO-BUTANE

96. $8 \%$ Iso-Butane, 2. $8 \%$ N-Butane, 0.4\% Propane

Critical Pressure PS IA

Iso-Butane

N-Butane

Propane

Mixture
529.056

551.10

617.232

530 .
Critical Temp. ${ }^{\circ} \mathrm{R}$

734.652

765.306

665.946

735.24
Molecular Weight

$1 \mathrm{~b} / 1 \mathrm{~b}-\mathrm{mole}$

58.124

58.124

44.097

58.068 
COMMERCIAL ISOUUTANE

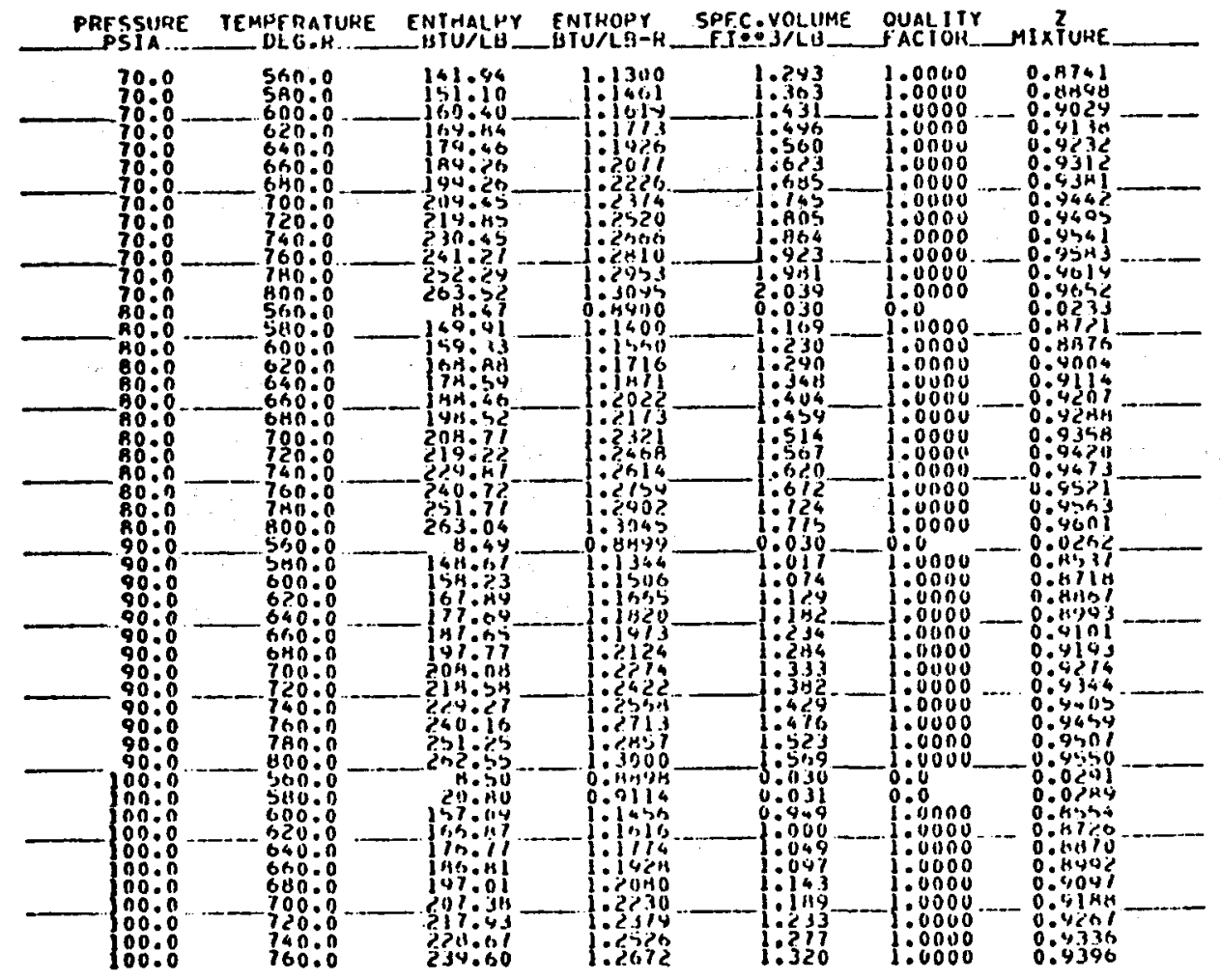

COMMENCIAL ISOHUTANE

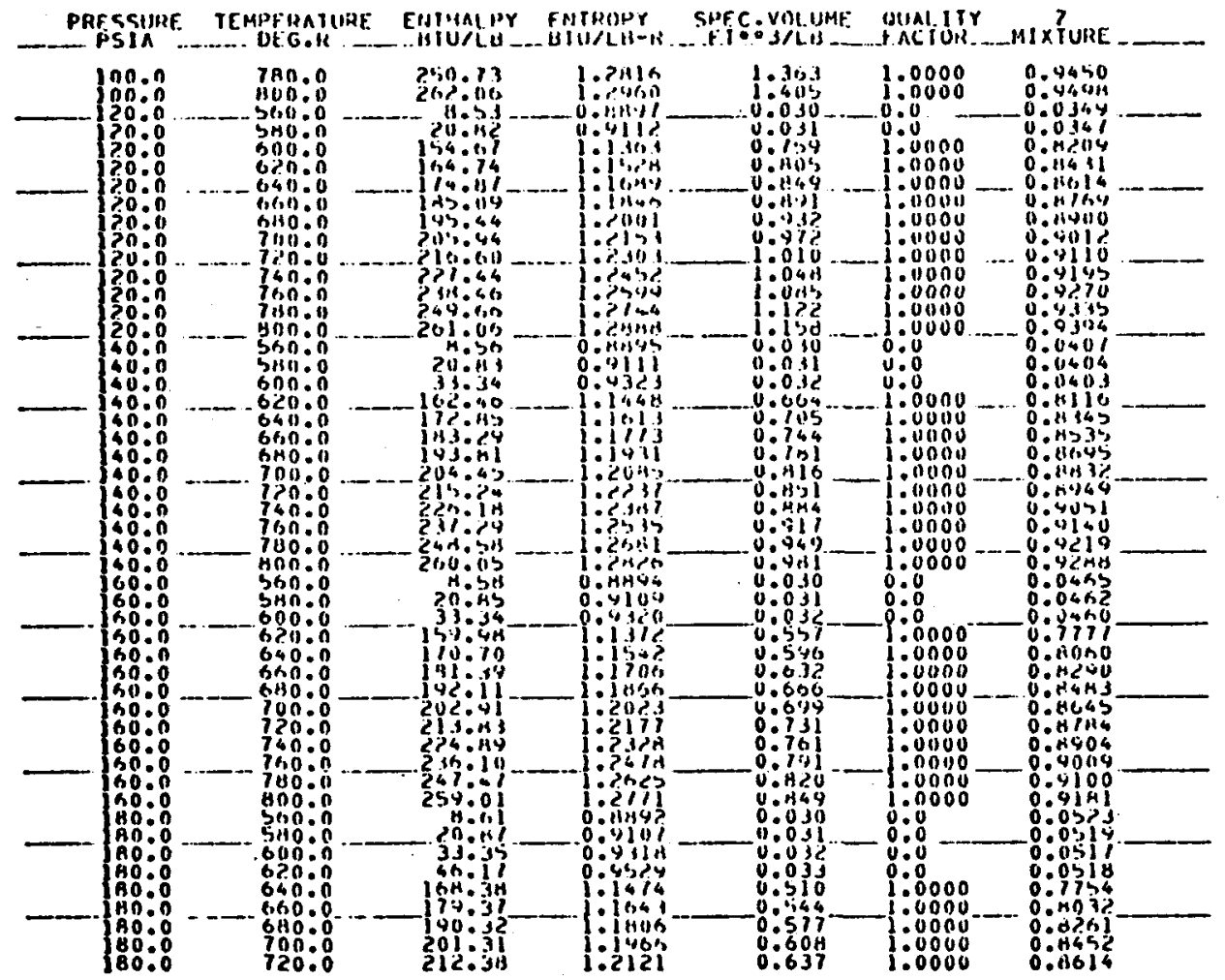


COMMERCIAL ISOBUTANE

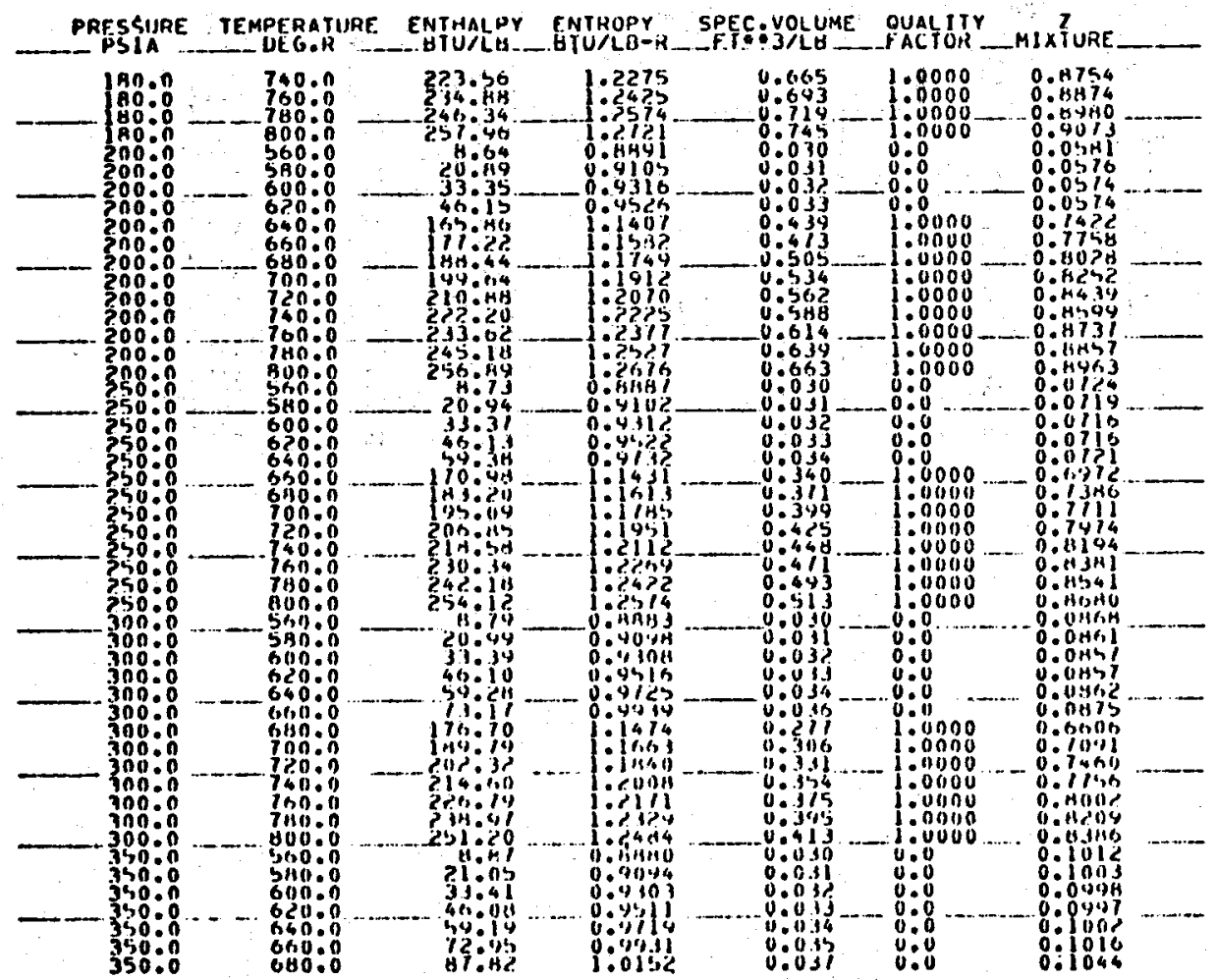

COMMERCIAL ISOBUTANE

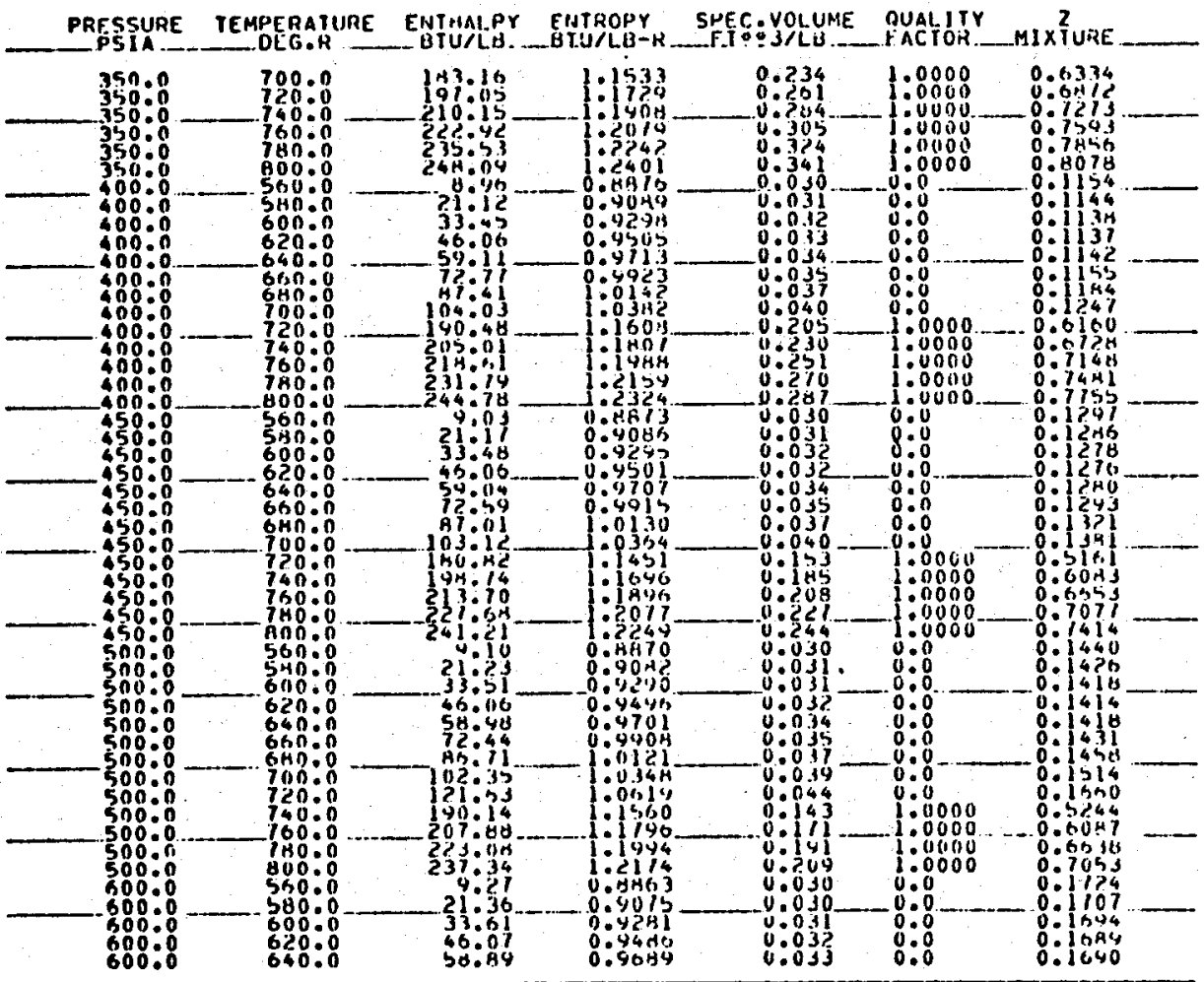


COMMERCIAL ISORUTANE

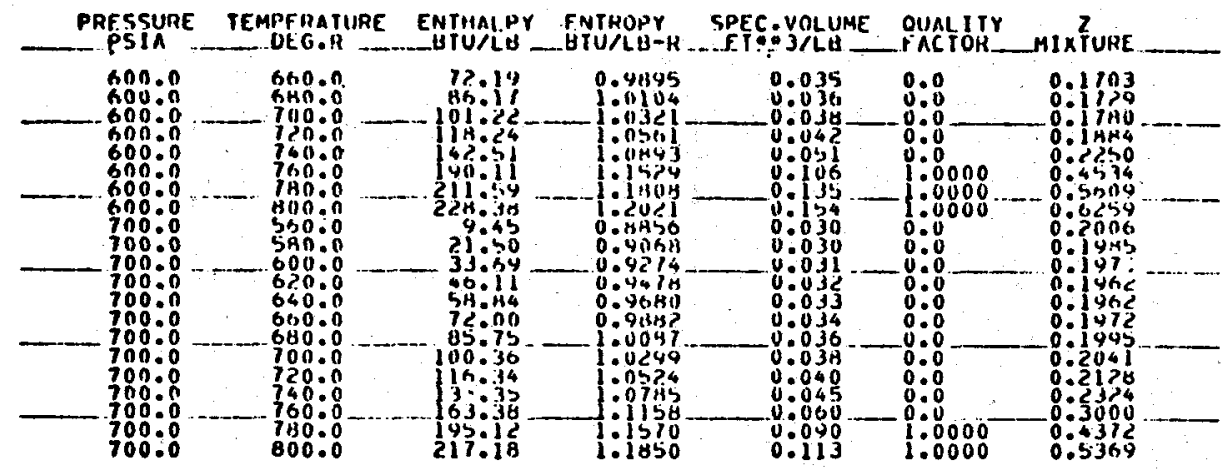


Appendix B1

EPRI 65MW AXIAL FLOW HC TURBINE

CRITICAL SPEED AND UNBALANCE RESPONSE ANALYS IS

STIFF ROTOR

A critical speed and unbalance response analysis was done for a stiff shaft rotor for the EPRI 65MW axial flow hydrocarbon turbine. For the final configuration of this rotor, the weight is $6515 \mathrm{~kg}(14,361 \mathrm{lbs})$ including a coupling half weight of $355 \mathrm{~kg}(782 \mathrm{lb})$. The bearing span is $2.89 \mathrm{~m}(113.7$ in.) and the overall shaft length is $4.0 \mathrm{~m}$ (157.2 in.). The center of mass of the shaft is $1.81 \mathrm{~m}(71.2 \mathrm{in.})$ from the coupling end and the static bearing reactions are $3521 \mathrm{~kg}(7763 \mathrm{lb})$ and $2993 \mathrm{~kg}(6599 \mathrm{lb})$ for the coupling and thrust end, respectively. The rotor analytical model and shaft outline are shown on Figure B1-1. The details of the shaft model are given on Figure B1-2.

The critical speed map for the rotor alone is shown on Figure 3. The coupling end and thrust end bearing parameters are given in Table B1-1 and B2-2 respectively These characteristics are for a lubricant with an average viscosity of $2 \times 10-6$ Reyns. These characteristics are shown in Figure 4 over-plotted on the rotor critical speed map to indicate the undamped critical speeds of the rotorbearing system.

The unbalance response analysis was run considering both static and dynamic unbalances on the rotor. Generally, a static unbalance excites the first critical, and a dynamic unbalance excites the second critical. The first unbalance run was a static unbalance located at the shaft center equivalent to $1 / 2 \mathrm{~g}$ at the running speed of $3600 \mathrm{RPM}$. The second set of unbalance weights run was a dynamic couple at the third stage discs, equivalent to $1 / 4 \mathrm{~g}$. The results are presented as plots of vibrational amplitude at the bearing stations versus rotor speed. It should be noted that this is a linear analysis, that is, the amplitudes predicted are proportional to the unbalance force. The half $\mathrm{g}$ total used for both sets of unbalances is more unbalance than is left in a rotor after balancing. A residual unbalance of $0.1 \mathrm{~g}$ or less is 
EPRI 65MW EXPANDER - STIFF ROTOR FINAL

ROTOR ANALYTIC MODEL AND SHAFT OUTL.INE

$04 / 25 / 77$

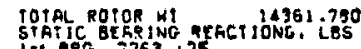

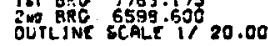

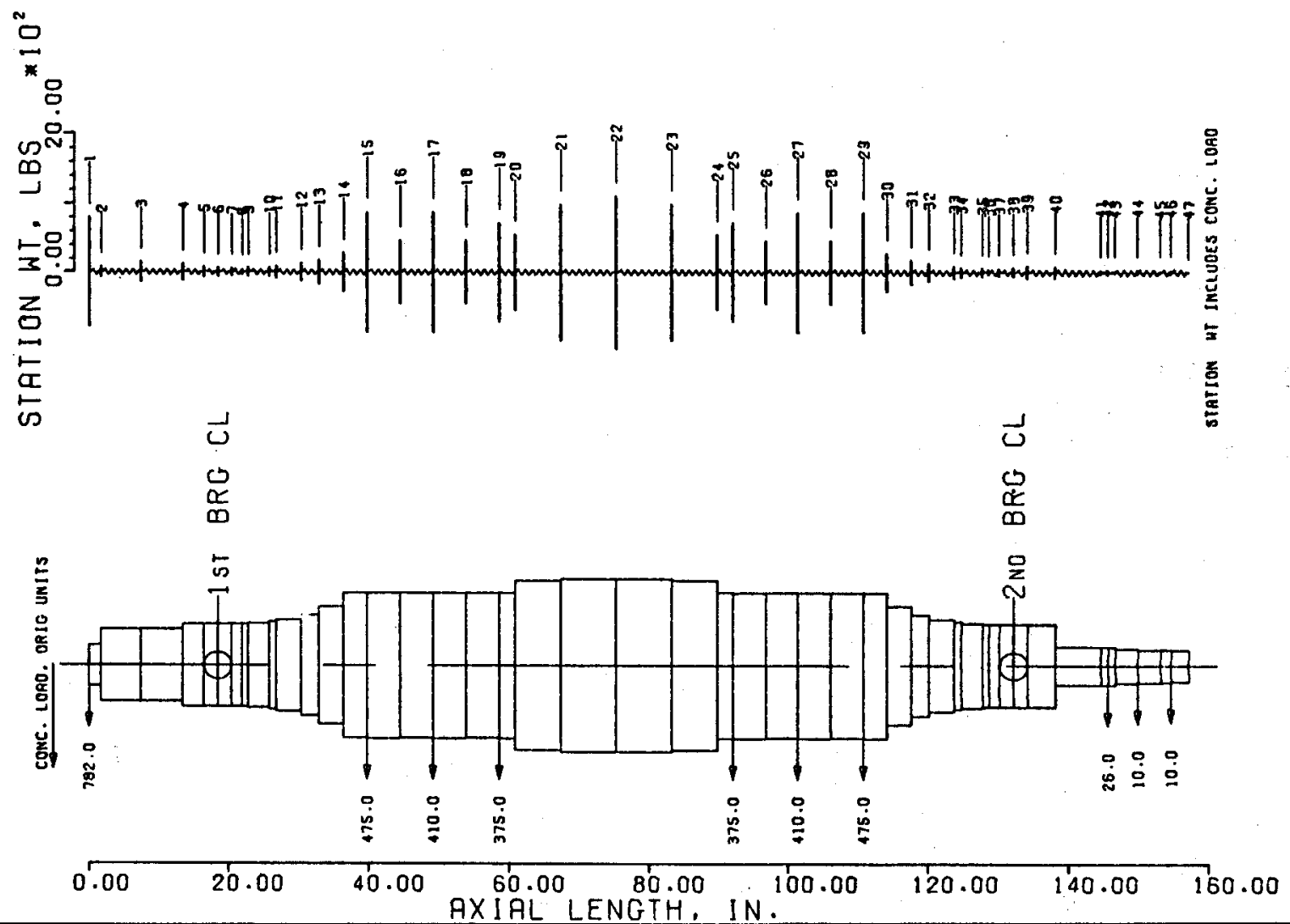

Figure B1-1. Rotor Analytical Mode1 
5.1.031.6 RUN: EPRI 65MW EXPAINDE - STIFF ROTOR FINAL
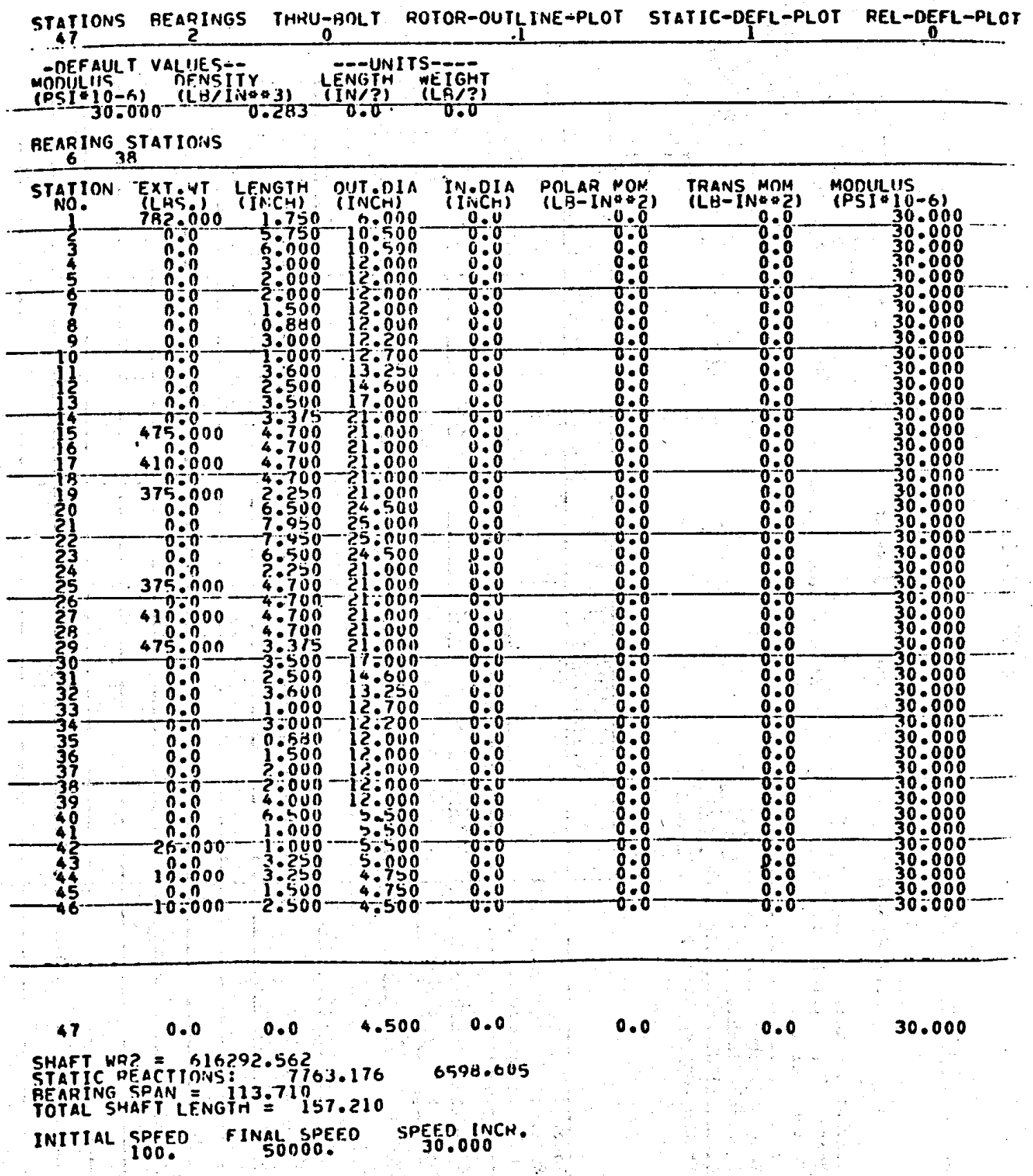

Figure B1-2. Rotor Computer Input Data 
BEARING PARAMETERS

Table * Bl-1

Shop Order

Customer $F P R I$

Frame size.

\section{区Journal End $\square$ Thrust Bnd $\square$ Compressor $\square$ Turbine}

Bearing station............ 5 5

Bear ing Type .............. T T T T

Part Number ..................

Preload .....................

Length (Inches)

D lameter (inches.............. $\frac{12.0}{12.0}$

DLametral Clearance (Inches)

stat 1c Load on Bearing (1bs.)

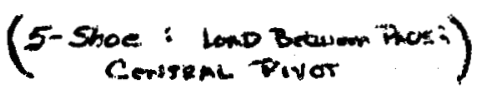

BEARINO SHELI

Braning shers

DTE LITE OIL \& T $T_{1}=120^{\circ} \mathrm{F}$

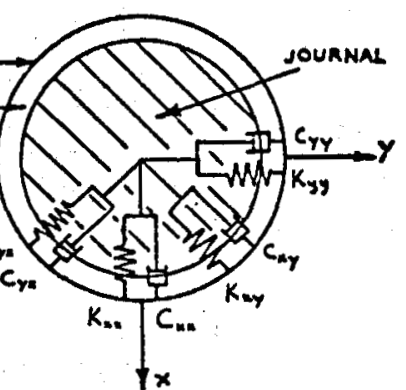

\begin{tabular}{|c|c|c|c|c|c|c|c|c|c|}
\hline & & & $\begin{array}{l}\text { uid } 1 \\
\text { Lbs /I }\end{array}$ & $\begin{array}{r}\text { Stiff } \\
\times 10^{-6} \\
\end{array}$ & & & $\begin{array}{r}\text { Do } \\
\text { (Lbs) }\end{array}$ & $2^{\text {lng }} \times 10^{-6}$ & \\
\hline $\begin{array}{c}\text { Speed } \\
\text { RPM }\end{array}$ & $\begin{array}{l}\text { Dimensionless } \\
\text { Summerfield No. }\end{array}$ & $\mathbb{R}_{x x}$ & $k_{x y}$ & $k_{y y}$ & $k_{y x}$ & $\omega c_{x x x}$ & $w c_{x y}$ & $\omega c_{y y}$ & $w c_{y x}$ \\
\hline 1000 & 0.1892 & 7.82 & 0. & 4.13 & 0 & 4.57 & 0. & 2.46 & 0. \\
\hline 2000 & 0.3785 & 5.91 & 1 & 3.12 & 1 & 4.54 & $i$ & $\because .54$ & 1 \\
\hline 3000 & 0.5672 & 5.04 & & 2.66 & & 4.56 & & 2.66 & \\
\hline 4000 & 0.1569 & 11.60 & & 2.37 & & $4.6 \ddot{a}$ & & 2.83 & \\
\hline 5000 & 0.9462 & 4.12 & & 2.17 & & 4.70 & & 3.01 & \\
\hline 6000 & 1.1354 & 3.23 & & 202 & & 4.72 & & 3.21 & \\
\hline 7000 & 1.32116 & 3.61 & & 1.00 & & 4.88 & & 3.43 & \\
\hline 8000 & 1,5135 & $3.1 / 2$ & & 1.81 & & 21.99 & & 3.65 & \\
\hline 2000 & 1.7031 & 3.27 & & 1.73 & & 5,09 & & 3.27 & \\
\hline 10000 & 1.8023 & 3.14 & & $1,4:$ & $Y$ & $\therefore \therefore 1$ & $\gamma$ & $4: 13$ & $\downarrow$ \\
\hline & & & & & & & & & \\
\hline & & & & & & & & & \\
\hline & & & & & & & & & \\
\hline & & & & & & & & & \\
\hline
\end{tabular}


BEARING PARAMETERS

Table $\$$ BI-2 Shop Order

Customer EPRI

\section{口journa1 Rnd Thrust Rnd}

$\square$ comprassor $\otimes_{\text {Turbine }}$

Bearing Station............ 33

Bearing Type ............. TiLT Phr

Part Number .................

Freload .................... O

Length (Inches) ............ 3,6

Dlameter (Inches............ $\frac{12.0}{12.0}$

Diametral Clearance (Inches) $\frac{120}{0.012}$

Static Load on Bearing (1bs.) $\quad 599$.

(5 shoe j lono Enosen faosis
Centeal Fivat

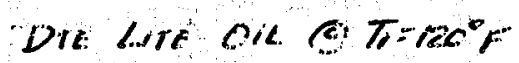

Frame size Aixial ELoun Ne

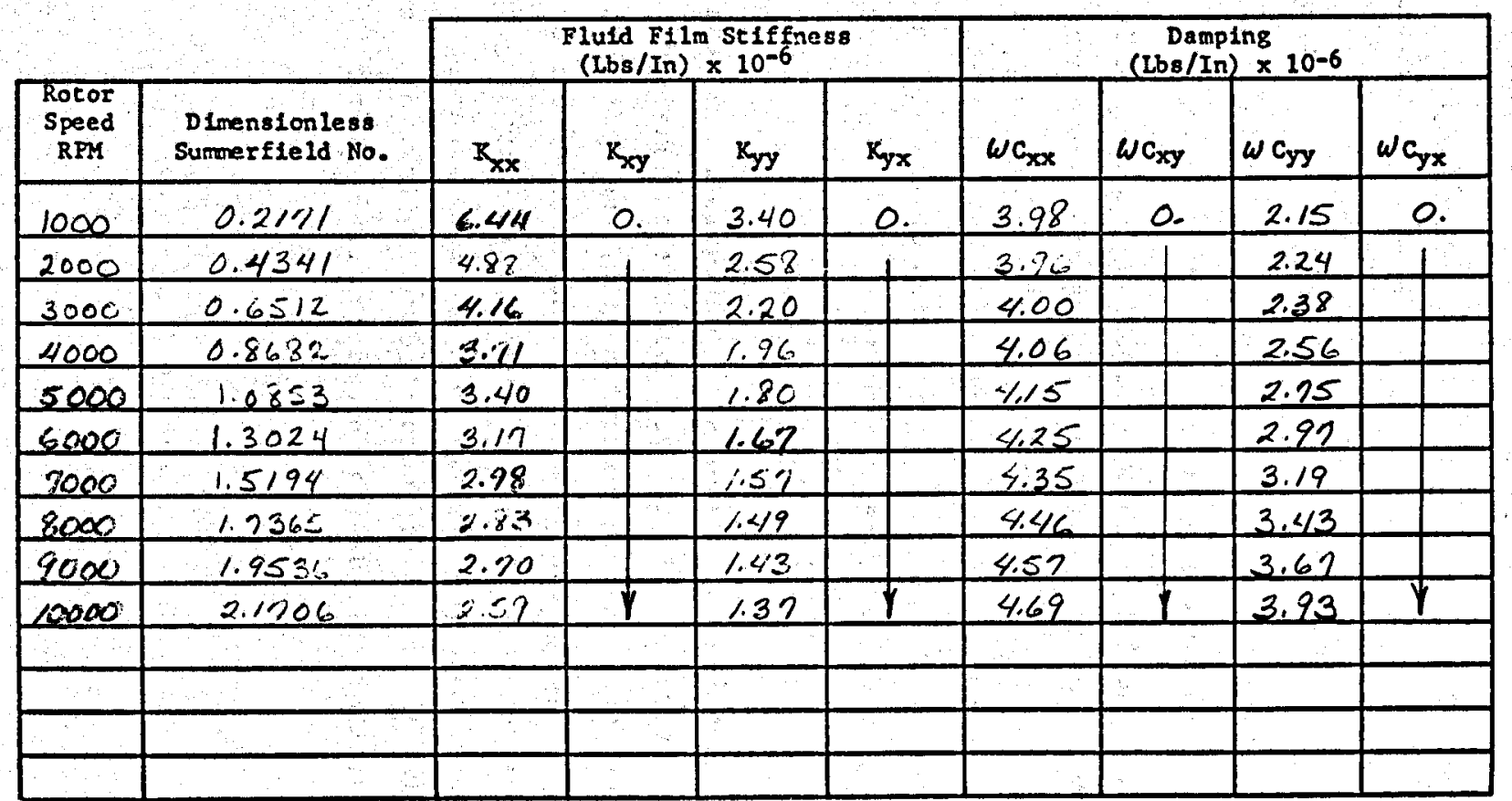


reasonable to expect and this would result in actual shaft amplitudes of approximately $1 / 5$ of those indicated on these unbalance response plots. Figures B1-5 and B1-6 show the rotor response to the static unbalance and Figures B1-7 and B1-8 show the response to the dynamic unbalance.

The unbalance response peaks are tabulated below:

Bearing

Plane

lst Critical

$\%$ Running speed

2nd Critical

$\%$ Running Speed
Coupling End Horizontal Vertical 4200

$117 \%$
5000 $139 \%$
Thrust End Horizontal Vertical 4200 5000

$117 \%$ $139 \%$ 7500 6400 $208 \%$

The coupling end bearing shows a steady rise in amplitude toward the third damped critical peak with the second set of unbalance. No response is shown at the first or second criticals. This is probably due to the location of the unbalance force and the damping in the bearing. The response could be excited by changing the position of the unbalance force. However, the bearing conditions are so similar to the thrust end that the response should be similar as well.

In conclusion, the present configuration of the stiff rotor is only marginally acceptable. First, even though the peaks indicating the damped system first criticals show sufficient margin, the fact that running speed lies on the steep up-slope of the curve is an undesirable characteristic. Then too, the peak on the second vertical is close to twice running speed. This also is not desirable. There is a possibility that the rotor-bearing system presented could be modified to give satisfactory results. However, at present there is no reason to say that this design should go stiff shaft. 


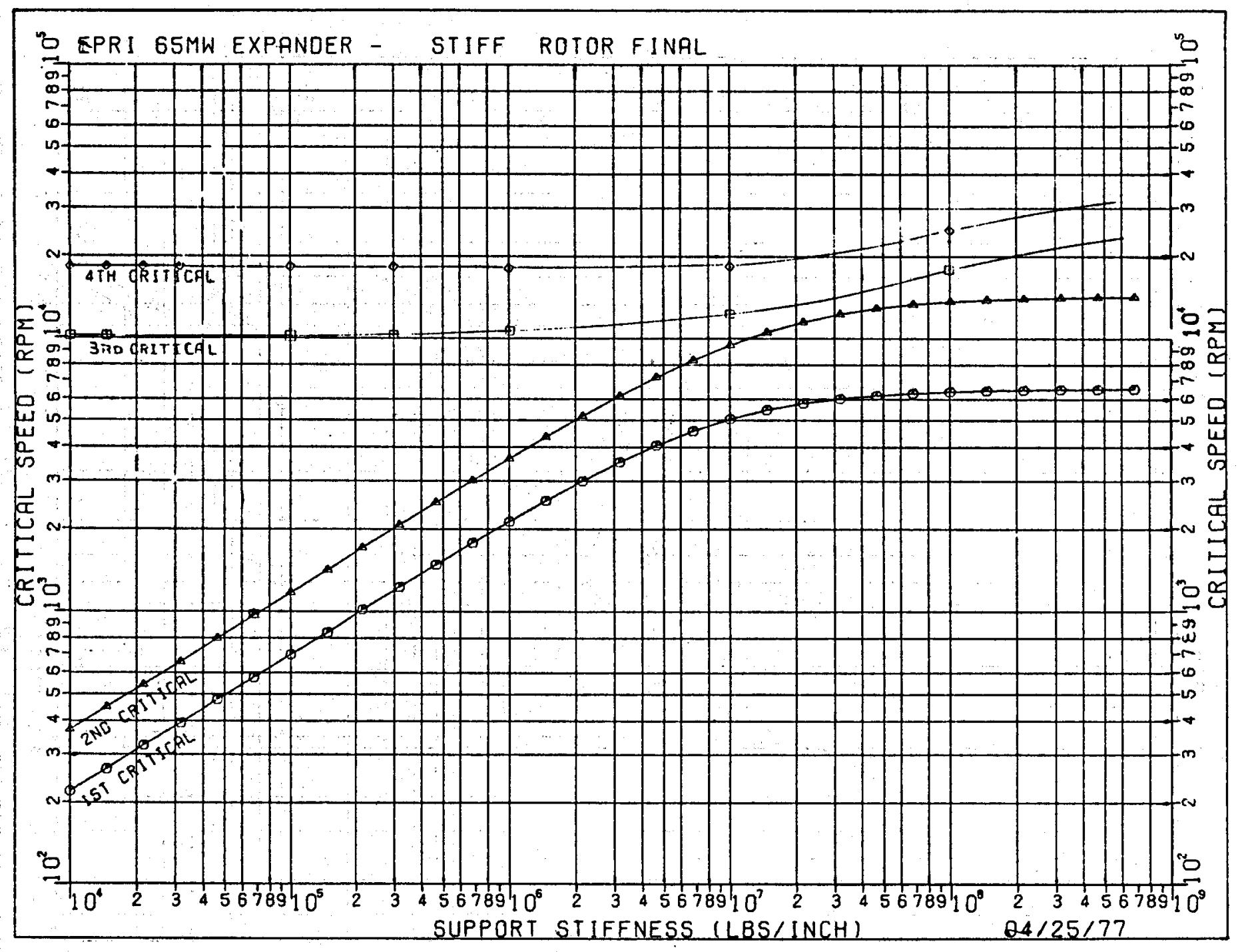

Figure B1-3. Support Stiffness versus Critical Speed 


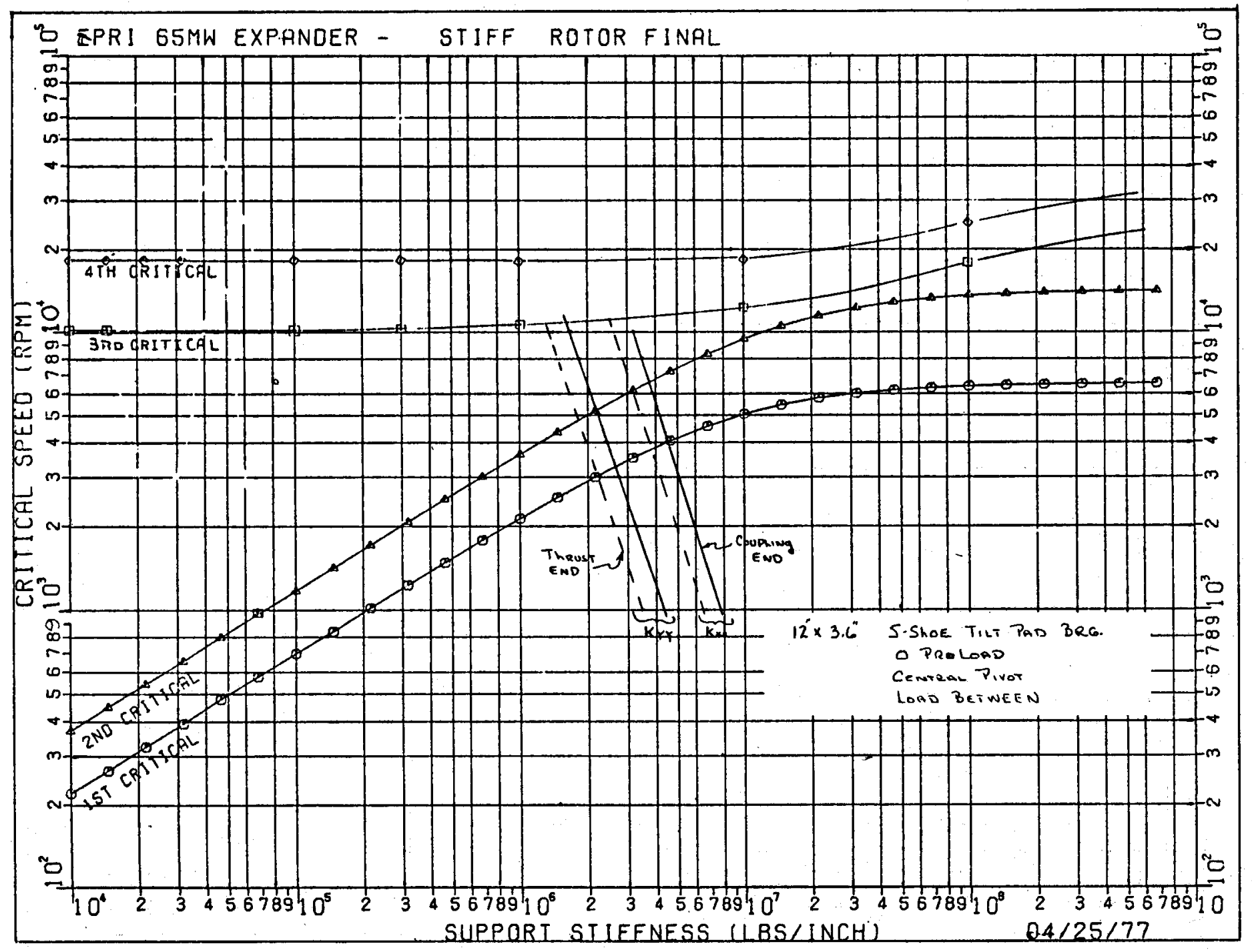

Figure B1-4. Support Stiffness versus Critical Speed 


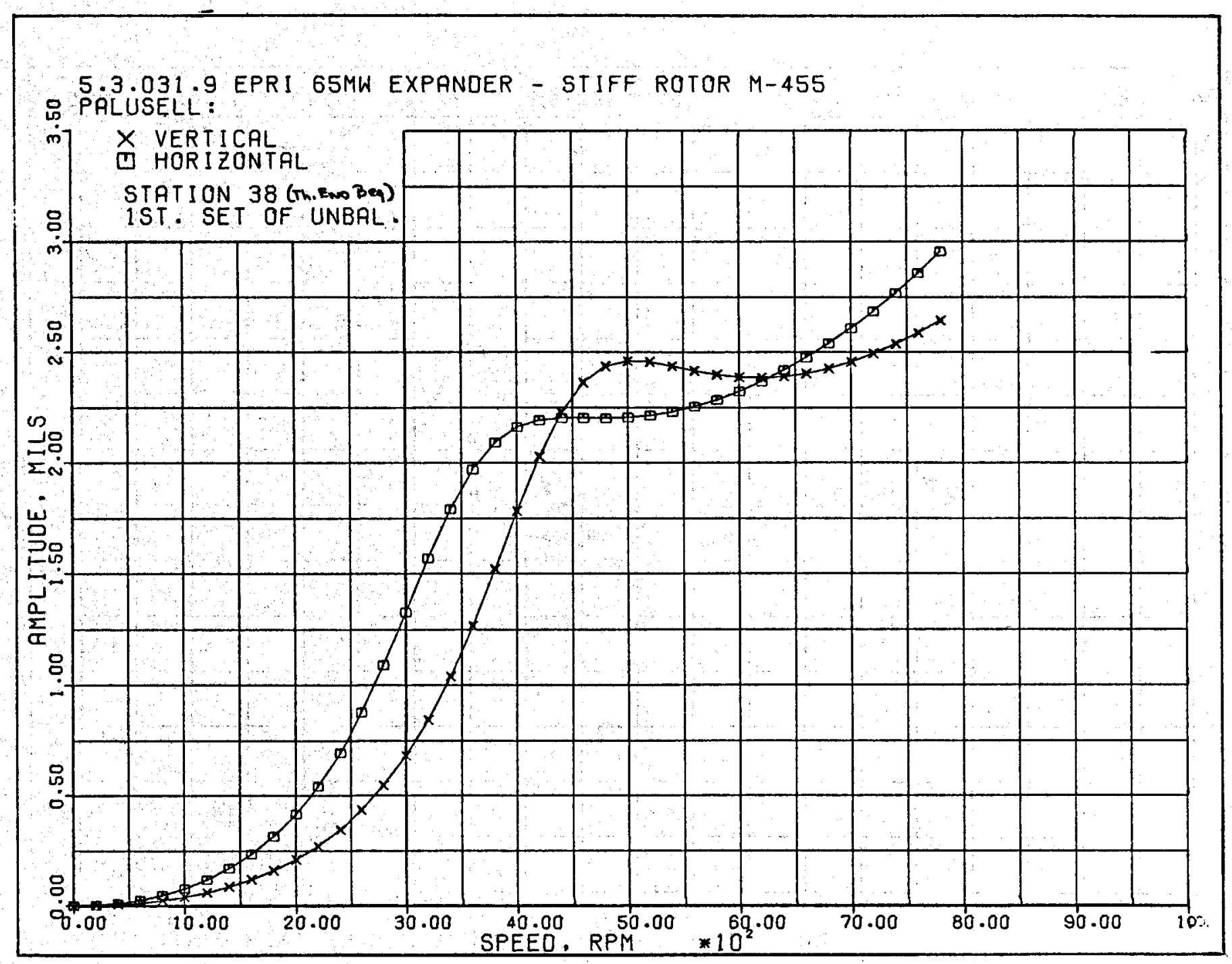

Figure B1-5. Amplitude versus Speed - Thrust End Bearing - Static 


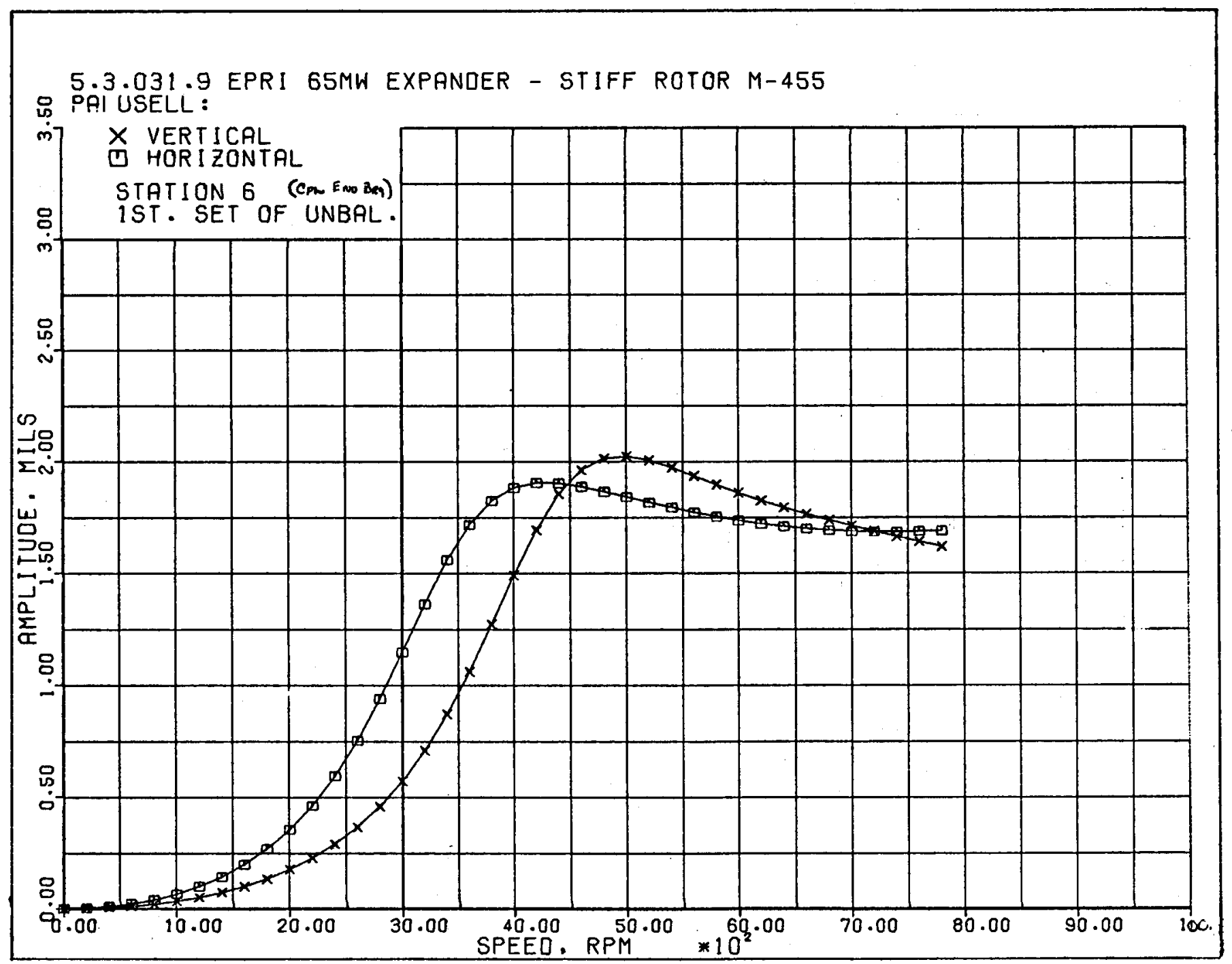

Figure B1-6. Amplitude versus Speed - Coupling End Bearing - Static 
5.3.031.9 EPR J 65MW EXPANDER - STIFF RCTOR M-455

吕 PALUSELL:

i.] $\begin{aligned} & \times \text { VERT ICAL } \\ & \text { O HORI ZONTAL }\end{aligned}$

STATION 38 (TWN E E B Bea)

\& 2NO. SET OF UNBAL

in

웅.

i

o

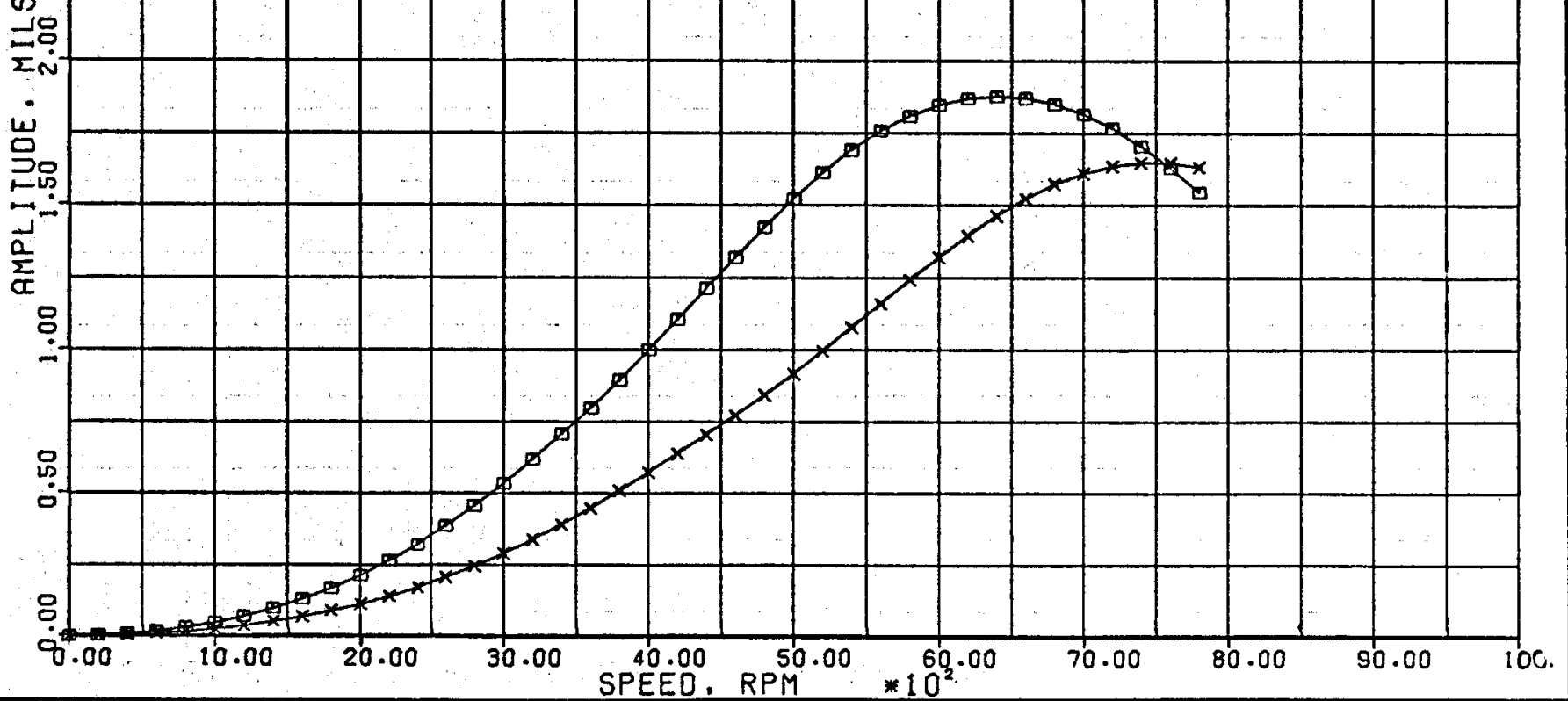

Figure B1-7. Amplitude versus Speed - Thrust End Bearing - Dynamic 


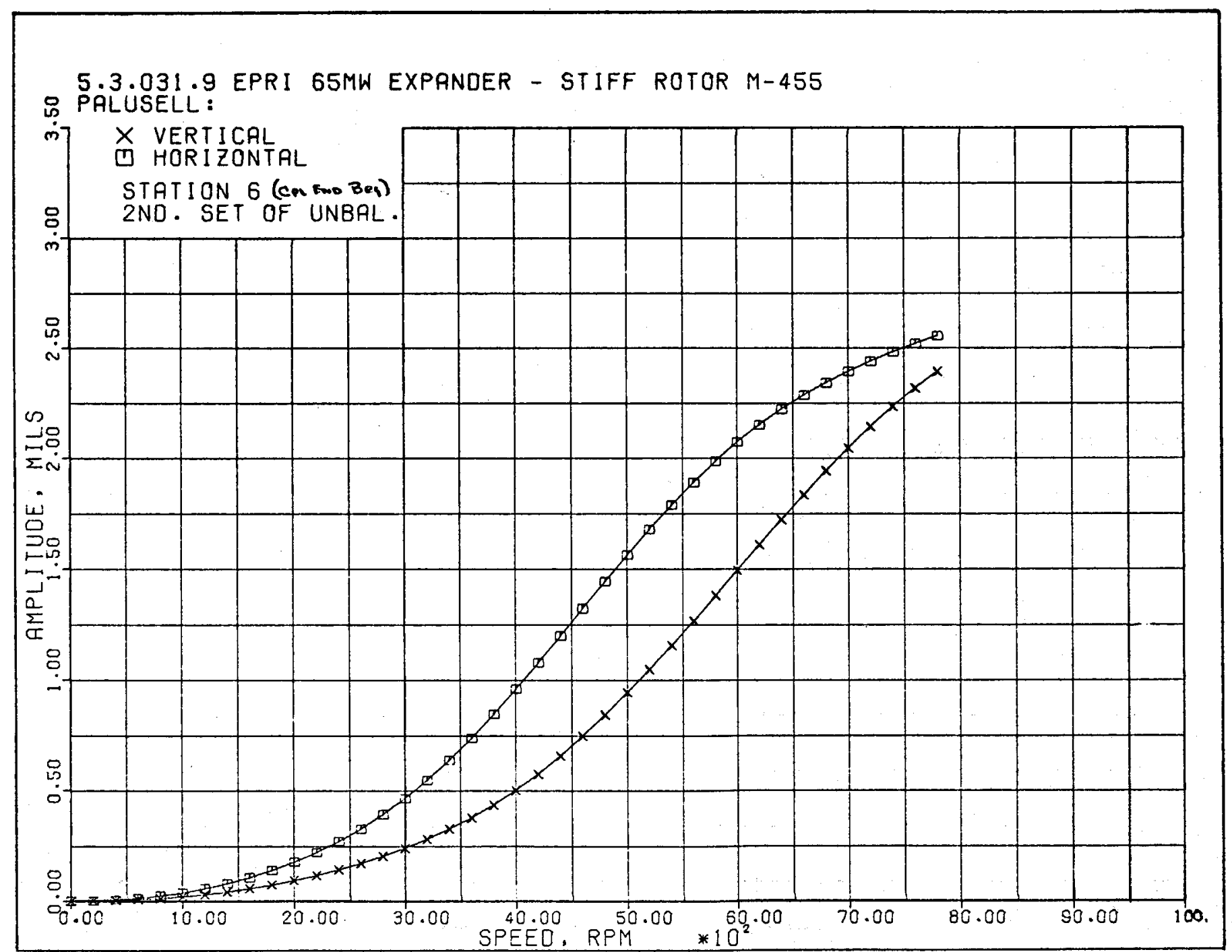

Figure B1-8. Amplitude versus Speed - Coupling End Bearing - Dynamic 
Appendix B2

ROTOR CRITICAL SPEED AND UNBALANCE RESPONSE ANALYS IS

EPRI 65 MW AXIAL FLOW HC TURBINE

FLEXIBLE ROTOR

A critical speed and unbalance response analysis was done for a flexible type rotor for the EPRI $65 \mathrm{MW}$ axial flow hydrocarbon turbine. For the final configuration, the rotor weight is $4495 \mathrm{~kg}$ (9910 1b), including a coupling half-weight of $355 \mathrm{~kg}(782 \mathrm{lb})$. The bearing span is $3.24 \mathrm{~m}(127.7 \mathrm{in})$ and the overall shaft length is $4.40 \mathrm{~m}(173.25 \mathrm{in})$. The center of mass of the shaft is $1.98 \mathrm{~m}(77.89 \mathrm{in})$ from the coupling end and the static reactions are $2517 \mathrm{~kg}(5549 \mathrm{lb})$ and $1978 \mathrm{~kg}$ (4361 1b) for the coupling and thrust ends respectively. The rotor analytical model and shaft outline are shown in Figure B2-1. The details of the shaft model are given in Figure $\mathrm{B} 2-2$.

The undamped critical speed map for the rotor only is shown on Figure B2-3. The coupling end and thrust end bearing parameters are given in Table B2-1 and B2-2 respectively. The undamped critical speed map for the rotor-bearing system is shown in Figure B2-4. The mode shape of the undamped criticals is shown on Figures $B 2-5$ and $B 2-6$ for bearing stiffnesses bracketing the expected bearing stiffness at the criticals of the system. The large amplitudes shown by these plots at the bearing locations indicate the bearings will be well damped.

The unbalance response analysis was run considering both static and dynamic unbalances on the rotor. Generally, a static unbalance excites the first critical, and a dynamic unbalance excites the second critical.

The first unbalance run was a static unbalance located at the shaft center equivalent to $1 / 2 \mathrm{~g}$ at the running speed of 3600 RPM. The second set of unbalance weights run was a dynamic couple at the third stage discs, equivalent to $1 / 4 \mathrm{~g}$. The results are presented as plots of vibrational amplitude at the bearing stations versus rotor speed. It should be noted that this is a linear analysis, that is, the amplitudes predicted are proportional to the 
EPRI 65MW EXPANDER - FLEXIBLE ROTOR FINAL

ROTOR ANALYTIC MODEL AND SHAFT OUTLINE

$03 / 14 / 77$

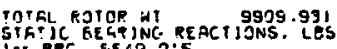

OUtL

음

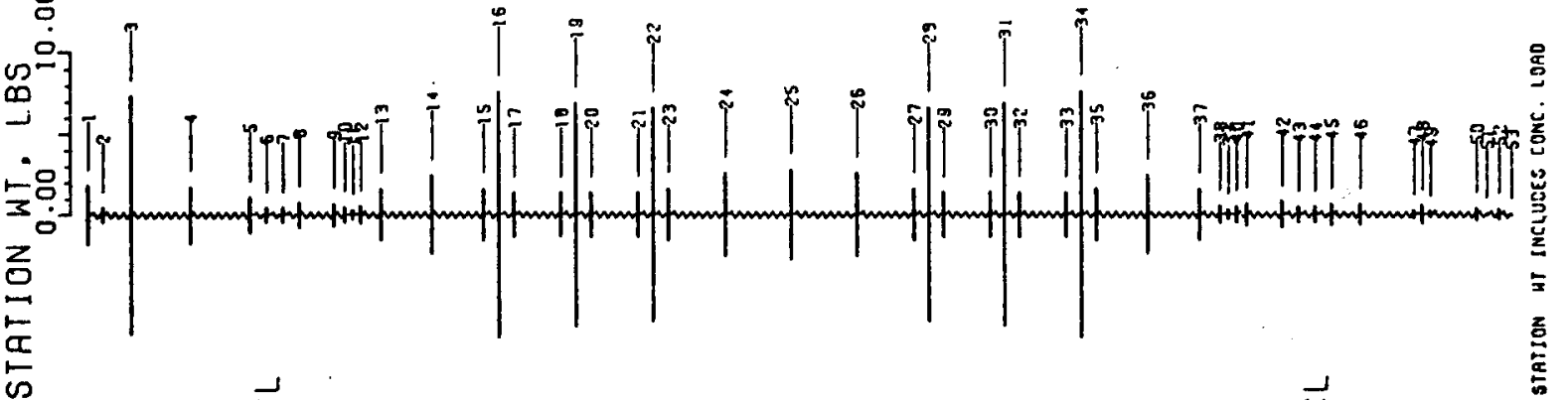

so

$\vec{u}$

0
or
0

品

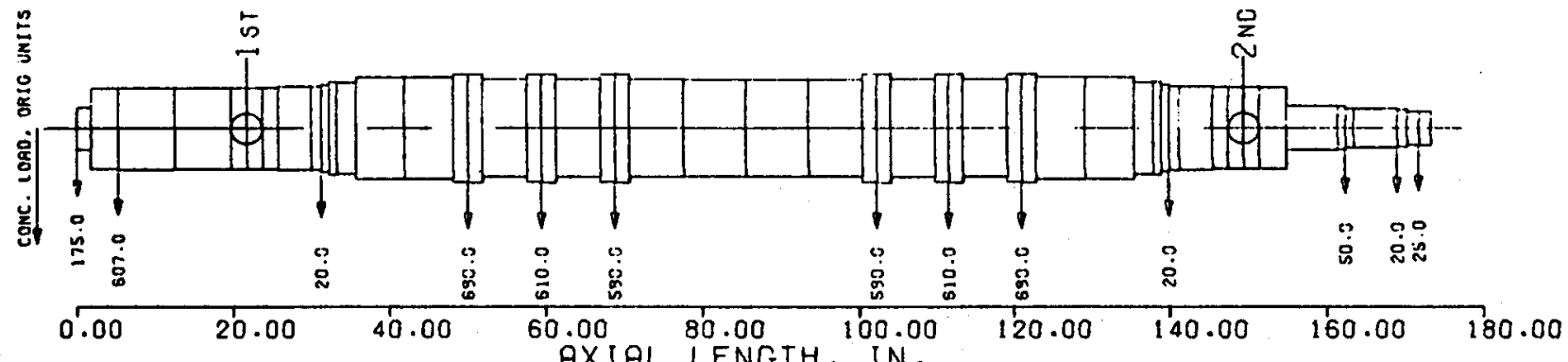

Figure B2-1. Rotor Analytical Model 
PHROL CRITICAL SPEEDS - EPRI FLEXIELE ROTDR - FINFL (3-9-77)

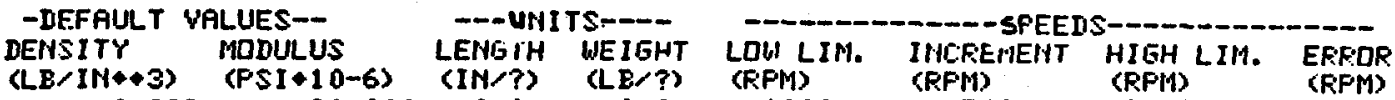

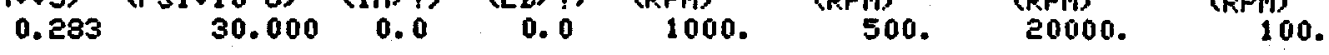

STATH EXT.WT LEHITH DUT.DIA IN.DIA MDDULUS IENSITY SHFIMK INERTIA TDT.WT

ND. (LES) (INCH) (INCH) (INCH) (PSI*10-6) ( $\mathrm{IE} / \mathrm{IH}+43$ ) FACTOR (IM+*4)

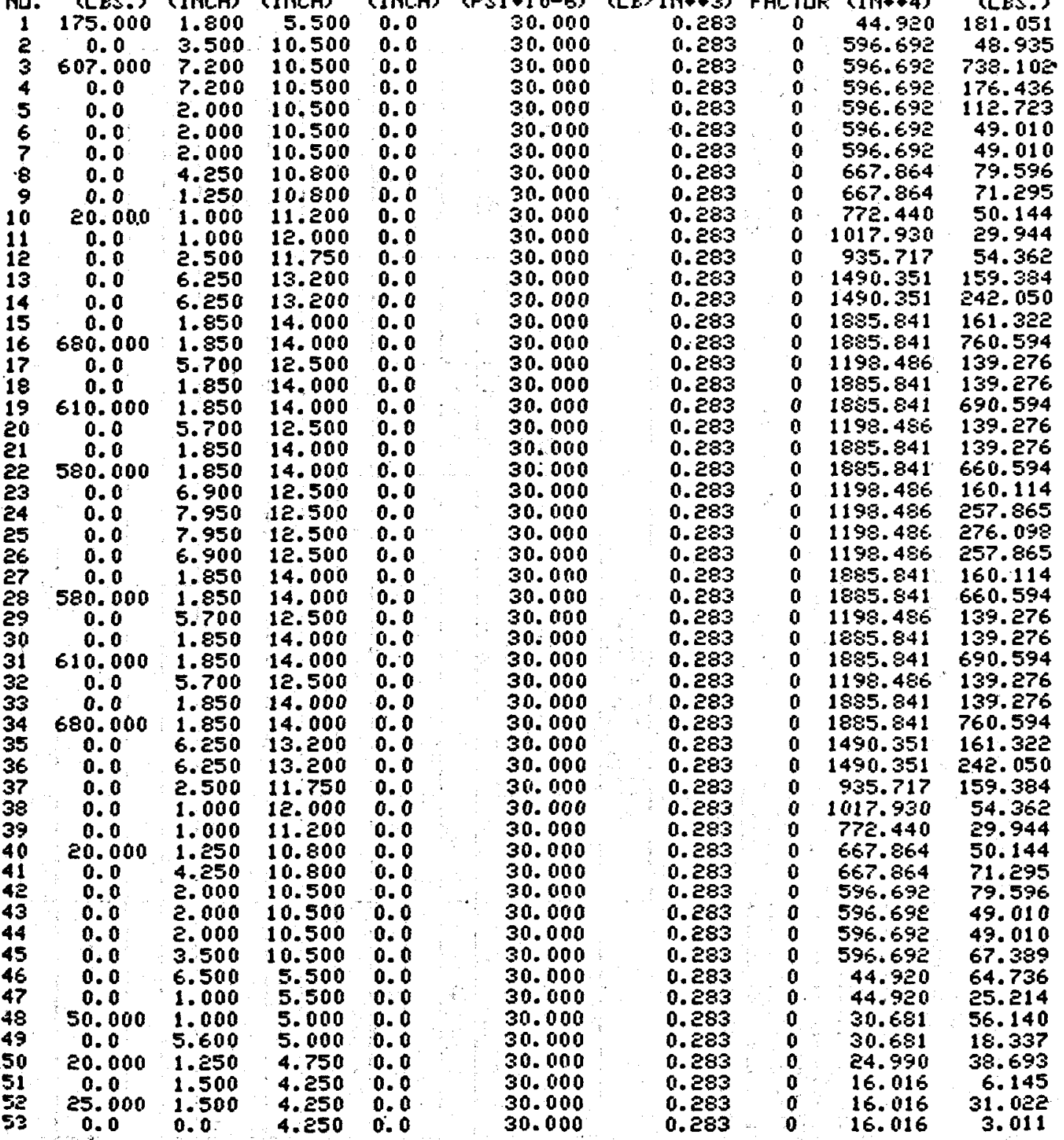

IEARING STATIONS: $6 \quad 44$

TOTAL RDTDF: WEIGHT (INCLUDING IEAD WEIGHTS) IS 9909.9 PDUNDS

SHAFT WIEE (HIT INCLUDING DEAD WEIGHTS) IS 100905.4

EEARING SFAN IS 127.700 IHCHES

STATIC REACTIUNS $\quad 5548.99 \quad 4360.94$

Figure B2-2. Rotor Computer Input Data 
BEARING PARAMETERS

Tabla B2-1 Shop Order

Customer EPRI

$\bigotimes_{\text {Journa1 Bnd }} \square_{\text {Thrust Rnd }} \square_{\text {compreasor }} \otimes_{\text {Turbhe }}$

Frame Size Ho zenpeline

- 5 Shoe; loso Bmwerw PaOsi
Contpal. Plvot Pos.

DTE LUE OIL COT: $120^{n} \mathrm{~F}$
Bearing station............. 6

Bearing Type ............... Tht PAs

Part Number .................

Length (Inches) ..............

D lameter (inches.............

DLametral Clearance (Inches) 012

Static Load on Boaring (16s.) 5 542
SEARINe SHELL $\rightarrow$ JOURNAL

Besarin

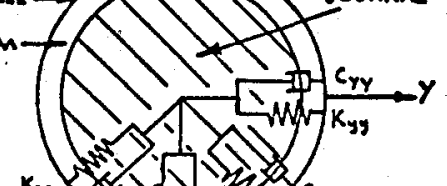

$c_{y+1}$

$x_{x=1} C_{\text {... }}$

$f_{x}$

\begin{tabular}{|c|c|c|c|c|c|c|c|c|c|}
\hline & & & $\begin{array}{l}\text { uid } E \\
\text { Lbs } / I\end{array}$ & $\begin{array}{l}\text { Se1ffen } \\
\times 10^{-6}\end{array}$ & & & $\begin{array}{r}D \\
\text { (Lbs }\end{array}$ & ing $\times 10^{-6}$ & \\
\hline $\begin{array}{c}\text { Rotor } \\
\text { Speed } \\
\text { RPM }\end{array}$ & $\begin{array}{l}\text { Dimensionless } \\
\text { Summerfield No. }\end{array}$ & $K_{x x}$ & $k_{x y}$ & $x_{y y}$ & $x_{y x}$ & $w c_{x x}$ & $w c_{x y}$ & $w c_{y y}$ & $\omega c_{y x}$ \\
\hline 1000 & $0.19<2$ & $4.9 i$ & 0. & 2.60 & 0. & 3.39 & 0. & 1.86 & 0. \\
\hline 2000 & 0.3924 & 3.72 & 1 & 1.96 & 1 & 3.39 & 1 & 1.97 & 1 \\
\hline 3000 & 0.5886 & 3.17 & & 1.67 & & 3.45 & & 2.17 & \\
\hline 4000 & 0.7848 & 2.82. & & 1,49 & & 3.54 & & 2.38 & \\
\hline 5000 & 0.9810 & 2.5 .9 & & .36 & & 3.64 & & 2.62 & \\
\hline 6000 & 1.1701 & 2.40 & & 1.26 & & $3 . ? 6$ & & 2.88 & \\
\hline 7000 & 1.3733 & 2.85 & & 1.19 & & 3.82 & & 3.14 & \\
\hline 8000 & 1.5695 & 2.13 & & 1.13 & & 4.06 & & 3.42 & \\
\hline 9000 & 1.7657 & 2.04 & & 1.07 & & 4.24 & & 3.71 & \\
\hline 10000 & $1.96 / 9$ & 1.95 & $Y$ & 1.03 & $y$ & 4.46 & $r$ & 4.00 & $\Psi$ \\
\hline & & & & & & & & & \\
\hline & & & & & & & & & \\
\hline & & & & & & & & & \\
\hline & & & & & & & & & \\
\hline
\end{tabular}


BEARING PARAMTERS

rable B2-2 Shop order

Customer EPRI

口Journa1 Rnd $\bigotimes_{\text {Thrust Rnd }} \square_{\text {compreasor }} \bigotimes_{\text {Turbine }}$

Bearing station............. 44

Bearing Type .............. ${\overline{\lambda_{1}}+P_{A P}}$

Part Number ................

Pre load .....................

Iength (Inches) ............. 4.0

Diametcr (Inches.............. $\frac{10.5}{10.5}$

Statle Load on Bearing (1bs.) $\frac{0.0126}{436}$

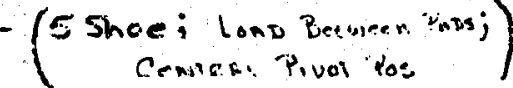

Bearime swach

DTE LITS SII I $1:$ F.

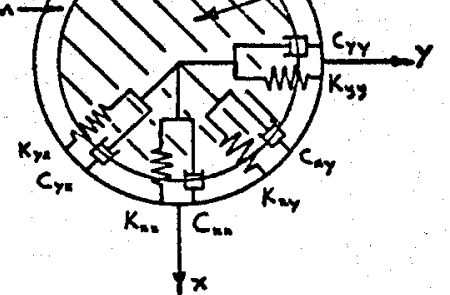

\begin{tabular}{|c|c|c|c|c|c|c|c|c|c|}
\hline \multirow[b]{2}{*}{$\begin{array}{l}\text { Rotor } \\
\text { Speed } \\
\text { RPM }\end{array}$} & \multirow[b]{2}{*}{$\begin{array}{l}\text { Dimensionless } \\
\text { Summerfield No. }\end{array}$} & \multicolumn{4}{|c|}{$\begin{array}{l}\text { Fluid Film St1ffness } \\
\text { (Lbs/In) } \times 10^{-6}\end{array}$} & \multicolumn{4}{|c|}{$\begin{array}{l}\text { Damping } \\
\text { (Lbs/In) } \times 10-6\end{array}$} \\
\hline & & $R_{x x}$ & $k_{x y}$ & $x_{y y}$ & $x_{y x}$ & $w c_{x x}$ & $\omega c_{x y}$ & $\omega C_{y y}$ & $\omega c_{y x}$ \\
\hline 1000 & 0.2616 & 3.29 & 0. & 1.73 & 0. & 2.53 & 0. & 1.42 & 0. \\
\hline 2000 & 0.5232 & 2.49 & 1 & 1.31 & 1 & 2.57 & 1 & 1.52 & 1 \\
\hline 3000 & 0.2848 & 2.12 & & 1.12 & & 2.65 & & 1.79 & \\
\hline 4000 & 1.0464 & 1.88 & & 1.00 & & 2.76 & & 2.03 & \\
\hline 5000 & $\angle .3072$ & 172 & & 0.8 & & 2.89 & & 2.29 & \\
\hline 6000 & 1.5695 & 1.60 & & 0.84 & & 3.04 & & 2.57 & \\
\hline 7000 & 1.8311 & 1.50 & & 0.22 & & 3.23 & & 2.86 & \\
\hline 8000 & 2.0927 & 1.43 & & 0.75 & & 3.46 & & 3.15 & \\
\hline 9000 & 2.3543 & 136 & & 0.72 & & 3.73 & & 3.46 & \\
\hline 10000 & $2.6 / 59$ & 1.30 & $y$ & 0.69 & $Y$ & 4.04 & & 3.77 & $y$ \\
\hline & & & & & & & & & \\
\hline & & & & & & & & & \\
\hline & & $\vdots$ & & & & & & & \\
\hline & & & & & & & & & \\
\hline
\end{tabular}


unbalance force. The half $g$ total used for both sets of unbalances is much more unbalance than is left in a rotor after balancing. A residual unbalance of $0.1 \mathrm{~g}$ or less is reasonable to expect and this would result in actual shaft amplitudes of approximately $1 / 5$ of those indicated on these unbalance plots. Figures B2-7 and 8 show the rotor response to the static unbalance and Figures B2-9 and B2-10 show the response to the dynamic unbalance.

The unbalance response peaks are tabulated below:

\begin{tabular}{|c|c|c|c|c|c|}
\hline Bearing & & Coupli & End & Thrust & End \\
\hline Plane & & Horizontal & Vertical & Horizontal & Vertical \\
\hline lst Critical & & 2400 RPM & 2400 RPM & 2400 RPM & 2400 RPM \\
\hline$\%$ Running & Speed & $67 \%$ & $67 \%$ & $67 \%$ & $67 \%$ \\
\hline 2nd Critical & & 5300 RPM & 5800 RPM & $-\infty$ & $-\infty$ \\
\hline$\%$ Running & Speed & $147 \%$ & $161 \%$ & -- & - \\
\hline
\end{tabular}

The thrust end bearing shows the amplitude rising steadily toward the third critical with no peaks for the second. This is due to the locations of the unbalance force and the damping in the bearing. This could be excited if the placement of the dynamic couple were shifted. However the response of this bearing will be similar to the coupling end bearing.

In conclusion, the unbalance response shows good critical speed margins. No critical speed problems should develop with this rotor. There should be sufficient damping in the system so that running up to speed through the first critical should prove no problem. In addition, the use of tilt pad bearings assures hydrodynamic stability throughout the operating speed range. The above results and conclusions assume an average viscosity of the lubricant of $2 \times 10^{-6}$ Reyns. 


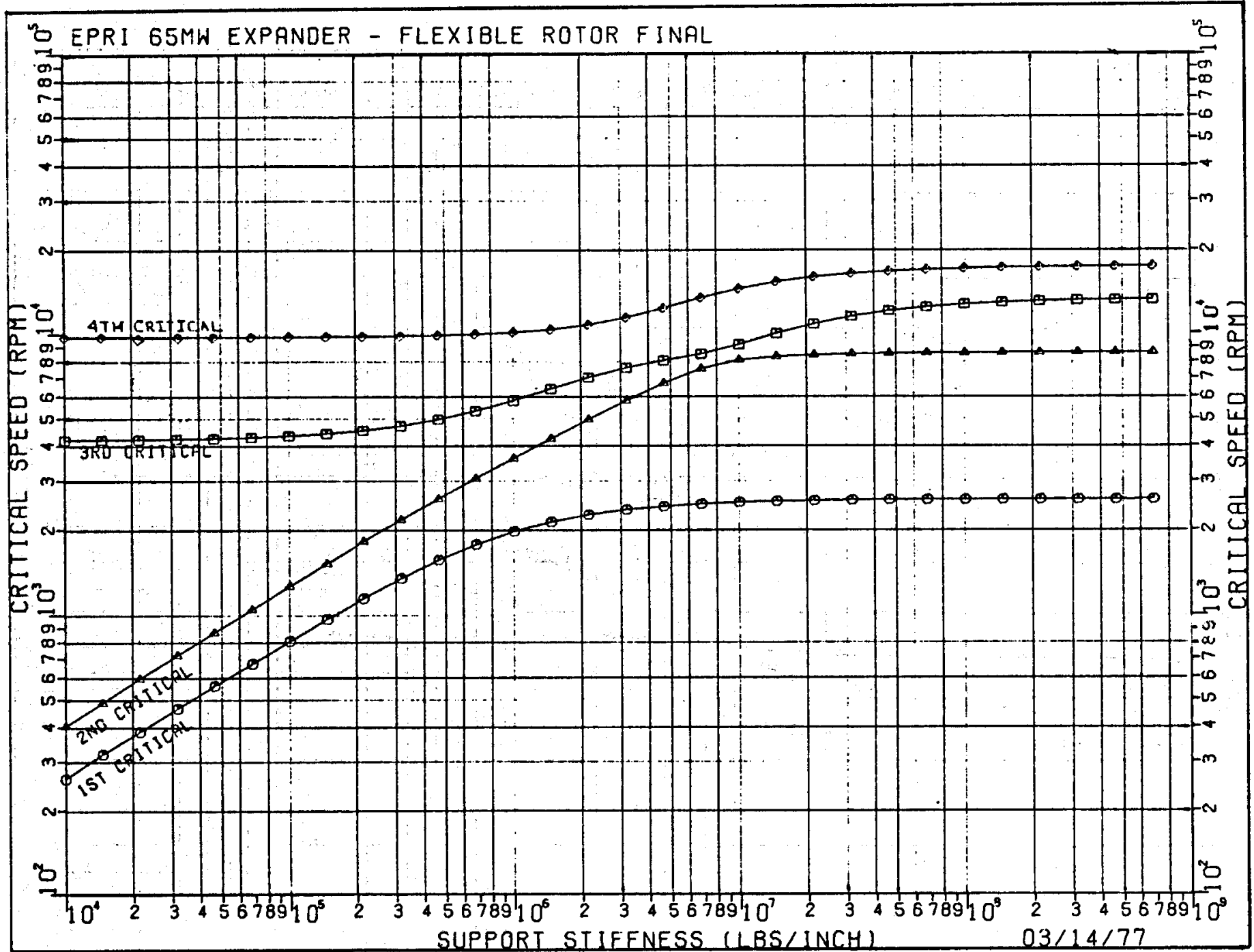

Figure B2-3. Support Stifiness versus Critical Speed 


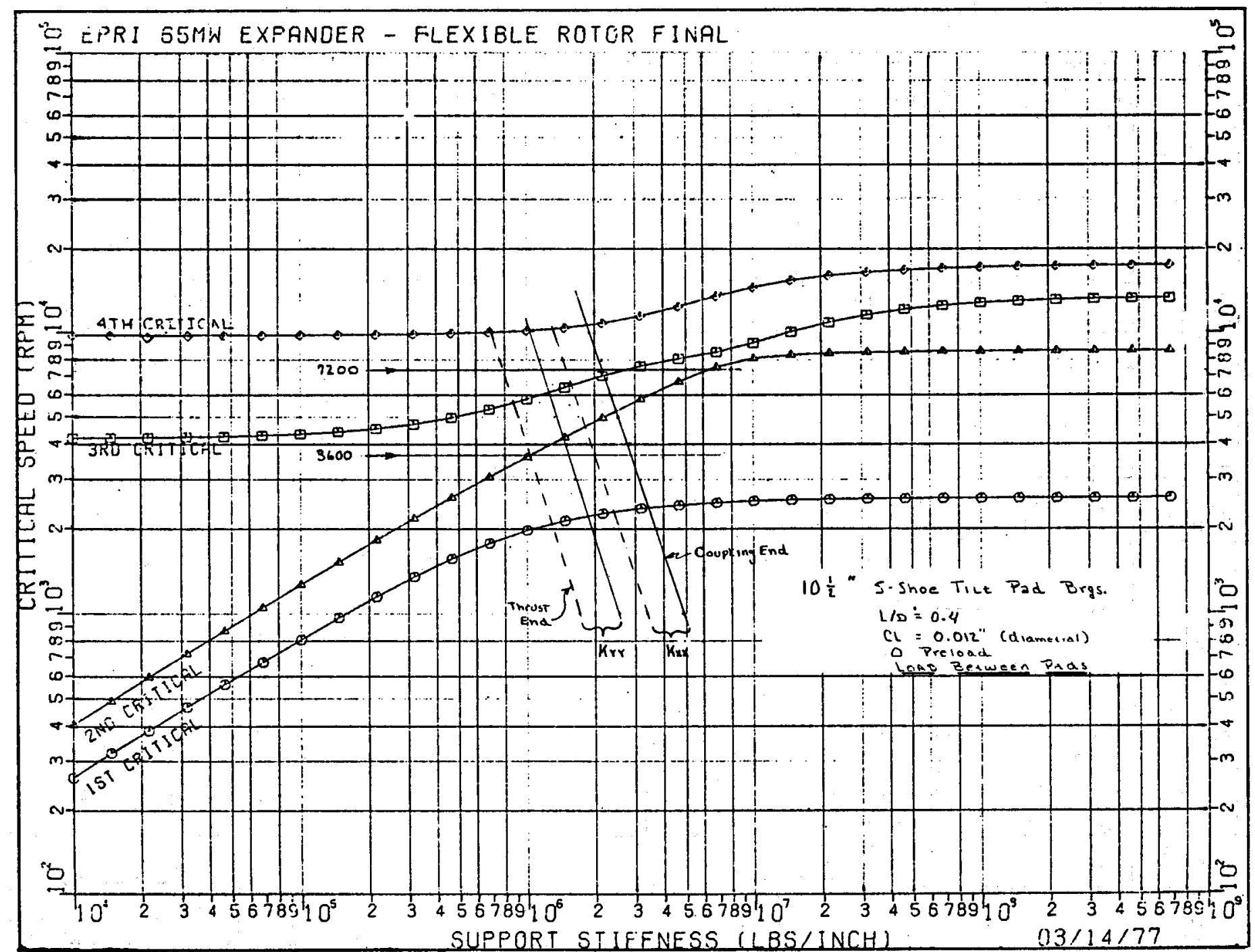

Figure B2-4. Support Stiffness versus Critical Speed 


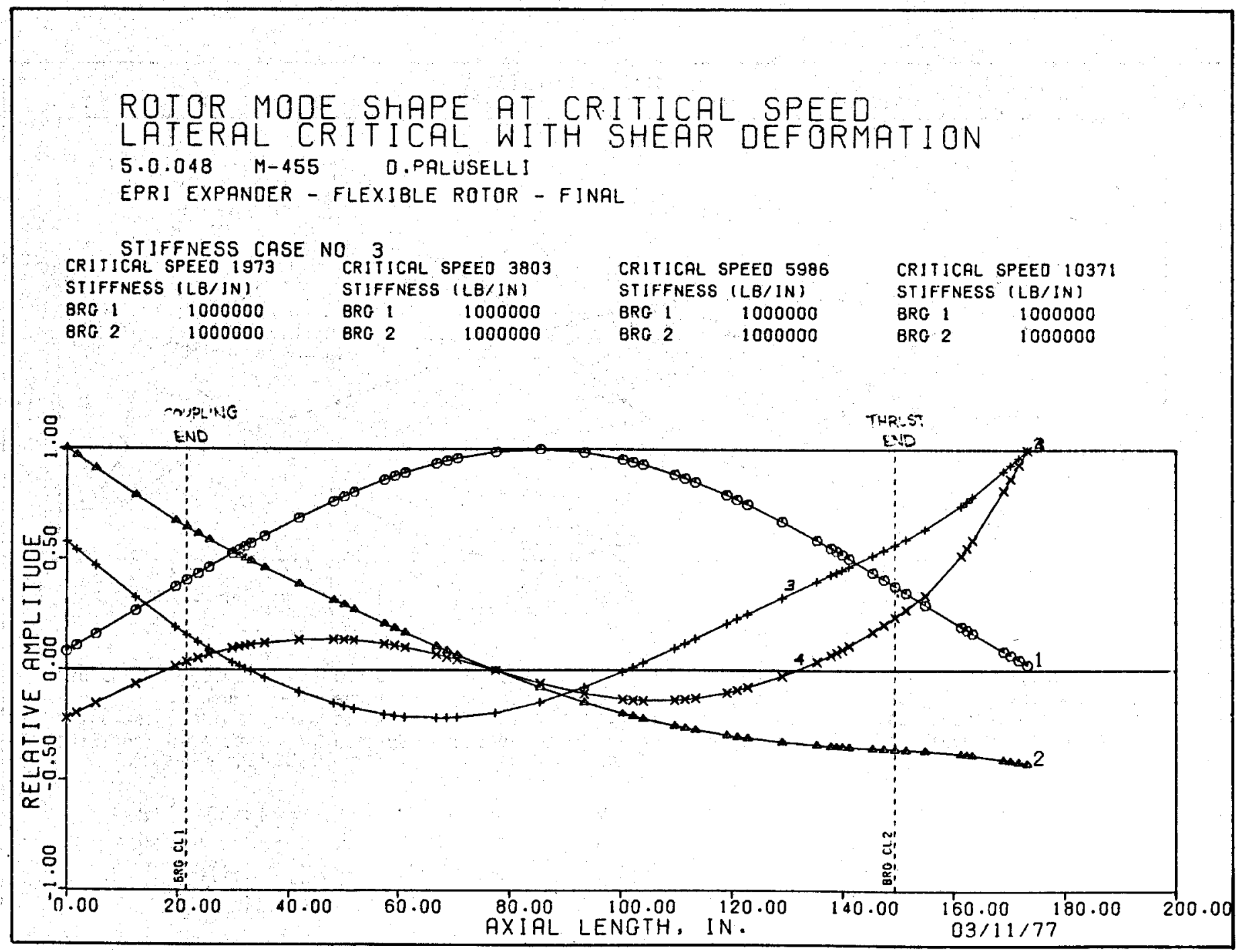

Figure B2-5. Rotor Mode Shape 


\section{ROTOR MODE SHAPE AT CRITICAL SPEED}

LATERAL CRITICAL WITH SHEAR DEFORMATION

$5.0 .048 \quad M-455$ D.PALUSELLI

EPRI EXPANDER - FLEXIBLE ROTOR - FINAL

STIFFNESS CASE NO 4

CRITICAL SPEEO 2352 CRITICAL SPEEO 6100 STJFFNESS (LB/IN) STIFFNESS (LB/IN)

BRC 13000000 BRC 1 3000000

$\begin{array}{llll}\text { BRG } 2 & 3000000 & \text { BRC } 2 & 3000000\end{array}$

CRITICAL SPEED 7734 STIFFNESS (LB/IN)

BRG $1 \quad 3000000$

BRG 23000000

CRITICAL SPEED 11538 STIFFNESS (LB/IN)

BRG 13000000

BRG 2

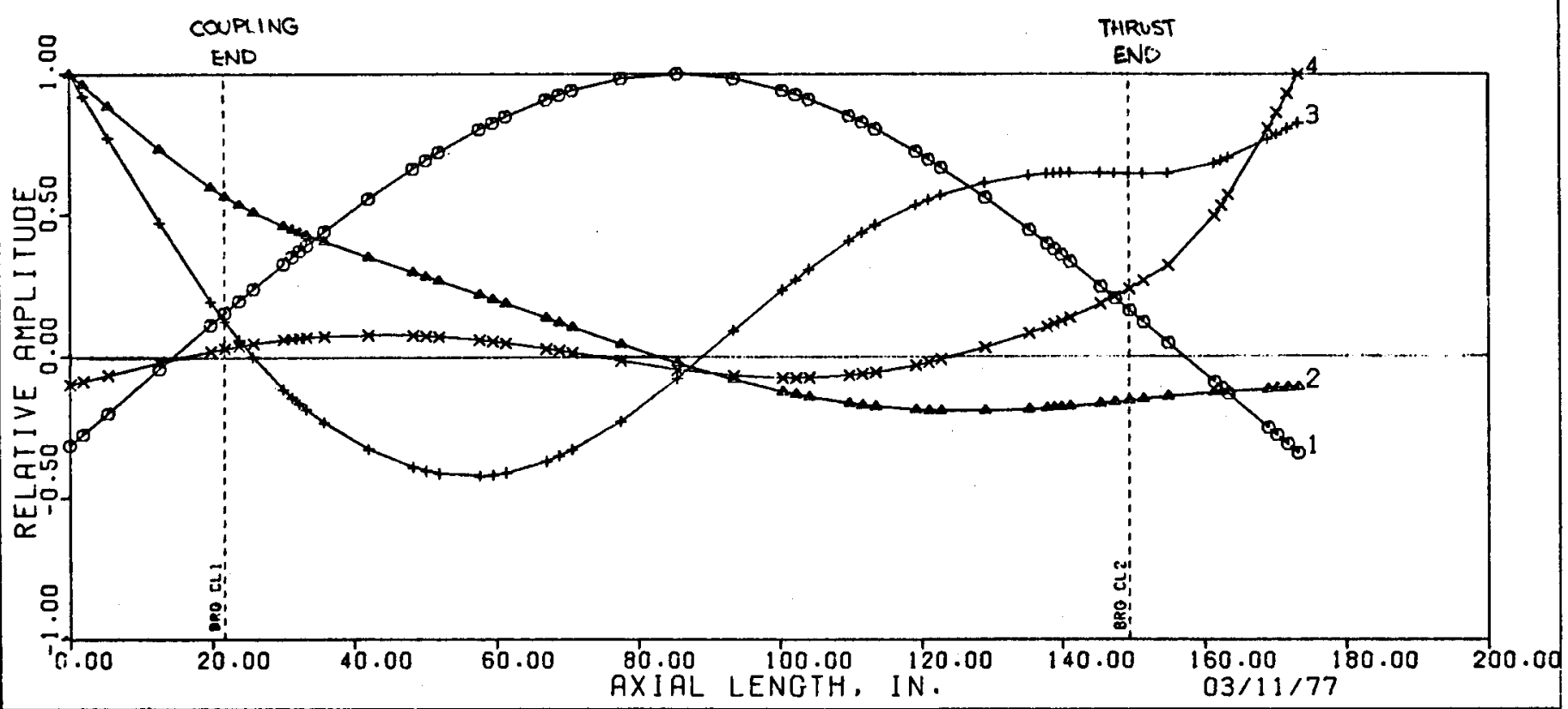

Figure B2-6. Rotor Mode Shape 


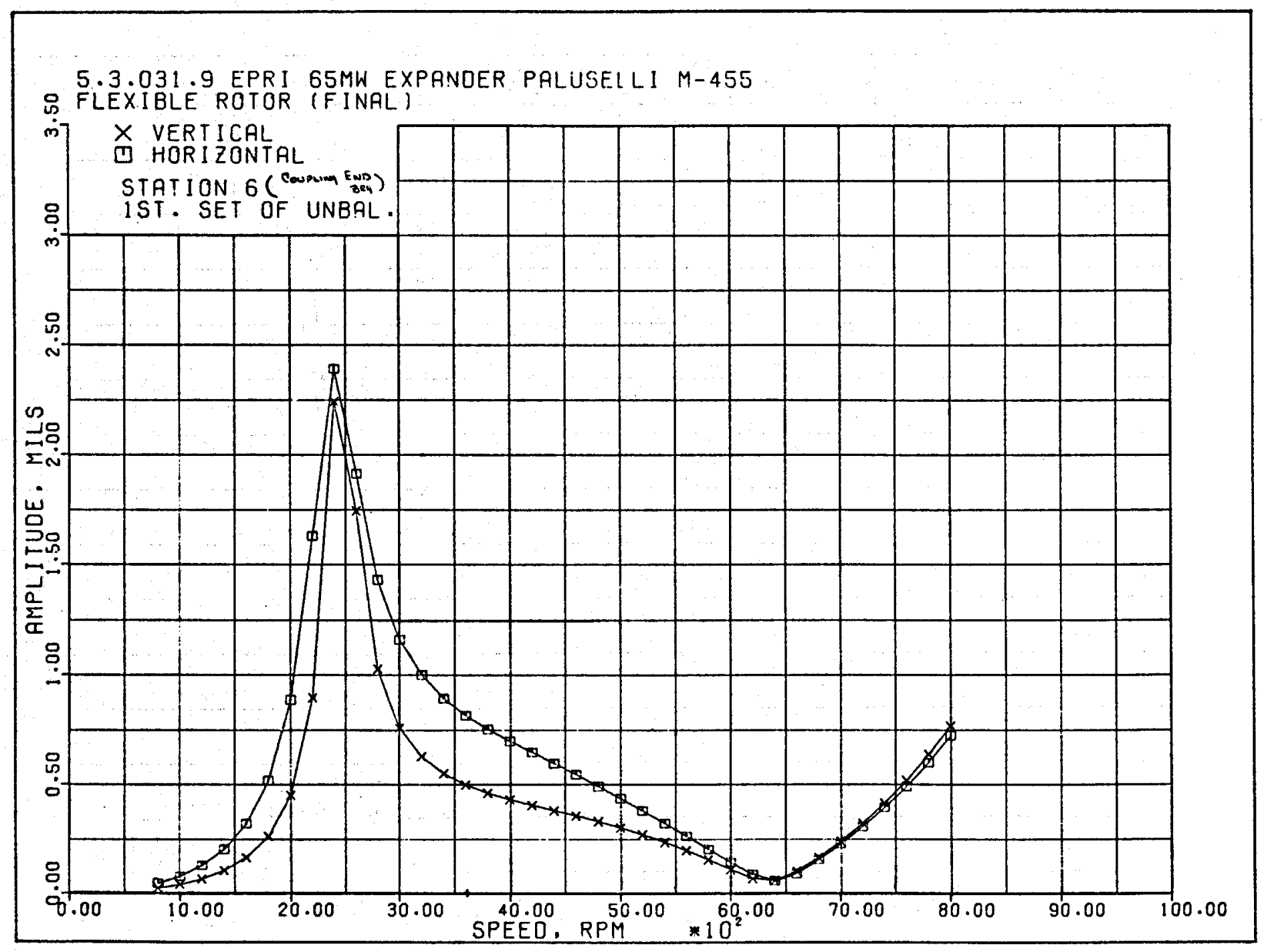

Figure B2-7. Amplitude versus Speed - Coupling End Bearing - Static 


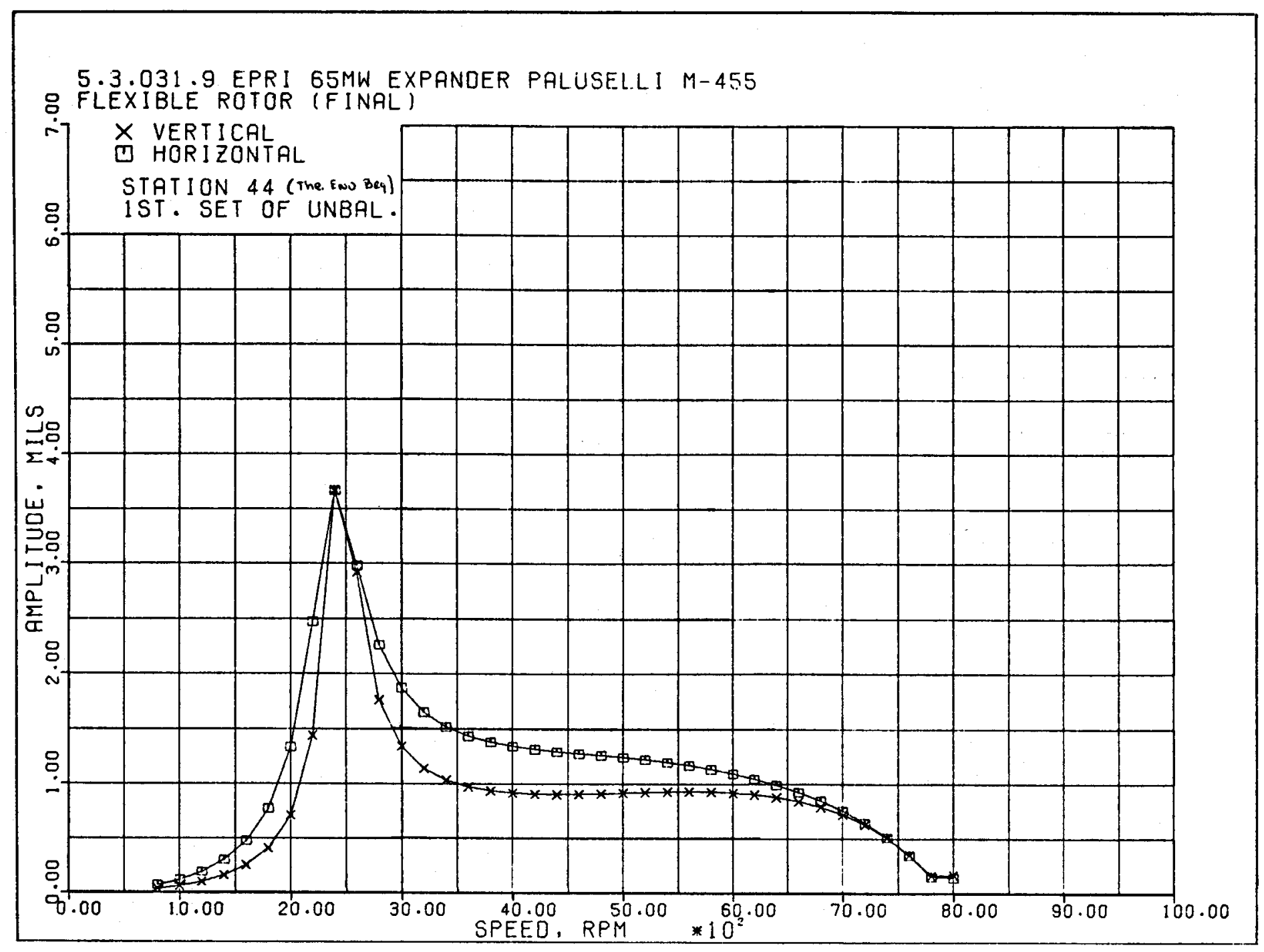

Figure B2-8. Amp1itude versus Speed - Thrust End Bearing - Static 


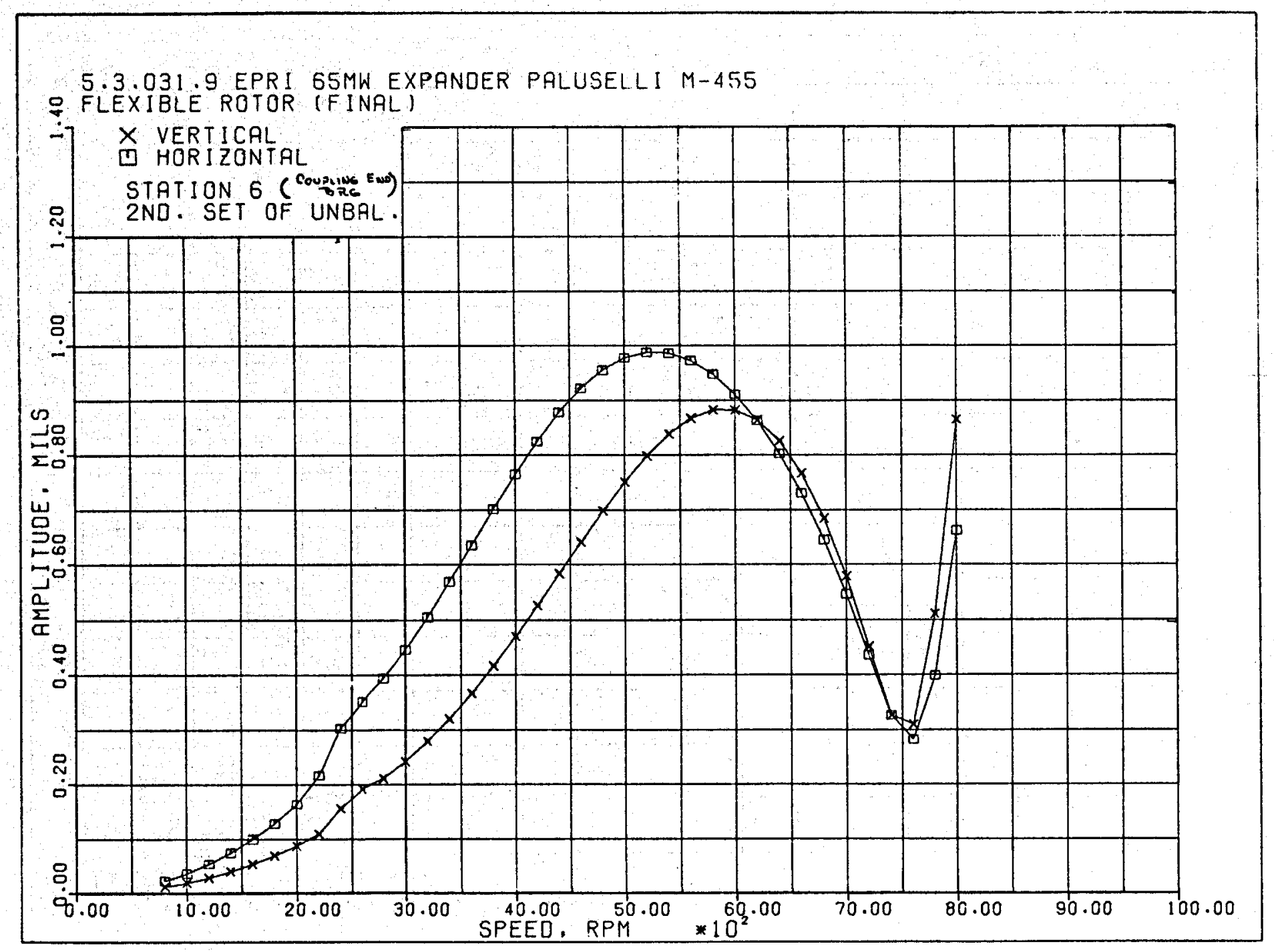

Figure B2-9. Amplitude versus Speed - Coupling End Bearing - Dynamic 


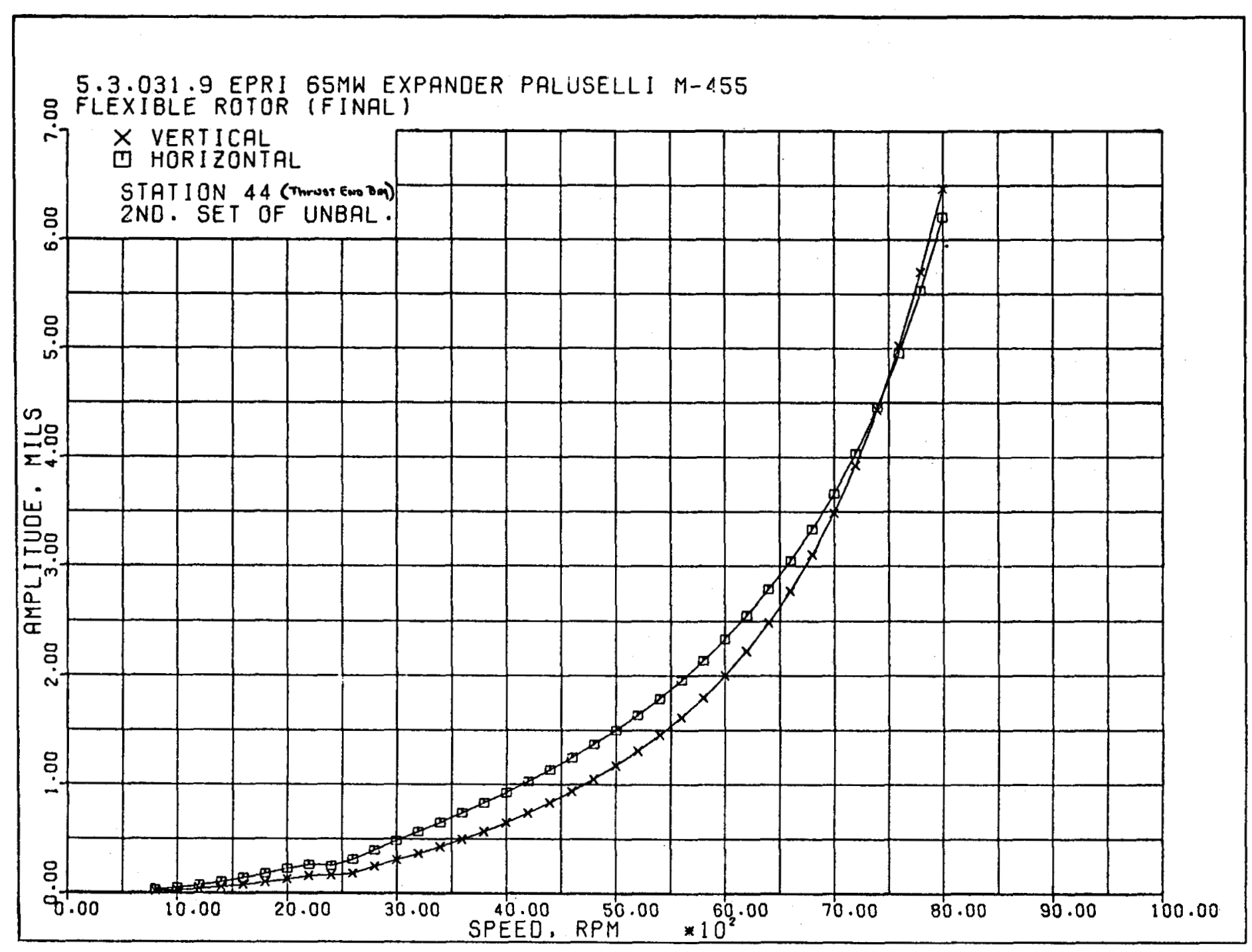

Figure B2-10. Amplitude versus Speed - Thrust End Bearing - Dynamic 


\section{Appendix C}

SPECIFICATION

FOR

HYDROCARBON TURBINE-GENERATOR SET

1. GENERAL

1.1 Scope: This specification is intended to cover the minimum requirements for a hydrocarbon turbine, lubrication and seal oil system, and generator used for electrical power generation in conjunction with a geothermal binary cycle.

\subsection{Referenced Publications:}

1.2.1 American National Standards Institute (ANSI)

B1:1: Unified Screw Threads

B2.1: Pipe Threads

B16.5: Steel Pipe Flanges and Flanged Fittings

B16.11: Forged Steel Fittings, Socket-Welding and Threaded

B31.3: Petroleum Refinery Piping

1.2.2 American Petroleum Institute (API)

API $605 \mathrm{~F} 1$ anges

API 612 Special Purpose Steam Turbines

API 614 Lubrication and Seal oil Systems

API 617 Centrifugal Compressors

1.2.3 American Society of Mechanical Engineers (ASME)

Boiler and Pressure Vessel Code:

Section VIII, Division 1, Unfired Pressure Vessels

Section IX, Welding Qualifications

1.2.4 American Society for Testing and Materials (ASTM)

Al06 Specification for Seamless Carbon Steel Pipe for HighTemperature Service

Al93 Specification for Alloy-Steel Bolting Materials for High-Temperature Service

Al94 Specification for Carbon and Alloy Steel Nuts for Bolts for High-Pressure and High-Temperature Service 
A266 Specification for Carbon Steel Drum Forgings

A307 Specification for Low-Carbon Steel Externally and Internally Threaded Standard Fasteners

E109 Dry Powder Magnetic Particle Inspection

E125 Reference Photographs for Magnetic Particle Testing of Ferrous Castings

E138 Wet Magnetic Particle Inspection

1.2.5 National Electrical Manufacturer's Association (NEMA)

SM-21 Turbines, Mechanical Drive Service Multi-Stage

MG-1 Motors and Gears

1.2.6 Tubular Exchanger Manufacturer's Association, Inc. (TEMA)

1.2.7 National Fire Protection Association (NFPA)

Bulletin No. 70: National Electrical Code, Article 500

"Hazardous Location"

\subsection{Definition of Terms:}

1.3.1 Design Point: That point in terms of output power, speed, and working fluid conditions at which usual operation is expected and optimum efficiency is desired.

1.3.2 Maximum Continuous Speed: The upper limit of speed for the turbine and generator. For direct drive two-pole 60 Hertz applications, this is 3600 RPM.

1.3.3 Trip Speed: The speed at which the trip valve is actuated to shut-off hydrocarbon gas to the turbine. It is $105 \%$ of maximum continuous speed, or $3780 \mathrm{RPM}$ for direct drive two-pole 60 Hertz applications.

1.3.4 Maximum Speed Rise: The maximum speed reached if the expander is operating with design output power at maximum continuous speed and the load is suddenly reduced to zero.

1.3.5 Maximum Inlet Case Design Pressure: The maximum internal pressure for which the inlet casing is designed, considering the most severe conditions of coincidence pressure and temperature expected with the specified gas conditions.

1.3.6 Maximum Exhaust Casing Pressure: The maximum internal exhaust pressure for which the exhaust casing is designed.

1.3.7 Coastdown Time: The time required after the trip valve is actuated for the equipment to come to rest. 


\subsection{Basic Design General:}

1.4.1 A combined lubrication and seal oil console shall be used for the turbine bearings and seals. A separate lubrication and seal oil system shall be used for the generator bearings and seals.

1.4.2 All electrical components shall be in accordance with NFPA Bulletin No. 70, Article 500 for Division 2, Class I, Group D hazard area.

1.04.3 Bolting for pressure joints and piping shall be in accordance with the following:

1.4.3.1 Bolting material shall be carbon steel ASTM A307 for cast iron joints and alloy steel ASTM A193 Grade B7 for steel joints.

1.4.3.2 Nuts shall be ASTM A194, Grade $2 \mathrm{H}$ or ASTM A307, Grade B, Case Hardened. 1.4.3.3 Threading shall conform to ANSI B1.1.

1.4.3.4 Actual bolting temperature used to determine bolting quality shall be as defined by ANSI B31.3.

1.4.4 All flanged connections shall conform to ANSI B16.1, ANS I B16.5 or API 605 as applicable. Flat face flanges are acceptable on steel casings.

1.4.5 All piping shall be designed to conform to ANSI B31.3.

1.4.6 Pipe sizes of $1 \frac{1}{4}$ inches, $2 \frac{1}{2}$ inches, $3 \frac{1}{2}$ inches, 5 inches, 7 inches and 9 inches are not acceptable.

1.4.7 A forged steel, flexible spacer type coupling shall be used between the turbine and generator. A flexible diafram type coupling is perferred. Rigid and removable spark-proof coupling guards conforming to state and local codes shall be provided.

1.4.7.1 The spacer shall be long enough to permit removal of the following without disturbing the rotors:

1. - elther coupling half

2. - complete seal unit

3. - bearing parts

1.4.8 The turbine and generator shall be mounted on individual soleplates.

1.4.9 Stainless steel nameplate and rotation arrows shall be provided.

The nameplate shall include the following:

- Vendor's name

- Serial number

- Unit model number 
- Output rating

- First critical speed

- Maximum continuous speed

- Maximum case design pressure

- Maximum exhaust casing pressure

- Maximum allowable temperature

1.4.10 The unit and its auxiliaries shall be suitable for operating in the prescribed environment. Factors such as the expected maximum and minimum temperatures, unusual dust problems, and any other related conditions should be a part of the design.

1.4.11 The arrangement of the turbine, generator and the required auxiliaries shall be as mutually agreed to by purchaser and vendor to assure proper clearance areas and safe access for operation and maintenance. In addition, vendor shall review and coment on the purchaser's piping and foundation drawing if requested.

1.4.12 The equipment shall be designed and built to conform with all state and local codes. Purchaser shall make avallable to the vendor all such codes which may apply.

1.4.13 The turbine vendor shall have unit responsibility.

2. TURBINE DESIGN

2.1 General:

2.1.1 The turbine sha11 be rated $65 \mathrm{MW}$ at 3600 RPM with design gas conditions.

2.1.2 The turbine shall be capable of continuous operation at design rating with the specified temperature, pressure, and gas composition.

2.1.3 The turbine shall be capable of continuous operation with all specified gas conditions. Vendor is to state in his proposal any rework required of turbine to meet future operating conditions specified.

2.1.4 The turbine shall be designed to facilitate maintenance. The casing shall be designed to permit removal of the rotor without breaking major piping connections. Casing components and bearing housing shall be shouldered or dowelled to insure accurate reassembly.

2.1.5 All welding of casings, pressure castings, piping and repairs shall be performed by welders qualified in accordance with Section IX of the ASME Code. 
2.1.6 The turbine shall be designed to minimize the entrance of dust, moisture and foreign matter into bearing housings, oil reservoirs, and shaft seal areas.

2.1.7 A grounding device shall be provided between the stationary and rotating parts of the turbine to prevent the flow of electrical current between the rotor and the bearings.

\subsection{Casings:}

2.2.1 The thickness of the casing shall be designed for operation at the most severe conditions of coincident pressure and temperature with the specified gas conditions. The thickness shall include a $1 / 8^{\prime \prime}$ corrosion allowance.

2.2.2 Materíals, casing factors, hoop-stress values and quality of any welding shall be in accordance with Section VIII of the ASME Boller and Pressure Vessel Code. However, the specified report forms and stamping are not required.

2.2.3 Casings shall be vertically split type construction when the maximum case design pressure exceeds 325 PSIG.

2.2.4 For horizontally split casings, the horizontal split shall be a metal-tometal joint. Gaskets, including string-type, shall not be used.

2.2.5 To facilitate alignment, disassembly and reassembly vertical and horizontal jackscrews, lifting lugs and guide dowels shall be provided.

2.2.6 Inlet and exhaust connections shall be flanged. To assure casing drainage, orientation shall be up for the inlet and down for the exhaust. Inlet and exhaust connections located in the end covers are not permitted.

2.2.7 The turbine shall be designed to withstand external forces and moments equal to those calculated in NEMA SM20.

2.2.8 Casing shall have center-1ine support to minimize thermal growth effects on alignment.

2.2.9 All casing connections for vents, drainers, lube and seal o1l, and such shall be flanged and not less than 3/4"' IPS. Where flanged openings are not possible, threaded openings are permissible. Pipe nipples shall be screwed and seal welded into the threaded openings and shall be provided with a steel flange. Pipe nipples shall be a minimum of Schedule 160 seamless steel for sizes $1^{\prime \prime}$ and smaller and Schedule 80 for size $1 \frac{1}{2} "$ and larger.

\subsection{Rotors:}

2.3.1 Integrally forged wheel and shaft construction is preferred. Built-up or thru-bolt rotors shall be assembled to prevent looseness when operating at 
the maximum possible speed allowed by the protective devices. Built-up rotor shall have wheels shrunk and keyed to shaft.

2.3.2 Rotors shall be capable of operating safely at a speed of $120 \%$ of maximum continuous speed or the speed attained during maximum speed rise, whichever is greater.

2.3.3 For "stiff-shaft" rotors, the first critical speed shall be at 1 east $10 \%$ over trip speed. For "flexible-shaft" rotors, the first critical speed shall be not more than $80 \%$ of maximum continuous speed and the second critical shall be at 1 east $10 \%$ over trip speed.

2.3.4 The turbine vendor shall perform a composite torsional vibration analysis of the turbine-generator unit to assure the unit's satisfactory performance.

2.3.5 The rotor shall be balanced in accordance with the following:

- Major parts of the rotor shall be statically balanced. For rotors with integrally forged disk and shaft construction, this includes the rotor only. For rotors with built-up construction, this includes shaft, disks, balancing drum and such.

- The rotor shall have multi-plane dynamic balancing. For integral rotor construction, there shall be a minimum of three balancing planes. For built-up construction, incremental dynamic balancing shall be used. The rotor shall be balanced after the addition of not more than two major elements. Balance correction shall be applied to new elements only with no alteration to previously balanced elements.

- After final balance, the maximum unbalanced forced at any journal at maximum continuous speed shall not exceed $10 \%$ of the static loading of the journal.

- If required after mechanical run test, all rotor balancing will be accomplished using the three-plane-balance method.

- Rotor vibration measured at journal bearing shall not exceed 2 mils peak-to-peak (plus allowance for any mechanical and electric run-out demonstrated to exist) when the unit is running at maximum continuous speed. Provisions shall be made for two radial non-contracting probes 90 degrees apart to measure radial vibration at each journal bearing.

2.3.6 Diagrams of the various natural frequencies of the turbine blades for the actual rotor or disk assembly shall be provided. All significant resonant frequencies shall be shown.

2.3.7 Goodman Factors shall be calculated for stress evaluation for each blade row.

2.3.8 The turbine shaft shall be equipped with a trip device capable of actuating the main turbine trip valve lever on overspeed condition. The device shall be accurate to $1 / 10$ of $1 \%$. 


\subsection{Bearings and Bearing Housings}

2.4.1 Radial bearings shall be horizontally split tilting pad type with renewable steel-backed pads. The tilting pads shall be removable without removing the end walls on vertically split units or top half on horizontally split units.

2.4.2 The thrust bearing shall be double-acting, self-leveling, fully equalized Kingsbury type. The thrust collar shall be replaceable. It shall be positively locked to the shaft.

2.4.3 Bearings and bearing housings shall be horizontally split.

\subsection{Shaft Sealing}

2.5.1 The turbine shall be provided with mechanical contact shaft seals to prevent any outward leakage of gas during operation. The seals shall also be capable of containing the motive fluid when the turbine is idle with or without seal oil pressure.

2.5.2 Seal design shall have provisions for injecting buffer gas.

2.5.3 The seals shall be replaceable without removing the top half of the casing on horizontally split units or the end wall on vertically split units.

\subsection{Materials}

2.6.1 All materials shäll be manufacturer's standard for the specified operating conditions except as noted herein. The material designation of all major components shall be stated in the vendor's proposal. Where possible, the appropriate ASTM designation or AISI type number shall be given. When this is not possible, the manufacturer's code of trade name may be used.

2.6.2 Cast steel casing parts shall be given a magnetic-particle inspection in accordance with ASTM E109 or ASTM E138.

2.6.3 Pressure castings shall not be repaired without purchaser approval. Steel casting shall be repaired by procedure and operator qualified per Section IX of the ASME code. Major weld repairs shall be stress relieved as required by ASME and given a magnetic-particle inspection per paragraph 2.6.2. 
2.6.4 Fabricated casings shall be welded in accordance with section IX of the ASME Code. All pressure containing welds shall be full penetration or equivalent. Casings shall be given a post-weld heat treatment.

3. LUBRICATION AND SEAL OIL SYSTEM DESIGN

\subsection{General:}

3.1.1 The system shall be designed to continuously provide lube oil to the turbine and generator bearing and seal oil to the expander seals.

3.1.2 All unit components and related valves, manifolds and the like shall be a console arrangement mounted on a structural steel baseplate. The components shall be arranged with clearances adequate to permit maintenance and replacement during operation.

3.1.3 Any necessary piping such as valved vent connections, block valves and such, shall be provided to permit cleaning, filling and draining of idle equipment while the system is in operation.

3.1.4 Pressure vessels such as coolers, filters, lube and seal oil rundown tanks and the like shall conform to Section VIII of the ASME Code. A code stamp is not required.

3.1.5 The normal supply of lube and seal oil shall not be interupted in the event of an electrical power failure until the rotating elements have come to rest.

3.1.6 Welding procedures shell be in accordance with Section VIII of the ASME Code and performed by welders qualified in accordance with Section IX of the ASME Code.

\subsection{Pumps and Drains:}

3.2.1 Main and stand-by pumps shall be provided. Pumps shall be horizontal positive displacement type with cast steel case and separate relief valves. Minimum capacity shall be $115 \%$ of maximum system demand. Main and stand-by pumps shall be duplicates.

3.2.2 The pump drivers shall be AC electrical motors with TEFC enclosures. Motor shall be sized to handle full capacity and pressure with $1000 \mathrm{SSU}$ oil. Motor shall comply with NEMA MG-l.

3.2.3 A common base shall be provided under pump and driver.

3.2.4 Rigid and removable coupling guards conforming to specified state and local regulation shall be provided. 
3.2.5 All pumps shall be installed with flooded suction.

3.2.6 If specified, an emergency oil pump shall be supplied. This pump shall be on a separate electrical circuit than the main and stand-by pump.

3.2.7 An automatic start-up system shall be provided to start the stand-by o1l pump in the event the main pump does not meet system requirements. Manual reset motor starters are to be furnished by the purchaser.

\subsection{Reservoir:}

3.3.1 The reservoir shall be sized for five minute normal flow capacity. between minimum operating level and suction loss level. The total retention time shall be 8 . minutes, based on the total column below the minimum operating level. The reservoir must al so be sized to include capacity for rundown from the bearing, seals, rundown tanks plus $10 \%$ minimum allowance for purchaser's inner-connecting piping.

3.3.2 The reservoir shall be constructed of welded carbon steel plate. It shall be internally baffled with the bottom sloping to drain. A $1 \frac{1}{2}$ " minimum blank flanged drain connection shall be provided.

3.3.3 All reservolr openings shall be gasketed and sealed to prevent the entrance of dirt and water. Top surface openings shall be raised at least one inch. Connections for pumps shall be located near the high end of the reservoir bottom. 011 return lines with less than three feet per second velocity shall enter the reservoir above the maximum operating level away from the pump suction. Oil return lines with greater than three feet per second velocity shall be discharged beneath the oil surface, away from the pump suction 1 ines, and will be baffled to aid in gas release. Relief valves shall be piped separately back to the reservoir. A fill opening with strainer shall be provided. A breather filter cap and a two inch minimum blind-flanged vent connection shall also be provided.

3.3.4 A weld pad type level gage glass spanning maximum and minimum operating level shall be provided.

3.3.5 A thermostatically controlled electric immersion heater shall be provided to heat the reservoir ofl from minimum site temperatures to minimum required temperature in 12 hours. Its watt density shall not exceed 15 wats per square inch. 
3.3.6 To minimize cavities and potential sources of corrosion and contamination, joint and connection shall be internally and externally welded. Full penetration welds from the outside are permitted on the reservoir wall-to-top junctions.

\subsection{Coolers:}

3.4.1 Twin coolers, each sized for total flow and heat load shall be provided. The coolers shall be piped in parallel utilizing a continuous flow transfer valve.

3.4.2 Cooler shall be constructed in accordance with TEMA Class "C" with removable tube bundles and channel cover. Tubes shall be 5/8" outside diameter with minimum 18 BWG. U-bend tubes are not permitted.

3.4.3 Water velocities at design conditions shall be between 5 and 8 feet per second. The water side fouling factor shall be 0.002 . The maximum water pressure drop shall not exceed 10 psi.

3.4.4 0il side design pressure shall be not less than the relief valve setting. Water side design pressure is 150 psig.

3.4.5 Materials shall be steel for she11, channels and covers; Naval brass tube sheets, and; inhibited admiralty for the tubes.

\subsection{Filters:}

3.5.1 Twin full flow oil filters shall be furnished, complete with a continuous flow transfer valve. Transfer valve may be the same valve as for coolers.

3.5.2 Filters shall be rated for not less than the relief valve setting. Cartridges shall have a minimum collapsing differential pressure of 50 psi.

3.5.3 Particle retention shall be 10 microns with a clean pressure drop of not more than 5 psi at design flow and temperature.

3.5.4 Filter cases and heads shall be of all steel construction.

3.5.5 Bypass relief valves are prohibited.

\subsection{Seal Oil Drain Traps:}

3.6.1 Each seal shall be provided with a drain trap. Seal drain traps shall be piped such that one trap may serve both seals if necessary. Inlet flow shall enter the traps above the oil level. Drain lines from the traps shall be individually piped to the degassing unit. 
3.6.2 Automatic traps shall be furnished and may be mechanical float-type traps or snap-acting with separate control valve. Reflex-type glass gages shall be provided.

\subsection{Degassing System}

3.7.1 A degassing drum shall be provided to assure the release of engaged gas.

3.7.2 The drum shall be constructed such that the disengaged gas is confined to one side of the drum. The gas side of the drum will have provisions to be vented to the main condenser.

3.7.3 An electric immersion heater shall be provided. The maximum watt density allowed is 15 watts per square inch.

\subsection{Piping:}

3.8.1 Piping shall be designed in accordance with ANSI B31.3.

3.8.2 All welding shall be performed by welders qualified in accordance with Section IX of the ASME Code.

3.8.3 Al1 piping shall be seamless carbon steel manufactured in accordance with ASME Al06 Grade B. As a minimum, Schedule 80 shall be used for $1 \frac{1}{2}$ " and smaller; Schedule 40 shall be used for 2" and larger. All fittings, valves, flanges, and such shall be a minimum of $3 / 4^{\prime \prime}$ NPS. Piping of $1 / 2$ " NPS or tubing $1 / 2$ " $0 . \mathrm{D}$. shall be permitted between instruments and valves.

3.8.4 Fittings $2 "$ and smaller shall be forged steel socket-weld type. Fittings $2 \frac{1}{2} "$ and larger shall be butt-welded type. To free piping of potential internal obstructions that could accumulate dirt, socket weld joints are not permitted downstream of the filters. Back-up rings are prohibited.

3.8.5 Threaded valve connection shall be held to a minimum. Threads shall conform to ANSI B2,1. Except for instrument connection, all threaded connections shall be seal welded to cover all exposed threads. Thread lubricants shall not be used on joints to be welded.

3.8.6 Valves $2^{\prime \prime}$ and smaller shall be forged steel, socket-welded or screwed (seal welded) with bolted bonnet and glands. Valves $2 \frac{1}{2}$ ", and larger shall be forged steel, ASA flanged with bolted bonnet and glands. Instrument valves shall be $3 / 4$ " male NPT $\times 1 / 2$ " female NPT with vent plugs for pressures to 200 psig and screwed vent valves for pressures above 200 psig. Unions shall be used to provide flexibility and permit proper instrument orientation. Instrument valve bonnets shall be secured with anti-rotation pins. 
3.8.7 All oil drain lines shall be sized to assure they operate at no more than one-half full. Drains must slope a minimum of $1 / 4^{\prime \prime}$ per foot.

\subsection{Controls and Instrumentation:}

3.9.1 The wiring of all controls and instrumentation shall be to a common terminal box.

3.9.2 Care shall be taken in the location and arrangement of all controls and instrumentation to assure good visibility and accessibility.

3.9.3 Back pressure regulators shall be self-operated wherever possible. They shall be sized to pass excess flow from one pump near mid-stroke. Pneumatic regulators, complete with controls shall be furnished for wide control ranges beyond the capability of self-operated regulators. The regulator station shall be complete with isolating gate valves, bypass and vent globe valves. All regulator bodies are steel. Heads may be steel or cast iron.

3.9.4 Pressure regulators shall be self-operated whenever possible. They shall be sized to pass the required flow and maintain the required pressure under all operating conditions utilizing between $25 \%$ and $75 \%$ of the valve of $\mathrm{C}_{\mathrm{v}}$. Pneumatic regulators, complete with controls shall be provided for wide control ranges beyond this capability of self-operated regulators. Each regulator station shall be complete with isolating gate valves and bypass and vent globe valves. All regulator bodies shall be steel. Heads may be steel or iron. Regulators shall be flanged for removal and maintenance.

3.9.5 All alarm and shutdown switches shall be locally mounted. Switches may be provided for the following:

1) One (1) dual SPDT for motor-driven auxiliary pump start and alarm.

2) One (1) dual SPDT in each pressure level header for alarm and trip.

3) One (1) differential dual SPDT in each differential controlled pressure level header for alarm and trip.

All switches are to have stainless steel pressure element with range and proof pressure to suit system pressure.

3.9.6 All thermometers shall be common panel mounted. Thermometers shall be provided for the following:

1) One at cooler inlet.

2) One at cooler discharge. 
3) One at outlet of each radial and thrust bearing of turbine and generator.

4) One at outlet of each expander seal.

All thermometers shall be $5 "$ dial, bi-metallic, angle typed or straight type with swivel nut as required by location. Thermometers shall have a range of $+20^{\circ} \mathrm{F}$ to $+240^{\circ} \mathrm{F}$ with an accuracy of $2 \%$ and external adjustment for field calibration. Each thermometer shall be complete with Type 304 stainless steel, 3/4" NPT separable socket.

3.9.7 All pressure gages shall be common panel mounted. Pressure gages shall be provided for the following:

1) One (1) before transfer valve.

2) One (1) after transfer valve.

3) One (1) in each pressure level header.

4) One (1) duplex gage in each differentially controlled pressure level header.

All pressure gages shall be $4 \frac{1}{2} "$ stainless steel bourdon tube dial type. The accuracy shall be $1 / 2$ of $1 \%$ of range over entire scale. Each gage shall be complete with $1 / 2$ " globe isolating valve and $1 / 2$ " connection to piping on equipment.

3.9.8 Carbon steel, non-restrictive type slight flow indicator shall be provided in each lube or seal drain 1ine.

4. GENERATOR DESIGN

4.1 General:

4.1.1 The generator shall be a three-phase synchronous generator rated $75 \mathrm{KVA}$ at 0.9 power factor with 13,800 volts at 60 Hertz. The generator shall be directly connected to and driven at 3600 RPM by the turbine described herein. It shall be hydrogen cooled.

4.1.2 Excitation shall be by a shaft mounted exciter with regulation by a static voltage regulator.

4.1.3 The generator with its associated sealing system for the hydrogen cooling gas shall be of manufacturer's standard design.

5. INSTRUMENTATION AND PROTECTIVE DEVICES

\subsection{Instrument Panel:}

5.1.1 If specified, a locally mounted instrument panel shall be provided. The panel should include but is not necessarfly limited to the following 
instruments:

1. Turbine inlet pressure

2. Turbine exhaust pressure

3. Turbine inlet temperature

4. Frequency meter

5. Volt meter

6. Amp meter

5.1.2 The purchaser shall as a minimum provide the following alarm devices.

High turbine inlet pressure

Al arm :

High turbine exhaust pressure

$\mathbf{x}$

High turbine inlet temperature

$\mathbf{x}$

5.1.3 The vendor shall as a minimum provide the following alarm and shutdown devices.

Overspeed Trip

High Turbine Axial Displacement

High Turbine Radial Vibration

High Oil Cooler Outlet Temperature

Alarm Shutdown

High Oil Filter $\triangle \mathrm{P}$

Low Lube Oil Pressure

Low Seal Oil Pressure

Low 0 il Reservoir Level

Stand-by Pump Running

High Generator Stator Temperature

Generator Hydrogen Purity

$\begin{array}{rr} & \mathbf{x} \\ \mathbf{x} & \mathbf{x} \\ \mathbf{x} & \\ \mathbf{x} & \mathbf{x} \\ \mathbf{x} & \mathbf{x} \\ \mathbf{x} & \\ \mathbf{x} & \mathbf{x} \\ \mathbf{x} & \mathbf{x} \\ \mathbf{x} & \\ \mathbf{x} & \end{array}$

5.1.3.1 Overspeed protection shall be by a mechanically operated trip valve.

5.1.3.2 The turbine shall have two (2) radial proximity type probes mounted at each radial bearing. These shall be 90 degrees apart. In addition, the turbine shall have one (1) axial position probe.

5.1.3.3 If specified, all radial bearings shall have provisions for embedded thermocouples or RTD's. There shall be a minimum of two (2) per bearing.

5.1.3.4 If specified, the turbine thrust bearing shall have thermocouples or RTD's embedded on both the active and inactive sides.

5.1.3.4 If specified, the turbine thrust bearing shall have a load cell to determine thrust loading. 


\section{INSPECTION}

6.1 The purchaser and the purchaser's representative reserve the right to inspect during vendor's normal working hours all phases of the manufacture of the turbine, generator, 1ube and seal system. The purchaser's inspection shall not relieve the vendor of his responsibilities to perform in accordance with the specification and good engineering practice.

7. TESTING

\subsection{General:}

7.1.1 The purchaser and the purchaser's representative reserve the right to observe any testing of the equipment.

7.1.2 Acceptance of shop test does not in anyway relieve the vendor of his responsibilities to meet the specified operating conditions.

\subsection{Hydro Test:}

7.2.1 The turbine casing, each cooler, filter and other pressure vessels shall be hydrotested at $1 \frac{1}{2}$ times its design pressure. Test shall be in accordance with ASME code requirements. Where the expander inlet and exhaust casing have different pressure ratings, a compartmentalized test shall be performed.

\subsection{Mechanical Running Test:}

\subsubsection{Turbine:}

7.3.1.1 The turbine shall be given a mechanical running test as follows:

1) The speed shall be increased from zero to maximum continuous Vibration measurements shall be taken throughout the speed range.

2) The turbine shall be run at maximum continuous speed for four hours. During this time, a sweep for vibration amplitudes shall be made at frequencies other than synchronous. The sweep shall be from 25 percent synchronous to 2 times first stage nozzle passing frequency. Amplitude of sub-synchronous vibrations will be allowed up to $0.5 \mathrm{mils}$.

3) The turbine trip speed shall be verified.

4) The turbine shall be given a final gas test at maximum sealing pressure.

5) The mechaincal run shall be made with contract bearings and seals in place. Seal oil leakage shall be measured during the four hour mechanical test. 
6) The first critical speed shall be measured for flexible shaft machines.

7) Af ter the mechanical run, all bearings shall be removed and inspected.

8) The turbine case may be evacuated and the shaft rotated by an auxiliary driver.

7.3.2 Lube and Seal 0il System

7.3.2.1 The lube and seal oil console shall be given a mechanical running test as follows:

1) The console shall be run for at least two hours under normal system operating conditions.

2) A transfer from one set of filter-cooler to the second set shall be demonstrated. System delivery pressure shall not drop to the point where the standby oil pump starts.

3) Operation of the low oil pressure alarm shall be demonstrated.

4) Standby pump start shall be demonstrated.

5) During the test, the system shall be free of all leaks.

\subsubsection{Generator:}

7.3.3.1 The generator shall be given the manufacturer's standard test.

8. PREPARATION FOR SHIPMENT

8.1 After completion of final mechanical test, all exterior parts of the equipment shall be thoroughly coated with a suitable rust preventative. Interior surfaces of the lube and seal console such as all reservoirs, tanks, coolers, filters and piping shall be thoroughly coated with a suitable rust preventative. Turbine and generator bearing and seal housing shall also be coated. Turbine interior shall be sprayed with a rust preventative which is disoluable by solvent flushing.

8.2 All flanged openings shall be provided with closures. These shall be a minimum $1 / 4^{\prime \prime}$ thick and secured by a minimum of four full size bolts. All threaded openings shall be provided with plugs or caps. 
Appendix D-1

API $614(9 / 73)$ LUBE AND SEAL OIL SYSTEMS

ELLIOTT COMMENTS AND EXCEPTIONS

2.1.4 Winterization is not included, as these requirements for the console are normally supplied by others.

2.1.5 Standard console baseplates are not provided with grout and vent holes, unless specified.

2.1.10 Unless specified, provisions are not necessarily included to assure equipment oil supply during console fallure or after equipment trip.

2.2.3 Certain oil return lines may enter the reservoir beneath the oil level in order to minimize foaming and turbulence.

2.2.4 Dipsticks are considered impractical on the majority of high reservoirs, and are not supplied unless specifled.

2.2.11 Only ladder clips are supplied due to variable ladder spectfications.

2.2.12 All carbon steel reservoirs are supplied with Esso Rust-ban 6297 on all Internal surfaces.

2.3.2 Spacer type couplings are only furnished as standard on centrifugal pumps which require impeller withdrawal towards the coupling. On most pumps, the spacer is not required for maintenance.

2.3.3 Pump seals with tungsten carbide and carbon mating faces are not provided as standard since their use is usually limited to pump applications in severe duties handling process chemicals or abrasive and non-lubricating fluids.

2.3.4 Some positive displacement pumps are furnished with permanent grease-packed ball bearings.

2.3.6 The overspeed trip on turbine driven pumps will be set per the API standard or to the maximum pump speed, whichever is lower. 
2.3.9 Relief valves used up to 500 psi ( 34.5 bar) gauge are piston-type (Fulflo), and are not ASME valves.

2.3.13 To minimize the amount of small diameter piping on the console, the test bleeder valve is not piped to the oil return line or the reservoir unless specified.

2.6.2 Gas pre-charged accumulators are used only as pulse dampeners, and only when specified. All other accumulators are furnished with constant-pressure regulating valves.

2.7.2 A 6 inch $(150 \mathrm{~mm})$ inspection opening on overhead tanks is not furnished as standard. A 4" ANS I nozzle is available as a mounting connection for the internal displacer control. Inspection openings are not required per UG-46, Section VIII, ASME code for non-corrosive service.

2.11.6 Instrument valve bonnets are secured with anti-rotation pins rather than bolts, and are 3/4" male NPT X 1/2" female NPT with vent plugs up to 200 psi ( 13.8 bar) gauge and with screwed vent valves above 200 psi ( 13.8 bar) gauge.

2.11.7 To minimize the amount of small diameter piping on the console, control valve heads actuated by oil are not vented to the reservoir unless specified.

2.11.10 Threaded joints of instrument valves and their associated vent plugs (or valves) are not seal-welded to provide accessibility for necessary maintenance. Unions are provided for flexibility in permitting proper instrument orientation. 
Appendix D-2

OIL SYSTEM COMPONENTS

OIL RESERVOIR

This tank is sized for a five-minute retention time based upon normal flow at steady state. Unit is welded carbon steel plate and all the openings are gasketed. The interior surface of the tank is coated with two coats of a suitable rust proof additive. The tank is normally supplied with a gauge glass spanning the high and low oil levels.

OIL COOLERS

Twin coolers are supplied each sized for total flow and heat load. The oil side design pressure is not less than the system relief valve setting. The water side design pressure is normally 150 psi.

TRANSFER VALVE

Transfer valves are supplied for switching between oil coolers and oil filters. These valves allow for the maintenance of filters and coolers without disrupting the turbine operation.

OIL FILTERS

The twin filters supplied are constructed for pressures not less than relief valve setting. Particle retention 1510 microns with clean pressure drop of not more than 5 psi at design flow and temperature.

MAIN AND AUXILIARY PUMPS

The oil pumps are horizontal positive displacement type. Minimum capacity of $115 \%$ of maximum system demand is normal design. The main and auxiliary pumps are normally duplicates. 
PUMP DRIVERS - MOTORS

TEFC for required electrical characteristics and have sufficient horsepower to drive the pump at full capacity and pressure when handling $1000 \mathrm{SSU}$ oil.

\section{ACCUMULATORS}

Accumulators on this console will be required to supply sufficient ofl for coastdown of 5 minutes duration. It is assumed that during this 5 minute period, the DC diesel generator set will be activated and the standby DC pump will then be operational. The accumulator gas charge will be by means of customers regulated air or inert gas supply. Recharging after the accumulator has been activated will be by manual means.

\section{AUXILIARY PUMP CONTROL}

A motor driven auxiliary oil pump will be automatically started by means of a pressure switch or differential pressure switch as required. These switches are located in the controlled pressure header downstream of the coolers and filters. Manual reset motor starters are to be furnished by the purchaser.

\section{BACK PRESSURE REGULATOR}

These valves are self operated or pneumatic and sized to pass excess flow from one pump near mid stroke. Normally, pneumatic regulators are supplied complete with controls and furnished for a wide control range beyond the capability of selfoperated regulators. The regulator station is complete with isolating gate valves, bypass, and vent globe valves.

\section{PRESSURE REGULATORS}

These valves are self-operated or pneumatic and sized to pass the required flow and maintain required pressure under all operating conditions utilizing between $25 \%$ and 75\% of the valve $C_{p}$. Pneumatic regulators are supplied complete with controls and furnished for wide control ranges beyond the capability of self-operated regulators. Each regulator station is complete with isolating gate valves and bypass and vent globe valves.

\section{THERMOME TERS}

Normally, thermometers are locally mounted on the console. The normal measurement points are: 1) One before the transfer valve, cooler inlet; 2) One after the 
transfer valve, cooler outlet; 3) One in the outlet of each radial and thrust bearing of the turbine and 4). One in the outlet of each mechanical seal.

Thermocouples may be used in place of thermometers or in parallel with thermometers for remote read-out stations.

PRESSURE GAUGES

The following pressure measurement points normally require locally mounted gauges:

- One before the cooler transfer valve

- One after the cooler transfer valve

- One in each pressure level header

- One at the seal oil feed inlet at the turbine

- One at the bearing oil feed inlet at the turbine

Pressure transducers can be supplied to operate in parallel with the locally mounted gauges for remote reading of the system conditions.

SIGHT FLOW INDICATORS

Sight flow indicators are normally provided in each lube, seal, and/or combined drain.

SWITCHES

The following pressure switches are normally locally mounted.

- One for the motor driven auxiliary pump auto start and alarm contitions.

- One switch for each pressure level header for alarm and turbine trip.

- One differential switch for differentially controlled pressure level headers such as the seal ofl and lube oil headers, for both alarm and turbine trip conditions.

\section{RELIEF VALVES}

Relief valves are sized and supplied for each pump to protect the system from over pressurizations. They are sized to pass the full capacity in the flow of one pump.

CUSTOMER CONNECTIONS AND PIPING

The normal customer connections are: 
- Water supply to and from oil coolers

- Lube and seal oil supply and return to main equipment

- Oil reservoir drain

- Turbine governor oil supply 1 ine

- Contaminated seal oil drains

- Gas reference 1 ine from turbine to the regulator

- Electrical and control air connections for the pressure regulators, electrical controls and motor connections 
Appendix E-1

ELLIOTT COMPANY GEOTHERMAL APPLICATION

HYDROGEN COOLED GENERATOR

\section{Nameplate Rating}

Rated Hydrogen Pressure PSIG

Rated Cold Gas Temperatures ${ }^{\circ} \mathrm{C}$

Rated Coolant (Glycol-water) Temp. ${ }^{\circ} \mathrm{F}$

Rated Ambient Temp. ' $F$

Altitude (Foot)

Rated kVA

72,222

Rated kW

65,000

Power Factor

90

Volts

13,800

Line Amperes

3,022

Phases

3

Hertz

60

.58

Short Circuit Ratio

3600

Speed (RPM)

B

Insulation Class

Temperature Rise at Rating

Stator (by Detector), ${ }^{\circ} \mathrm{C}$

54

Rotor (by Resistance), ${ }^{\circ} \mathrm{C}$

\section{Total Temperature}

Hot Spot (by Calculation), ${ }^{\circ} \mathrm{C}$

Telephone Influence Factor

Balanced T.I.F.

Residual T.I.F. 
Generator Excitation Data

Field Amperes at No Load

Field Volts at No Load

Field Amperes Under Rated Load

Field Volts Under Rated Load

Generator Reactances (\%)*

Synchronous, Direct Axis

Synchronous, Quadrature Axis

Transient, Unsaturated

Transient, Saturated

Subtransient, Saturated

Negative Sequence

Zero Sequence

Potier

Time Constants (Seconds)**

Transient, Open Circuit

Transient, Short Circuit

Subtransient, Open Circuit

Subtransient, Short Circuit

Armature (or D.C.) $\mathbf{x}_{\mathbf{d}}$

$x_{q}$

$x^{\prime} d u$

$x^{\prime} d$

$x " d$

$x_{2}$

$\mathrm{x}_{\mathbf{0}}$

$\mathbf{x}_{\mathbf{p}}$

$T^{\prime}$ do

T'd

T"do

T"d

$\mathrm{T}_{\mathbf{a}}$
At Nameplate Rating

575

75

1124

156

135.5

132.5

25.4

22.4

13.3

13.2

6.1

13.8

* All reactances are based upon rated kVA and rated vol tage. They may be converted to any other kVA base by ratioing them to proportion to the kVA.

** Time constants are independent of capability.

Calculated Efficiencies (\%)

(Based on generator and exciter

losses, but not including

bearing loss.)

Rated Load

98.8

$3 / 4$ Load

98.6

1/2 Load

98.3

1/4 Load

97.0 
(Es timated at Specified kVA)

At $0.85 \mathrm{PF}$

30.4 est.

At $0.90 \mathrm{PF}$

28.6 est.

At $1.0 \mathrm{PF}$

21.0 est.

\section{Space Heaters}

Generator Option (Energized from 480 Volt, 3 Phase, 60 Hertz Circuit)

In Generator

KW

Volts

Hertz
In Exciter

Compartment

.75

120

60

Temperature Detectors

Resistance temperature detectors (copper, 10 ohms at $25^{\circ} \mathrm{C}$ ):

6 in stator winding

2 in generator gas discharge

1 in exciter inlet air

1 in exciter, discharge air

Thermocouples

2 simplex chromel-alumel in each generator bearing metal

1 duplex chromel-alumel in exciter bearing metal

$W R^{2}\left(1 b f t^{2}\right)$

Generator

41,800

Exciter

1,100

Total

42,900

Brushless Exciter (with Permanent Magnet Generator)

Rated Power (kW)

Rated Voltage (Volts, DC)

Speed (RPM)

Insulation Class

Speed of Response

Number of Diodes 
Weights (Approximate) (lbs.)

(1) Generator Rotor

(2) Generator Stator

(3) Generator \& Exciter, Complete

(4) Heaviest Piece to be handled during installation

(5) Exciter Rotor

(6) Exciter Stationary Parts

Misce1laneous:

Cooling Water Requirements

Hydrogen Leakage ( $\mathrm{cu} \mathrm{ft/day)}$

Expected

Guaranteed

Shaft Coefficients (in $1 \mathrm{~b} / \mathrm{rad}$ )

Turbine-Generator Shaft

Generator Exciter Shaft
At Nameplate Rating

$$
\begin{array}{r}
46,000 \\
200,000 \\
311,000 \\
200,000 \\
2,500 \\
9,000
\end{array}
$$

$600 \mathrm{GPM}$ at $95^{\circ} \mathrm{F}$ water 2.2 PSI Drop

225

350

$$
1.25 \times 10^{8}
$$

$4.63 \times 10^{8}$ 